\title{
Therapeutic drug monitoring of thiopurine therapy in IBD patients
}

Citation for published version (APA):

Gilissen, L. P. (2008). Therapeutic drug monitoring of thiopurine therapy in IBD patients. [Doctoral Thesis, Maastricht University]. Universitaire Pers Maastricht. https://doi.org/10.26481/dis.20080130lg

Document status and date:

Published: 01/01/2008

DOI:

10.26481/dis.20080130lg

Document Version:

Publisher's PDF, also known as Version of record

\section{Please check the document version of this publication:}

- A submitted manuscript is the version of the article upon submission and before peer-review. There can be important differences between the submitted version and the official published version of record.

People interested in the research are advised to contact the author for the final version of the publication, or visit the DOI to the publisher's website.

- The final author version and the galley proof are versions of the publication after peer review.

- The final published version features the final layout of the paper including the volume, issue and page numbers.

Link to publication

\footnotetext{
General rights rights.

- You may freely distribute the URL identifying the publication in the public portal. please follow below link for the End User Agreement:

www.umlib.nl/taverne-license

Take down policy

If you believe that this document breaches copyright please contact us at:

repository@maastrichtuniversity.nl

providing details and we will investigate your claim.
}

Copyright and moral rights for the publications made accessible in the public portal are retained by the authors and/or other copyright owners and it is a condition of accessing publications that users recognise and abide by the legal requirements associated with these

- Users may download and print one copy of any publication from the public portal for the purpose of private study or research.

- You may not further distribute the material or use it for any profit-making activity or commercial gain

If the publication is distributed under the terms of Article $25 \mathrm{fa}$ of the Dutch Copyright Act, indicated by the "Taverne" license above, 


\section{Therapeutic drug monitoring of}

\section{thiopurine therapy in IBD patients}


(C) Lennard Gilissen, Maastricht 2008

ISBN: 978-90-5278-690-2

Layout: Tiny Wouters

Cover: Peter Gorter, www.pgm-design.com

Cover illustration: ulcerative saxophonitis and thiopurine metabolites

Production: Datawyse | Universitaire Pers Maastricht

Financial support by Abbott, AstraZeneca, Boston Scientific, Cook Endoscopy, Ferring, FMH Medical, Norgine, Nycomed-Altana, Roche, Schering-Plough, Solvay Pharma, Tramedico, UCB Pharma, Zambon, Maasland ziekenhuis Sittard, Wetenschappelijk Fonds Catharina ziekenhuis Eindhoven is gratefully acknowledged. 


\title{
Therapeutic drug monitoring of \\ thiopurine therapy in IBD patients
}

\author{
Proefschrift \\ ter verkrijging van de graad van doctor \\ aan de Universiteit Maastricht, \\ op gezag van de Rector Magnificus, Prof. mr. G.P.M.F. Mols, \\ volgens het besluit van het College van Decanen, \\ in het openbaar te verdedigen \\ op woensdag 30 januari 2008 om 12.00 uur
}

door

Leonardus (Lennard) Petrus Lucia Gilissen 


\section{Promotor}

Prof. em. dr. R.W. Stockbrügger

\section{Co-promotores}

Dr. L.G.J.B. Engels, Maaslandziekenhuis Sittard

Dr. P.M. Hooymans, Maaslandziekenhuis Sittard

\section{Beoordelingscommissie}

Prof. dr. R.P. Koopmans, azM (voorzitter)

Prof. dr. J.M.J.P. van der Linden, azM

Prof. dr. A.A.M. Masclee, azM

Prof. dr. C.J.J. Mulder, VU Amsterdam

Dr. M.G.V.M. Russel, Medisch Spectrum Twente, Enschede

Prof. dr. S. Vermeire, KU Leuven, België 
The more you know, the more you know you don't know (Tower of Power) 



\section{Contents}

Abbreviations

Section A Introduction and outline of the thesis

Chapter 1 Introduction and outline of the thesis

Section B Therapeutic drug monitoring of thiopurine metabolites in patients with inflammatory bowel disease

Chapter 2 Pharmacokinetics of 6-mercaptopurine in patients with inflammatory bowel disease. Implications for therapy

Chapter 3 Some cases demonstrating the clinical usefulness of therapeutic drug monitoring in thiopurine treated inflammatory bowel disease patients

Section C Therapeutic drug monitoring and non-compliance

Chapter 4 Therapeutic drug monitoring in fifteen patients with inflammatory bowel disease and established azathioprine therapy

Chapter 5 Is therapeutic drug monitoring useful in exacerbations of 95 inflammatory bowel disease during thiopurine therapy in adult patients?

Section D Monitoring of interactions with thiopurine therapy by therapeutic drug monitoring

Chapter 6 Pharmacokinetic effect of discontinuation of mesalamine on 6-mercaptopurine metabolite levels in inflammatory bowel disease patients 
Section E 6-Thioguanine: the revival of an old drug

Chapter 7 Pharmacokinetics of 6-thioguanine in patients with inflammatory bowel disease

Chapter 8 6-Thioguanine seems promising in azathioprine- or 6-mercaptopurine intolerant inflammatory bowel disease patients

Chapter 9 One year 6-thioguanine experience in azathioprine- or 6-mercaptopurine-intolerant inflammatory bowel disease patients

Chapter 10 Toxicity of 6-thioguanine: no hepatotoxicity in a series of inflammatory bowel disease patients treated with longterm, low dose 6-thioguanine

Section F General discussion, conclusions and clinical advice, summary

Chapter 11 Discussion

Chapter 12 Conclusions and clinical advice

Chapter 13 Summary

Chapter 14 Samenvatting (Summary in Dutch)

Curriculum vitae (in Dutch)

List of publications

Dankwoord 


\section{Abbreviations}

\begin{tabular}{|c|c|}
\hline$A E$ & adverse events \\
\hline ALT & alanine transaminase \\
\hline 6-AMMP & 2-amino-'6-methylmercaptopurine \\
\hline 5-ASA & 5-aminosalicylic acid \\
\hline AST & aspartate transaminase \\
\hline AUC & area under the curve \\
\hline AZA & azathioprine \\
\hline CAI & Colitis activity index \\
\hline CD & Crohn's disease \\
\hline CDAI & Crohn's disease activity index \\
\hline C195\% & $95 \%$ confidence interval \\
\hline CRP & C-reactive protein \\
\hline Css & steady state concentration \\
\hline DPK & diphosphate kinase \\
\hline DTT & dithiothreitol \\
\hline ESR & erythrocyte sedimentation rate \\
\hline $\mathrm{F}$ & female \\
\hline GMPS & guanosine monophosphate synthetase \\
\hline GTPase & guanidine triphosphatase \\
\hline $\mathrm{Hb}$ & haemoglobin \\
\hline HPLC & high-performance liquid chromatography \\
\hline HPRT & hypoxanthine phosphoribosyl transferase \\
\hline $\mathrm{Hr}$ & hour \\
\hline IBD & inflammatory bowel disease \\
\hline IMPD & inosine monophosphate dehydrogenase \\
\hline ITPase & inosine triphosphate pyrophosphohydrolase \\
\hline $\mathrm{kg}$ & kilogram \\
\hline 6-MP & 6-mercaptopurine \\
\hline M & male \\
\hline 6-MMP & 6-methylmercaptopurine \\
\hline 6-MMPR & 6-methylmercaptopurine ribonucleotides \\
\hline MPK & monophosphate kinase \\
\hline MRI & magnetic resonance imaging \\
\hline 6-MTGN & 6-methylthioguanine nucleotides \\
\hline MTX & methotrexate \\
\hline Mw & molecular weight \\
\hline $\mathrm{N}$ & number of patients \\
\hline ND & not determined \\
\hline NNT & number needed to treat \\
\hline $\mathrm{NRH}$ & nodular regenerative hyperplasia \\
\hline
\end{tabular}




$\begin{array}{ll}\text { OR } & \text { Odds ratio } \\ \text { ORF } & \text { open reading frame } \\ \text { PBS } & \text { phosphate buffered saline } \\ \text { PCR } & \text { polymerase chain reaction } \\ \text { pmol } & \text { picomoles } \\ \text { Pt } & \text { patient } \\ \text { RBC } & \text { red blood cells (erythrocytes) } \\ \text { ROC curve } & \text { receiver operating characteristic curve } \\ \text { SNPs } & \text { single nucleotide polymorphisms } \\ \text { t } & \text { time point } \\ \text { TDM } & \text { therapeutic drug monitoring } \\ \text { 6-TG } & \text { 6-thioguanine } \\ \text { 6-TGN } & \text { 6-thioguanine nucleotides } \\ \text { 6-TGTP } & \text { 6-thioguanine triphosphate } \\ \text { 6-TIMP } & \text { 6-thioinosine monophosphate } \\ \text { TPMT } & \text { thiopurine S-methyltransferase } \\ \text { 6-TUA } & \text { 6-thiouric acid } \\ \text { TWDAI } & \text { Truelove-Witts disease activity index } \\ \text { 6-TXMP } & \text { 6-thioxanthosine monophosphate } \\ \text { UC } & \text { ulcerative colitis } \\ \text { VAS } & \text { visual analog scale } \\ \text { VNTR } & \text { variable number tandem repeat } \\ \text { VOD } & \text { veno-occlusive disease } \\ \text { XO } & \text { xanthine oxidase }\end{array}$


Section A

Introduction and outline of the thesis 


\section{Chapter}

\section{Introduction and outline of the thesis}

Adapted from:

LJJ Derijks, LPL Gilissen, PM Hooymans, DW Hommes

Aliment Pharm Ther 2006;24:715-29. 
Chapter 1 


\section{Introduction}

Inflammatory bowel diseases (IBD) include Crohn's disease (CD), ulcerative colitis (UC) and indetermined colitis. These diseases are relatively new and their incidence is still increasing. The first report, most probably describing a case of Crohn's disease, originates from 1769 and was written by Morgagni ${ }^{1}$. Until the $20^{\text {th }}$ century however, these diseases were very rarely described in medical literature. Only in 1932, Burril B. Crohn introduced the term 'regional ileitis' as an entity ${ }^{2}$. Later, his name was given to this disease.

Until now, it is still not clear why a patient gets IBD. Due to an unknown agent or process, a pro-inflammatory cascade is set up, leading to bowel inflammation differing from mild local mucositis to deep penetrating or even perforating ulceration. Crohn's disease can be found from mouth to anus, while ulcerative colitis is limited to the colon. Several extra-intestinal organs can be involved: eyes, liver, joints and skin. These great inter-individual differences in disease phenotype make IBD difficult to study in clinical research, but also fascinating. During the last 60 years, IBD have become one of the major problems in gastroenterology.

Nowadays, many contributing factors in IBD have been revealed: genetic, environmental, nutritional, smoking and medication ${ }^{3}$. Because of the lack of aetio-pathogenetic clues, it has been very difficult to develop a targeting treatment for IBD. Only recently, the wind seems to turn positively due to the development of the so called 'biologicals': antibodies against specific cytokines, such as infliximab, in the inflammatory cascade (although these medications do not treat the still unknown cause of IBD!). These biologicals, such as infliximab, adalimumab and certolizumab show good short term efficacy and safety ${ }^{4,5}$. However, they are expensive and their longterm safety profiles are not known yet. Therefore older medications like mesalamines, corticosteroids and thiopurines (azathioprine and 6-mercaptopurine) are still very important in daily practice. In thiopurine therapy new strategies were developed in recent years to improve efficacy and safety. One of these strategies is therapeutic drug monitoring (TDM), which means measurement of thiopurine metabolite levels with the purpose of improving safety and efficacy of thiopurine therapy ${ }^{6,7}$. Thiopurines are widely used in the treatment of inflammatory bowel disease (IBD). However, in clinical practice, azathioprine (AZA) or 6-mercaptopurine (6-MP) are not effective in one-third of patients and up to one-fifth of patients discontinues thiopurine therapy due to adverse events. Major advances in mechanistic and biochemical fields contributed to develop new strategies to improve pharmacotherapy. This review of literature focuses on thiopurine pharmacology, pharmacogenetics, interactions and new strategies for optimization of pharmacotherapy. Thiopurine efficacy and toxicity are described 
in less detail because it is respectively well established and generally understood.

\section{Efficacy}

Thiopurines have proven efficacy in $\mathrm{IBD}^{8-10}$. In clinical practice, in $68 \%$ of IBDpatients the initial therapeutic goal (i.e. mucosal healing, elimination of steroids, healing of internal fistulas or abscesses, pain relief, etc) is achieved and after initial response efficacy is reasonably well sustained with remission rates of $95 \%, 69 \%$ and $55 \%$ after 1,3 and 5 years respectively ${ }^{11,12}$.

Both AZA and 6-MP have proven efficacy in induction of remission in active Crohn's disease (CD) with odds ratios (OR) up to 3.1 compared to placebo ${ }^{9-13}$. The OR of response increases after 17 weeks, suggesting there is a minimum length of time for trial of thiopurine therapy ${ }^{13}$. Thereby, the thiopurines have a considerable steroid-sparing effect and the combination of AZA with prednisolone is superior to treatment with prednisolone alone $e^{9,14}$.

AZA and 6-MP seem to be effective in maintaining remission of quiescent CD patients that are steroid dependent or -refractory or in CD-patients finished with surgical treatment with a number needed to treat (NNT) of $7^{9,15-18}$, though not everybody is convinced ${ }^{19}$. Also, in the prevention of exacerbations, the addition of 6-MP to a regimen of steroids significantly lessens the need for prednisone ${ }^{20,21}$. There is debate for how long thiopurines should be given to $\mathrm{CD}$-patients in prolonged remission. Some question the use of potential toxic immunosuppressant for longer than four years ${ }^{22}$, whereas others demonstrate that their efficacy is reasonably well sustained over a period of five years ${ }^{13}$. AZA and 6-MP in combination with other immunosuppressants like cyclosporine, tacrolimus, methotrexate, thalidomide or infliximab have proven efficacy in CD perianal fistulas with prolonged fistula closure in $30-40 \%$ of cases $^{23-26}$. Also, both thiopurines help to prevent the recurrence of $C D$ after surgery, especially in high risk patients, with a NNT of 4 in two years to prevent one clinical relaps ${ }^{27-30}$.

Although less pronounced than in CD populations, both AZA and 6-MP are effective in inducing remission in ulcerative colitis (UC) with remission rates up to $70 \%{ }^{8,31,32}$. However, scarce but conflicting data have been published, demonstrating AZA had no effect at all in achieving remission ${ }^{33}$.

The role of thiopurines in maintaining remission of UC is less controversial ${ }^{8}$. AZA maintenance treatment in UC is beneficial for at least two years after an initial response and significantly lowers the proportion of relapses ${ }^{33,34}$. Moreover, combination therapy is more effective than treatment with steroids $^{8,21,35}$ or 5 -aminosalicylic acids (5-ASA) alone ${ }^{36}$. Also the combination of thiopurines and oral cyclosporine has proven to be safe and effective for 
maintenance of intravenous cyclosporine-induced remission of severe steroidrefractory $U C^{37,38}$, though monotherapy with a thiopurine may be sufficient ${ }^{39}$.

\section{Toxicity}

In IBD-patients treated with thiopurines, up to $20 \%$ has to discontinue drug therapy due to the occurrence of adverse events ${ }^{40-42}$. The adverse events of thiopurines can be divided into dose-dependent, pharmacologically explainable events (type $A$ ) on one hand and dose-independent, hypersensitivity reactions (type B) on the other. Type A adverse events, which often reveal themselves in a subsequent stage, are largely associated with the formation of potentially toxic metabolites and include general malaise and nausea $(11 \%)$, infectious complications $(7.4 \%)$, hepatitis $(0.3-1.3 \%)$ and myelosuppression $(1.4-5 \%)^{9.41-}$ 43 . The reported frequency of leukopenia even varies up to $11 \%$, depending on the definition of leukopenia and the dose prescribed ${ }^{44}$. At present, frequent blood tests are advocated after start of thiopurine therapy to prevent myelotoxicity. The manufacturers of AZA and 6-MP recommend full blood counts weekly up to eight weeks after start of therapy followed by blood tests at least three-monthly. However, there is no evidence that this is effective as severe leukopenia can develop swiftly within two blood tests. Less frequent monitoring (within four weeks of starting therapy and every six-twelve weeks thereafter) may be sufficient ${ }^{45}$.

Type B reactions (2\%) often occur within three to four weeks after start of treatment and result in immune-mediated symptoms like fever, rash and arthralgia $^{46,47}$. Also, pancreatitis $(1.4-3.3 \%)$ is thought to be an idiosyncratic reaction $^{13,41}$.

Although increased frequencies of malignancies are reported in other patient populations on thiopurines, this seems not to be the case in IBD patients ${ }^{48}$. Moreover, in a decision analysis it was concluded that the benefits of thiopurines outweigh the potential risk of lymphoma ${ }^{49}$. Recently however, Kandiel and colleagues reported an approximate four-fold increased risk of lymphoma in IBD patients treated with thiopurines. The authors stated that the increased risk of lymphoma could be a result of the medications, the severity of the underlying disease, or a combination of the two ${ }^{50}$.

The use of thiopurines before or during pregnancy appears to be safe as there is no statistical difference in abortions, congenital malformations or neoplasia among IBD patients on thiopurines compared with healthy controls ${ }^{51}$. 


\section{Pharmacology}

\section{Pharmacokinetics}

Neither AZA nor 6-MP has intrinsic activity, hence have to undergo extensive metabolic transformations. AZA is a pro-drug, that is rapidly and almost completely (88\%) converted to 6-MP and methylnitroimidazole (Figure 1.1, cleavage site 1) by a non-enzymatic reaction in the liver. The latter causes intolerance in a considerable group of patients of whom $75 \%$ successfully switches to $6-\mathrm{MP}^{52}$, but may have immunosuppressive properties of its own ${ }^{53}$. The remaining $12 \%$ of AZA yields hypoxanthine and methylnitrothioimidazole (Figure 1.1, cleavage site 2$)^{54}$. These non-enzymatic conversions are aided by glutathione or other endogenous sulphydryl-containing proteins ${ }^{55,56}$. Smoking and higher age lower glutathione levels ${ }^{57}$ and may cause larger variability in the amount of 6-MP originating from $A Z A^{58}$.

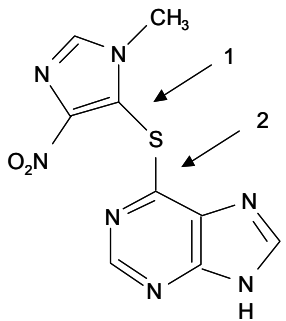

Azathioprine<smiles>Sc1ncnc2[nH]cnc12</smiles>

6-Mercaptopurine<smiles>Nc1nc(S)c2nc[nH]c2n1</smiles>

6-Thioguanine

Figure 1.1 Chemical structures of the thiopurines.

For azathioprine, cleavage sites of the non-enzymatic reaction in the liver are depicted. Cleavage site 1 yields 6-mercaptopurine and methylnitroimidazole while cleavage site 2 yields hypoxanthine and methylnitrothioimidazole.

The absorption of AZA is incomplete and variable resulting in a bioavailability of $16-72 \%{ }^{55}$. The bioavailability of 6 -MP originating from AZA is approximately $60 \%$ compared to only $5-37 \%$ when $6-\mathrm{MP}$ is administered as such, mainly as a result of extensive catabolic conversion of the latter to 6-thiouric acid (6-TUA) in the bowel and liver by xanthine oxidase $(\mathrm{XO})^{59}$. The molecular weight of 6-MP $\left(\mathrm{M}_{\mathrm{w}}=152.18 \mathrm{~g} / \mathrm{mol}\right)$ is $55 \%$ of the molecular weight of AZA $\left(\mathrm{M}_{\mathrm{w}}=277.27\right.$ $\mathrm{g} / \mathrm{mol})$, resulting in a conversion factor of $2.08(1 / 0.55 \times 1 / 0.88)$ when converting 6-MP to an equivalent pharmaceutical dose of AZA assuming $100 \%$ bioavailability ${ }^{60}$. The plasma half-life of 6 -MP is very short, at the most two hours. 


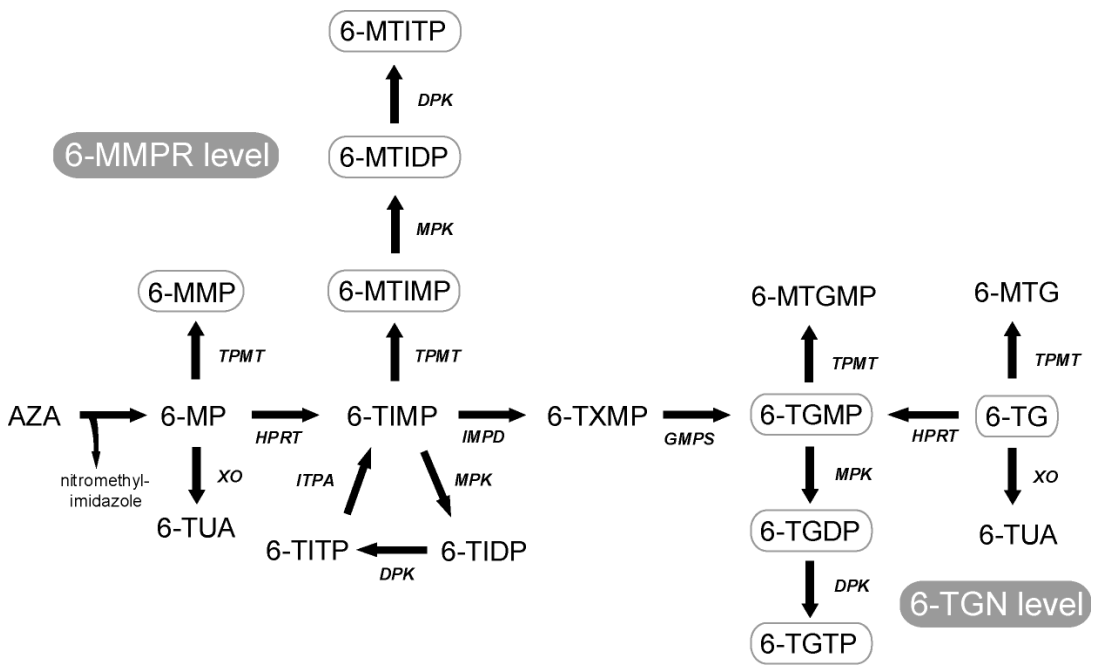

Figure 1.2 Proposed thiopurine metabolism.

AZA, azathioprine; 6-MP, 6-mercaptopurine; 6-MMPR, 6-methylmercaptopurine; 6-TUA, 6-thiouric acid; 6-MTIMP, 6-methylthioinosine monophosphate; 6-MTIDP, 6-methylthioinosine diphosphate; 6-MTITP, 6-methylthioinosine triphosphate; 6-TIMP, 6-thioinosine monophosphate; 6-TIDP, 6-thioinosine diphosphate; 6-TITP, 6-thioinosine triphosphate; 6-TXMP, 6-thioxanthosine monophosphate; 6-TGMP, 6-thioguanine monophosphate; 6-TGDP, 6-thioguanine diphosphate; 6-TGTP, 6-thioguanine triphosphate; 6-MTGMP, 6-methylthioguanine monophosphate; 6-TG, 6-thioguanine; 6-MTG, 6-methylthioguanine; XO, xanthine oxidase; TPMT, thiopurine S-methyltransferase; HPRT, hypoxanthine phosphoribosyl transferase; IMPD, inosine monophosphate dehydrogenase; GMPS, guanosine monophosphate synthetase; MPK, monophosphate kinase; DPK, diphosphate kinase; ITPA, inosine triphosphate pyrophosphatese (ITPase).

6-MTIMP, 6-MTIDP and 6MTITP together form the 6-methylmercaptopurine ribonucleotides (6-MMPR). 6-TGMP, 6-TGDP and 6-TGTP together form the 6-thioguanine nucleotides (6-TGN). In therapeutic drug monitoring, a 6-MMPR level consists of the sum of 6-MMP, 6-MTIMP, 6-MTIDP and 6-MTITP levels, while a 6-TGN level consists of the sum of 6-TGMP, 6-TGDP, 6-TGTP (if AZA or 6-MP is administered) and 6-TG levels (if 6-TG is administered as such).

Following intracellular uptake, 6-MP is then further metabolised by three enzymes (Figure 1.2); two of which are catabolic, $\mathrm{XO}$ and thiopurine S-methyltransferase (TPMT), and one is anabolic, hypoxanthine phosphoribosyl transferase $(\mathrm{HPRT})^{54}$. XO metabolises 6-MP to 6-TUA, whereas TPMT methylates 6-MP to 6-methylmercaptopurine (6-MMP). HPRT carries out the first anabolic step to produce 6-thioinosine monophosphate (6-TIMP), which by inosine monophosphate dehydrogenase (IMPD) is further transformed by a rate-limiting step into 6-thioxanthosine monophosphate (6-TXMP), which is ultimately metabolised to 6-thioguanine monophosphate 
(6-TGTP), -diphosphate (6-TGDP) and -triphosphate (6-TGTP), together the so-called 6-thioguanine nucleotides (6-TGN). The 6-TGN have a half-life of approximately 5 days with a large variability of 3-13 days ${ }^{55,61}$. 6-TIMP can alternatively be methylated by TPMT, yielding 6-methylthioinosine monophosphate (6-MTIMP), -diphosphate (6-MTIDP) and -triphosphate (6-MTITP), the so-called 6-methylmercaptopurine ribonucleotides (6-MMPR). Finally, it is hypothesized that 6-TIMP successively is converted into 6-thioinosine diphosphate (6-TIDP) and -triphosphate (6-TITP) to form 6-TIMP once again by the enzyme inosine triphosphate pyrophosphatase (ITPA or ITPase).

In contrast to AZA and 6-MP, pharmacokinetics (metabolism in particular) of 6-thioguanine (6-TG) is much less complicated. The absorption of oral 6-TG is incomplete and variable, resulting in a bioavailability of $14-46 \%{ }^{59}$. Plasma $6-T G$ concentrations may range up to thirty-fold ${ }^{62}$ and become undetectable after six hours as it is rapidly transported into the cell ${ }^{63,64}$. HPRT directly converts 6-TG to the 6-TGN, whereas the competing TPMT and XO yield 6-methylthioguanine (6-MTG) and 6-TU respectively ${ }^{65}$.

\section{Pharmacodynamics}

In recent years, the molecular mechanisms of action of the thiopurines have been elucidated at least in part. The 6-TGN (Figure 1.3), as a result of their structural similarity to the endogenous purine-base guanine, are incorporated into DNA (Figure 1.4) of leucocytes as fraudulent bases, resulting in strand breakage and subsequently immunosuppression ${ }^{54,66}$. Also, one of the 6-TGN in particular, 6-TGTP, is considered to contribute to the immunosuppressive effects due to inhibition of Rac1 upon CD28 co-stimulation, inducing T-cell apoptosis $^{67}$. Rac1 is a small GTPase and plays a role in inhibiting T-cell apoptosis. 6-TGTP binds to Rac1 instead of GTP, thereby suppressing the activation of Rac1 target genes like mitogen-activated protein kinase, NF-KB, and $\mathrm{bcl}-\mathrm{x}_{\mathrm{L}}$.

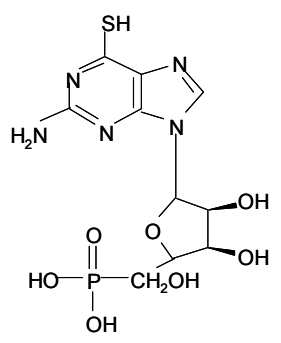

6-TGMP

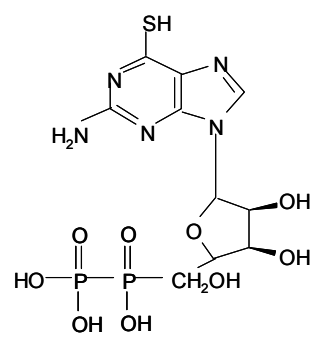

6-TGDP

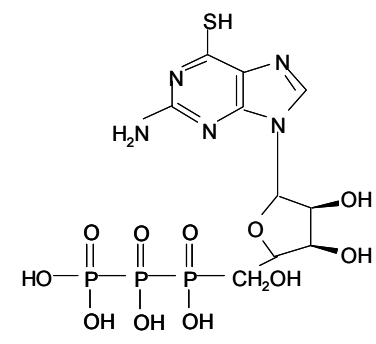

6-TGTP

Figure 1.3 Chemical structures of the 6-thioguanine nucleotides (6-TGN). 6-TGMP, 6-thioguanine monophosphate; 6-TGDP, 6-thioguanine diphosphate; 6-TGTP, 6-thioguanine triphosphate. 


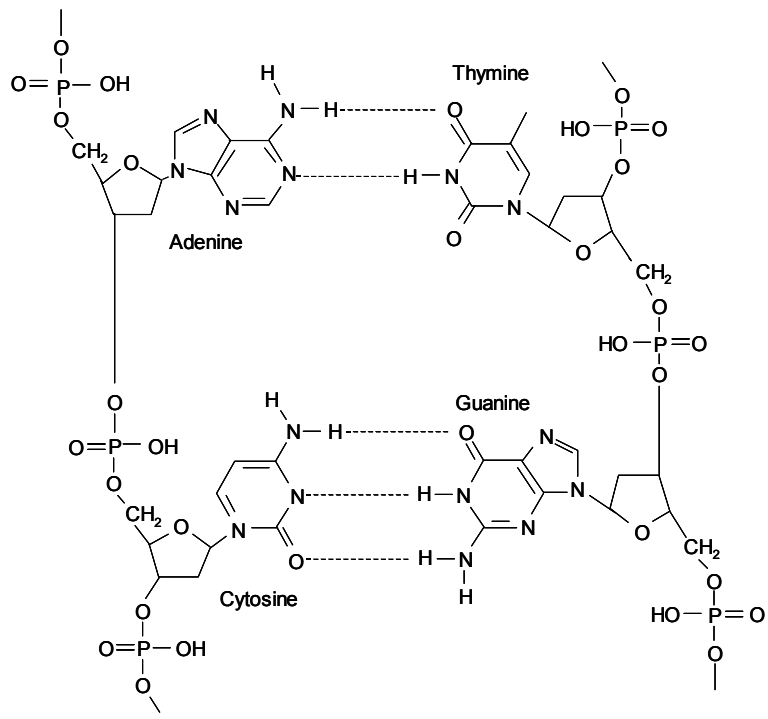

Figure 1.4 Chemical structure of DNA. The 6-thioguanine nucleotides strongly exhibit structural similarity to the endogenous purine-base guanine. They possess a thiole-group instead of an oxygen-atom, resulting in strand breakage when they are incorporated into DNA as fraudulent bases.

Also, the 6-MMPR contribute to the anti-proliferative properties of the thiopurines, probably through inhibition of de novo purine synthesis ${ }^{68}$. Furthermore, as mentioned before, AZA has an immunosuppressive effect additional to that attributable to 6-MP alone and it is proposed that this is associated with an action of the nitromethylimidazol substituent by a so far unsolved mechanism ${ }^{53}$. In addition to this, other mechanisms may contribute to the immunosuppressive effects of the thiopurines, such as interference with function of similar endogenous molecules like ATP and GTP, which play an important role as carriers of energy and cellular second messengers ${ }^{69}$. It is obvious, that the immunosuppressive properties of the thiopurines are not attributable to one unique mechanism, but are based on multiple and complex mechanisms. To date however, it is unclear to what extent these mechanisms contribute to the overall effect of the thiopurines.

\section{Pharmacogenetics}

The observed interindividual differences in therapeutic response or toxicity are partly explained by the variable formation of active metabolites due to genetic polymorphisms of the genes encoding crucial enzymes in thiopurine metabolism. These enzymes include TPMT, XO, HPRT and ITPase. 


\section{TPMT}

One of the most intensively studied genetic polymorphisms is that of TPMT, though neither its biological function nor the endogenous substrates are known ${ }^{70}$. In thiopurine treated patients, TPMT determines the delicate balance between the 6-MMPR and the 6-TGN. The gene encoding TPMT is located upon chromosome $6(6 \mathrm{p} 22.3)$ and contains ten exons. To date, two wild type alleles (TPMT*1 and *1S) and 20 mutant alleles (TPMT*2, *3A, *3B, *3C, *3D, $\left.{ }^{*} 4,{ }^{*} 5,{ }^{*} 6,{ }^{*} 7,{ }^{*} 8,{ }^{*} 9,{ }^{*} 10,{ }^{*} 11,{ }^{*} 12,{ }^{*} 13,{ }^{*} 14,{ }^{*} 15,{ }^{*} 16,{ }^{*} 17,{ }^{*} 18\right)$ responsible for TPMT deficiency have been described (Figure 1.5) ${ }^{71,72}$. These alleles are characterised by one or more single nucleotide polymorphisms (SNPs) in the open reading frame (ORF) sequences of the TPMT gene. Besides, several intronic mutations and mutations outside the ORF exist. Recently, a variable number tandem repeat (VNTR) within the TPMT promoter region of the TPMTgene has also been reported to modulate levels of TPMT activity ${ }^{73,74}$. Enhanced degradation of TPMT proteins encoded by certain mutant alleles has been proposed as mechanisms for lower TPMT protein and catalytic activity: whereas the degradation half-life of TPMT ${ }^{*} 1$ is 18 hours, TPMT*2 and TPMT $^{*} 3 \mathrm{~A}$ have a strongly decreased half-life of 15 minutes ${ }^{75}$. The distribution of TPMT mutant alleles differs significantly among ethnic populations. TPMT $^{*} 3 \mathrm{~A}(3.2-5.7 \%)$ is the most occurring mutant allele in Caucasian populations, followed by TPMT*2 (0.2-0.5\%) and TPMT*3C (0.2-0.8\%) accounting for the vast majority $(>95 \%)$ of mutant alleles ${ }^{69-71,76-82}$. In Asians and African populations however, TPMT*3C is the most frequent mutant allele ${ }^{83-85}$. There is high correlation between TPMT geno- and phenotype ${ }^{43,72}$. The resulting frequency distribution of TPMT activity in Caucasian populations is trimodal: approximately $89 \%$ of the population are homozygous for the wildtype allele (homozygous TPMT $^{\mathrm{H}}$ ) and consequently have high enzyme activity $(13.50 \pm 1.86 \mathrm{U} / \mathrm{ml} \mathrm{RBC}), 11 \%$ inherit one wild type allele and one mutant allele (heterozygous $\mathrm{TPMT}^{\mathrm{H}} / \mathrm{TPMT}^{\mathrm{L}}$ ) and have intermediate levels of enzyme activity $(7.20 \pm 1.08 \mathrm{U} / \mathrm{ml} \mathrm{RBC})$, while one in 300 subjects has two mutant alleles (homozygous $\mathrm{TPMT}^{\mathrm{L}}$ ) and low or no detectable enzyme activity at all ${ }^{69,86}$. TPMT activity is high in children compared to adults, among adults higher in men than in women and higher in smokers than in non-smokers ${ }^{72,87,88}$. Also, TPMT activity significantly increases during thiopurine treatment as a result of enzyme induction ${ }^{54}$.

\section{$\mathrm{XO}$}

Xanthine oxidase is a cytoplasmic enzyme that oxidises endogenous substrates such as hypoxanthine and xanthine, but also the exogenous 6-MP. Its activity is particularly high in the intestinal mucosa and liver ${ }^{89}$, resulting in a substantial reduction of 6-MP bioavailability. On the other hand, oxidised thiopurine metabolites may inhibit TPMT, resulting in higher levels of the active 
6-TGN ${ }^{90}$. There exists four-fold interindividual variation in hepatic $\mathrm{XO}$ activity and the presence of a subgroup of patients with low activity is suspected. XO activity is approximately $20 \%$ higher in men than in women ${ }^{91}$. The molecular basis of these differences remains unclear ${ }^{54}$.

TPMT wild type

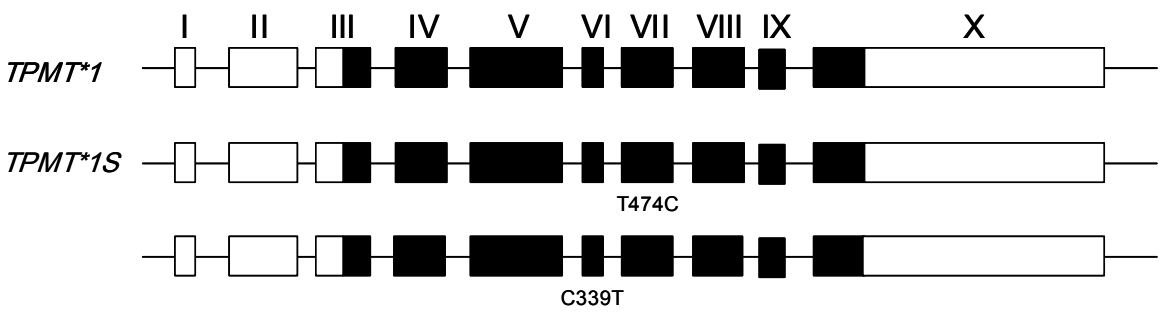

TPMT mutant alleles (1)

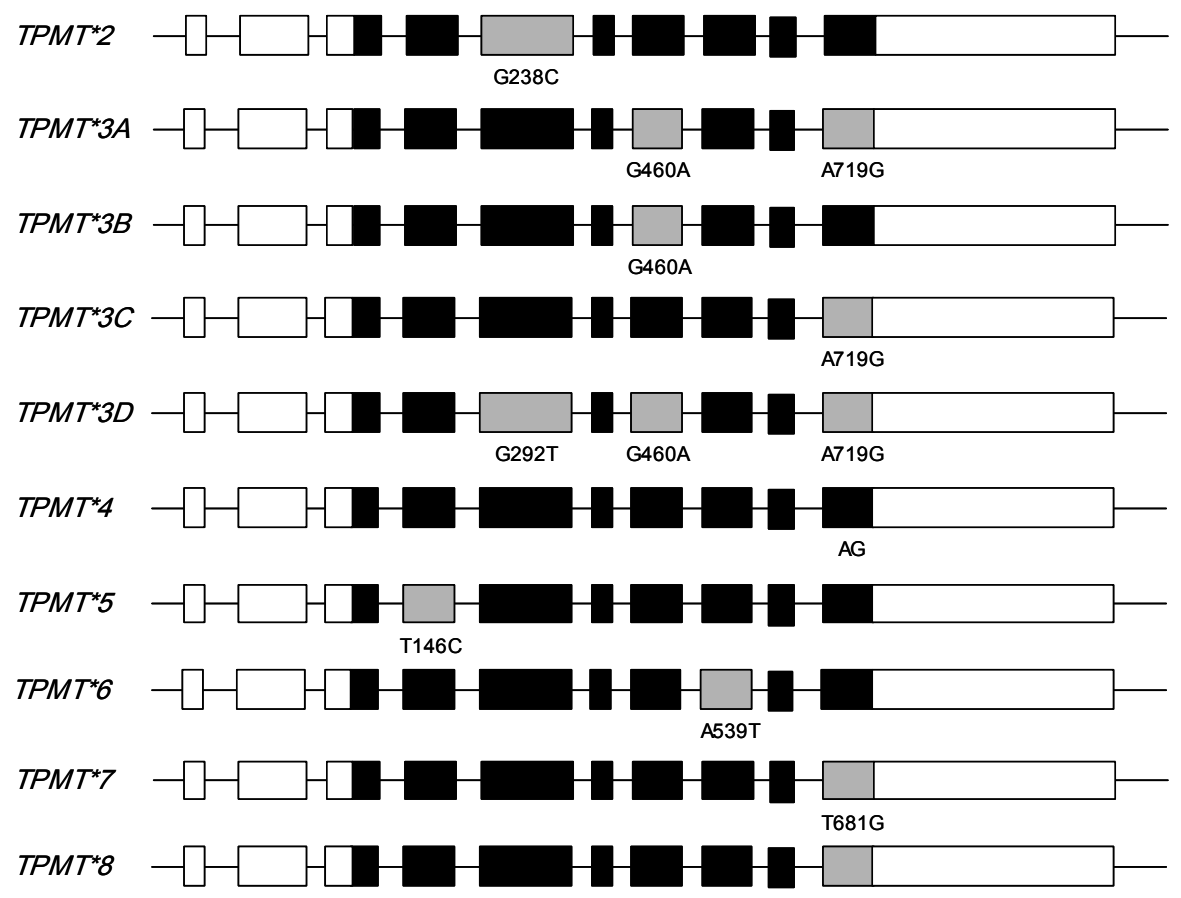

Figure 1.5a Thiopurine S-methyltransferase (TPMT) genotypes (1). The black and white boxes represent translated and untranslated exons respectively. The grey boxes represent translated exons on mutant alleles containing a single nucleotide polymorphism (SNP); the SNP is captioned below the relevant exon. 
TPMT mutant alleles (2)

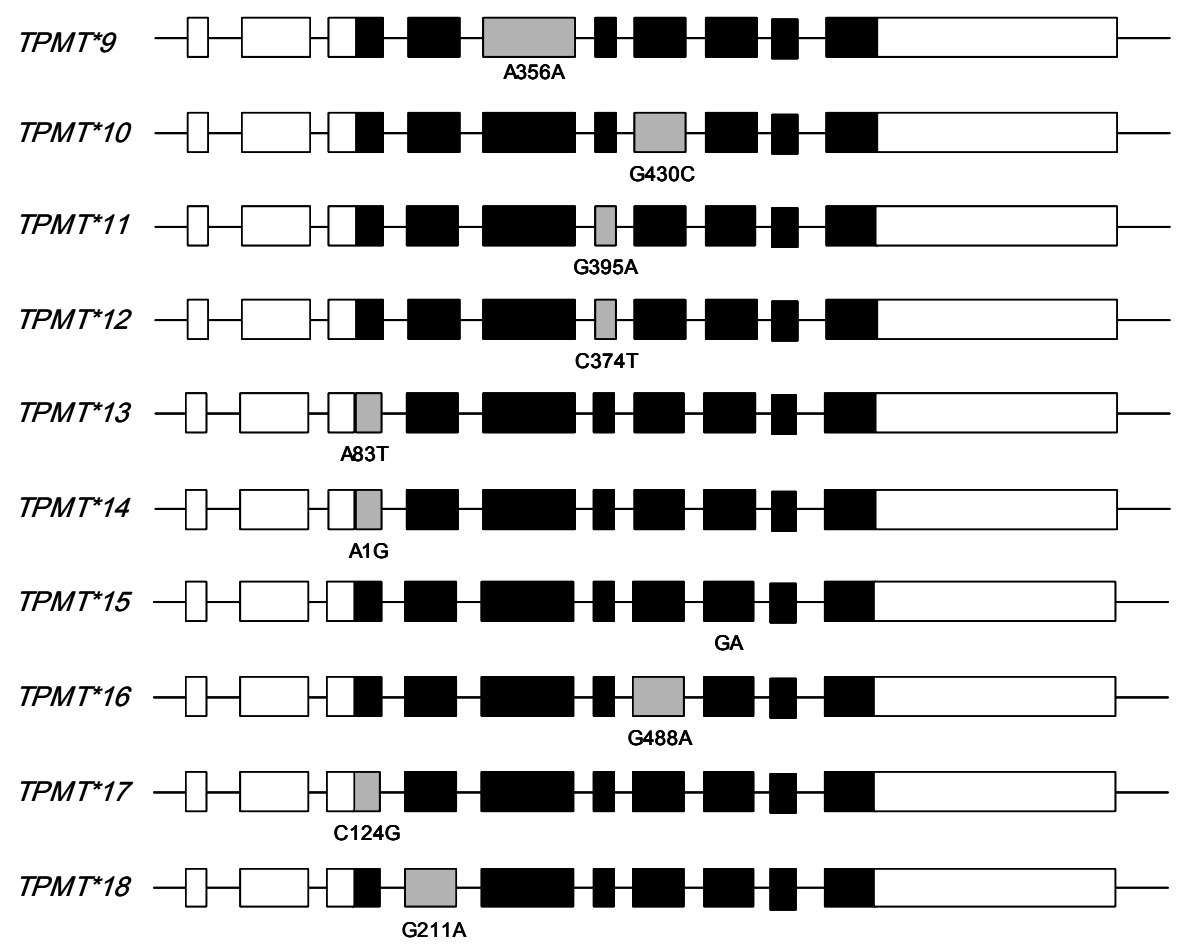

Intronic- and outside ORF mutations

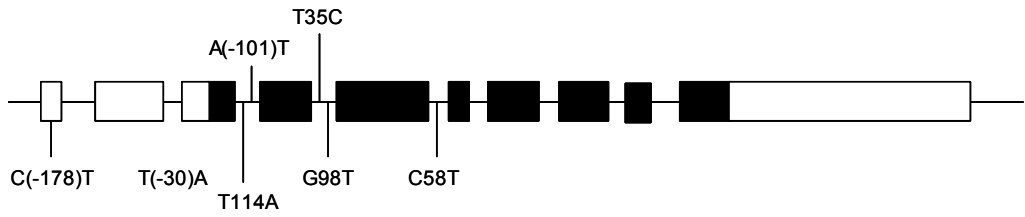

Figure 1.5b Thiopurine S-methyltransferase (TPMT) genotypes (2). The black and white boxes represent translated and untranslated exons respectively. The grey boxes represent translated exons on mutant alleles containing a single nucleotide polymorphism (SNP); the SNP is captioned below the relevant exon. ORF, open reading frame.

\section{HPRT}

Only limited information exists on the range of HPRT activity. What is known however, is that HPRT is completely deficient in subjects with the very rare $(1: 100,000) \quad$ Lesch-Nyhan syndrome characterized by self-mutilating behaviours such as lip biting and head banging ${ }^{54}$. Thiopurines are not cytotoxic in Lesch-Nyhan patients and SNPs in the HPRT-gene appear to be the molecular basis of this syndrome ${ }^{92}$. Moreover, HPRT activity increases during long-term thiopurine treatment ${ }^{54}$. 


\section{ITPase or ITPA}

Inosine triphosphate pyrophosphatase (ITPase) catalyzes the pyrophosphohydrolysis of inosine triphosphate (ITP) to inosine monophosphate (IMP) and deficiency leads to abnormal accumulation of ITP, which is not known to be associated with any defined pathology ${ }^{93}$. In ITPase deficient patients treated with AZA or 6-MP, accumulation of 6-TITP is suggested ${ }^{94}$. The gene encoding ITPase is located on chromosome 20 and five SNPs have been identified so far, of which three (G138A, G561A, G708A) are silent and two (C94A, IVS2 + A21C) are associated with decreased ITPase activity (Figure 1.6) $)^{94}$. C94A is the most frequently occurring SNP. Homozygotes for the C94A missense mutation have no enzyme activity at all and IVS2+A21C homozygotes have approximately $60 \%$ of normal ITPase activity, but the incidence is unknown. It is estimated that approximately $6 \%$ of the population are C94A heterozygotes and they possess $22.5 \%$ of normal enzyme activity ${ }^{95}$.

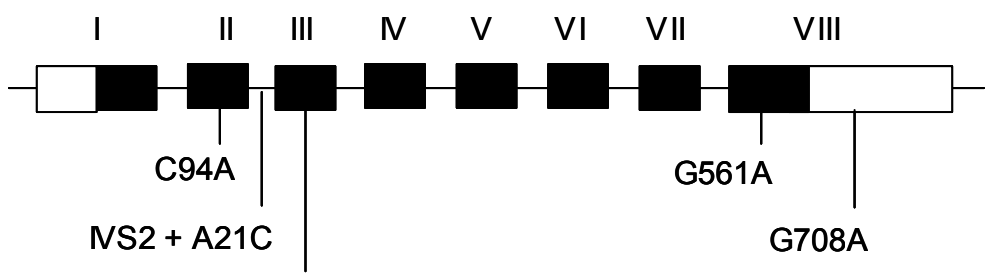

G138A

Figure 1.6 Location of the five single nucleotide polymorphisms (SNPs) on the inosine triphosphate pyrophosphatase (ITPase) gene. The black and white boxes represent translated and untranslated exons respectively. G138A, G561A and G708A are silent SNPs, while C94A and IVS2+A21C are missense mutations associated with decreased ITPase activity.

\section{Interactions}

A number of co-administered drugs may potentially influence thiopurine metabolism and consequently has to be taken into account. In vitro studies have demonstrated 5-aminosalicylic acid (5-ASA) compounds (i.e. balsalazide, olsalazine and sulphasalazine) to be potent TPMT inhibitors ${ }^{96-98}$. In vivo, 6-TGN concentrations are significantly higher when thiopurines are combined with 5-ASA. The observed higher 6-TGN levels can not solely be explained by TPMT inhibition and other yet unknown interaction mechanisms may exist ${ }^{99}$. Consequently, a higher frequency of leukopenia is observed in patients using this combination ${ }^{96,100}$. Other frequently prescribed TPMT inhibitors include acetylsalicylic acid $^{101}$ and furosemide ${ }^{102}$. 
Allopurinol potently inhibits $\mathrm{XO}$ and a dose-reduction to $25-33 \%$ of standard daily dosages of AZA or 6-MP is recommended when combined to prevent serious myelotoxicity ${ }^{59,103}$. Mycophenolate inhibits IMPD, theoretically reducing the conversion of 6-TIMP to 6-TXMP and 6-TGN consequently ${ }^{43}$.

\section{New strategies}

In the past 10-20 years, knowledge of both thiopurine pharmacology and -pharmacogenetics has been extended dramatically and used to develop new strategies to improve efficacy and reduce toxicity. These strategies include therapeutic drug monitoring (TDM) of thiopurine metabolites, geno- or phenotyping crucial enzymes in thiopurine metabolism like TPMT and ITPA and the use of 6-TG as such. All strategies and their potential are discussed.

\section{Therapeutic drug monitoring}

The active metabolites of the thiopurines, 6-TGN and 6-MMPR, can be quantified in the human red blood cell (RBC) by a reversed-phase highperformance liquid chromatographic (HPLC) assay with UV-detection developed by Lennard and colleagues ${ }^{104,105}$. In brief, for measurement of intracellular thionucleotides the free base is obtained by acid hydrolysis of the nucleotide back to the purine. The resulting purines are extracted from the biological matrix by forming a phenylmercury adduct into toluene. During backextraction with hydrochloric acid the adduct is splitted and the free thiopurine is liberated into the acid layer once again. RBC are a good surrogate matrix because they are easily obtained, exist in sufficient numbers and contain concentrations of 6-TGN that reflect concentrations of 6-TGN in the less accessible putative target tissues, the leucocytes ${ }^{6}$. Various other chromatographic methods for the same purpose have been developed ever since, but considerable differences in 6-TGN concentrations are observed when comparing these methods, probably attributable to the extent of nucleotide hydrolysis, extraction procedure, chromatographic conditions and method of detection ${ }^{106,107}$. Direct comparison of several methods with the Lennard-method showed that metabolite concentrations are 2.6-fold higher in the Dervieux-method ${ }^{108}, 1.4$-fold higher when both slightly modified ${ }^{109}$ and 1.6-fold lower when determined by the Erdmann-method ${ }^{110}$. The Lennardmethod has found the greatest application in clinical studies yet and has served as the basis for the establishment of treatment-related therapeutic ranges for thiopurine therapy ${ }^{107}$.

In one of the first clinical studies in which thiopurine metabolites were assayed, a correlation was found between 6-TGN levels and therapeutic efficacy on one hand and between 6-MMPR levels and toxicity on the other ${ }^{6}$. In another study 
with a paediatric population specific metabolite target levels were proposed: the frequency of therapeutic response increased at 6-TGN levels above 235 $\mathrm{pmol} / 8 \times 10^{8} \mathrm{RBC}(\mathrm{OR}: 5.0$ ) and hepatotoxicity correlated with 6-MMPR levels above $5700 \mathrm{pmol} / 8 \times 10^{8} \mathrm{RBC}$, the risk increasing three-fold ${ }^{7}$. In a subpopulation with leukopenia a mean $6-\mathrm{TGN}$ level of $490 \mathrm{pmol} / 8 \times 10^{8} \mathrm{RBC}$ was measured ${ }^{7}$. Since then, in large cohorts of both paediatric and adult populations, conflicting data have been published. A comparable correlation between metabolite concentrations and efficacy and toxicity was demonstrated by several studies. In a study with 82 adult IBD patients 6-TGN concentrations above $250 \mathrm{pmol} / 8 \times 10^{8} \mathrm{RBC}$ correlated with treatment efficacy ${ }^{111}$. In another study with 60 adult IBD patients, 6-TGN levels also were associated with clinical response and though there was a fair amount of overlap, the maximal differentiation between responders and non-responders was seen at 6-TGN levels above 260 $\mathrm{pmol} / 8 \times 10^{8} \mathrm{RBC}^{112}$. In yet another study with 131 adult IBD patients with evaluable 6-TGN levels over a two year period, patients who remained in remission had significantly higher mean 6-TGN levels than those patients who developed active disease. 6-MMPR levels did neither correlate with drug efficacy nor toxicity ${ }^{58}$. Similar results were found in a study with 55 IBD patients: 6-TGN level but not drug dose was related to disease activity ${ }^{113}$. Finally, an inverse relationship between 6-MMPR/6-TGN ratio and therapeutic efficacy has been described and a ratio of 11 has been suggested as a cut-off point above which the frequency of response is diminished ${ }^{114,115}$. Other immunosuppressive therapy should be considered in this case.

These results are contradicted by the findings of other studies that showed no or weak correlation between metabolite concentrations and efficacy or toxicity. In 28 patients with CD, there was a broad overlap in 6-TGN concentrations between patients in remission or not and responders to AZA/6-MP therapy or not $^{116}$. Also, 6-TGN concentrations did not correlate with disease activity in a cohort of 170 IBD patients $^{117}$. In another study with 101 pediatric IBD patients, $58 \%$ of the patients in remission had 6-TGN levels less than the 235 pmol/8x $10^{8}$ RBC proposed by Dubinsky and colleagues ${ }^{118}$. Furthermore, poor correlation between metabolite levels and efficacy or toxicity was found in a study with 74 eligible IBD patients: $38 \%$ of patients with active disease had a 6-TGN level above $235 \mathrm{pmol} / 8 \times 10^{8} \mathrm{RBC}$ and no hepatotoxicity was observed despite 6-MMPR levels above $5700 \mathrm{pmol} / 8 \times 10^{8} \mathrm{RBC}$ in $12.2 \%$ of patients ${ }^{119}$.

Currently, it is much debated whether assessment of metabolite concentrations is clinically useful in predicting both drug efficacy and toxicity ${ }^{120,121}$. These controversies, at least in part, result from the lack of proper pharmacokinetic data in IBD patients. In the near future, these data need to be collected in prospective pharmacokinetic trials to elucidate this matter. Unquestioned however, is the fact that therapeutic drug monitoring (TDM) is the only way to reveal non-compliance ${ }^{122,123}$. 
If TDM is used for optimizing thiopurine pharmacotherapy in IBD patients, the explanations for measured steady state thiopurine metabolite concentrations summarized in Table 1.1 can be used.

In conclusion, TDM seems to be an attractive approach for optimizing thiopurine therapy in IBD patients, but there is an unmet need for prospective studies.

Table 1.1 Possible utilization of metabolite measurement in inflammatory bowel disease patients treated with azathioprine or 6-mercaptopurine

\begin{tabular}{lccc}
\hline Explanation & $\begin{array}{c}6-T G N \text { level } \\
\left(\mathrm{pmol} / 8 \times 10^{8} \mathrm{RBC}\right)\end{array}$ & $\begin{array}{c}\text { 6-MMPR level } \\
\left(\mathrm{pmol} / 8 \times 10^{8} \mathrm{RBC}\right)\end{array}$ & 6-MMPR/6-TGN ratio \\
\hline therapeutic target achieved & $250-500$ & $<5700$ & $5-25$ \\
non-compliance & $<<250$ & $<<5700$ & $5-25$ \\
$\begin{array}{l}\text { under-dosing } \\
\text { potential myelotoxicity }\end{array}$ & $>250$ & $<5700$ & $5-25$ \\
$\begin{array}{l}\text { (absent TPMT activity) } \\
\text { possible myelotoxicity }\end{array}$ & $>500$ & $<<5700$ & 0 \\
$\begin{array}{l}\text { (low TPMT activity) } \\
\text { possible hepatotoxicity } \\
\text { (high TPMT activity) }\end{array}$ & $<250-500$ & $>5700$ & 0 \\
$\begin{array}{l}\text { potential myelotoxicity } \\
\text { (very high TPMT activity) }\end{array}$ & $<<250$ & $>5700$ & $30-100$ \\
\hline
\end{tabular}

6-TGN, 6-thioguanine nucleotides; 6-MMPR, 6-methylmercaptopurine ribonucleotides; pmol, picomoles; RBC, red blood cells; TPMT, thiopurine S-methyltransferase.

\section{Geno- and phenotyping}

Another strategy that may contribute to a better pharmacotherapy of IBD with thiopurines is genotyping genes encoding key enzymes in their metabolism, such as TPMT. Reliable polymerase chain reaction (PCR)-based methods have been developed for detecting the major inactivating mutations at the human TPMT locus ${ }^{70,78,124}$. In brief, leukocyte DNA is amplified by PCR techniques and digested by specific restriction enzymes. The resulting DNAfragments are analyzed by gel electrophoresis. Finally, the identified SNPs yield a specific TPMT genotype (Figure 1.5).

Alternatively, TPMT phenotype can be determined by measuring TPMT activity based on the in vitro conversion of 6-MP to 6-MMP ${ }^{125}$. Phenotyping may be more relevant in some cases, as there is a large variation in TPMT activity among individuals with the same genotype and thus will give more information. Also, as mentioned before, phenotype can alter due to thiopurine therapy and the use of concomitant medication whereas genotype can not. On the other side, sometimes phenotyping may lead to misclassification of a patient's TPMT status, for example after a blood transfusion ${ }^{126}$. 
Lately, the use of determining TPMT status, the exact moment when to perform geno- or phenotyping and the clinical implications are subject to discussion $^{69,127}$. Patients with one or two mutant alleles have less TPMT activity, consequently grossly elevated 6-TGN concentrations, leading to an increased risk for the development of bone marrow suppression ${ }^{69}$. Conversely, some wild type patients with very high TPMT activity, so called ultramethylators, develop suboptimal 6-TGN concentrations by shunting 6-MP away to 6-MMPR resulting in treatment failure ${ }^{114}$.

In a retrospective study with 106 IBD patients, TPMT genotype predicted phenotype which correlated to drug efficacy and toxicity: intermediate TPMT activity was associated with an increased risk of AZA toxicity (OR: 5.4), while high activity $(>14 \mathrm{U} / \mathrm{ml} \mathrm{RBC})$ predicted treatment failure (OR: 0.21$)^{80}$. In a prospective study with 67 patients with rheumatic disease, six patients were heterozygous for mutant TPMT alleles, of which five discontinued therapy within the first month of AZA treatment due to reduced total leukocyte counts $^{128}$. In another study with 262 IBD patients, TPMT genotype predicted leukopenia with an OR of 6.32 for patients with mutant TPMT alleles compared to wild type patients ${ }^{129}$. In yet another study with 113 IBD patients, it was demonstrated that during the initial four months, lower TPMT activities correlated with low neutrophil counts. Also, patients with lower TPMT activity could be safely managed on a low $(<2.0 \mathrm{mg} / \mathrm{kg})$ AZA dose ${ }^{130}$. Similar results were reported in a cohort of 71 patients with CD: patients with normal TPMT status received AZA in an initial dose of $2-2.5 \mathrm{mg} / \mathrm{kg} /$ day compared to $1-1.5$ $\mathrm{mg} / \mathrm{kg} /$ day for patients with intermediate enzyme activity and neither developed acute leukopenia ${ }^{131}$. In general, a $50 \%$ starting dose, that is $1-1.5 \mathrm{mg} / \mathrm{kg} / \mathrm{day}$ AZA or $0.75 \mathrm{mg} / \mathrm{kg} /$ day $6-\mathrm{MP}$, is advocated in patients with heterozygous TPMT alleles ${ }^{132}$. Some recommend an even safer initial dose reduction to $33 \%$ of the standard dose in heterozygotes ${ }^{133}$. It is generally recommended that homozygous mutants should not receive thiopurines at all for their $\mathrm{IBD}^{132,133}$. Recently however, three case-reports demonstrated that TPMT deficiency does not preclude thiopurine therapy and hence offers a further option for homozygous mutants; these patients were safely treated with $0.16-0.29 \mathrm{mg} / \mathrm{kg}$ AZA daily which is approximately $10 \%$ of standard dose $e^{134}$.

In several other studies no or very poor correlation was found between TPMT status and thiopurine toxicity. In a study with 41 leukopenic patients with Crohn's disease (CD) treated with AZA, only $27 \%$ of the patients had one or two mutant TPMT alleles ${ }^{135}$. Myelosuppression was more often caused by other factors, such as viral infections, drugs interfering with AZA metabolism (allopurinol and 5-aminosalicylates) or causing bone marrow suppression by their own (trimethoprim-sulfamethoxazole, captopril and metronidazole). In the majority of cases however, no obvious cause of the developed myelosuppression was apparent. The lag time to the first appearance of 
myelosuppression was longer in patients with wild type alleles though. Similar results were found in another study with 56 IBD patients: a slight trend for more frequent TPMT mutations in patients with adverse reactions on AZA or 6-MP was reported, though not statistically significant ${ }^{136}$. Therefore, it was concluded that TPMT genotype does not predict adverse reactions due to thiopurines in this population.

Another enzyme of interest in thiopurine metabolism is ITPase. The identification of SNPs in the ITPase-gene is done in a similar way as TPMT genotyping with other primers and restriction enzymes of course ${ }^{95}$. ITPaseactivity can be determined by measuring the in vitro conversion of ITP to IMP by a HPLC method ${ }^{137}$.

Recently, in a study with 62 IBD patients, the association between polymorphism in the ITPase gene and adverse drug reactions to AZA therapy was investigated: the C94A ITPase deficiency-associated allele significantly correlated with adverse events (OR 4.2), such as flu-like symptoms, rash and pancreatitis ${ }^{94}$. Besides, in the same study, no correlation was found between these adverse events and TPMT genotype. However, these results were contradicted by two other studies with 73 and 41 IBD patients respectively ${ }^{133,138}$.

In a study by Zelinkova and colleagues it was demonstrated that the C94A allele predicted leukopenia with an OR of 3.50 for patients with mutant ITPase alleles compared to wild type patients ${ }^{129}$.

In conclusion, whereas TPMT genotyping seems to play a role in the prediction of early drug toxicity in patients who have not been previously exposed to AZA or 6-MP, the predictive value for drug toxicity in patients established on thiopurines may be limited ${ }^{69}$. Studies with larger number of patients are needed to confirm this hypothesis. If TPMT genotyping is available, it is appropriate to genotype an IBD-patient before start of thiopurine treatment. Homozygous mutants should receive $10 \%$ of standard starting dose or no thiopurine at all, heterozygous mutants $50 \%$ of standard starting dose and wild-type patients can be safely given standard starting dose.

There is little experience in ITPase genotyping in IBD populations and its predictive value, but the first results are promising. More and larger studies are needed to confirm and clarify these provisional data.

\section{6-Thioguanine}

Yet another strategy to avoid AZA or 6-MP related toxicity or to enhance efficacy is the administration of 6-TG, an agent more directly leading to the formation of the active 6-TGN and until recently used only in patients suffering from leukaemia. In a small pilot-study, 6-TG was given as such to ten ultramethylators, that is IBD patients with a preferential overproduction of 6-MMPR when given $\mathrm{AZA}$ or $6-\mathrm{MP}^{65}$. These therapy-resistant patients continued to have 
suboptimal 6-TGN levels despite dose escalation of their AZA or 6-MP and $70 \%$ experienced dose related toxicity. On 6-TG treatment, seven out of ten patients responded or were in remission after one to four months. Though 6-TGN levels were nine-fold higher on 6-TG than on 6-MP, no patient experienced a recurrence of previous hepatic or haematologic toxicity. 6-MMPR concentrations were undetectable at all times. The authors concluded that 6-TG is a safer and more efficacious thiopurine in this subgroup of IBD patients resistant to 6-MP therapy.

Theoretically, the administration of 6-TG also seems an attractive approach in patients with AZA or 6-MP intolerance because the number of possibly toxic metabolites is strongly reduced ${ }^{139}$. Accordingly, several clinical studies have been performed in this patient population ${ }^{140-145}$. In a short-term safety assessment with $32 \mathrm{AZA}$ or 6-MP intolerant IBD patients it was shown that $81 \%$ of patients were able to tolerate 6 -TG in the first 8 weeks of treatment ${ }^{140}$. Comparable results were found in another study with 21 IBD patients with rechallenged allergic reactions on AZA or 6-MP: $82 \%$ were able to tolerate $6-\mathrm{TG}^{141}$. In a study with 49 AZA or 6-MP intolerant or resistant IBD patients, only $10 \%$ was forced to discontinue $6-T G$ due to the occurrence of adverse events $^{142}$. 6-TGN concentrations were considerably higher on 6-TG compared to the concentrations measured on AZA or 6-MP therapy in all studies. Despite higher 6-TGN levels no haematological toxicity occurred.

6-TG efficacy was demonstrated in a 24-week prospective study with 37 patients with active CD: $35 \%$ achieved remission (CDAl <150) and 57\% achieved a response (decrease of $>70$ points in CDAI) ${ }^{143}$. In a follow-up study, remission was maintained for one year in $88 \%$ of responders to $6-\mathrm{TG}^{144}$. Initial enthusiasm tempered when nodular regenerative hyperplasia $(\mathrm{NRH})$ of the liver was reported in a substantial number of 6-TG treated IBD patients ${ }^{144-}$ ${ }^{147}$. NRH is a serious complication also associated with AZA and 6-MP and a frequent cause of portal hypertension ${ }^{148,149}$. Currently, the use of 6-TG in IBD therapy is strongly discouraged until more definite results on toxicity are available.

In conclusion, important issues like 6-TG short- and long term safety, efficacy in IBD, pharmacokinetics and the significance of higher 6-TGN levels during a longer period of time merit further exploration before 6-TG can be recommended in routine practice or be banned. 


\section{Conclusions}

TPMT genotyping and TDM are useful instruments for individualizing thiopurine pharmacotherapy of IBD. TPMT genotyping before initiation of treatment prevents early and severe myelosuppression by identifying homozygous mutants. Furthermore, in case of TPMT heterozygosity, safety measures such as precautionary dose reductions can be taken. Subsequently, TDM can guide thiopurine dosing to optimal metabolite levels herewith reducing the risk of drug related toxicity and increasing the chance on drug efficacy. Furthermore, TDM is useful whenever non-compliance is suspected. ITPase genotyping may be helpful in case of inexplicable myelotoxicity. At present, it is clear however that neither TDM nor TPMT or ITPase genotyping will replace or exclude frequent blood monitoring in the screening for possible myelotoxicity.

In case of AZA- or 6-MP-intolerance, 6-TG seems a promising alternative. However, in the near future more knowledge needs to be gathered about its potential hepatotoxicity before it can be advocated or banned. 


\section{Outline of the thesis}

After the publications about therapeutic drug monitoring (TDM) of thiopurine therapy in IBD by Cuffari and Dubinsky, we became interested in thiopurine metabolism and the clinical use of metabolite levels measurement in our own thiopurine treated IBD patients ${ }^{6,7}$. This was the start of a fruitful collaboration between the Departments of Gastroenterology and Clinical Pharmacy in the Maasland Hospital, Sittard, Netherlands.

With increasing knowledge about thiopurine metabolism and recognition of large inter-individual differences in metabolism, we decided to perform TDM in an organised way with study protocols approved by the local Medical Ethical Committee. Subsequently, gastroenterologists from other Dutch hospitals (Laurentius Hospital Roermond, University Medical Centre St.Radboud Nijmegen, Rijnstate Hospital Arnhem, VU Medical Centre Amsterdam, Academic Medical Centre Amsterdam, Isala Hospital Zwolle, University Hospital Maastricht and Catharina Hospital Eindhoven) participated in these studies.

The aim of this clinical research was to improve efficacy and safety of thiopurine therapy in individual patients by TDM, but also to demonstrate the usefulness of TDM in thiopurine treated IBD patients on a larger scale. 


\section{Outline of thesis:}

Chapter 2: At first, this chapter describes the methods of metabolite measurements and TPMT genotyping, which are the pharmacological fundaments of this manuscript. Secondly, therapeutic drug monitoring is described prospectively in a 6-mercaptopurine (6-MP) treated IBD cohort of thirty patients.

Chapter 3: $\quad$ Some cases are reported, showing the clinical usefulness of therapeutic drug monitoring in individual IBD patients treated with azathioprine (AZA) or 6-MP.

Chapter 4: Non-compliance to therapy is a well known problem in chronic diseases, such as diabetes and hypertension. Theoretically, measuring metabolite levels can reveal non-compliance. This chapter describes compliance, measured by therapeutic drug monitoring, in a cohort of AZA treated patients with IBD in remission.

Chapter 5: The proposed therapeutic and toxic thresholds of 6-TGN and 6-MMPR metabolites are based on retrospective studies in mostly paediatric IBD cohorts. Chapter 5 describes a prospective study on thiopurine treated adult IBD patients comparing metabolite levels between patients with active disease and patients with IBD in remission. A therapeutic 6-TGN threshold is calculated and compared with previously proposed metabolite threshold levels.

Chapter 6: In vitro studies showed evidence for TPMT inhibition by mesalazine. Only two in vivo studies have been performed. This chapter describes an in vivo interaction study of oral mesalazine and 6-MP in IBD patients. 6-MP metabolite levels and TPMT activity are measured during steady state combination therapy with mesalazine, after interruption of mesalazine, and after reintroduction.

Chapter 7: 6-Thioguanine (6-TG) is a thiopurine that has been used in haemato-oncology for more than thirty years. This thiopurine is closer to the effective 6-thioguanine nucleotides (6-TGN), leading to fewer toxic metabolites, such as 6-methylmercaptopurine ribonucleotides (6-MMPR). Due to the increasing knowledge about thiopurine metabolism, 6-TG was introduced as an alternative for AZA- and 6-MP-intolerant IBD patients in 2001. This chapter describes the pharmacokinetics of this thiopurine. 
Chapter 8: $\quad$ Short term effects and safety of 6-TG in AZA- or 6-MPintolerant IBD patients are described in this part of the thesis.

Chapter 9: This chapter describes the one-year efficacy and safety of 6-TG therapy in a Dutch IBD cohort.

Chapter 10: In 2004, nodular regenerative hyperplasia of the liver was reported in 6-TG treated IBD patients. This chapter describes the results of 6-TG metabolite measurements, liver histology and MRI of the liver after intravenous gadolinium and ferrumoxide in long term 6-TG treated IBD patients.

Chapter 11: The results described in this thesis are discussed in relation to relevant literature on TDM in thiopurine treatment.

Chapter 12: A clinical advice is formulated, based on the findings of this thesis.

Chapter 13: Summary

Chapter 14: Samenvatting (Summary in Dutch) 


\section{References}

1. Morgagni GB. Letter XXXI, article 2. Published under auspices of the Library of the New York Academy of Medicine. Seat and causes of diseases. New York: Hafner Publishing;1960:64.

2. Crohn BB, Ginzburg L, Oppenheimer GD. Regional enteritis. JAMA 1932;99: 1323-8.

3. Inflammatory bowel disease, from bench tot bedside. Second edition by Stephen R. Targan, Fergus Shanahan, Loren C. Karp. Kluwer Academic Publishers, 2003.

4. Nakamura K, Honda K, Mizutani T, Akiho H, Harada N. Novel strategies for the treatment of inflammatory bowel disease: Selective inhibition of cytokines and adhesion molecules. World J Gastroenterol 2006;12:4628-35.

5. Schreiber S, Khaliq-Kareemi M, Lawrance IC, Thomsen $O \varnothing$, Hanauer SB, McColm J, Bloomfield R, Sandborn WJ; PRECISE 2 Study Investigators. Maintenance therapy with certolizumab pegol for Crohn's disease. N Engl J Med 2007;357:239-50.

6. Cuffari C, Theoret Y, Latour S, Seidman G. 6-Mercaptopurine metabolism in Crohn's disease: correlation with efficacy and toxicity. Gut 1996;39:401-6.

7. Dubinsky MC, Lamothe S, Yang HY, Targan SR, Sinnett D, Théorêt Y, Seidman EG. Pharmacogenomics and metabolite measurement for 6-mercaptopurine therapy in inflammatory bowel disease. Gastroenterology 2000;118:705-13.

8. Adler DJ, Korelitz BI. The therapeutic efficacy of 6-mercaptopurine in refractory ulcerative colitis. Am J Gastroenterol 1990;85:717-22.

9. Pearson DC, May GR, Fick GH, Sutherland LR. Azathioprine and 6-mercaptopurine in Crohn disease. A meta-analysis. Ann Intern Med 1995;123:132-42.

10. Sandborn WJ. A review of immune modifier therapy for inflammatory bowel disease: azathioprine, 6-mercaptopurine, cyclosporine, and methotrexate. Am J Gastroenterol 1996;91:423-33.

11. Korelitz BI, Adler DJ, Mendelsohn RA, Sacknoff AL. Long-term experience with 6-mercaptopurine in the treatment of Crohn's disease. Am J Gastroenterol 1993;88:1198-205.

12. Fraser AG, Orchard TR, Jewell DP. The efficacy of azathioprine for the treatment of inflammatory bowel disease: a 30 year review. Gut 2002;50:485-9.

13. Sandborn W, Sutherland L, Pearson D, May G, Modigliani R, Prantera C. Azathioprine or 6-mercaptopurine for inducing remission of Crohn's disease. Cochrane Database Syst Rev 2000:CD000545.

14. Ewe K, Press AG, Singe CC, Stufler M, Ueberschaer B, Hommel G, Meyer zum Büschenfelde $\mathrm{KH}$. Azathioprine combined with prednisolone or monotherapy with prednisolone in active Crohn's disease. Gastroenterology 1993;105:367-72.

15. Pearson DC, May GR, Fick G, Sutherland LR. Azathioprine for maintaining remission of Crohn's disease. Cochrane Database Syst Rev 2000:CD000067.

16. Candy S, Wright J, Gerber M, Adams G, Gerig M, Goodman R. A controlled double blind study of azathioprine in the management of Crohn's disease. Gut 1995;37:674-8.

17. Hanauer SB, Korelitz BI, Rutgeerts P, Peppercorn MA, Thisted RA, Cohen RD, Present $\mathrm{DH}$. Postoperative maintenance of Crohn's disease remission with 6-mercaptopurine, mesalamine, or placebo: a 2-year trial. Gastroenterology 2004;127:723-9. 
18. Ardizzone S, Maconi G, Sampietro GM, Russo A, Radice E, Colombo E, Imbesi V, Molteni M, Danelli PG, Taschieri AM, Bianchi Porro G. Azathioprine and mesalamine for prevention of relapse after conservative surgery for Crohn's disease. Gastroenterology 2004;127:730-40.

19. Sandborn WJ, Feagan BG. The efficacy of azathioprine and 6-mercaptopurine for the prevention of postoperative recurrence in patients with Crohn's disease remains uncertain. Gastroenterology 2004;127:990-3.

20. Markowitz J, Grancher K, Kohn N, Lesser M, Daum F. A multicenter trial of 6-mercaptopurine and prednisone in children with newly diagnosed Crohn's disease. Gastroenterology 2000;119:895-902.

21. Mate-Jimenez J, Hermida C, Cantero-Perona J, Moreno-Otero R. 6-mercaptopurine or methotrexate added to prednisone induces and maintains remission in steroid-dependent inflammatory bowel disease. Eur J Gastroenterol Hepatol 2000;12:1227-33.

22. Bouhnik Y, Lemann M, Mary JY, Scemama G, Taï R, Matuchansky C, Modigliani $\mathrm{R}$, Rambaud JC. Long-term follow-up of patients with Crohn's disease treated with azathioprine or 6-mercaptopurine. Lancet 1996;347:215-9.

23. Lowry PW, Weaver AL, Tremaine WJ, Sandborn WJ. Combination therapy with oral tacrolimus (FK506) and azathioprine or 6-mercaptopurine for treatmentrefractory Crohn's disease perianal fistulae. Inflamm Bowel Dis 1999;5:239-45.

24. Hinterleitner TA, Petritsch W, Aichbichler B, Fickert P, Ranner G, Krejs GJ. Combination of cyclosporine, azathioprine and prednisolone for perianal fistulas in Crohn's disease. Z Gastroenterol 1997;35:603-8.

25. Pare P. Management of fistulas in patients with Crohn's disease: antibiotic to antibody. Can J Gastroenterol 2001;15:751-6.

26. Ochsenkuhn T, Goke B, Sackmann M. Combining infliximab with 6-mercaptopurine/azathioprine for fistula therapy in Crohn's disease. Am J Gastroenterol 2002;97:2022-5.

27. Kader HA, Raynor SC, Young R, Kaufman SS, Vanderhoof J, Ruby EI, Mack DR. Introduction of 6-mercaptopurine in Crohn's disease patients during the perioperative period: a preliminary evaluation of recurrence of disease. J Pediatr Gastroenterol Nutr 1997;25:93-7.

28. D'Haens G. Prevention of postoperative recurrence in Crohn's disease. Curr Gastroenterol Rep 1999;1:476-81.

29. Travis S. Azathioprine for prevention of postoperative recurrence in Crohn's disease. Eur J Gastroenterol Hepatol 2001;13:1277-9.

30. Cuillerier E, Lemann M, Bouhnik Y, Allez M, Rambaud JC, Modigliani R. Azathioprine for prevention of postoperative recurrence in Crohn's disease: a retrospective study. Eur J Gastroenterol Hepatol 2001;13:1291-6.

31. Kornbluth A, Sachar DB. Ulcerative colitis practice guidelines in adults. American College of Gastroenterology, Practice Parameters Committee. Am J Gastroenterol 1997;92:204-11.

32. Paoluzi OA, Pica R, Marcheggiano A, Crispino P, lacopini F, lannoni C, Rivera M, Paoluzi $P$. Azathioprine or methotrexate in the treatment of patients with steroiddependent or steroid-resistant ulcerative colitis: results of an open-label study on efficacy and tolerability in inducing and maintaining remission. Aliment Pharmacol Ther 2002;16:1751-9.

33. Sood A, Midha V, Sood N, Kaushal V. Role of azathioprine in severe ulcerative colitis: one-year, placebo-controlled, randomized trial. Indian J Gastroenterol 2000;19:14-6. 
34. Hawthorne AB, Logan RF, Hawkey CJ, Foster PN, Axon AT, Swarbrick ET, Scott $\mathrm{BB}$, Lennard-Jones JE. Randomised controlled trial of azathioprine withdrawal in ulcerative colitis. Bmj 1992;305:20-2.

35. Ardizzone S, Molteni P, Imbesi V, Bollani S, Bianchi Porro G. Azathioprine in steroid-resistant and steroid-dependent ulcerative colitis. J Clin Gastroenterol 1997;25:330-3.

36. Sood A, Kaushal V, Midha V, Bhatia KL, Sood N, Malhotra V. The beneficial effect of azathioprine on maintenance of remission in severe ulcerative colitis. J Gastroenterol 2002;37:270-4.

37. Actis GC, Bresso F, Astegiano M, Demarchi B, Sapone N, Boscaglia C, Rizzetto $M$. Safety and efficacy of azathioprine in the maintenance of ciclosporin-induced remission of ulcerative colitis. Aliment Pharmacol Ther 2001;15:1307-11.

38. Ramakrishna J, Langhans N, Calenda K, Grand RJ, Verhave M. Combined use of cyclosporine and azathioprine or 6-mercaptopurine in pediatric inflammatory bowel disease. J Pediatr Gastroenterol Nutr 1996;22:296-302.

39. Domenech E, Garcia-Planella E, Bernal I, Rosinach M, Cabré E, Fluvià L, Boix J, Gassull MA. Azathioprine without oral ciclosporin in the long-term maintenance of remission induced by intravenous ciclosporin in severe, steroid-refractory ulcerative colitis. Aliment Pharmacol Ther 2002;16:2061-5.

40. Kirschner BS. Safety of azathioprine and 6-mercaptopurine in pediatric patients with inflammatory bowel disease. Gastroenterology 1998;115:813-21.

41. Present DH, Meltzer SJ, Krumholz MP, Wolke A, Korelitz BI. 6-Mercaptopurine in the management of inflammatory bowel disease: short- and long-term toxicity. Ann Intern Med 1989;111:641-9.

42. Connell WR, Kamm MA, Ritchie JK, Lennard-Jones JE. Bone marrow toxicity caused by azathioprine in inflammatory bowel disease: 27 years of experience. Gut 1993;34:1081-5.

43. Sanderson J, Ansari A, Marinaki T, Duley J. Thiopurine methyltransferase: should it be measured before commencing thiopurine drug therapy? Ann Clin Biochem 2004;41:294-302.

44. de Jong DJ, Derijks LJ, Naber AH, Hooymans PM, Mulder CJ. Safety of thiopurines in the treatment of inflammatory bowel disease. Scand $\mathrm{J}$ Gastroenterol Suppl 2003:69-72.

45. Carter MJ, Lobo AJ, Travis SP. Guidelines for the management of inflammatory bowel disease in adults. Gut 2004;53 Suppl 5:V1-16.

46. Korelitz BI, Zlatanic J, Goel F, Fuller S. Allergic reactions to 6-mercaptopurine during treatment of inflammatory bowel disease. J Clin Gastroenterol 1999; 28:341-4.

47. Sandborn WJ. Azathioprine: state of the art in inflammatory bowel disease. Scand J Gastroenterol Suppl 1998;225:92-9.

48. Connell WR, Kamm MA, Dickson M, Balkwill AM, Ritchie JK, Lennard-Jones JE. Long-term neoplasia risk after azathioprine treatment in inflammatory bowel disease. Lancet 1994;343:1249-52.

49. Lewis JD, Schwartz JS, Lichtenstein GR. Azathioprine for maintenance of remission in Crohn's disease: benefits outweigh the risk of lymphoma. Gastroenterology 2000;118:1018-24.

50. Kandiel A, Fraser AG, Korelitz BI, Brensinger C, Lewis JD. Increased risk of lymphoma among inflammatory bowel disease patients treated with azathioprine and 6-mercaptopurine. Gut 2005;54:1121-5. 
51. Francella A, Dyan A, Bodian C, Rubin P, Chapman M, Present DH. The safety of 6-mercaptopurine for childbearing patients with inflammatory bowel disease: a retrospective cohort study. Gastroenterology 2003;124:9-17.

52. McGovern DP, Travis SP, Duley J, Shobowale-Bakre el M, Dalton HR. Azathioprine intolerance in patients with IBD may be imidazole-related and is independent of TPMT activity. Gastroenterology 2002;122:838-9.

53. Crawford DJ, Maddocks JL, Jones DN, Szawlowski P. Rational design of novel immunosuppressive drugs: analogues of azathioprine lacking the 6-mercaptopurine substituent retain or have enhanced immunosuppressive effects. J Med Chem 1996;39:2690-5.

54. Lennard L. The clinical pharmacology of 6-mercaptopurine. Eur J Clin Pharmacol 1992;43:329-39.

55. Schwab $M$, Klotz U. Pharmacokinetic considerations in the treatment of inflammatory bowel disease. Clin Pharmacokinet 2001;40:723-51.

56. Ardizzone S, Porro GB. Comparative tolerability of therapies for ulcerative colitis. Drug Saf 2002;25:561-82.

57. Richards GA, Van Antwerpen VL, Hunter S, Theron AJ. Aging and cigarette smoking are associated with decreased glutathione levels in humans. S Afr J Sci 1996;92:445-7.

58. Wright S, Sanders DS, Lobo AJ, Lennard L. Clinical significance of azathioprine active metabolite concentrations in inflammatory bowel disease. Gut 2004;53: 1123-8.

59. Micromedex.

60. Cuffari C, Hunt S, Bayless TM. Enhanced bioavailability of azathioprine compared to 6-mercaptopurine therapy in inflammatory bowel disease: correlation with treatment efficacy. Aliment Pharmacol Ther 2000;14:1009-14.

61. Lennard L, Lilleyman JS. Individualizing therapy with 6-mercaptopurine and 6-thioguanine related to the thiopurine methyltransferase genetic polymorphism. Ther Drug Monit 1996;18:328-34.

62. Brox LW, Birkett L, Belch A. Clinical pharmacology of oral thioguanine in acute myelogenous leukemia. Cancer Chemother Pharmacol 1981;6:35-8.

63. Lancaster DL, Patel N, Lennard L, Lilleyman JS. 6-Thioguanine in children with acute lymphoblastic leukaemia: influence of food on parent drug pharmacokinetics and 6-thioguanine nucleotide concentrations. $\mathrm{Br} \mathrm{J}$ Clin Pharmacol 2001;51:531-9.

64. Lennard L, Davies HA, Lilleyman JS. Is 6-thioguanine more appropriate than 6-mercaptopurine for children with acute lymphoblastic leukaemia? $\mathrm{Br} \mathrm{J}$ Cancer 1993;68:186-90.

65. Dubinsky MC, Hassard PV, Seidman EG, Kam LY, Abreu MT, Targan SR, Vasiliauskas EA. An open-label pilot study using thioguanine as a therapeutic alternative in Crohn's disease patients resistant to 6-mercaptopurine therapy. Inflamm Bowel Dis 2001;7:181-9.

66. Fairchild CR, Maybaum J, Kennedy KA. Concurrent unilateral chromatid damage and DNA strand breakage in response to 6-thioguanine treatment. Biochem Pharmacol 1986;35:3533-41.

67. Tiede I, Fritz G, Strand S, Poppe D, Dvorsky R, Strand D, Lehr HA, Wirtz S, Becker C, Atreya R, Mudter J, Hildner K, Bartsch B, Holtmann M, Blumberg R, Walczak H, Iven H, Galle PR, Ahmadian MR, Neurath MF. CD28-dependent Rac1 activation is the molecular target of azathioprine in primary human CD4+ T lymphocytes. J Clin Invest 2003;111:1133-45. 
68. Dervieux T, Blanco JG, Krynetski EY, Vanin EF, Roussel MF, Relling MV. Differing contribution of thiopurine methyltransferase to mercaptopurine versus thioguanine effects in human leukemic cells. Cancer Res 2001;61:5810-6.

69. Lennard L. TPMT in the treatment of Crohn's disease with azathioprine. Gut 2002;51:143-6.

70. Krynetski EY, Evans WE. Genetic polymorphism of thiopurine S-methyltransferase: molecular mechanisms and clinical importance. Pharmacology 2000;61:136-46.

71. Schaeffeler E, Lang T, Zanger UM, Eichelbaum M, Schwab M. High-throughput genotyping of thiopurine S-methyltransferase by denaturing HPLC. Clin Chem 2001;47:548-55.

72. Schaeffeler E, Fischer C, Brockmeier D, Wernet D, Moerike K, Eichelbaum M, Zanger UM, Schwab M. Comprehensive analysis of thiopurine S-methyltransferase phenotype-genotype correlation in a large population of GermanCaucasians and identification of novel TPMT variants. Pharmacogenetics 2004;14:407-17.

73. Yan L, Zhang S, Eiff B, Szumlanski CL, Powers M, O'Brien JF, Weinshilboum RM. Thiopurine methyltransferase polymorphic tandem repeat: genotype-phenotype correlation analysis. Clin Pharmacol Ther 2000;68:210-9.

74. Alves S, Amorim A, Ferreira F, Prata MJ. Influence of the variable number of tandem repeats located in the promoter region of the thiopurine methyltransferase gene on enzymatic activity. Clin Pharmacol Ther 2001;70:165-74.

75. Tai HL, Krynetski EY, Schuetz EG, Yanishevski Y, Evans WE. Enhanced proteolysis of thiopurine S-methyltransferase (TPMT) encoded by mutant alleles in humans (TPMT*3A, TPMT*2): mechanisms for the genetic polymorphism of TPMT activity. Proc Natl Acad Sci U S A 1997;94:6444-9.

76. Weinshilboum R. Thiopurine pharmacogenetics: clinical and molecular studies of thiopurine methyltransferase. Drug Metab Dispos 2001;29:601-5.

77. Reuther LO, Sonne J, Larsen N, Dahlerup JF, Thomsen OO, Schmiegelow K. Thiopurine methyltransferase genotype distribution in patients with Crohn's disease. Aliment Pharmacol Ther 2003;17:65-8.

78. Yates CR, Krynetski EY, Loennechen T, Fessing MY, Tai HL, Pui CH, Relling MV, Evans WE. Molecular diagnosis of thiopurine S-methyltransferase deficiency: genetic basis for azathioprine and mercaptopurine intolerance. Ann Intern Med 1997;126:608-14.

79. Coulthard SA, Hall AG. Recent advances in the pharmacogenomics of thiopurine methyltransferase. Pharmacogenomics J 2001;1:254-61.

80. Ansari A, Hassan C, Duley J, Marinaki A, Shobowale-Bakre EM, Seed P, Meenan J, Yim A, Sanderson J. Thiopurine methyltransferase activity and the use of azathioprine in inflammatory bowel disease. Aliment Pharmacol Ther 2002;16:1743-50.

81. Evans WE. Pharmacogenetics of thiopurine S-methyltransferase and thiopurine therapy. Ther Drug Monit 2004;26:186-91.

82. Kurzawski M, Gawronska-Szklarz B, Drozdzik M. Frequency distribution of thiopurine s-methyltransferase alleles in a polish population. Ther Drug Monit 2004;26:541-5.

83. Kubota T, Chiba K. Frequencies of thiopurine S-methyltransferase mutant alleles $\left(\mathrm{TPMT}^{*} 2,{ }^{*} 3 \mathrm{~A},{ }^{*} 3 \mathrm{~B}\right.$ and ${ }^{*} 3 \mathrm{C}$ ) in 151 healthy Japanese subjects and the inheritance of $\mathrm{TPMT}^{*} 3 \mathrm{C}$ in the family of a propositus. $\mathrm{Br} \mathrm{J}$ Clin Pharmacol 2001;51:475-7. 
84. Ameyaw MM, Collie-Duguid ES, Powrie RH, Powrie RH, Ofori-Adjei D, McLeod $\mathrm{HL}$. Thiopurine methyltransferase alleles in British and Ghanaian populations. Hum Mol Genet 1999;8:367-70.

85. Collie-Duguid ES, Pritchard SC, Powrie RH, Sludden J, Collier DA, Li T, McLeod $\mathrm{HL}$. The frequency and distribution of thiopurine methyltransferase alleles in Caucasian and Asian populations. Pharmacogenetics 1999;9:37-42.

86. Weinshilboum RM, Sladek SL. Mercaptopurine pharmacogenetics: monogenic inheritance of erythrocyte thiopurine methyltransferase activity. Am J Hum Genet 1980;32:651-62.

87. Pettersson B, Almer S, Albertioni F, Söderhäll S, Peterson C. Differences between children and adults in thiopurine methyltransferase activity and metabolite formation during thiopurine therapy: possible role of concomitant methotrexate. Ther Drug Monit 2002;24:351-8.

88. Indjova D, Atanasova S, Shipkova M, Armstrong VW, Oellerich M, Svinarov D. Phenotypic and genotypic analysis of thiopurine s-methyltransferase polymorphism in the bulgarian population. Ther Drug Monit 2003;25:631-6.

89. Parks DA, Granger DN. Xanthine oxidase: biochemistry, distribution and physiology. Acta Physiol Scand Suppl 1986;548:87-99.

90. Deininger M, Szumlanski CL, Otterness DM, Van Loon J, Ferber W, Weinshilboum RM. Purine substrates for human thiopurine methyltransferase. Biochem Pharmacol 1994;48:2135-8.

91. Guerciolini R, Szumlanski C, Weinshilboum RM. Human liver xanthine oxidase: nature and extent of individual variation. Clin Pharmacol Ther 1991;50(6):663-72.

92. Wilson JM, Young AB, Kelley WN. Hypoxanthine-guanine phosphoribosyltransferase deficiency. The molecular basis of the clinical syndromes. $\mathrm{N}$ Engl J Med 1983;309:900-10.

93. Fraser JH, Meyers H, Henderson JF, Brox LW, McCoy EE. Individual variation in inosine triphosphate accumulation in human erythrocytes. Clin Biochem 1975;8:353-64.

94. Marinaki AM, Ansari A, Duley JA, Arenas M, Sumi S, Lewis CM, ShobowaleBakre el-M, Escuredo E, Fairbanks LD, Sanderson JD. Adverse drug reactions to azathioprine therapy are associated with polymorphism in the gene encoding inosine triphosphate pyrophosphatase (ITPase). Pharmacogenetics 2004;14: 181-7.

95. Sumi S, Marinaki AM, Arenas M, Fairbanks L, Shobowale-Bakre M, Rees DC, Thein SL, Ansari A, Sanderson J, De Abreu RA, Simmonds HA, Duley JA. Genetic basis of inosine triphosphate pyrophosphohydrolase deficiency. Hum Genet 2002;111:360-7.

96. Lewis LD, Benin A, Szumlanski CL, Otterness DM, Lennard L, Weinshilboum RM, Nierenberg DW. Olsalazine and 6-mercaptopurine-related bone marrow suppression: a possible drug-drug interaction. Clin Pharmacol Ther 1997;62: 464-75.

97. Lowry PW, Szumlanski CL, Weinshilboum RM, Sandborn WJ. Balsalazide and azathioprine or 6-mercaptopurine: evidence for a potentially serious drug interaction. Gastroenterology 1999;116:1505-6.

98. Szumlanski CL, Weinshilboum RM. Sulphasalazine inhibition of thiopurine methyltransferase: possible mechanism for interaction with 6-mercaptopurine and azathioprine. Br J Clin Pharmacol 1995;39:456-9. 
99. Dewit O, Vanheuverzwyn R, Desager JP, Horsmans $\mathrm{Y}$. Interaction between azathioprine and aminosalicylates: an in vivo study in patients with Crohn's disease. Aliment Pharmacol Ther 2002;16:79-85.

100. Lowry PW, Franklin CL, Weaver AL, Szumlanski CL, Mays DC, Loftus EV, Tremaine WJ, Lipsky JJ, Weinshilboum RM, Sandborn WJ. Leucopenia resulting from a drug interaction between azathioprine or 6-mercaptopurine and mesalamine, sulphasalazine, or balsalazide. Gut 2001;49:656-64.

101. Woodson LC, Ames MM, Selassie CD, Hansch C, Weinshilboum RM. Thiopurine methyltransferase. Aromatic thiol substrates and inhibition by benzoic acid derivatives. Mol Pharmacol 1983;24:471-8.

102. Lysaa RA, Giverhaug T, Wold HL, Aarbakke J. Inhibition of human thiopurine methyltransferase by furosemide, bendroflumethiazide and trichlormethiazide. Eur J Clin Pharmacol 1996;49:393-6.

103. Kennedy DT, Hayney MS, Lake KD. Azathioprine and allopurinol: the price of an avoidable drug interaction. Ann Pharmacother 1996;30:951-4.

104. Lennard L, Singleton HJ. High-performance liquid chromatographic assay of the methyl and nucleotide metabolites of 6-mercaptopurine: quantitation of red blood cell 6-thioguanine nucleotide, 6-thioinosinic acid and 6-methylmercaptopurine metabolites in a single sample. J Chromatogr 1992;583:83-90.

105. Lennard L. Assay of 6-thioinosinic acid and 6-thioguanine nucleotides, active metabolites of 6-mercaptopurine, in human red blood cells. J Chromatogr 1987;423:169-78.

106. Shipkova M, Armstrong VW, Wieland E, Oellerich M. Differences in nucleotide hydrolysis contribute to the differences between erythrocyte 6-thioguanine nucleotide concentrations determined by two widely used methods. Clin Chem 2003;49:260-8.

107. Armstrong VW, Shipkova M, von Ahsen N, Oellerich M. Analytic aspects of monitoring therapy with thiopurine medications. Ther Drug Monit 2004;26:220-6.

108. Dervieux T, Boulieu R. Simultaneous determination of 6-thioguanine and methyl 6-mercaptopurine nucleotides of azathioprine in red blood cells by HPLC. Clin Chem 1998;44:551-5.

109. Stefan C, Walsh W, Banka T, Adeli K, Verjee Z. Improved HPLC methodology for monitoring thiopurine metabolites in patients on thiopurine therapy. Clin Biochem 2004;37:764-71.

110. Erdmann GR, France LA, Bostrom BC, Canafax DM. A reversed phase high performance liquid chromatography approach in determining total red blood cell concentrations of 6-thioguanine, 6-mercaptopurine, methylthioguanine, and methylmercaptopurine in a patient receiving thiopurine therapy. Biomed Chromatogr 1990;4:47-51.

111. Cuffari $\mathrm{C}$, Hunt S, Bayless T. Utilisation of erythrocyte 6-thioguanine metabolite levels to optimise azathioprine therapy in patients with inflammatory bowel disease. Gut 2001;48:642-6.

112. Achkar JP, Stevens T, Easley K, Brzezinski A, Seidner D, Lashner B. Indicators of clinical response to treatment with six-mercaptopurine or azathioprine in patients with inflammatory bowel disease. Inflamm Bowel Dis 2004;10:339-45.

113. Hindorf U, Lyrenas E, Nilsson A, Schmiegelow K. Monitoring of long-term thiopurine therapy among adults with inflammatory bowel disease. Scand $\mathrm{J}$ Gastroenterol 2004;39:1105-12. 
114. Dubinsky MC, Yang H, Hassard PV, Seidman EG, Kam LY, Abreu MT, Targan SR, Vasiliauskas EA. 6-MP metabolite profiles provide a biochemical explanation for 6-MP resistance in patients with inflammatory bowel disease. Gastroenterology 2002;122:904-15.

115. Derijks LJ, Gilissen LP, Engels LG, Bos LP, Bus PJ, Lohman JJ, Curvers WL, Van Deventer SJ, Hommes DW, Hooymans PM. Pharmacokinetics of 6-mercaptopurine in patients with inflammatory bowel disease: implications for therapy. Ther Drug Monit 2004;26:311-8.

116. Belaiche J, Desager JP, Horsmans Y, Louis E. Therapeutic drug monitoring of azathioprine and 6-mercaptopurine metabolites in Crohn disease. Scand $\mathrm{J}$ Gastroenterol 2001;36:71-6.

117. Lowry PW, Franklin CL, Weaver AL, Pike MG, Mays DC, Tremaine WJ, Lipsky JJ, Sandborn WJ. Measurement of thiopurine methyltransferase activity and azathioprine metabolites in patients with inflammatory bowel disease. Gut 2001;49:665-70.

118. Gupta P, Gokhale R, Kirschner BS. 6-mercaptopurine metabolite levels in children with inflammatory bowel disease. J Pediatr Gastroenterol Nutr 2001;33:450-4.

119. Goldenberg BA, Rawsthorne P, Bernstein CN. The utility of 6-thioguanine metabolite levels in managing patients with inflammatory bowel disease. Am J Gastroenterol 2004;99:1744-8.

120. Sandborn WJ. 6-MP metabolite levels: a potential guide to Crohn's disease therapy. Gastroenterology 1997;113:690-2.

121. Cohen RD. Forecast for using metabolite measurements in the dosing of azathioprine or 6-mercaptopurine for IBD patients: "partly cloudy". Gastroenterology 2002;122:2082-4; discussion 2084.

122. Gilissen LP, Derijks LJ, Bos LP, Verhoeven HM, Bus PJ, Hooymans PM, Engels LG. Some cases demonstrating the clinical usefulness of therapeutic drug monitoring in thiopurine-treated inflammatory bowel disease patients. Eur $\mathrm{J}$ Gastroenterol Hepatol 2004;16:705-10.

123. Gilissen LP, Derijks LJ, Bos LP, Bus PJ, Hooymans PM, Engels LG. Therapeutic drug monitoring in patients with inflammatory bowel disease and established azathioprine therapy. Clin Drug Invest 2004;24:479-86.

124. Krynetski EY, Schuetz JD, Galpin AJ, Pui CH, Relling MV, Evans WE. A single point mutation leading to loss of catalytic activity in human thiopurine S-methyltransferase. Proc Natl Acad Sci U S A 1995;92:949-53.

125. Indjova D, Shipkova M, Atanasova S, Niedmann PD, Armstrong VW, Svinarov D, Oellerich M. Determination of thiopurine methyltransferase phenotype in isolated human erythrocytes using a new simple nonradioactive HPLC method. Ther Drug Monit 2003;25:637-44.

126. Schwab M, Schaeffeler E, Marx C, Zanger U, Aulitzky W, Eichelbaum M. Shortcoming in the diagnosis of TPMT deficiency in a patient with Crohn's disease using phenotyping only. Gastroenterology 2001;121:498-9.

127. Louis E, Belaiche J. Optimizing treatment with thioguanine derivatives in inflammatory bowel disease. Best Pract Res Clin Gastroenterol 2003;17:37-46.

128. Black AJ, McLeod HL, Capell HA. Thiopurine methyltransferase genotype predicts therapy-limiting severe toxicity from azathioprine. Annals of Internal Medicine 1998;129:716-8. 
129. Zelinkova Z, Derijks LJ, Stokkers PC, Vogels EW, van Kampen AH, Curvers WL, Cohn D, van Deventer SJ, Hommes DW. Inosine triphosphate pyrophosphatase and thiopurine s-methyltransferase genotypes relationship to azathioprineinduced myelosuppression. Clin Gastroenterol Hepatol 2006;4:44-9.

130. Campbell S, Kingstone K, Ghosh S. Relevance of thiopurine methyltransferase activity in inflammatory bowel disease patients maintained on low-dose azathioprine. Aliment Pharmacol Ther 2002;16:389-98.

131. Regueiro $M$, Mardini $H$. Determination of thiopurine methyltransferase genotype or phenotype optimizes initial dosing of azathioprine for the treatment of Crohn's disease. J Clin Gastroenterol 2002;35:240-4.

132. Sandborn WJ. Rational dosing of azathioprine and 6-mercaptopurine. Gut 2001;48:591-2.

133. Seidman EG. Clinical use and practical application of TPMT enzyme and 6-mercaptopurine metabolite monitoring in IBD. Rev Gastroenterol Disord 2003; 3 Suppl 1:S30-8.

134. Kaskas BA, Louis E, Hindorf U, Schaeffeler E, Deflandre J, Graepler F, Schmiegelow K, Gregor M, Zanger UM, Eichelbaum M, Schwab M. Safe treatment of thiopurine S-methyltransferase deficient Crohn's disease patients with azathioprine. Gut 2003;52:140-2.

135. Colombel JF, Ferrari N, Debuysere H, Marteau P, Gendre JP, Bonaz B, Soulé JC, Modigliani R, Touze Y, Catala P, Libersa C, Broly F. Genotypic analysis of thiopurine S-methyltransferase in patients with Crohn's disease and severe myelosuppression during azathioprine therapy. Gastroenterology 2000;118: 1025-30.

136. Gearry RB, Barclay ML, Burt MJ, Collett JA, Chapman BA, Roberts RL, Kennedy MA. Thiopurine S-methyltransferase (TPMT) genotype does not predict adverse drug reactions to thiopurine drugs in patients with inflammatory bowel disease. Aliment Pharmacol Ther 2003;18:395-400.

137. Duley JA, Simmonds HA, Hopkinson DA, Levinsky RJ. Inosine triphosphate pyrophosphohydrolase deficiency in a kindred with adenosine deaminase deficiency. Clin Chim Acta 1990;188:243-52.

138. Allorge D, Hamdan R, Broly F, Libersa C, Colombel JF. ITPA genotyping test does not improve detection of Crohn's disease patients at risk of azathioprine/6-mercaptopurine induced myelosuppression. Gut 2005;54:565.

139. Baert F, Rutgeerts P. 6-Thioguanine: a naked bullet? (Or how pharmacogenomics can make old drugs brand new). Inflamm Bowel Dis 2001;7:190-1.

140. Derijks LJ, De Jong DJ, Gilissen LP, Engels LG, Hooymans PM, Jansen JB, Mulder CJ. 6-Thioguanine seems promising in azathioprine- or 6-mercaptopurineintolerant inflammatory bowel disease patients: a short-term safety assessment. Eur J Gastroenterol Hepatol 2003;15:63-7.

141. Dubinsky MC, Feldman EJ, Abreu MT, Targan SR, Vasiliauskas EA. Thioguanine: a potential alternate thiopurine for IBD patients allergic to 6-mercaptopurine or azathioprine. Am J Gastroenterol 2003;98:1058-63.

142. Bonaz B, Boitard J, Marteau $\mathrm{P}$, Lémann M, Coffin B, Flourié B, Belaiche J, Cadiot G, Metman EH, Cortot A, Colombel JF; Getaid. Tioguanine in patients with Crohn's disease intolerant or resistant to azathioprine/mercaptopurine. Aliment Pharmacol Ther 2003;18:401-8. 
143. Herrlinger KR, Kreisel W, Schwab $M$, Schoelmerich J, Fleig WE, Ruhl A, Reinshagen M, Deibert P, Fellermann K, Greinwald R, Stange EF. 6-Thioguanineefficacy and safety in chronic active Crohn's disease. Aliment Pharmacol Ther 2003;17:503-8.

144. Herrlinger KR, Deibert P, Schwab M, Kreisel W, Fischer C, Fellermann K, Stange EF. Remission maintenance by tioguanine in chronic active Crohn's disease. Aliment Pharmacol Ther 2003;17:1459-64.

145. Dubinsky MC, Vasiliauskas EA, Singh H, Abreu MT, Papadakis KA, Tran T, Martin P, Vierling JM, Geller SA, Targan SR, Poordad FF. 6-Thioguanine can cause serious liver injury in inflammatory bowel disease patients. Gastroenterology 2003;125:298-303.

146. Shastri S, Dubinsky MC, Fred Poordad F, Vasiliauskas EA, Geller SA. Early nodular hyperplasia of the liver occurring with inflammatory bowel diseases in association with thioguanine therapy. Arch Pathol Lab Med 2004;128:49-53.

147. Geller SA, Dubinsky MC, Poordad FF, Vasiliauskas EA, Cohen AH, Abreu MT, Tran T, Martin P, Vierling JM, Targan SR. Early hepatic nodular hyperplasia and submicroscopic fibrosis associated with 6-thioguanine therapy in inflammatory bowel disease. Am J Surg Pathol 2004;28:1204-11.

148. Naber AH, Van Haelst U, Yap SH. Nodular regenerative hyperplasia of the liver: an important cause of portal hypertension in non-cirrhotic patients. J Hepatol 1991;12:94-9.

149. Stromeyer FW, Ishak KG. Nodular transformation (nodular "regenerative" hyperplasia) of the liver. A clinicopathologic study of 30 cases. Hum Pathol 1981;12:60-71. 
Therapeutic drug monitoring of thiopurine metabolites in patients with inflammatory bowel disease 


\section{Chapter}

\section{Pharmacokinetics of 6-mercaptopurine in patients with inflammatory bowel disease. Implications for therapy}

LJJ Derijks, LPL Gilissen, LGJB Engels, LP Bos, PJ Bus, JJHM Lohman, WL Curvers, SJH van Deventer, DW Hommes, PM Hooymans 


\section{Abstract}

\section{Background \& aims}

Proper prospective pharmacokinetic studies of 6-mercaptopurine (6-MP) in inflammatory bowel disease (IBD) patients are lacking, which have resulted in conflicting recommendations for metabolite monitoring in routine practice. The authors have evaluated 6-MP pharmacokinetics in IBD patients, including the genetic background for thiopurine methyltransferase (TPMT).

\section{Methods}

Red blood cell (RBC) 6-thioguanine nucleotides (6-TGN) and 6-methylmercaptopurine ribonucleotides (6-MMPR) concentrations were measured in thirty IBD-patients at $t=1,2,4$ and 8 weeks after starting 6-MP, $50 \mathrm{mg}$ once daily. Outcome measures included mean 6-TGN and 6 -MMPR concentrations $( \pm 95 \%$ confidence interval $(\mathrm{Cl} 95 \%)$ ), and their associations with TPMT genotype, 6-MP dose, hematologic-, hepatic-, pancreatic- and efficacy parameters during the eight week period.

\section{Results}

Steady state concentrations were reached after four weeks, indicating a half life of approximately five days for both 6-TGN and 6-MMPR, and were 368 (Cl95\%: 284-452) and 2837 (CI95\%: 21013573) $\mathrm{pmol} / 8 \times 10^{8} \mathrm{RBCs}$ respectively. Large inter-patient variability occurred at all time-points. TPMT genotype correlated with 6-TGN concentrations $(0.576, p<0.01)$ and patients with mutant alleles had a relative risk (RR) of 12.0 (CI95\%: 1.7-92.3) of developing leukopenia. A 6-MMPR/ $6-\mathrm{TGN}$ ratio $<11$ was associated with therapeutic efficacy.

\section{Conclusions}

Based on this pharmacokinetic analysis, therapeutic drug monitoring is essential for rational 6-MP dosing. 


\section{Introduction}

6-Mercaptopurine (6-MP) is widely used in treatment of inflammatory bowel disease (IBD) and has proven to be effective for both inducing and maintaining long-term remission of Crohn's disease (CD) and ulcerative colitis (UC) $)^{1-3}$. $6-\mathrm{MP}$ is more frequently used in the United States, whereas its precursor azathioprine $(\mathrm{AZA})$ is the thiopurine of choice in Europe. 6-MP is transformed along competing enzymatic pathways ${ }^{4}$ and individual differences probably account for variations in metabolite concentrations ${ }^{4}$. Thiopurine metabolism, as depicted in Figure 2.1, ends with the formation of 6-thioguanine nucleotides (6-TGN), which are incorporated into DNA inducing cytotoxicity and immunosuppression ${ }^{4,5}$.

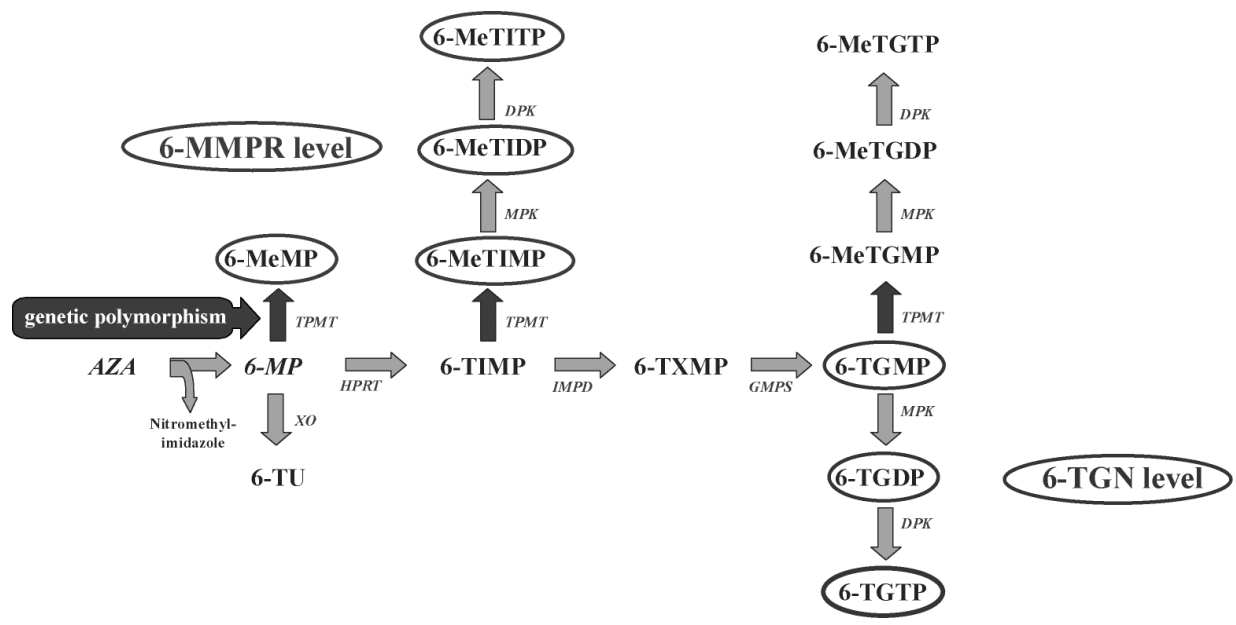

Figure 2.1 Thiopurine metabolism.

AZA, azathioprine; 6-MP, 6-mercaptopurine; 6-MMPR, 6-methylmercaptopurine ribonucleotides; 6-TU, 6-thiouric acid; 6-MeTIMP, 6-methylmercaptopurine ribonucleotide; 6-TIMP, 6-thioinosine monophosphate; 6-TXMP, 6-thioxanthosine monophosphate; 6-TGMP+6-TGDP+6-TGTP, 6-thioguanine nucleotides; 6-MeTGMP, 6-methylthioguanine nucleotide; $X O$, xanthine oxidase; TPMT, thiopurine S-methyltransferase; HPRT, hypoxanthine phosphoribosyl transferase; IMPD, inosine monophosphate dehydrogenase; GMPS, guanosine monophosphate synthetase; MPK, monophosphate kinase; DPK, diphosphate kinase

Currently, it is much debated whether assessment of metabolite concentrations is clinically useful in predicting both drug efficacy and toxicity and conflicting results have been published: a correlation between 6-TGN concentrations and clinical efficacy was shown in paediatric patients ${ }^{6}$, but not in a large cohort of adult patients ${ }^{7,8}$. In addition, thiopurine dosing did not correlate with clinical efficacy $^{6,7}$. It is also uncertain which 6-MP metabolites are responsible for 
specific side effects. It has been suggested that high 6-TGN concentrations are associated with leukopenia, whereas elevated 6-methylmercaptopurine ribonucleotides (6-MMPR) concentrations correlate with hepatotoxicity. However, the precise role of 6-MMPR remains unclear, since this metabolite also has anti-proliferative properties that may result in clinical efficacy ${ }^{9}$.

These controversies in part result from a lack of prospective pharmacokinetic data in IBD patients. Besides, the clinical implications of genetic differences in 6-MP metabolism such as the much reported thiopurine S-methyltransferase (TPMT) polymorphism remain uncertain, leading to various recommendations on the use of metabolite measurements ${ }^{10,11}$.

The aim of this study was to collect pharmacokinetic data of thiopurines in IBD patients in a prospective study.

\section{Materials and methods}

\section{Patient selection}

IBD patients in which 6-MP was indicated, aged between 18 and 75 years and attending the out-patient clinics of Maasland Hospital Sittard or St Laurentius Hospital Roermond, were eligible for the study. Considered as indications for 6-MP treatment were steroid-dependency, steroid-resistancy and AZAintolerance. Exclusion criteria were: pregnancy or expected pregnancy within six months, inadequate contraception in women, lactation, presence of active infection, history of tuberculosis, HIV, hepatitis B or C, severe pancreatitis (necrotizing pancreatitis or pancreatitis leading to multi organ failure), malignancy, ongoing treatment with other immunosuppressive drugs like cyclosporine, methotrexate, thalidomide or infliximab, impaired renal function (serum creatinin $>2$ times normal upper limit), elevated liver function tests $(>2$ times normal upper limit) and bone marrow suppression.

\section{Study design}

The trial design was a prospective open-label multicentre study. At entry patient demographics and clinical history were collected as well as medicationuse during the past year. Subsequently, 6-MP (Puri-Nethol ${ }^{\mathrm{TM}}$, tablet $50 \mathrm{mg}$, Glaxo Wellcome, Zeist, the Netherlands) was prescribed as a single oral $50 \mathrm{mg}$ evening dose. Concomitant medication was continued. Laboratory parameters and disease activity scores (Crohn's Disease Activity Index (CDAI) for CD and Truelove-Witts Disease Activity Index (TWDAI) for UC) were obtained at 0 (baseline), 1, 2, 4 and 8 weeks after start of medication. Blood was drawn at each visit for measurement of 6-TGN and 6-MMPR concentrations, alanine 
transaminase (ALT), aspartate transaminase (AST), bilirubin, amylase, lipase, leukocytes (plus differentiation), platelets and haemoglobin $(\mathrm{Hb})$.

\section{Ethical considerations}

The protocol was approved by the local medical ethics committee and in accordance with the Helsinki Declaration. Informed written consent was obtained before enrolment.

\section{Outcome measures}

Outcome measures were mean 6-TGN and 6-MMPR concentrations $\pm \mathrm{Cl}$ - $95 \%$, correlation between either steady state 6-TGN or 6-MMPR concentrations with several other parameters including dose per kg bodyweight, TPMT genotype (TPMT ${ }^{*} 1 / \mathrm{TPMT}^{*} 2 / \mathrm{TPMT}^{*} 3 \mathrm{~A} / \mathrm{TPMT}^{*} 3 \mathrm{~B} / \mathrm{TPMT}^{*} 3 \mathrm{C}$ ), leukocyte counts, platelet counts, $\mathrm{Hb}$, the occurrence of myelotoxicity (leukocyte count $<4.0 \times 10^{9} / \mathrm{l}$, platelet count $\left.<100 \times 10^{9} / \mathrm{l}\right)$, alanine transaminase (ALT), aspartate transaminase (AST), amylase, lipase, bilirubins, the occurrence of hepatic toxicity (ALT >80 U/l, AST $>80 \mathrm{U} / \mathrm{l}$, bilirubins $>40 \mu \mathrm{mol} / \mathrm{l}$ ), pancreatic toxicity (amylase $>220 \mathrm{U} / \mathrm{l}$, lipase $>120 \mathrm{U} / \mathrm{l}$ (elevations >2 times normal upper limit)), CDAI (CD) or TWDAI (UC) during the 8 week period.

\section{Analytical procedures}

\section{TPMT genotype}

TPMT-genotyping of leukocyte DNA was carried out by the laboratory of the Department of Gastroenterology and Hepatology, Academic Medical Centre, Amsterdam, based on a previously reported assay ${ }^{12}$. TPMT-genotyping of leukocyte DNA was carried out by polymerase chain reaction (PCR) amplification in a thermocycler Gene AMP ${ }^{\circledR}$ PCR System 9700 (Perkin Elmer, Norwalk, CT, USA) followed by digestion with specific restriction enzymes. The products were separated by $2 \%$ agarose gel containing $1 \times$ TAE with $0,5 \mu \mathrm{g} / \mathrm{ml}$ ethidium bromide and read using the GeneGenius (Syngene, Cambridge, UK). The $\mathrm{TPMT}^{\star} 2$ allele contains a single G238C transversion mutation. The $\mathrm{TPMT}^{\star} 3 \mathrm{~A}$ allele contains two nucleotide transition mutations, being G460A and A719G. The TPMT*3B allele contains only the G460A mutation, whereas the $\mathrm{TPMT}^{\star} 3 \mathrm{C}$ allele only has a single $\mathrm{A} 719 \mathrm{G}$ mutation.

G238C detection: The detection of the G238C mutation was carried out using a mutant primer P2M (5'-GTATGATTTTATGCAGGTTTG-3') or a wild primer P2W (5'-GTATGATTTTATGCAGGTTTC-3') and a reverse primer P2C (5'-TAAATAGGAACCATCGGACAC-3'). $100 \mu \mathrm{l}$ PCR-mix was prepared using $49 \mu \mathrm{l} \mathrm{H}{ }_{2} \mathrm{O}, 49 \mu \mathrm{l}$ Reddymix ${ }^{\mathrm{TM}}$ PCR Mastermix [2,5 mM MgCl${ }_{2}$ ] (Abgene, Surney, UK), $1 \mu \mathrm{l} \mathrm{P} 2 \mathrm{M}$ or P2W and $1 \mu \mathrm{l} \mathrm{P} 2 \mathrm{C} .1 \mu \mathrm{l}$ of worksolution (one part of 
above mentioned DNA by ten parts TE) was used as template in $10 \mu \mathrm{l} \mathrm{PCR}-$ mix. The PCR reaction was carried out using the following cycles: an initial cycle of five minutes at $94^{\circ} \mathrm{C}$ followed by 30 cycles of 30 seconds at $94^{\circ} \mathrm{C}$, one minute at $54^{\circ} \mathrm{C}$, one minute at $72^{\circ} \mathrm{C}$, and a single final extension cycle at $72^{\circ} \mathrm{C}$ for five minutes. The PCR-products were analyzed by electrophoresis under the conditions as mentioned above. A DNA fragment was amplified with P2M and $\mathrm{P} 2 \mathrm{C}$ primers when the $\mathrm{G} 238 \mathrm{C}$ allele was present and with $\mathrm{P} 2 \mathrm{~W}$ and $\mathrm{P} 2 \mathrm{C}$ primers when the wild-type allele was present.

G460A detection: The detection of the G460A mutation was done using restriction fragment length polymorphism (rplf) analysis. The primers used for amplification by PCR were G460Afor (5'-ATAACAGAGTGGGAGGCTGC-3') and G460Arev (5'-CTAGAACCCAGAAAAAGTATAG). $100 \mu \mathrm{l} \mathrm{PCR-} \mathrm{mix} \mathrm{was}$ prepared using $49 \mu \mathrm{l} \mathrm{H}_{2} \mathrm{O}, 49 \mu \mathrm{l}$ Reddymix ${ }^{\mathrm{TM}}$ PCR Mastermix, $1 \mu \mathrm{l} \mathrm{G460Afor}$ and $1 \mu \mathrm{l} \mathrm{G460Arev.} \mathrm{One} \mu$ l of worksolution (one part of above mentioned DNA by 10 parts TE) was used as template in $10 \mu$ PCR-mix. The PCR reaction was carried out in the same way as with the G238C detection. The PCR-products were digested by the endonuclease Mwol (New England Biolabs) for three

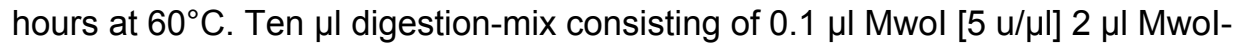
buffer and $7.9 \mu \mathrm{l} \mathrm{H}_{2} \mathrm{O}$ was used per $10 \mu \mathrm{l} \mathrm{PCR}$-products. Digested products were analyzed by electrophoresis under the conditions as mentioned above. Mwol digestion of wild-type DNA yields fragments of 267 and 98 base pairs, whereas DNA containing the G460A mutation is not digested and yields an uncleaved fragment of 365 base pairs.

A719G detection: This detection was also carried out by rflp analysis. The primers used for this amplification by PCR were p719f (5'-GJGKJGKJHGJHG$3^{\prime}$ ) and the p719r (5'-GJHFGFHJGFJH-3'). A $100 \mu \mathrm{l} \mathrm{PCR-} \mathrm{mix} \mathrm{was} \mathrm{prepared}$ using $49 \mu \mathrm{l} \mathrm{H}_{2} \mathrm{O}, 49 \mu \mathrm{l}$ Reddymix ${ }^{\mathrm{TM}}$ PCR Mastermix, $1 \mu \mathrm{l} \mathrm{p719f}$ and $1 \mu \mathrm{l} \mathrm{p719r.}$ $1 \mu \mathrm{l}$ of worksolution (one part of above mentioned DNA by ten parts TE) was used as template in $10 \mu \mathrm{l} \mathrm{PCR-mix.} \mathrm{The} \mathrm{PCR} \mathrm{reaction} \mathrm{was} \mathrm{carried} \mathrm{out} \mathrm{using}$ the following cycles: an initial cycle of five minutes at $94^{\circ} \mathrm{C}$ followed by 30 cycles of 30 seconds at $94^{\circ} \mathrm{C}, 40$ seconds at $55^{\circ} \mathrm{C}$, one minute at $72^{\circ} \mathrm{C}$, and a single final extension cycle at $72^{\circ} \mathrm{C}$ for five minutes. The PCR-products were digested by the endonuclease Accl (New England Biolabs) overnight by $37^{\circ} \mathrm{C}$. Per $10 \mu \mathrm{l} \mathrm{PCR-products} \mathrm{was} \mathrm{used} 20 \mu \mathrm{l}$ digestion-mix consisting of $0.05 \mu \mathrm{l}$ Accl

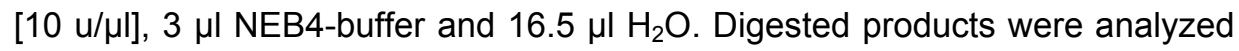
by electrophoresis under the conditions as mentioned above. DNA containing the A719G mutation was digested in two fragments of 201 and 62 base pairs, whereas wild-type DNA was not digested. 


\section{6-TGN and 6-MMPR concentrations}

6-TGN and 6-MMPR concentrations were measured in the laboratory of the Department of Clinical Pharmacy, Maasland Hospital, Sittard, using a slightly modified assay previously reported by Lennard and colleagues ${ }^{13}$. Erythrocytes are a good surrogate matrix as they are easily obtained, exist in sufficient numbers and contain concentrations of 6-TGN that reflect concentrations of $6-T G N$ in the less accessible putative target-tissue, the leukocytes ${ }^{14}$. All modified procedures are described.

\section{Sample preparation}

Whole blood samples were collected in coated lithium heparin tubes at least twelve hours after medication intake. The samples were centrifuged at $160 \mathrm{~g}$ for ten minutes and plasma and "buffy coat" were discarded. RBC were washed with a same volume of phosphate buffered saline (PBS) solution, mixed and centrifuged at $160 \mathrm{~g}$ for ten minutes again. The supernatant was removed, $\mathrm{RBC}$ were washed following the described procedure once again and centrifuged at $640 \mathrm{~g}$ for ten minutes. Finally, the RBC were resuspended in the same volume of PBS solution and erythrocyte counts were carried out with a Cell Dyn 4000 cell counter (Abbott, Hoofddorp, The Netherlands). Samples were stored at $-20^{\circ} \mathrm{C}$ until required.

\section{Extraction}

For measurement of intracellular thionucleotides the free base was obtained by acid hydrolysis of the nucleotide back to the purine. In brief, $200 \mu \mathrm{l}$ RBC (approximately $8 \times 10^{8} \mathrm{RBC}$ ) were added to a $10-\mathrm{ml}$ round-botommed extraction-tube containing $500 \mu \mathrm{l}$ water and $300 \mu \mathrm{l}$ of $10 \mathrm{mM}$ DL-dithiothreitol (DTT). To this was added $500 \mu 1.5 \mathrm{M}$ sulphuric acid and the tubes were heated at $100^{\circ} \mathrm{C}$ for exactly one hour in a ThermoChem heating block (Marius, Germany). After cooling, $500 \mu \mathrm{l} 3.4 \mathrm{M}$ sodium hydroxide was added, followed by $5 \mathrm{ml}$ of $1 \mathrm{mM}$ phenylmercuric chloride in dichloromethane. After shaking and centrifugation at $3500 \mathrm{rpm}$ for five minutes, $3 \mathrm{ml}$ of the organic layer was transferred to another $10-\mathrm{ml}$ round-bottomed extraction tube and $200 \mu \mathrm{l}$ of $0.1 \mathrm{M}$ hydrochloric acid was added. Again the tubes were shaken and centrifuged at $3500 \mathrm{rpm}$ for five minutes. Finally, $10 \mu 10 \mathrm{mM}$ DTT was added to $100 \mu \mathrm{l}$ of the acid layer and the solution was transferred to a HPLC injectionvial.

\section{HPLC procedure}

For 6-thioguanine nucleotide (6-TGN) determination $40 \mu \mathrm{l}$ of the acidic extract was injected through a 717 plus Autosampler (Waters Chromatography BV, 
Etten-leur, The Netherlands) onto a NovaPak $\mathrm{C}_{18}$ column $(3,9 \times 150 \mathrm{~mm}), 4 \mu \mathrm{m}$ particle size (Waters Chromatography BV). 6-TGN was detected by a 2487 Dual $\lambda$ Absorbance UV Detector (Waters Chromatography BV) set at $343 \mathrm{~nm}$ and the chromatographic traces were stored on a personal computer for further analysis using Millennium ${ }^{32}$ Chromatography Manager software (Waters Chromatography BV). A model 510 HPLC pump (Waters Chromatography BV) was used for solvent delivery. The mobile phase consisted of $50 \mathrm{mM}$ orthophosphoric acid and $0.5 \mathrm{mM}$ DTT. For 6-MMPR determination, $30 \mu \mathrm{l}$ of the acidic extract was processed as indicated above with the following modifications: the wavelenght was set at $303 \mathrm{~nm}$ and the mobile phase consisted of a methanol:water mixture $(4: 96 \mathrm{v} / \mathrm{v})$, containing $150 \mathrm{mM}$ triethylamine and $0.5 \mathrm{mM}$ DTT, adjusted to $\mathrm{pH} 3.2$ with orthophosphoric acid $85 \%$.

\section{Calibration}

Calibration curves were constructed by spiking RBC with 6-TGN (Sigma, St Louis, USA) in the range of $120-3600 \mathrm{pmol} / 8 \times 10^{8} \mathrm{RBC}$ and 6-MMPR (Sigma, St Louis, USA) in the range of $700-36000 \mathrm{pmol} / 8 \times 10^{8} \mathrm{RBC}$. These curves were lineair with correlation coefficients of 0.992 and 0.998 for 6-TGN and 6-MMPR. Control samples were obtained and prepared by pooling blood samples of several patients on 6-MP treatment. The run-to-run coefficient of variation was $6.6 \%$ and $9.7 \%$ for $6-$ TGN and 6-MMPR respectively. The lower limit of quantification of the assay was determined at $30 \mathrm{pmol} / 8 \times 10^{8} \mathrm{RBC}$ for $6-\mathrm{TGN}$ and $300 \mathrm{pmol} / 8 \times 10^{8} \mathrm{RBC}$ for $6-\mathrm{MMPR}$.

\section{Statistical analysis}

Normality was tested by the Kolmogorov-Smirnov test. Data are expressed as means with range or $95 \%$ confidence interval (Cl95\%). Pearson's correlation was used to test the relationship between the measured parameters. The $\chi^{2}$ test was used to test the association between TPMT-genotype and the occurrence of leukopenia. $P$ values $<0.05$ were considered significant. SPSS for Windows (version 10.0.7) software was used to perform statistics.

\section{Results}

\section{Patients}

Patient characteristics, reasons for 6-MP initiation and for study failure are shown in Table 2.1. Thirty patients were enrolled between March 2001 and June 2002. Of the 30 patients that started 6-MP treatment, 23 patients $(77 \%)$ were on 6-MP treatment for four weeks and 17 patients (57\%) completed the 
eight week period. Steady state was reached after a period of four weeks. Thirteen patients failed to reach the end of the observed period and three failures were classified as non-6-MP related (Table 2.1). Drug intolerance in two patients included generalised malaise in one and palpitations/headache in the other, latter patient also demonstrating intolerance to previous AZA treatment. The other AZA-intolerant patient suffered from acute pancreatitis.

Table 2.1 Patient characteristics.

\begin{tabular}{|c|c|c|c|}
\hline & & \multicolumn{2}{|c|}{$N=30$} \\
\hline \multicolumn{2}{|c|}{$\overline{\operatorname{Sex}(M / F)}$} & \multicolumn{2}{|c|}{$20 / 10$} \\
\hline \multicolumn{2}{|c|}{ Age (yrs) (mean + range) } & \multicolumn{2}{|c|}{$41(19-68)$} \\
\hline \multicolumn{2}{|c|}{ Disease (CD/UC) } & \multicolumn{2}{|c|}{ 19/11 } \\
\hline \multicolumn{2}{|c|}{ Duration of disease $(\mathrm{yrs})(\mathrm{mean}+\mathrm{Cl} 95 \%)$} & \multicolumn{2}{|c|}{$6.5(4.1-8.9)$} \\
\hline \multicolumn{4}{|c|}{ Disease activity at baseline } \\
\hline \multirow[t]{3}{*}{$C D$} & remission, $\mathrm{CDAl}<150$ & \multicolumn{2}{|c|}{12} \\
\hline & active, CDAI 150-300 & \multicolumn{2}{|l|}{6} \\
\hline & unknown & \multicolumn{2}{|l|}{1} \\
\hline & remission, TWDAI $\leq 6$ & \multicolumn{2}{|l|}{5} \\
\hline & active, TWDAI >6 & \multicolumn{2}{|l|}{4} \\
\hline & unknown & \multicolumn{2}{|l|}{2} \\
\hline \multicolumn{2}{|c|}{ Quality of Life at baseline* } & \multicolumn{2}{|c|}{62} \\
\hline \multicolumn{2}{|c|}{ 5-ASA / no 5-ASA } & \multicolumn{2}{|c|}{$28 / 2$} \\
\hline \multicolumn{2}{|c|}{ 5-ASA dose $(\mathrm{mg})$ (median + range) } & \multicolumn{2}{|c|}{$3000(1500-4000)$} \\
\hline \multicolumn{4}{|c|}{ Reason for 6-MP initiation } \\
\hline \multicolumn{2}{|c|}{ Disease activity/steroid dependency } & \multicolumn{2}{|c|}{28} \\
\hline \multicolumn{2}{|c|}{ AZA intolerance } & \multicolumn{2}{|l|}{2} \\
\hline $6-M$ & $(\mathrm{mg} / \mathrm{kg})($ mean $+\mathrm{Cl} 95 \%)$ & \multicolumn{2}{|c|}{$0.71(0.66-0.76)$} \\
\hline \multicolumn{4}{|c|}{ TPMT genotype } \\
\hline *1/* & & 20 & \\
\hline$* 1 / *$ & & 2 & \\
\hline$* 1 / *$ & & 2 & \\
\hline *3A & & 1 & \\
\hline not & ned & 5 & \\
\hline Study fail & & 13 & \\
\hline non & elated & 3 & \\
\hline $6-M$ & & 10 & \\
\hline & intolerance & 2 & (1 AZA intolerant patient) \\
\hline & leukopenia & 4 & \\
\hline & hepatotoxicity & 1 & \\
\hline & pancreatitis & 3 & (1 AZA intolerant patient) \\
\hline
\end{tabular}

$\mathrm{N}$, number of patients; M, male; F, female; CD, Crohn's disease; UC, ulcerative colitis; CDAI, Crohn's disease activity index; TWDAl, Truelove-Witts disease activity index; 5-ASA, 5-aminosalicylic acid (-analogues); 6-MP, 6-mercaptopurine; AZA, azathioprine; TPMT, thiopurine S-methyl transferase.

* according VAS-score (0-100\%). 


\section{Metabolite concentrations and TPMT genotype}

Metabolite concentrations were normally distributed. Mean 6-TGN and 6-MMPR concentrations are shown in Table 2.2. Individual 6-TGN and 6-MMPR level curves are shown in Figure 2.2 and 2.3 respectively. No correlation was found between steady state 6-TGN and 6-MMPR concentrations or between either 6-TGN or 6-MMPR level and dose per $\mathrm{kg}$ bodyweight. The TPMT genotype (wild type- versus mutant type TPMT) showed a significant and clinically important correlation with 6-TGN concentrations $(0.576, \mathrm{Cl} 95 \%$ : 0.18-0.81, $\mathrm{p}<0.01)$, but not with 6-MMPR concentrations.

Table 2.2 6-TGN and 6-MMPR levels.

\begin{tabular}{lcc}
\hline week & $\begin{array}{c}6-\mathrm{TGN} \\
\left(\mathrm{pmol} / 8 \times 10^{8} \mathrm{RBC}\right)\end{array}$ & $\begin{array}{c}6-\mathrm{MMPR} \\
\left(\mathrm{pmol} / 8 \times 10^{8} \mathrm{RBC}\right)\end{array}$ \\
\hline $1(\mathrm{~N}=30)$ & $236(149-323)$ & $1691(1316-2066)$ \\
$2(\mathrm{~N}=26)$ & $306(223-386)$ & $2783(2123-3443)$ \\
$4(\mathrm{~N}=23)$ & $368(284-452)$ & $2837(2101-3573)$ \\
$8(\mathrm{~N}=17)$ & $355(262-447)$ & $2318(1327-3308)$ \\
\hline
\end{tabular}

$\mathrm{N}$, number of patients; 6-TGN, 6-thioguanine nucleotides; 6-MMPR, 6-methylmercaptopurine ribonucleotides. Data are expressed as means (with 95\% confidence interval)

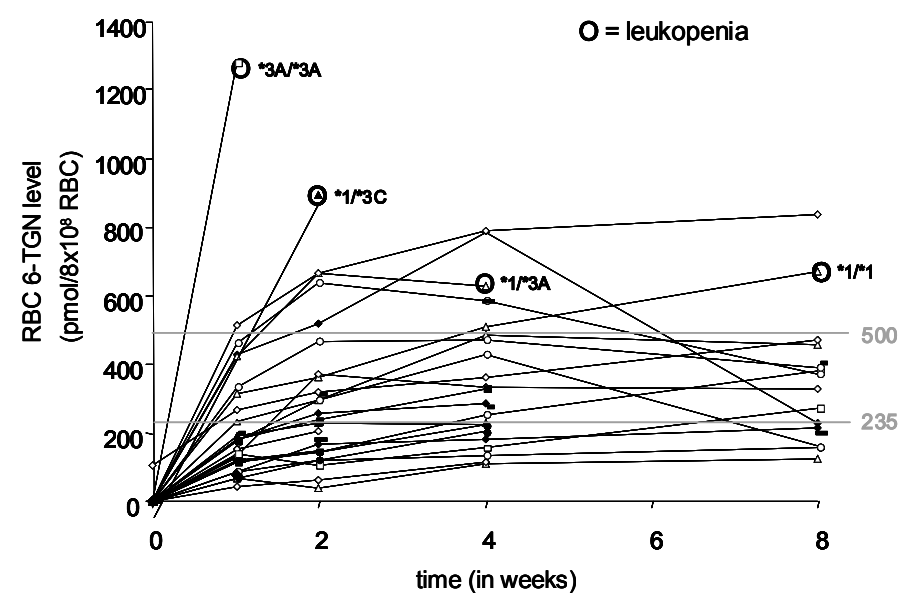

Figure 2.2 Individual 6-TGN concentration curves. The four patients that discontinued 6-MP therapy due to the occurrence of leukopenia are circled and their corresponding TPMT genotypes are displayed. The in literature suggested therapeutic lower- and upper limit are indicated ${ }^{6}$.

6-TGN, 6-thioguanine nucleotides; RBC, red blood cell; 6-MP, 6-mercaptopurine; TPMT, thiopurine S-methyltransferase. 


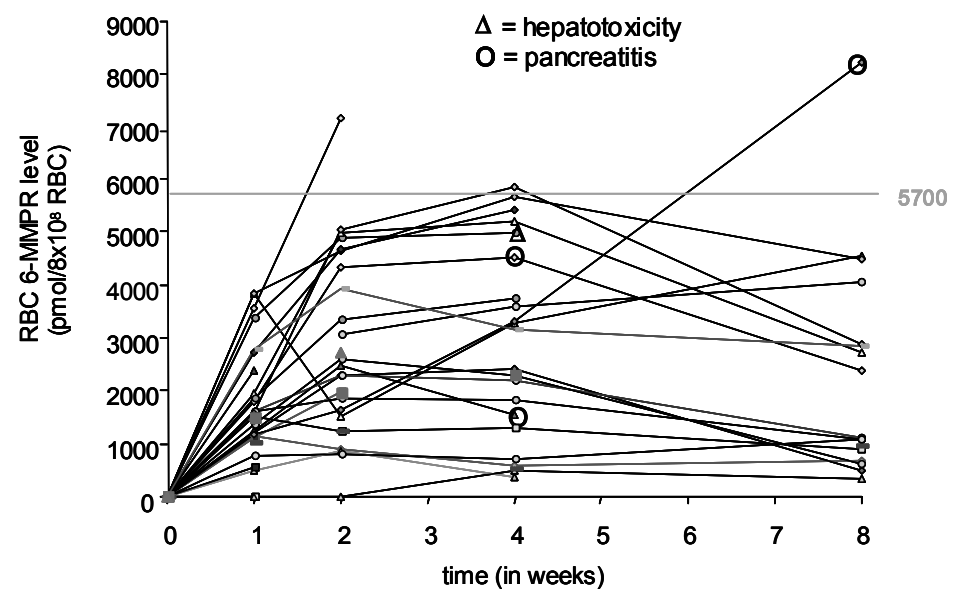

Figure 2.3 Individual 6-MMPR concentrations curves. The three patients that discontinued 6-MP therapy due to the occurrence of pancreatitis are circled and the one patient with drug-induced hepatotoxicity is displayed with a square. The in literature suggested therapeutic upper limit is indicated ${ }^{6}$.

6-MMPR, 6-methylmercaptopurine ribonucleotides; RBC, red blood cells; 6-MP, 6-mercaptopurine

\section{Adverse events}

Ten patients discontinued therapy because of adverse events (Table 2.1). Only for the occurrence of leukopenia, a significant correlation with TPMT genotype was observed with an increase in relative risk (RR) of 12.0 (Cl95\%: 1.7-92.3) (Table 2.3). Notably, 6-TGN concentrations in all four patients who developed leukopenia were above $300 \mathrm{pmol} / 8 \times 10^{8} \mathrm{RBC}$ after one week.

TPMT genotype was not predictive of drug intolerance, hepatotoxicity or the development of pancreatitis. 6-TGN did not show any correlation with hepatotoxicity or other adverse events. In this study, 6-MMPR concentrations did not correlate with ALT, AST, amylase, lipase, bilirubins or the occurrence of hepatotoxicity. In one of the three patients who developed pancreatitis however, the 6-MMPR level was considerably high $\left(8224 \mathrm{pmol} / 8 \times 10^{8} \mathrm{RBC}\right.$ after six weeks). 
Table 2.3 TPMT genotype and metabolite levels of all leukopenic patients.

\begin{tabular}{lcccc}
\hline Patient & TPMT genotype & Week & $\begin{array}{c}\text { RBC 6-TGN level } \\
\left(\mathrm{pmol} / 8 \times 10^{8} \mathrm{RBC}\right)\end{array}$ & $\begin{array}{c}\text { RBC 6-MMPR level } \\
\left(\mathrm{pmol} / 8 \times 10^{8} \mathrm{RBC}\right)\end{array}$ \\
\hline 1 & ${ }^{*} 3 \mathrm{~A} /{ }^{*} 1$ & 4 & 628 & 362 \\
2 & ${ }^{*} 3 \mathrm{~A} /{ }^{*} 3 \mathrm{~A}$ & 1 & 1284 & 0 \\
3 & ${ }^{*} 1 /{ }^{*} 1$ & 8 & 670 & 337 \\
4 & ${ }^{*} 3 \mathrm{C} /{ }^{*} 1$ & 2 & 894 & 2707 \\
\hline
\end{tabular}

TPMT, thiopurine S-methyltransferase; RBCs, red blood cells; 6-TGN, 6-thioguanine nucleotides; 6-MMPR, 6-methylmercaptopurine ribonucleotides

\section{Efficacy}

Disease activity was assessed in all patients at baseline and after eight weeks. Ten of the 30 patients had active disease at baseline (Table 2.4). The mean CDAl of the six CD patients was 229, the mean TWDAI for the four UC patients was 10. Three of six CD patients $(50 \%)$ achieved clinical remission (CDAI $<150)$ after the study period of eight weeks, versus three of four UC patients (75\%).

Five of the six patients (83\%) with active disease at baseline and clinical remission at week 8 had 6-TGN concentrations above the recently proposed lower therapeutic limit of $235 \mathrm{pmol} / 8 \times 10^{8} \mathrm{RBC}^{6}$. Three of the four patients $(75 \%)$ with no clinical improvement had concentrations below the proposed threshold. Interestingly, the proposed therapeutic 6-MMPR/6-TGN ratio of 11 also correlated with clinical efficacy: Four of six IBD patients $(67 \%)$ with a ratio $<11$ achieved clinical remission within the study period, whereas three of four patients $(75 \%)$ with a ratio $>11$ failed to do so ${ }^{15}$.

Table 2.4 Disease activity and metabolite levels in patients with active disease at baseline.

\begin{tabular}{|c|c|c|c|c|c|}
\hline & & $\begin{array}{l}\text { Remission } \\
\text { after } 8 \text { wks }\end{array}$ & $\begin{array}{l}\text { 6-MMPR/ } \\
\text { 6-TGN ratio }\end{array}$ & $\begin{array}{l}\text { Active disease } \\
\text { after } 8 \text { wks }\end{array}$ & $\begin{array}{l}\text { 6-MMPR/ } \\
\text { 6-TGN ratio }\end{array}$ \\
\hline \multicolumn{2}{|c|}{ Active Crohn's disease (CDAI>150) } & $\mathrm{N}=3$ & \multicolumn{3}{|c|}{$\mathrm{N}=3$} \\
\hline Css RBC 6-MMPR/6-TGN & Pt 1 & $600 / 180$ & 3.3 & $2196 / 134$ & 16.4 \\
\hline \multirow[t]{2}{*}{ 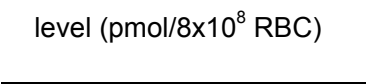 } & Pt 2 & $2290 / 585$ & 3.9 & $4520 / 364$ & 12.4 \\
\hline & Pt 3 & $5193 / 486$ & 10.7 & $1298 / 156$ & 8.3 \\
\hline \multicolumn{2}{|c|}{ Active ulcerative colitis (TWDAI>6) } & $\mathrm{N}=3$ & \multicolumn{3}{|c|}{$\mathrm{N}=1$} \\
\hline Css RBC 6-MMPR/6-TGN & Pt 1 & $5412 / 288$ & 18.8 & $3740 / 203$ & 18.4 \\
\hline \multirow[t]{2}{*}{ 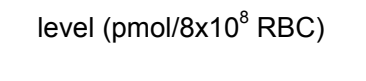 } & Pt 2 & $3166 / 277$ & 11.4 & & \\
\hline & Pt 3 & $2295 / 330$ & 7.0 & & \\
\hline
\end{tabular}

CDAI, Crohn's Disease Activity Index; Css, steady state level; TWDAI, Truelove-Witts Disease Activity Index; N, patient number; Pt, patient; RBC, red blood cells; 6-TGN, 6-thioguanine nucleotides; 6-MMPR, 6-methylmercaptopurine ribonucleotides. 


\section{Discussion}

Despite a large body of recent research on metabolite determination and TPMT genotyping in IBD patients treated with thiopurines, there are no uniform therapeutic guidelines and it is unclear whether such measurements should guide dosing. Recently, it has been stated that the confusion over this "correct" dosing of purine analogues was partly caused by "the lack of typical doseranging and pharmacokinetic studies in this patient population"16. We therefore prospectively performed such a study in 30 IBD patients. No distinction was made between $C D$ and $U C$ patients, because we did not expect a difference in thiopurine metabolism or toxicity.

We found that both 6-TGN and 6-MMPR concentrations showed large interpatient variability, similar to results from pharmacokinetic studies in other patient populations ${ }^{17,18} \cdot 6-\mathrm{TGN}$ and 6-MMPR concentrations reached steady state after four weeks, suggesting a half-life of approximately five days. For 6-TGN concentrations, this was already demonstrated in other studies, but the half-life of 6-MMPR has not been previously reported ${ }^{19}$. At steady state there was a seven-fold range in 6-TGN concentrations, and this is an underestimation as patients with extremely high 6-TGN concentrations discontinued 6-MP treatment after 1-2 weeks because of leukopenia. Steady state 6-MMPR concentrations reached an even larger sixteen-fold range.

As has been reported in children suffering from lymphoblastic leukaemia, no correlation was found between 6-TGN and 6-MMPR concentrations ${ }^{18}$. Drug dose per kg bodyweight correlated neither with 6-TGN nor with 6-MMPR concentrations. These data do not support the use of standard doses of $1-2 \mathrm{mg} / \mathrm{kg} /$ day as is commonly advised, because this results in unpredictable 6-MP metabolite concentrations.

TPMT genotype correlated with 6-TGN concentrations, even though patients with mutant TPMT alleles who discontinued 6-MP before reaching steady state metabolite concentrations were not included in statistical analysis. It has been reported that the presence of mutant alleles of the gene encoding TPMT results in elevated 6-TGN concentrations and leukopenia ${ }^{20}$. In our study five patients with mutant alleles were identified and three (60\%) developed leukopenia within four weeks of treatment. In all leukopenic patients high 6-TGN concentrations were measured and the highest 6-TGN level was measured in the patient homozygous for the TPMT*3A alleles $\left(1284 \mathrm{pmol} / 8 \times 10^{8} \mathrm{RBC}\right.$ after one week). No leukopenia was observed in the other two patients with heterozygous alleles (steady state 6-TGN concentrations of 786 and 427 $\mathrm{pmol} / 8 \times 10^{8} \mathrm{RBC}$ ). One of the 20 patients (5\%) with wild type alleles developed leukopenia. This patient had a steady state 6 -TGN level of $670 \mathrm{pmol} / 8 \times 10^{8}$ RBC, which is substantially higher than the measured mean steady state 6 -TGN level of $368 \mathrm{pmol} / 8 \times 10^{8} \mathrm{RBC}$. The risk of developing leukopenia was 
twelve-fold higher in the patients with mutant alleles compared to patients with wild type alleles. Similar results were reported in a rheumatic population treated with $A Z A^{21}$. All patients that subsequently developed leukopenia had 6-TGN concentrations above $300 \mathrm{pmol} / 8 \times 10^{8} \mathrm{RBC}$ after one week. Mean steady state concentrations would theoretically have been above $500 \mathrm{pmol} / 8 \times 10^{8} \mathrm{RBC}$ in this group of patients (mean 6-TGN level week 4 / 6-TGN level week $1 \approx 1,7$ ). In fact, the mean steady state 6-TGN level in leukopenic individuals in another study was $490 \mathrm{pmol} / 8 \times 10^{8} \mathrm{RBC}^{6}$. Hence, a dose reduction would be recommended if a 6 -TGN level above $300 \mathrm{pmol} / 8 \times 10^{8} \mathrm{RBC}$ is measured after one week of 6-MP treatment.

If the results of TPMT genotyping had been known prior to initiation of 6-MP treatment, at least one episode of leukopenia (in the patient homozygous for the TPMT* 3 A alleles) would have certainly been prevented and in the patients with heterozygous TPMT alleles, a 50\% starting-dose reduction in combination with weekly TDM until steady state probably would have reduced the risk of developing leukopenia.

This study was not powered to study therapeutic efficacy. However, we found therapeutic efficacy to be associated with a 6-TGN level above the recently proposed lower therapeutic limit of $235 \mathrm{pmol} / 8 \times 10^{8} \mathrm{RBC}$. Though the described number of patients with efficacy data is small, these data are in accordance with the results of Dubinsky and colleagues ${ }^{6}$. In addition, a 6-MMPR/6-TGN ratio $<11$ correlated with drug efficacy as was also previously suggested ${ }^{15}$. We must be reserved in drawing conclusions for the group of non-responders too early, as the clinical effect of 6-MP may have a lack-time of 3-6 months.

Steady state 6-MMPR concentrations did not correlate with any of the hepatic or pancreatic parameters. Three patients developed pancreatitis and in one the 6-MMPR concentration was high: although the 6-MMPR level seemed normal after four weeks of treatment $\left(3308 \mathrm{pmol} / 8 \times 10^{8} \mathrm{RBC}\right)$, concentrations rapidly increased after five weeks (7420 pmol/ $\left.8 \times 10^{8} \mathrm{RBC}\right)$ and six weeks (8224 $\left.\mathrm{pmol} / 8 \times 10^{8} \mathrm{RBC}\right)$. In the other two patients steady state 6-MMPR concentrations were 1558 and $4989 \mathrm{pmol} / 8 \times 10^{8} \mathrm{RBC}$ respectively. Therefore, although high 6-MMPR concentrations are sometimes detected in patients developing pancreatitis, pancreatitis often occurs in the absence of toxic 6MMPR concentrations ( $>5700 \mathrm{pmol} / 8 \times 10^{8} \mathrm{RBC}$ ) and the role of 6-MMPR in the pathogenesis of pancreatitis is uncertain ${ }^{6,22}$.

In one patient (TPMT genotype *1/*1) the 6-MP dose was raised to $100 \mathrm{mg}$ once daily because of suboptimal steady state 6-TGN concentrations. As a result, 6-MMPR concentrations increased dramatically from 3740 to $12995 \mathrm{pmol} / 8 \times 10^{8} \mathrm{RBC}$ in four weeks, and simultaneously ALT and AST increased from 47 and $32 \mathrm{U} / \mathrm{l}$ to 139 and $61 \mathrm{U} / \mathrm{l}$ respectively, suggesting druginduced hepatotoxicity and necessitating discontinuation of 6-MP treatment. This patient obviously had preferential shunting to 6-MMPR, resulting in an 
increase of the 6-MMPR/6-TGN ratio from 18.4 to 32.5 after dose escalation. Recently, Dubinsky and colleagues found that only $27 \%$ of non-responders to 6-MP treatment respond to a dose escalation ${ }^{15}$. In most patients dose escalation did not significantly increase 6-TGN concentration, but significant increased potentially toxic 6 -MMPR concentrations. The results of that study suggested that metabolite profiles provide a biochemical explanation for 6-MP resistance and 6-MMPR related toxicity. In a second patient in our study, high 6-MMPR concentrations (7155 pmol/ $8 \times 10^{8}$ RBC after two weeks) were accompanied by palpitations and headache leading to discontinuation of 6-MP treatment. Both patients successfully switched from 6-MP to 6-TG $20 \mathrm{mg}$ orally once daily, making a causal role of 6-MMPR in the occurrence of adverse events even more likely ${ }^{23}$.

\section{Conclusions}

Our data indicate that future study designs should consider measurement of thiopurine metabolite concentrations after one week (to prevent early toxicity: 6 -TGN $<300 \mathrm{pmol} / 8 \times 10^{8} \mathrm{RBC}$ ) and four weeks (to detect suboptimal dosing or non-compliance: $6-\mathrm{TGN}>250 \mathrm{pmol} / 8 \times 10^{8} \mathrm{RBC}$ and late toxicity: 6-TGN $<500 \mathrm{pmol} / 8 \times 10^{8} \mathrm{RBC}$ ) in order to validate our findings.

In conclusion, in IBD patients on 6-MP treatment, large non-dose related interindividual differences in metabolite concentrations occur. Our study clearly indicates the usefulness TPMT genotyping and especially TDM in this population. Our suggestions need to be confirmed in a prospective, randomised intervention study. TPMT genotyping before start of thiopurine treatment may prevent early myelotoxicity due to thiopurine treatment in a selection of patients. TDM will facilitate the clinician to improve the 6-MP efficacy by demonstrating suboptimal dosing, and predicting risks of complications such as leukopenia and hepatitis. TDM may also be helpful in revealing poor compliance. 


\section{References}

1. Adler DJ, Korelitz BI. The therapeutic efficacy of 6-mercaptopurine in refractory ulcerative colitis. Am J Gastroenterol 1990;85:717-22.

2. Pearson DC, May GR, Fick GH, Sutherland LR. Azathioprine and 6-mercaptopurine in Crohn disease. A meta-analysis. Ann Intern Med 1995;123: $132-42$.

3. Sandborn WJ. A review of immune modifier therapy for inflammatory bowel disease: azathioprine, 6-mercaptopurine, cyclosporine, and methotrexate. Am J Gastroenterol 1996;91:423-33.

4. Lennard L. The clinical pharmacology of 6-mercaptopurine. Eur J Clin Pharmacol 1992;43:329-39.

5. Fairchild CR, Maybaum J, Kennedy KA. Concurrent unilateral chromatid damage and DNA strand breakage in response to 6-thioguanine treatment. Biochem Pharmacol 1986;35:3533-41.

6. Dubinsky MC, Lamothe S, Yang HY, Targan SR, Sinnett D, Théorêt Y, Seidman EG. Pharmacogenomics and metabolite measurement for 6-mercaptopurine therapy in inflammatory bowel disease. Gastroenterology 2000;118:705-13.

7. Lowry PW, Franklin CL, Weaver AL, Pike MG, Mays DC, Tremaine WJ, Lipsky JJ, Sandborn WJ. Measurement of thiopurine methyltransferase activity and azathioprine metabolites in patients with inflammatory bowel disease. Gut 2001; 49:665-70.

8. Belaiche J, Desager JP, Horsmans Y, Louis E. Therapeutic drug monitoring of azathioprine and 6-mercaptopurine metabolites in Crohn disease. Scand J Gastroenterol 2001;36:71-6.

9. Dervieux T, Blanco JG, Krynetski EY, Vanin EF, Roussel MF, Relling MV. Differing contribution of thiopurine methyltransferase to mercaptopurine versus thioguanine effects in human leukemic cells. Cancer Res 2001;61:5810-6.

10. Lennard L. TPMT in the treatment of Crohn's disease with azathioprine. Gut 2002; 51:143-6.

11. Sandborn WJ. Rational dosing of azathioprine and 6-mercaptopurine. Gut 2001; 48:591-2.

12. Yates CR, Krynetski EY, Loennechen T, Fessing MY, Tai HL, Pui CH, Relling MV, Evans WE. Molecular diagnosis of thiopurine S-methyltransferase deficiency: genetic basis for azathioprine and mercaptopurine intolerance. Ann Intern Med 1997;126:608-14.

13. Lennard L, Singleton HJ. High-performance liquid chromatographic assay of the methyl and nucleotide metabolites of 6-mercaptopurine: quantitation of red blood cell 6-thioguanine nucleotide, 6-thioinosinic acid and 6-methylmercaptopurine metabolites in a single sample. J Chromatogr 1992;583:83-90.

14. Cuffari C, Seidman EG, Latour S, Théorêt $Y$. Quantitation of 6-thioguanine in peripheral blood leukocyte DNA in Crohn's disease patients on maintenance 6-mercaptopurine therapy. Can J Physiol Pharmacol 1996;74:580-5.

15. Dubinsky MC, Yang H, Hassard PV, Seidman EG, Kam LY, Abreu MT, Targan SR, Vasiliauskas EA. 6-MP metabolite profiles provide a biochemical explanation for 6 -MP resistance in patients with inflammatory bowel disease. Gastroenterology 2002; 122:904-15.

16. Cohen RD. Forecast for using metabolite measurements in the dosing of azathioprine or 6-mercaptopurine for IBD patients: "partly cloudy". Gastroenterology 2002;122:2082-4; discussion 2084. 
17. Lennard L, Keen D, Lilleyman JS. Oral 6-mercaptopurine in childhood leukemia: parent drug pharmacokinetics and active metabolite concentrations. Clin Pharmacol Ther 1986;40:287-92.

18. Chrzanowska M, Kolecki P, Duczmal-Cichocka B, Fiet J. Metabolites of mercaptopurine in red blood cells: a relationship between 6-thioguanine nucleotides and 6-methylmercaptopurine metabolite concentrations in children with lymphoblastic leukemia. Eur J Pharm Sci 1999;8:329-34.

19. Lennard L, Lilleyman JS. Individualizing therapy with 6-mercaptopurine and 6 -thioguanine related to the thiopurine methyltransferase genetic polymorphism. Ther Drug Monit 1996;18:328-34.

20. Lennard L. Clinical implications of thiopurine methyltransferase--optimization of drug dosage and potential drug interactions. Ther Drug Monit 1998;20:527-31.

21. Black AJ, McLeod HL, Capell HA. Thiopurine methyltransferase genotype predicts therapy-limiting severe toxicity from azathioprine. AnnIntern Med 1998;129:716-8.

22. Cuffari C, Theoret Y, Latour S, Seidman G. 6-Mercaptopurine metabolism in Crohn's disease: correlation with efficacy and toxicity. Gut 1996;39:401-6.

23. Derijks LJ, de Jong DJ, Gilissen LP, Engels LG, Hooymans PM, Jansen JB, Mulder CJ. 6-Thioguanine seems promising in azathioprine-or 6-mercaptopurine-intolerant inflammatory bowel disease patients: a short-term safety assessment. Eur J Gastroenterol Hepatol 2003;15:63-7. 


\section{Chapter}

\section{Some cases demonstrating the clinical usefulness of therapeutic drug monitoring in thiopurine treated IBD patients}

LPL Gilissen, LJJ Derijks, LP Bos, HMJM Verhoeven, PJ Bus, PM Hooymans, LGJB Engels

Eur J Gastroenterol Hepatol 2004;16:705-710 


\section{Abstract}

The thiopurines azathioprine (AZA) and 6-mercaptopurine (6-MP) are effective drugs in steroid dependant and refractory IBD patients. Therapeutic drug monitoring (TDM) is a new concept to improve drug efficacy and prevent toxic adverse events. As thiopurine metabolism is influenced by genetic polymorphisms of methylating enzymes, metabolite levels may vary considerably, enabling significant adverse effects. In this paper five patients are described to demonstrate the clinical usefulness of TDM when applying thiopurines for IBD. Emphasized are patients with liver function test abnormalities and myelosuppression due to inappropriate 6-MP metabolite levels and subsequently the treatment of these events. In addition, sophisticated 6-MP metabolite levels guided therapy, including non-compliance is demonstrated. These cases demonstrate that TDM can improve efficacy and safety of thiopurine treatment. 


\section{Introduction}

The thiopurines azathioprine (AZA) and 6-mercaptopurine (6-MP) are established drugs in steroid dependent and refractory inflammatory bowel disease $(\mathrm{IBD})^{1,2}$. New ideas in improving drug efficacy and minimizing toxicity have emerged last years. In this regard concepts have been developed including therapeutic drug monitoring (TDM) by measuring metabolites of AZA and 6-MP. After elucidating thiopurine metabolism and analytical procedures of metabolite measurement some cases are presented emphasizing the clinical usefulness of TDM in thiopurine treated IBD patients.

\section{Metabolism of AZA and 6-MP}

AZA is rapidly converted to 6-MP by splitting off an imidazole group, and then metabolised to the pharmacologically active 6-thioguanine nucleotides (6-TGN) and 6-methylmercaptopurine ribonucleotides (6-MMPR). 6-TGN are purine nucleotides, which are incorporated into DNA of leucocytes, inducing immunosuppression ${ }^{1-4}$ (Figure 3.1).

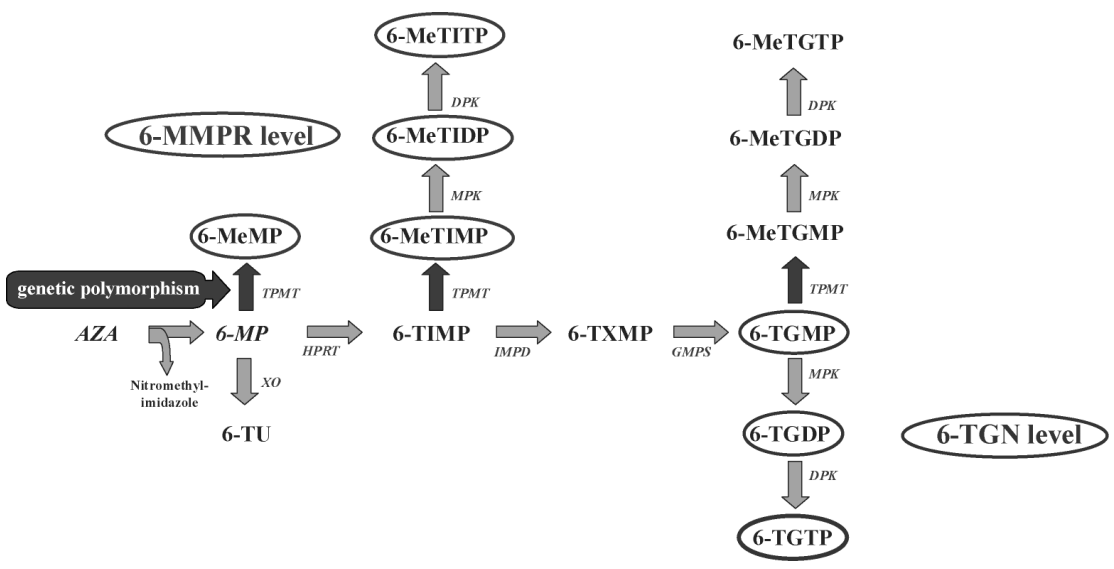

Figure 3.1 Thiopurine metabolism.

AZA, azathioprine; 6-MP, 6-mercaptopurine; 6-MeMP, 6-methylmercaptopurine; 6-TU, 6-thiouric acid; 6-MeTIMP+6-MeTIDP+6-MeTITP, 6-methylmercaptopurine ribonucleotides; 6-TIMP, 6-thioinosine monophosphate; 6-TXMP, 6-thioxanthosine monophosphate; 6-TGMP+6-TGDP+6-TGTP, 6-thioguanine nucleotides; 6-MeTGMP+ 6-MeTGDP+6-MeTGTP, 6-methylthioguanine nucleotides; XO, xanthine oxidase; TPMT, thiopurine S-methyltransferase; HPRT, hypoxanthine phosphoribosyl transferase; IMPD, inosine monophosphate dehydrogenase; GMPS, guanosine monophosphate synthetase; MPK, monophosphate kinase; DPK, diphosphate kinase. Note: laboratory measurements consist of a combination of several metabolites: -Measured 6-MMPR level: 6-MeMP and 6-MeTIMP + 6-MeTIDP + 6-MeTITP (6-methylmercaptopurine ribonucleotides) -Measured 6-TGN level: 6-TG and 6-TGMP + 6-TGDP + 6-TGTP (6-thioguanine nucleotides) 
Historically, controlled trials demonstrated that AZA at a dose of $2.0-3.0 \mathrm{mg} / \mathrm{kg} / \mathrm{day}$ and $6-\mathrm{MP}$ at $1.5 \mathrm{mg} / \mathrm{kg} /$ day (equivalent of $\mathrm{AZA}$ of $3.0 \mathrm{mg} / \mathrm{kg} /$ day) are effective and generally well tolerated ${ }^{1,5-8}$. More recently, Cuffari and Dubinsky found in paediatric IBD patients that the clinical response only correlates with 6-TGN levels and not with other variables, such as drug dose $^{9,10}$. These observations were the first indices of the usefulness of TDM in thiopurine treated patients. Otherwise, conflicting results in adult IBD patients have been described ${ }^{11,12}$. Furthermore, it was demonstrated that red blood cell (RBC) 6-TGN levels correlate with bone marrow suppression, while on the other hand 6-MMPR levels correlate with hepatotoxicity ${ }^{9,10}$. The lower therapeutic limit of $6-T G N$ was established at $235 \mathrm{pmol} / 8 \times 10^{8} \mathrm{RBC}$, whereas 6-MMPR levels above $5700 \mathrm{pmol} / 8 \times 10^{8} \mathrm{RBC}$ seemed potentially hepatotoxic. Hepatitis is found in $4-17 \%$ of patients ${ }^{9,10,14}$.

A drawback of AZA and 6-MP is the occurrence of side effects, leading to discontinuation of thiopurine therapy in $10-20 \%$ of patients ${ }^{14-16}$. Approximately $10 \%$ of AZA treated patients have non specific side effects, disappearing after changing to $6-\mathrm{MP}^{17}$. The cleaved imidazole derivative may be the cause of these side effects ${ }^{18}$. Opposite, when patients do not tolerate 6-MP, AZA is not tolerated as well, because 6-MP originates from AZA. Bypassing the first step of thiopurine metabolism by giving 6-MP in stead of AZA may improve therapeutic efficacy.

Adverse events in thiopurine treatment can also be non-metabolic, like pancreatitis. This complication occurs in $4-17 \%$ of patients ${ }^{9,10,14}$.

Toxicity due to metabolites may be explained by polymorphisms of the gene encoding thiopurine S-methyltransferase (TPMT), the enzyme that methylates 6-MP to 6-MMPR. Eighty-nine percent of individuals have normal to high enzyme activity. These individuals are homozygous TPMT ${ }^{\mathrm{H} / \mathrm{H}}$ for the wildtype ${ }^{*}$ allele $^{19}$. Eleven percent has intermediate (heterozygous TPMT ${ }^{\mathrm{H} / \mathrm{L}}$ ) and $0.3 \%$ has low to absent enzyme activity (homozygous TPMT ${ }^{\mathrm{L} / L}$ ) ${ }^{9}$. TPMT * $3 \mathrm{~A}$ is the most frequently occurring variant allele $\left(\mathrm{TPMT}^{\mathrm{L}}\right.$ ) in Caucasians ${ }^{19,20}$. Other mutations are ${ }^{*} 2,{ }^{*} 3 \mathrm{~B},{ }^{*} 3 \mathrm{C},{ }^{*} 3 \mathrm{D},{ }^{*} 4,{ }^{*} 5,{ }^{*} 6,{ }^{*} 7$ and ${ }^{*} 8$. In case of reduced enzyme activity toxic 6-TGN levels may arise on regular doses of AZA or 6-MP causing myelosuppression ${ }^{21}$. Alternatively, in some patients high 6-MMPR levels are noted, while 6-TGN levels remain subtherapeutic. Theoretically, the available 6-MP is largely transformed into 6-MMPR due to preferential metabolism through TPMT, increasing the risk of hepatitis. There is no clinical evidence for this hypothesis yet. We recently performed a study with TDM and TPMT genotyping in 6-MP treated IBD patients and found no relation between TPMT and hepatotoxicity ${ }^{22}$.

Theoretically, 6-TG would be a good alternative in patients with AZA and 6-MP intolerance. The idea of using a metabolite at the end of the enzymatic pathway in stead of a prodrug like AZA or 6-MP seems to be an attractive approach. In 
theory toxicity by potentially toxic metabolites may be avoided. There still is a lot of debate on this issue (see Discussion).

\section{Analytical procedures}

Blood samples are taken at least twelve hours after medication intake and centrifuged to isolate erythrocytes. A slightly modified high-performance liquid chromatography (HPLC) assay as reported by Lennard et al. has been implemented to measure thiopurine metabolites in erythrocytes ${ }^{23}$. It should be emphasised that 6-TGN and 6-MMPR levels consist of a sum of several metabolites including 6-mercaptopurine ribonucleotides and 6-thioguanine phosphates as shown in Figure 3.1. The run-to-run coefficient of variation in our laboratory is $6.6 \%$ and $9.7 \%$ for $6-\mathrm{TGN}$ and 6 -MMPR respectively. The detection limit of the assay is $30 \mathrm{pmol} / 8 \times 10^{8} \mathrm{RBC}$ for $6-\mathrm{TGN}$ and 300 $\mathrm{pmol} / 8 \times 10^{8} \mathrm{RBC}$ for $6-\mathrm{MMPR}$.

\section{Case reports}

\section{Case 1}

A 48-year-old man known with left sided ulcerative colitis (UC) for eleven years was unsuccessfully treated with betamethasone enemas, mesalazine and azathioprine $100 \mathrm{mg}$ daily $(1.0 \mathrm{mg} / \mathrm{kg})$. After detecting zero levels of 6-MMPR and 6-TGN the patient admitted that he had not taken azathioprine for a year but had not dared to tell his gastroenterologist.

\section{Case 2}

A 50-year-old man with left sided UC for fourteen months had been unsuccessfully treated with budenoside, mesalazine enemas and prednisone $30 \mathrm{mg}$ daily. When starting $50 \mathrm{mg} \mathrm{6-MP}$ daily $(0.6 \mathrm{mg} / \mathrm{kg})$, he had moderately severe disease activity according to Truelove-Witts ${ }^{24}$.

Because of insufficient clinical improvement and subtherapeutic 6-TGN levels (203 pmol $/ 8 \times 10^{8}$ RBC) 6-MP dose was increased to $100 \mathrm{mg}$ daily $(1.2 \mathrm{mg} / \mathrm{kg}$ ) after four weeks. Three days later the patient complained about nausea and slightly increased serum transaminase levels were measured (ALAT $139 \mathrm{U} / \mathrm{I}$ (5-50) and ASAT $73 \mathrm{U} /(5-40))$. Two weeks after dose escalation his 6-TGN level had risen to $348 \mathrm{pmol} / 8 \times 10^{8} \mathrm{RBC}$ and $6-\mathrm{MMPR}$ even to $8686 \mathrm{pmol} / 8 \times 10^{8}$ RBC. After changing 6-MP treatment to $20 \mathrm{mg}$ 6-thioguanine (6-TG) (Lanvis ${ }^{\circledR}$, GlaxoSmithKline) $(0.3 \mathrm{mg} / \mathrm{kg})$, nausea disappeared and serum transaminases normalised as 6-MMPR levels decreased to zero. Steady state 6-TGN level was $884 \mathrm{pmol} / 8 \times 10^{8} \mathrm{RBC}$ after eight weeks of therapy. Afterwards, TPMT genotyping revealed a wildtype or homozygous $\operatorname{TPMT}^{\mathrm{H} / \mathrm{H}}\left({ }^{*} 1 /{ }^{*} 1\right)$ genotype. This 
patient has been treated for more than one year now and still has a mild disease activity with stable 6-TGN levels. There are still no signs of myelosuppression or hepatotoxicity.

\section{Case 3}

A 60-year-old man with UC for eleven years treated with olsalazine $1000 \mathrm{mg}$ t.i.d. experienced a flare of the disease combined with a perianal abscess. The latter was treated surgically. Thereafter $6-\mathrm{MP} 50 \mathrm{mg}(0.7 \mathrm{mg} / \mathrm{kg})$ was added to treatment. After one week he already had 6-TGN levels of 425 and 6-MMPR of $482 \mathrm{pmol} / 8 \times 10^{8} \mathrm{RBC}$. Two months later it was decided to decrease 6 -MP dose to $25 \mathrm{mg}(0.4 \mathrm{mg} / \mathrm{kg})$ daily because of high $6-\mathrm{TGN}$ levels $\left(628 \mathrm{pmol} / 8 \times 10^{8}\right.$ $\mathrm{RBC})$ compared to 6 -MMPR $\left(362 \mathrm{pmol} / 8 \times 10^{8} \mathrm{RBC}\right)$. On this dose steady state 6-TGN levels are $417 \mathrm{pmol} / 8 \times 10^{8} \mathrm{RBC}$ while 6-MMPR is undetectable. Disease activity is in remission. Subsequently, TPMT analysis showed a heterozygous genotype: $\operatorname{TPMT}^{\mathrm{L} / \mathrm{H}}\left({ }^{*} 3 \mathrm{~A} /{ }^{*} 1\right)$.

\section{Case 4}

A 32-year-old man with UC eight years was treated with mesalazine and prednisolone without effect. One week after starting $50 \mathrm{mg}$ 6-MP daily $(0.5 \mathrm{mg} / \mathrm{kg})$ he had an extremely high $6-\mathrm{TGN}$ level (1284 pmol/ $\left.8 \times 10^{8} \mathrm{RBC}\right)$. Because of suspected poor TPMT metabolism therapy was interrupted. He did not show up for follow up and visited another hospital were AZA $50 \mathrm{mg}$ daily was started (without knowledge of the former high 6-TGN level). After several weeks he developed a severe leucopenia. Genotyping revealed a poor metaboliser: $\operatorname{TPMT}^{\mathrm{L} / \mathrm{L}}\left({ }^{*} 3 \mathrm{~A} /{ }^{*} 3 \mathrm{~A}\right)$.

\section{Case 5}

A 23-year-old female with Crohn's disease (CD) for three months had ongoing disease activity in spite of mesalazine and prednisolone $25 \mathrm{mg}$ daily. 6-MP was started at $1.7 \mathrm{mg} / \mathrm{kg}$ without controls of metabolite levels. After seven weeks she had fever. Laboratory analysis showed a pancytopenia: haemoglobin 4.3 $\mathrm{mmol} /(7.5-9.9)$, leucocytes $1,5 \times 10^{9} / \mathrm{l}(4.0-12.0)$, neutrophils $16 \%$, thrombocytes $13 \times 10^{9} / /(150-350) .6-M P$ was discontinued and she was successfully treated with a broad spectrum antibiotic. No clear focus of inflammation was found except her CD. Metabolite levels showed an extremely rare profile: 6-MMPR 57000 and 6-TGN $126 \mathrm{pmol} / 8 \times 10^{8}$ RBC. Pancytopenia recovered spontaneously within a few weeks. Genotyping revealed a wildtype TPMT $T^{H / H}$ $\left({ }^{*} 1 /{ }^{*} 1\right)$ genotype. 


\section{Discussion}

TDM is an established way of improving efficacy and preventing toxicity of many drugs, like gentamicin, digitoxin, antiepileptics and immunosuppressives (eg. tacrolimus and ciclosporine). The described cases emphasize the potentials of TDM in thiopurine treated IBD patients. All patients are part of a study group of 46 which has been partially described previously or will be soon $^{22,25}$.

Case 1 is a typical case of non-compliance, as is often seen in chronic patients in general. TDM is the only method to detect this phenomenon.

The second case shows that high 6-MMPR levels may give rise to a toxic hepatitis. This patient with wildtype TPMT $T^{\mathrm{H} / \mathrm{H}}$ genotype has a preferential metabolism of 6-MP to 6-MMPR, resulting in a failure to achieve adequate clinical benefit from 6-MP treatment even after dose increasement. Recently, Dubinsky found that only $27 \%$ of non-responders to 6-MP treatment (median dose $0.9 \mathrm{mg} / \mathrm{kg}$ ) respond to a dose escalation ${ }^{26}$. The other $73 \%$ had minimal changes in 6-TGN levels after escalation, but prominent elevations of potentially toxic 6-MMPR levels. This study suggests that metabolite profiles provide a biochemical explanation for 6-MP resistance. Thereby it shows that TDM can reveal a subgroup of patients resistant to 6-MP treatment, in danger of hepatotoxicity when 6-MP dose is increased.

Case 2 also demonstrates that TDM can give the clinician a false sense of security. It is important that levels are measured early, enabling a quick intervention. In this case we received the results too late to prevent hepatotoxicity.

Besides, case 2 is an example of treatment with 6-TG, a product near the end of the metabolic pathway of thiopurines as mentioned before (Figure 3.1). It was given in an experimental setting including intensive clinical and laboratory evaluations and TDM, as described earlier ${ }^{25}$. After one year of treatment no signs of myelosuppression or liver function disturbance were found.

As mentioned before, there is still a lot of debate on the use of 6-TG. Until now few short term studies in 6-TG treated IBD patients have been published, which showed no clinically relevant toxic adverse events ${ }^{25,27}$. Recently the first long term study described improvement of disease activity in $82 \%$ of 21 AZA or 6-MP intolerant, 6-TG treated patients ${ }^{28}$. Four patients (19\%) had a harmless hypersensitivity reaction and no serious adverse events occurred. 6-TG was presented as an effective and safe treatment under strict monitoring in this study. Surprisingly, in a more recent report from the same authors it is concluded that 6-TG should not be considered for IBD patients because of a high frequency of nodular regenerative hyperplasia (NRH) in the liver ${ }^{29}$. This conclusion should be discussed. At first, preceding immunosuppressive medication could have contributed to these findings as well, especially because 
92\% of patients had used AZA or 6-MP for more than one year before 6-TG treatment, accompanied by liver function disturbances in $40 \%$ of these patients. $\mathrm{NRH}$ may well have been started in this period, as reported previously in AZA treated patients ${ }^{30}$. Besides, high 6-TGN levels of $1230-1280 \mathrm{pmol} / 8 \times 10^{8} \mathrm{RBC}$ were reported, while no median dose was mentioned. Based on median duration of 6-TG treatment and median cumulative dose this must have exceeded $40 \mathrm{mg}$ daily. In the past it is demonstrated AZA may lead to venoocclusive disease due to dose dependent toxicity to murine sinusoidal endothelial cells and hepatocytes ${ }^{31}$.

In another study, follow-up of 50 AZA or 6-MP intolerant IBD patients treated with 6-TG for more than one year did not reveal hepatotoxicity correlated to 6-TG ${ }^{32}$. In the latter study substantially lower doses of 6-TG were used (mean 6-TG dose $21 \mathrm{mg}$ daily, range $10-40 \mathrm{mg}$ ) and consequently lower 6-TGN levels achieved (mean $650 \mathrm{pmol} / 8 \times 10^{8} \mathrm{RBC}$, range 158-1402) ${ }^{31}$. Nevertheless, NRH was also found in leukemic children, but again high 6-TG or 6-MP doses were used, resulting in high 6-TGN levels (median $1592 \mathrm{pmol} / 8 \times 10^{8} \mathrm{RBC}$, range 1240-1965) ${ }^{33}$.

In conclusion, more and prolonged experiences with 6-TG treatment are warranted before widespread use or expel of it.

In case 3 relatively high 6-TGN and low 6-MMPR levels were measured. Sufficient 6-TGN levels were reached at $50 \%$ starting dose. This patient is an example of an intermediate metaboliser (heterozygous TPMT ${ }^{L / H}$ ). It also illustrates the inter-individual differences in TPMT activity and corresponds with earlier findings of Dubinsky et al. in which clinical response only correlates with $6-$ TGN levels and not with any other variable such as drug dose ${ }^{10}$.

The fourth case represents the one out of 300 patients with no functional TPMT activity $\left(T_{P M T}{ }^{L / L}\right.$ ) showing extremely high 6-TGN levels within just one week of 6 -MP treatment. This patient had a homozygous variant allele (TPMT ${ }^{*} 3 \mathrm{~A} /{ }^{*} 3 \mathrm{~A}$ ). In this case 6-TG treatment is considered.

Case 5 is extraordinarily interesting, presenting reversible pancytopenia due to extremely high 6-MMPR levels. This phenomenon has not been published previously and points out the capacity of myelotoxicity due to all 6-MP metabolites and not 6-TG alone.

The question remains when to perform TDM. In case of preferential metabolism to 6-MMPR or 6-TGN rapid elevations of either level may be expected in the first week. Steady state levels of either metabolite are reached within four weeks ${ }^{22}$. Therefore we suggest to do TDM combined with liver function tests, amylase/lipase and blood cell count after one week to exclude early myelotoxicity and after four weeks to detect myelotoxicity, suboptimal dosing, high 6-MMPR levels or non-compliance. At least TDM is recommended in case of any leucopenia, suspected hepatotoxicity or non-compliance. Finally, TDM 
may provide new data on thiopurine metabolism, such as in case five, proving myelotoxicity due to 6-MMPR.

TDM is not the only way of improving thiopurine treatment efficacy and safety. TPMT genotyping before starting thiopurine treatment enables identification of patients at risk for early myelosuppression ${ }^{20,34}$. Heterozygous patients like case 3 should have a dose reduction and intensive TDM, while homozygous poor metabolisers (TPMT ${ }^{\mathrm{L} / \mathrm{L}}$ ) like case 4 are candidates for treatment with 6-TG or a significant dose reduction, according to a recent report ${ }^{35}$. On the other hand, several studies demonstrated that there is no role for TPMT genotyping in established thiopurine treatment ${ }^{20,36}$.

When comparing the use of TDM and TPMT genotyping we prefer TDM. Metabolite levels correlate better with efficacy and toxicity of thiopurine treatment than TPMT genotype. Costs for thiopurine metabolite measurements and TPMT genotyping are similar (50-60 Euro's).

\section{Conclusions}

TDM already is an important tool in accomplishing safe and effective drug therapy in many diseases, especially when potentially toxic drugs are employed. The present article illustrates that it is worthwhile employing TDM during thiopurine treatment because of great inter-individual differences in metabolism. TDM improves efficacy of treatment and diminishes risks of serious complications such as myelosuppression and hepatitis. For this purpose thiopurine metabolite levels, blood cell count, liver function tests and amylase should be measured after one and four weeks. TDM can also be used to reveal bad compliance or undertreatment in steady state treated patients and might help clinicians to overcome their fear for overdosing.

TPMT-genotyping before starting thiopurine treatment may be complementary to TDM. The TPMT genotype predicts the chance of early neutropenia, while TDM can be used to adjust 6-TGN and 6-MMPR levels. However, TPMT genotyping is not useful in established thiopurine treatment. Nevertheless, genotyping may be considered in case of neutropenia or high 6-TGN levels to reveal intermediate and poor metabolisers to further adjust thiopurine treatment.

Increasing experiences of TDM in AZA and 6-MP stimulate the already growing interest in pharmacogenetics and -kinetics in general. TDM might also be of use for other medications in future. 


\section{References}

1. Pearson DC, May GR, Fick GH, Sutherland LR. Azathioprine and 6-mercaptopurine in Crohn's disease. A meta-analysis. Ann Intern Med 1995;123: 132-42.

2. Sandborn WJ. A review of immune modifier therapy for inflammatory bowel disease: azathioprine, 6-mercaptopurine, cyclosporine and methotrexate. Am J Gastroenterol 1996;91;423-33.

3. Adler DJ, Korelitz BI. The therapeutic efficacy of 6-mercaptopurine in refractory ulcerative colitis. Am J Gastroenterol 1990;85:717-22.

4. Lennard L. The clinical pharmacology of 6-mercaptopurine. Eur J Clin Pharmacol 1992;43:329-39.

5. Hanauer SB and Meyers SM. Management of Crohn's disease in adults. Am J Gastroenterol 1997;92:559-566.

6. Candy S, Wright J, Gerber M, Adams G, Gerig M, Goodman R. A controlled double blind study of azathioprine in the management of Crohn's disease. Gut 1995; 37:674-8.

7. Present DH, Korelitz BI, Wisch N, Glass JL, Sachar DB, Pasternack BS. Treatment of Crohn's disease with 6-mercaptopurine. A long-term randomised double-blind study. N Engl J Med 1980;302:981-7.

8. Sandborn WJ. Rational dosing of azathioprine and 6-mercaptopurine. Gut 2001; 48:591-2.

9. Cuffari C, Theoret Y, Latour S, Seidman G. 6-Mercaptopurine metabolism in Crohn's disease: correlation with efficacy and toxicity. Gut 1996;39:401-6.

10. Dubinsky MC, Lamothe S, Yang HY, Targan SR, Sinnett D, Théorêt Y, Seidman EG. Pharmacogenomigc and metabolite measurement for 6-mercaptopurine therapy in inflammatory bowel disease. Gastroenterology 2000;118:705-13.

11. Lowry PW, Franklin CL, Weaver AL, Pike MG, Mays DC, Tremaine WJ, Lipsky JJ, Sandborn WJ. Measurement of thiopurine methyltransferase activity and azathioprine metabolites in patients with inflammatory bowel disease. Gut 2001; 49:665-70.

12. Belaiche J, Desager JP, Horsmans Y, Louis E. Therapeutic drug monitoring of azathioprine and 6-mercaptopurine metabolites in Crohn disease. Scand J Gastroenterol 2001;36:71-6.

13. Cuffari $\mathrm{C}$, Hunt $\mathrm{S}$, Bayless $\mathrm{T}$. Utilisation of erythrocyte 6-thioguanine metabolite levels tot optimise azathioprine therapy in patients with inflammatory bowel disease. Gut 2001;48:642-6.

14. Kirschner BS. Safety of azathioprine and 6-mercaptopurine in pediatric patients with inflammatory bowel disease. Gastroenterology 1998;115:813-21.

15. Present DH. Meltzer SJ, Krumholz MP, Wolke A, Korelitz BI. 6-Mercaptopurine in the management of inflammatory bowel disease: short- and long-term toxicity. Ann Intern Med 1989;111:641-9.

16. Connell WR, Kamm MA, Ritchie JK, Lennard-Jones JE. Bone marrow toxicity caused by azathioprine in inflammatory bowel disease: 27 years of experience. Gut 1993;34:1081-5.

17. Boulton-Jones JR, Pritchard $\mathrm{K}$ and Mahmoud AA. The use of 6-mercaptopurine in patients with inflammatory bowel disease after failure of azathioprine. Aliment Pharmacol Ther 2000;14:1561-5. 
18. McGovern DP, Travis SPL, Duley J, el Shobowale-Bakre M, Dalton HR. Azathioprine intolerance in patients with IBD may be imidazole-related and is independent of TMPT activity. Gastroenterology 2002;122:838-9.

19. Otterness D, Szumlanski C, Lennard L, Klemetsdal B, Aarbakke J, Park-Hah JO, Iven H, Schmiegelow K, Branum E, O'Brien J, Weinshilboum R. Human thiopurine methyltransferase pharmacogenetics: gene sequence polymorphisms. Clin Pharmacol Ther 1997;62:60-73.

20. Lennard L. TPMT in the treatment of Crohn's disease with azathioprine. Gut 2002;51:143-6.

21. Lennard L. Clinical implications of thiopurine methyltransferase-optimization of drug dosage and potential drug interactions. Ther Drug Monit 1998;20:527-31.

22. Derijks LJJ, Gilissen LPL, Engels LGJB, Bos LP, Bus PJ, Lohman JJHM, Curvers WL, van Deventer SJH, Hommes DW, Hooymans PM. Pharmacokinetics of 6-mercaptopurine in patients with inflammatory bowel disease. Implications for therapy. Ther Drug Monit 2004;26:311-8.

23. Lennard L, Singleton HJ. High performance liquid chromatographic assay of the methyl and nucleotide metabolites of 6-mercaptopurine: quantitation of red blood cell 6-thioguanine nucleotide, 6-thioinosinic acid and 6-mercaptopurine metabolites in a single sample. J Chromatogr 1992;583:83-90.

24. Truelove SC, Witts LJ. Cortisone in ulcerative colitis: final report on a therapeutic trial. BMJ 1955;1041-8.

25. Derijks LJJ, De Jong DJ, Gilissen LPL, Engels LGJB, Hooymans PM, Jansen JBMJ and Mulder CJJ. 6-Thioguanine seems promising in azathioprine- or 6-mercaptopurine-intolerant inflammatory bowel disease patients: a short-term safety assessment. Eur J Gastroent Hep 2003;15:63-7.

26. Dubinsky MC, Yang H, Hassard PV, Seidman EG, Kam LY, Abreu MT, Targan SR, Vasiliauskas EA. 6-MP metabolite profiles provide a biochemical explanation for 6-MP resistance in patients with inflammatory bowel disease. Gastroenterology 2002;122:904-15.

27. Dubinsky MC, Hassard PV, Seidman EG, Kam LY, Abreu MT, Targan SR, Vasiliauskas EA. An open-label pilot study using thioguanine as a therapeutic alternative in Crohn's disease patients resistant to 6-mercaptopurine therapy. Inflamm Bowel Dis 2001;7:181-9.

28. Dubinsky MC, Feldman EJ, Abreu MT, Targan SR, Vasiliauskas EA. Thioguanine: a potential alternate thiopurine for IBD patients allergic to 6-mercaptopurine or azathioprine. Am J Gastroenterology 2003;98:1058-63.

29. Dubinsky MC, Vasiliauskas EA, Singh H, Abreu MT, Papadakis KA, Tran T, Martin P, Vierling JM, Geller SA, Targan SR, Poordad FF. 6-Thioguanine can cause serious liver injury in inflammatory bowel disease patients. Gastroenterology 2003;125:298-303.

30. Naber AH, Van Haelst U, Yap SH. Nodular regenerative hyperplasia of the liver: an important cause of portal hypertension in non-cirrhotic patients. J Hepatol 1991;12:94-9.

31. Deleve LD, Wang X, Kuhlenkamp JF, Kaplowitz N. Toxicity of azathioprine and monocrolatine in murine sinusoidal endothelial cells and hepatocytes: the role of glutathione and relevance to hepatic venoocclusive disease. Hepatology 1996;23:589-99.

32. De Jong DJ, Derijks LJJ, Gilissen LPL et al. Maintenance treatment with 6-thioguanine over one year in azathioprine or 6-mercaptopurine intolerant IBD patients. Gut 2003;52(suppl VI):A58. 
33. Stork LC, Broxson EH, Sather $\mathrm{H}$ et al. Oral 6-thioguanine causes late onset splenomegaly and portal hypertension in a subset of children with acute lymphoblastic leukemia. Gastroenterology 2002;1222:T833.

34. Schwab M, Schaffeler E, Marx C, Fischer C, Lang T, Behrens C, Gregor M, Eichelbaum M, Zanger UM, Kaskas BA. Azathioprine therapy and adverse drug reactions in patients with inflammatory bowel disease: impact of thiopurine S-methyltransferase polymorphism. Pharmacogenetics 2002;12:429-36.

35. Kaskas BA, Louis E, Hindorf U, Schaeffeler E, Deflandre J, Graepler F, Schmiegelow K, Gregor M, Zanger UM, Eichelbaum M, Schwab M. Safe treatment of thiopurine S-methyltransferase deficient Crohn's disease patients with azathioprine. Gut 2003;52:140-2.

36. Derijks LJJ, Curvers WL, Hooymans PM, Van Deventer SJH, Hommes DW. No predictive value of thiopurine S-methyltransferase genotyping for myelosuppression or hepatotoxicity in inflammatory bowel disease patients established on azathioprine. Gut 2003;52(suppl VI):A58. 


\section{Section C}

Therapeutic drug monitoring and non-compliance 


\section{Chapter 4}

\section{Therapeutic drug monitoring in fifteen patients with IBD and established azathioprine therapy}

LPL Gilissen, LJJ Derijks, LP Bos, PJ Bus, PM Hooymans, LGJB Engels 


\section{Abstract}

\section{Introduction}

Azathioprine (AZA) is widely used in the treatment of steroid dependant and refractory inflammatory bowel disease (IBD). The efficacy of this treatment is based on the production of 6-thioguanine nucleotides (6-TGN), but extremely elevated levels may cause bone marrow suppression. Other AZA metabolites, 6-methylmercaptopurine ribonucleotides (6-MMPR), are associated with hepatotoxicity. Therapeutic drug monitoring (TDM) may be of help in optimizing AZA treatment, but data on TDM in established AZA therapy are lacking. Therefore we measured metabolite levels in a small cohort of patients established on AZA.

\section{Patients and methods}

6-Thioguanine nucleotides (6-TGN) and 6-methylmercaptopurine ribonucleotides (6-MMPR) levels in erythrocytes were measured in fifteen IBD out-patients established on AZA for at least three months at $\mathrm{t}=0,1,4$ and 8 weeks after inclusion (mean duration of treatment 28 months; range 7-67 months). Disease activity was evaluated by CDAI (Crohn's disease) or Truelove-Witts (Ulcerative Colitis) scores. Metabolite levels were measured by a modified high-performance liquid chromatography assay (HPLC). Primary outcome measures were 6-TGN and 6-MMPR metabolite levels and $95 \%$ confidence intervals (Cl95\%). Secondary outcomes were correlations between metabolite levels and drug dose, disease activity and laboratory parameters and compliance. Statistical analysis was done by Pearson's correlation test. $\mathrm{P}$ values $<0.05$ were considered significant.

\section{Results}

One patient had active disease during the study period. Eleven out of fifteen patients $(73 \%)$ completed the eight week study period. Drop out reasons were non-compliance in one patient $(7 \%)$, intolerance in one $(7 \%)$ or incomplete data in two patients $(13 \%)$.

Primary outcomes: At baseline mean 6-TGN levels were 158 (CI95\%: 113-203) pmol/8x10 ${ }^{8}$ RBC, steadily increasing over the eight week study period, but not significantly. Two patients had zero levels. Another two had significantly increasing levels also suggesting non-compliance.

Mean 6-MMPR levels showed almost a similar pattern. At baseline levels were 2213 (Cl 95\%: $722-$ 3704) $\mathrm{pmol} / 8 \times 10^{8} \mathrm{RBC}$.

Secondary outcomes: Correlations were found between all RBC 6-MMPR levels and AZA dose (mg/kg bodyweight) $(\mathrm{r}=0.43$ and $\mathrm{p}=0.001)$ and also between 6-MMPR/6-TGN ratio and AZA dose $(\mathrm{mg} / \mathrm{kg})(\mathrm{r}=0.36$ and $\mathrm{p}=0.010)$. There was no correlation between RBC 6-TGN or 6-MMPR levels and hematological parameters or disease activity scores. No hepatic, pancreatic or myelotoxicity occurred.

\section{Discussion}

Thirtheen of fifteen patients ( $87 \%$ ) had baseline steady state 6 -TGN levels below the therapeutic threshold of $235 \mathrm{pmol} / 8 \times 10^{8}$ RBC. Forty percent $(6 / 15)$ of our patients was non-compliant $(40 \%)$. TDM revealed this non-compliance in four of six patients.

\section{Conclusions}

Our small study demonstrates that TDM may give insight in individual pharmacokinetics. Nevertheless, TDM seems not useful in IBD patients established on AZA and without disease activity. TDM may be helpful in worsening IBD activity to elucidate non-compliance or inefficient treatment. 


\section{Introduction}

Thiopurines are known for more than 40 years, and were originally used in treatment of childhood leukemia, transplantation medicine and rheumatic disorders ${ }^{1-3}$. Since 1990 azathioprine (AZA) and 6-mercaptopurine (6-MP) are widely used for immunosuppressive therapy in steroid dependant or refractory inflammatory bowel disease (IBD) and have proven to be effective for inducing and maintaining remission of disease activity ${ }^{4-7}$. For IBD, AZA is generally used in Europe while there seems a preference for 6-MP in North America, especially in case of AZA intolerance. Recently 6-thioguanine (6-TG) has been introduced in thiopurine therapy of $I B D^{8}$.

Despite the widespread use of thiopurines the precise mechanism of action was only discovered in recent years (Figure 4.1) $)^{9}$. AZA is a prodrug which is non-enzymatically transformed to 6-MP, and then metabolised to the pharmacological active 6-thioguanine nucleotides (6-TGN) and 6-methylmercaptopurine ribonucleotides (6-MMPR). 6-TGN are purine nucleotides, which were believed to be incorporated into DNA of leucocytes, blocking the de novo purine synthese and thereby inducing immunosuppression.

Until 1996 controlled trials demonstrated effective dosages of AZA at $2.0-3.0 \mathrm{mg} / \mathrm{kg} / \mathrm{day}$ and 6-MP at $1.5 \mathrm{mg} / \mathrm{kg} /$ day in IBD patients $\mathrm{s}^{4,10-13}$. From 1996 on the first publications about therapeutic drug monitoring (TDM) appeared, based on the knowledge of the metabolic pathway. It was shown that clinical response only correlates with 6-TGN metabolite levels and not with other variables, like drug dose ${ }^{14,15}$. Besides, it was demonstrated that red blood cell (RBC) 6-TGN levels correlate with bone marrow suppression, while RBC 6-MMPR levels correlate with hepatotoxicity ${ }^{14,16}$. The lower limit of therapeutic 6-TGN level was established at $235 \mathrm{pmol} / 8 \times 10^{8} \mathrm{RBC}$, an upper limit was not described. In the same study however, a mean $6-$ TGN level of $490 \mathrm{pmol} / 8 \times 10^{8}$ RBC was measured, in patients developing leucopenia. 6-MMPR levels above $5700 \mathrm{pmol} / 8 \times 10^{8} \mathrm{RBC}$ correlated with hepatotoxicity ${ }^{14,15}$.

Others found conflicting data. Lowry was one of the first to describe pharmacokinetic results of long term AZA treatment in 170 adult IBD patients ${ }^{17}$. He found lower mean 6-TGN levels (163 pmol/ $\left.8 \times 10^{8} \mathrm{RBC}\right)$ and no correlation between 6-TGN levels and disease activity. A study in 55 children with IBD also showed no relation between $6-$ TGN levels and clinical remission ${ }^{18}$. On the other hand Cuffari described a threshold therapeutic 6-TGN level, which was even higher: $250 \mathrm{pmol} / 8 \times 10^{8} \mathrm{RBC}^{19}$. These findings were based on $82 \mathrm{AZA}$ or 6 -MP treated IBD adults.

Besides, in studies on direct administration of 6-TG, higher levels of 6-TGN were found, without correlation between 6-TGN levels and clinical response or 
toxicity $^{20-22}$. This may reflect other involved mechanisms or that 6-TGN levels are not exclusively responsible for thiopurine efficacy or toxicity.

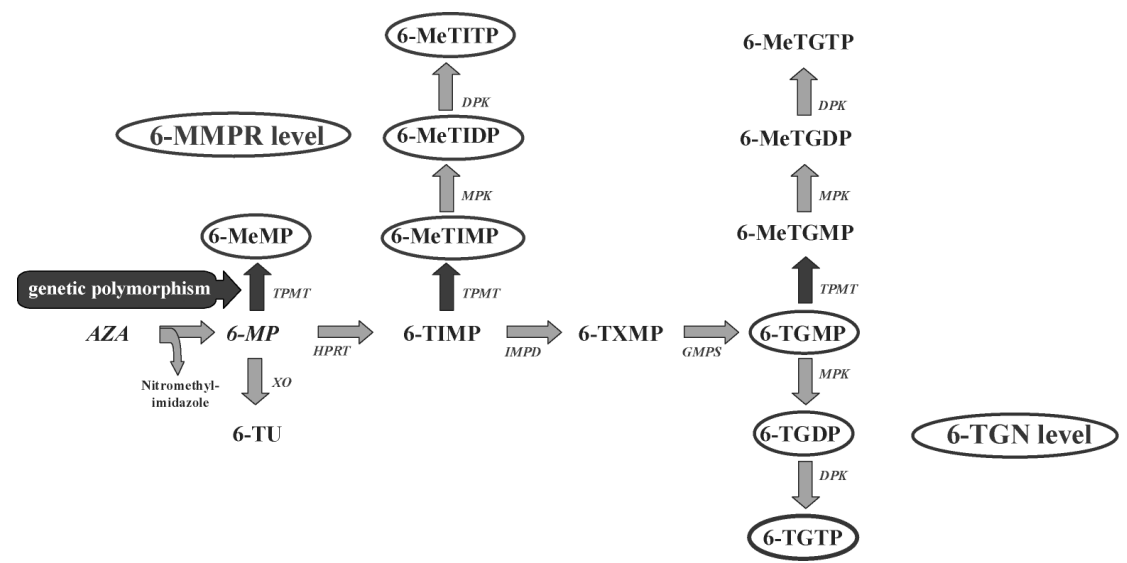

Figure 4.1 Thiopurine metabolism.

AZA, azathioprine; 6-MP, 6-mercaptopurine; 6-MeMP, 6-methylmercaptopurine; 6-TU, 6-thiouric acid; 6-MeTIMP+6-MeTIDP+6-MeTITP, 6-methylmercaptopurine ribonucleotides; 6-TIMP, 6-thioinosine monophosphate; 6-TXMP, 6-thioxanthosine monophosphate; 6-TGMP+6-TGDP+6-TGTP, 6-thioguanine nucleotides; 6-MeTGMP+ 6-MeTGDP+6-MeTGTP, 6-methylthioguanine nucleotides; XO, xanthine oxidase; TPMT, thiopurine S-methyltransferase; HPRT, hypoxanthine phosphoribosyl transferase; IMPD, inosine monophosphate dehydrogenase; GMPS, guanosine monophosphate synthetase; MPK, monophosphate kinase; DPK, diphosphate kinase. Note: laboratory measurements consist of a combination of several metabolites: -Measured 6-MMPR level: 6-MeMP and 6-MeTIMP + 6-MeTIDP + 6-MeTITP (6-methylmercaptopurine ribonucleotides)

-Measured 6-TGN level: 6-TG and 6-TGMP + 6-TGDP + 6-TGTP (6-thioguanine nucleotides)

More recently new details in the mechanism of action of thiopurines have been discovered. AZA and its metabolites were found to be responsible for $T$ cell apoptosis by modulation of Rac1 activation upon CD28 costimulation ${ }^{23}$.

Rac1, a small GTPase that plays a role in inhibiting T cell apoptosis is a target for 6-thioguanine triphosphate (6-thio-GTP), a metabolite of AZA, which is one of the measured nucleotides of the 6-TGN level (see Figure 4.1). 6-Thio-GTP binds to Rac1 in stead of GTP, thereby suppressing the activation of Rac1 target genes like mitogen activated protein kinase MEK, NF-KB and bcl- $\mathrm{x}_{\mathrm{L}}$, leading to apoptosis. CD28 is a transmembrane protein which plays a role in the anti-apoptotic signaling pathway as well. T-cell apoptosis by 6-thio-GTP is increased upon co-stimulation of Rac1 by CD28. It was demonstrated that especially specific $T$ memory lymphocytes (CD45RO), which are the main effector cells in IBD, become apoptotic. These recent findings suggest a new molecular mechanism of action of AZA. In future, 6-thio-GTP derivatives with 
more affinity for Rac1 may be designed, leading to stronger and more specific immunosuppressive effects.

Toxicity due to thiopurine metabolites may be explained by gene polymorphisms encoding thiopurine S-methyltransferase (TPMT), the enzyme that methylates 6-MP to 6-MMPR. Eighty-nine percent of individuals have normal to high enzyme activity, corresponding to homozygous/wildtype $\mathrm{TPMT}^{\mathrm{H}}$. Eleven percent has intermediate (heterozygote $\mathrm{TPMT}^{\mathrm{H}} / \mathrm{TPMT}^{\mathrm{L}}$ ) and $0.3 \%$ has low to absent enzyme activity (homozygous $\left.\mathrm{TPMT}^{\mathrm{L}}\right)^{14,24}$. Reduced enzyme activity leads to toxic 6-TGN levels on regular doses of AZA or 6-MP ${ }^{25}$. Alternatively, in some patients high 6-MMPR levels are noted, while 6-TGN levels remain subtherapeutic. Due to preferential metabolism to 6-MMPR these patients are at risk for hepatitis. Pancreatitis is an idiosyncratic side effect of thiopurine treatment without any relation to metabolite levels. There may be a relationship between pancreatitis and 6-MMPR metabolites though, because it has not been described in patients treated with 6-TG, the third thiopurine which more directly leads to the formation of 6-TGN. The overall incidence of hepatitis and pancreatitis varies between $4-17 \%$ for both independently ${ }^{14,16,26}$. AZA and $6-\mathrm{MP}$ treatment are discontinued in $10-20 \%$ of patients because of side effects $^{26,27}$.

More recently, 6-TG as such was introduced as an alternative in IBD-patients with AZA and 6-MP intolerance. The idea of using a metabolite at the end of the enzymatic pathway seems to be an attractive approach. After the publication of just a few articles on nodular regenerative hyperplasia (NRH) of the liver there is a lot of debate on the safety of this treatment ${ }^{20-22,28}$. More studies should be performed before conclusions can be made.

Taken together, thiopurines are back in business due to new insights in their metabolic pathway last years. New concepts like therapeutic drug monitoring (TDM) and genotyping of TPMT are based on these new data, but controversies remain ${ }^{8}$.The aim of our study was to add more clinical information to this topic. We examined our IBD out-patients established on AZA by questionnaire, examination, laboratory controls and TDM at week $0,1,4$ and 8 after inclusion.

\section{Patients and methods}

\section{Patient selection}

Fifteen IBD patients were recruited, aged between 18 and 75 years, established on AZA (Imuran ${ }^{\mathrm{TM}}$, tablet $100 \mathrm{mg}$, Glaxo Wellcome, Zeist, The Netherlands) for at least three months, attending the out-patient clinics of 
Maasland Hospital Sittard and St.Laurentius Hospital Roermond, the Netherlands.

\section{Study design}

A prospective open-label multicentre study was carried out. At $0,1,4$ and 8 weeks after inclusion blood was drawn for measurement of RBC 6-TGN and 6-MMPR levels, haemoglobin, leucocytes and differentiation, platelets, bilirubin, alanine and aspartate transaminase, lipase, amylase and C-reactive protein (CRP). Crohn's Disease Activity Index (CDAI) or Truelove-Witts (for Ulcerative Colitis) scores were collected at each visit (CDAl<150: remission; CDAl>150: active disease $)^{29}$. Dose adjustments of AZA were not carried out during the study period. Concomitant 5-aminosalicylic acid (5-ASA) medication was continued.

\section{Ethics}

The protocol was approved by the local medical ethics committee and in accordance with the Helsinki Declaration. Written informed consent was obtained before inclusion.

\section{Outcome measures}

Primary outcome measures were mean RBC 6-TGN and 6-MMPR levels and $95 \%$ confidence intervals (CI95\%) during the eight week period. Secondary outcomes were compliance, the correlation between steady state RBC 6-TGN and 6-MMPR levels and other parameters like dose per $\mathrm{kg}$ bodyweight, CDAI/Truelove-Witts scores and laboratory parameters.

\section{Analytical procedures}

6-TGN and 6-MMPR levels were measured by the laboratory of the Department of Clinical Pharmacy, Maasland Hospital in Sittard. Blood samples were taken at least twelve hours after medication intake and centrifuged to isolate erythrocytes. A slightly modified high-performance liquid chromatography assay (HPLC) as reported by Lennard and our group has been implemented to measure thiopurine metabolites in erythrocytes ${ }^{30,31}$. The run-to-run coefficient of variation in our laboratory is $6.6 \%$ and $9.7 \%$ for $6-T G N$ and 6-MMPR respectively. The lower limit of quantification of the assay is $30 \mathrm{pmol} / 8 \times 10^{8} \mathrm{RBC}$ for $6-\mathrm{TGN}$ and $300 \mathrm{pmol} / 8 \times 10^{8} \mathrm{RBC}$ for $6-M M P R$. 


\section{Statistical analysis}

Data are expressed as means with range or Cl95\%. Pearson's correlation test was used for determination of correlation. $\mathrm{P}$ values $<0.05$ were considered significant.

\section{External sources}

This study was not sponsored by external sources.

\section{Results}

Fifteen IBD patients established on AZA for at least three months (mean duration 28 months; range 7-67 months) were followed for eight weeks. Mean age was 45 years (range 29-55), six patients were male and nine were female. Ten patients had CD $(67 \%)$, four had UC $(27 \%)$ and one had indeterminate colitis (6\%). Mean bodyweight was $73 \mathrm{~kg}$ (Cl95\%: 67-79). Mean AZA dose was $1.71 \mathrm{mg} / \mathrm{kg}$ (Cl95\%: 1.48-1.95). All patients used 5-ASA as concomitant medication.

Nearly all patients had a stable disease activity during the study interval according to CDAl and Truelove-Witts scores. Fourteen patients had remission of disease (CDAI<150; Truelove-Witts: mild-moderate disease). In one patient mean CDAl was 182, implying a mild disease activity. Eleven of fifteen patients (73\%) completed the eight week study period. Drop out reasons were noncompliance in three patients $(20 \%)$ and intolerance in one $(7 \%$ : unexplained muscle pains, without signs of rhabdomyolysis, reoccurring after rechallenge).

\section{Primary outcomes}

At baseline mean 6-TGN levels were 158 (Cl95\%: 113-203) pmol/8x $10^{8} \mathrm{RBC}$

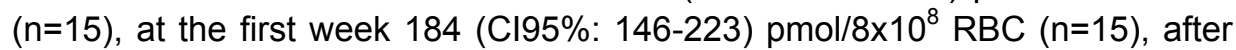
four weeks 222 (Cl95\%: 200-243) pmol/8x10 $\mathrm{RBC}(\mathrm{n}=14)$ and 282 (Cl95\%: 183-380) pmol $/ 8 \times 10^{8} \mathrm{RBC}$ at week $8(\mathrm{n}=11)$ (Figure $\left.4.2 \mathrm{~A}\right)$.

At baseline mean 6-MMPR levels were 2213 (Cl 95\%: 722-3704) pmol/8x10 RBC $(n=15)$, at the first week 2639 (Cl95\%: 1225-4053) pmol/8x $10^{8} \mathrm{RBC}$

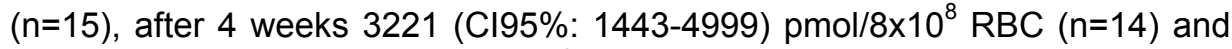

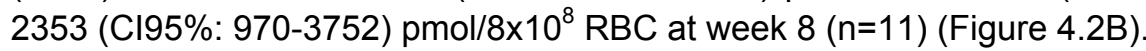


A

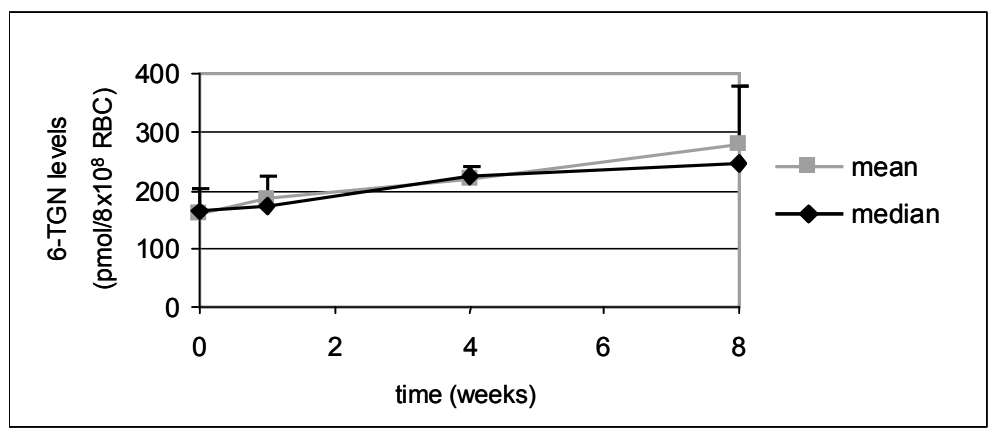

B

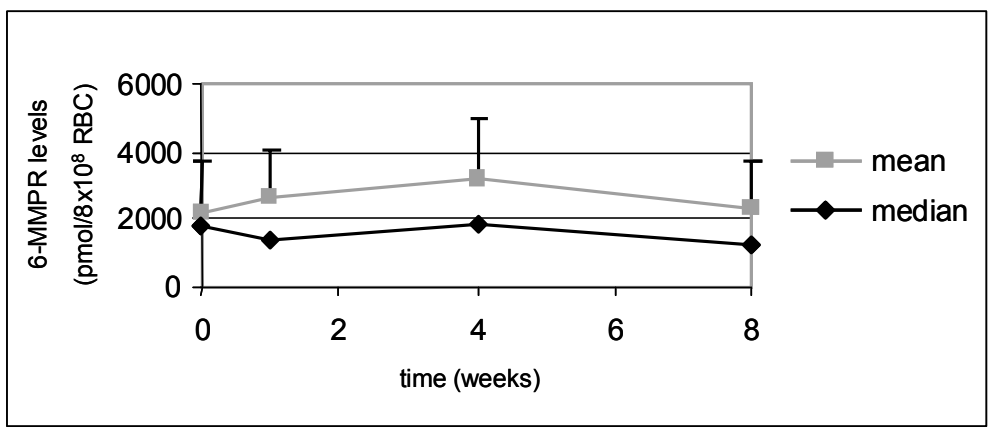

Figure 4.2 Median and mean 6-TGN levels on AZA (all doses) (A), median and mean 6-MMPR levels on AZA (all doses) (B).

\section{Secondary outcomes}

There was no correlation between RBC 6-TGN and 6-MMPR levels. There also was no correlation between RBC 6-TGN levels and dose per $\mathrm{kg}$ bodyweight (Figure 4.3) idem. RBC 6-MMPR levels and dose per kg bodyweight showed a significant correlation $(r=0.43$ and $p=0.001)$. Either did 6-MMPR/6-TGN ratio and AZA dose $(\mathrm{mg} / \mathrm{kg})(\mathrm{r}=0.36$ and $\mathrm{p}=0.010)$.

There was no correlation between RBC 6-TGN or 6-MMPR levels and CDAI or Truelove-Witts scores. There was also no correlation between RBC 6-TGN or 6-MMPR levels and haematological parameters. 


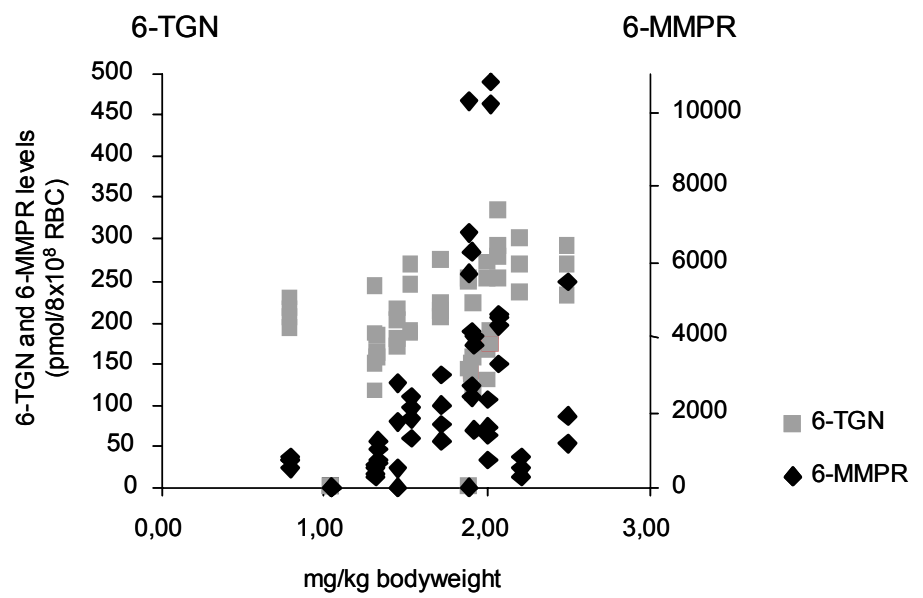

Figure 4.3 Mean 6-TGN and 6-MMPR levels against AZA dose all measurements

\section{Discussion}

Notably, in our study thirteen of fifteen patients $(87 \%)$ had baseline steady state 6 -TGN levels below $235 \mathrm{pmol} / 8 \times 10^{8} \mathrm{RBC}$, which is the lower therapeutic level according to Dubinsky ${ }^{14}$. During the study period 6-TGN levels steadily increased, but not significantly, whilst not employing dose escalation (Figure 4.2A). This suggests that most patients were treated suboptimally. However, all patients but one had a stable disease in remission on these subtherapeutical levels. A possible explanation is the fact that the mentioned threshold levels were set by studies in a paediatric population and our population mainly consists of adults ${ }^{14,16,32}$. On the other hand it seems very difficult to define a single therapeutic window for IBD patients, because of the great inter-individual differences in disease phenotype.

Another consideration based on our results is that TDM may not be helpful in established AZA treated IBD patients without disease activity. In practice, metabolite levels of AZA will not change the therapeutic strategy when patients have an IBD in remission and without adverse events. The initiating period in thiopurine treatment seems more crucial because adverse events occur most times in this stage of treatment. Furthermore, a steady state treated population is biased, because all patients with adverse events are already excluded. This is demonstrated in this study as well: all patients except one had no disease activity, without toxicity, despite two patients who had potentially toxic 6-MMPR levels. 
The only indication for TDM in steady state treated patients may be worsening disease activity or possibly related adverse events like hepatotoxicity and myelotoxicity. In that case metabolite levels can help excluding non-compliance or inefficient treatment.

This theory has been mentioned for TPMT genotyping as well. Recent studies showed no benefit of TPMT genotyping in steady state treated patients ${ }^{14,15,33-35}$. Likely, this may be explained by the fact that most of these studies were performed retrospectively. Patients with adverse events had already discontinued thiopurine treatment leading to a biased steady state population.

Secondly, it is striking how many of our patients were non-compliant. Noncompliance is a well known problem in treatment of chronic patients in general. In this study TDM revealed non-compliance in four patients (27\%). Two of them had zero levels at baseline, leading to discontinuation of follow up in one patient after one week therefore. The other one had significantly increasing levels without dose escalation. Eight weeks after the study interval, this patient mentioned worsening disease activity. 6-TGN and 6-MMPR levels at this time were zero again. The two other patients were suspected to be non-compliant because of significant higher 6-TGN levels at week 1, 4 and/or 8 than at baseline. The described drop out of two patients because of incomplete data was caused by forgetting to let draw blood. This behaviour may also be considered as poor compliance. Altogether $40 \%(6 / 15)$ of our study group was non-compliant! This percentage exceeds the $10 \%$ non-compliance described in previous studies ${ }^{36,37}$.

Statistical analysis for the nine true compliant patients reveals no differences compared to the previous analysis, but this number of patients is too small to make conclusions.

This brings us to a critical reflection of our study. We are aware of the limitations of a study based on fifteen patients. Powered statistical analysis is hardly to perform and therefore important conclusions can not be made. When studying patients on established AZA therapy, there is always some selection bias because of loss of patients with adverse events in the initiating period of this therapy. Nevertheless, TDM has proven its value to unmask noncompliance, even in this small study. 


\section{Conclusions}

Great inter-individual differences in pharmacokinetics occur in thiopurine treated IBD patients. TDM is known to help getting insight in individual pharmacokinetics. This study demonstrates two striking facts. At first, it shows the limited usefulness of TDM in steady state AZA treated patients with IBD in remission. Secondly, it illustrates that TDM can unmask non-compliance. In clinical practice, there still seems to be a role for TDM in established AZA therapy in case of worsening disease activity or possibly related adverse events like hepatotoxicity and myelotoxicity. TDM can also help to exclude noncompliance or inefficient treatment in these situations. 


\section{References}

1. Lancaster DL, Lennard L, Rowland K, Vora AJ, Lilleyman JS. Thioguanine versus mercaptopurine for therapy of childhood lymphoblastic leukaemia: a comparison of haematological toxicity and drug metabolite concentrations. British Journal of Hematology 1998;102:439-43.

2. Bergan S, Rugstad HE, Bentdal O, Endresen L, Stokke O. Kinetics of mercaptopurine and thioguanine nucleotides in renal transplant recipients during azathioprine treatment. Ther Drug Monit 1994;16:13-20.

3. Suarez-Almazor M, Spooner C, Belseck E. Azathioprine for rheumatoid arthritis. Cochrane Database Syst Rev. 2000;(2):CD001461.

4. Pearson DC, May GR, Fick GH, Sutherland LR. Azathioprine and 6-mercaptopurine in Crohn disease. A meta-analysis. Ann Intern Med 1995; 123:132-42.

5. Sandborn WJ. A review of immune modifier therapy for inflammatory bowel disease: azathioprine, 6-mercaptopurine, cyclosporine and methotrexate. Am J Gastroenterol 1996;91;423-33.

6. Present DH. Meltzer SJ, Krumholz MP, Wolke A, Korelitz BI. 6-Mercaptopurine in the management of inflammatory bowel disease: short- and long-term toxicity. Ann Intern Med 1989;111:641-9.

7. Adler DJ, Korelitz BI. The therapeutic efficacy of 6-mercaptopurine in refractory ulcerative colitis. The American Journal of Gastroenterology, 1990;85:717-22.

8. Baert $F$ and Rutgeerts P. 6-Thioguanine: a naked bullet? (or how pharmacogenomics can make old drugs brand new). Inflamm Bowel Dis 2001;7:190-1.

9. Lennard L. The clinical pharmacology of 6-mercaptopurine. Eur J Clin Pharmacol 1992;43:329-39.

10. Hanauer SB and Meyers SM. Management of Crohn's disease in adults. Am J Gastroenterol 1997;92:559-566.

11. Candy S, Wright J, Gerber M, Adams G, Gerig M, Goodman R. A controlled double blind study of azathioprine in the management of Crohn's disease. Gut 1995;37:674-8.

12. Present DH, Korelitz BI, Wisch N, Glass JL, Sachar DB, Pasternack BS. Treatment of Crohn's disease with 6-mercaptopurine. A long-term randomised double-blind study. N Engl J Med 1980;302:981-7.

13. Sandborn WJ. Rational dosing of azathioprine and 6-mercaptopurine. Gut 2001;48:591-2.

14. Dubinsky MC, Lamothe S, Yang HY, Targan SR, Sinnett D, Théorêt Y, Seidman EG. Pharmacogenomics and metabolite measurement for 6-mercaptopurine therapy in inflammatory bowel disease. Gastroenterol 2000;118:705-13.

15. Cuffari C, Hunt S, Bayless T. Utilisation of erythrocyte 6-thioguanine metabolite levels tot optimise azathioprine therapy in patients with inflammatory bowel disease. Gut 2001;48:642-6.

16. Cuffari C, Theoret Y, Latour S, Seidman G. 6-Mercaptopurine metabolism in Crohn's disease: correlation with efficacy and toxicity. Gut 1996;39:401-6.

17. Lowry PW, Franklin CL, Weaver AL, Pike MG, Mays DC, Tremaine WJ, Lipsky JJ, Sandborn WJ. Measurement of thiopurine methyltransferase activity and azathioprine metabolites in patients with inflammatory bowel disease. Gut 2001;49:665-70.

18. Gupta P, Gokhale R, Kirschner B. 6-Mercaptopurine (6-MP) metabolite levels in children with IBD. J Ped Gastroent Nutr 2001;33:450-4. 
19. Cuffari C, Hunt S, Bayless T. Enhanced bioavailability of azathioprine compared to 6-mercaptopurine therapy in inflammatory bowel disease: correlation with treatment efficacy. Aliment Pharmacol Ther 2000;14:1009-14.

20. Dubinsky MC, Hassard PV, Seidman EG, Kam LY, Abreu MT, Targan SR, Vasiliauskas EA. An open-label pilot study using thioguanine as a therapeutic alternative in Crohn's disease patients resistant to 6-mercaptopurine therapy. Inflamm Bowel Dis 2001;7:181-9.

21. Derijks LJ, de Jong DJ, Gilissen LP, Engels LG, Hooymans PM, Jansen JB, Mulder CJ. 6-Thioguanine seems promising in azathioprine- or 6-mercaptopurine-intolerant inflammatory bowel disease patients: a short-term safety assessment. Eur $\mathrm{J}$ Gastroent Hep 2003;15:63-7.

22. Dubinsky MC, Feldman EJ, Abreu MT, Targan SR, Vasiliauskas EA. Thioguanine: a potential alternate thiopurine for IBD patients allergic to 6-mercaptopurine or azathioprine. Am J Gastroenterology 2003;98:1058-63.

23. Tiede I, Fritz G, Strand S, Poppe D, Dvorsky R, Strand D, Lehr HA, Wirtz S, Becker C, Atreya R, Mudter J, Hildner K, Bartsch B, Holtmann M, Blumberg R, Walczak H, Iven $\mathrm{H}$, Galle PR, Ahmadian MR, Neurath MF. CD28-dependent Rac1 activation is the molecular target of azathioprine in primary human CD4+ T lymphocytes. J Clin Invest 2003;111:133-45.

24. Lennard L. TPMT in the treatment of Crohn's disease with azathioprine. Gut 2002;51:143-6.

25. Colombel JF, Ferrari N, Debuysere H, Marteau P, Gendre JP, Bonaz B, Soulé JC, Modigliani R, Touze Y, Catala P, Libersa C, Broly F. Genotypic analysis of thiopurine S-methyltransferase in patients with Crohn's disease and severe myelosuppression during azathioprine therapy. Gastroenterology 2000;188: 1025-30.

26. Kirschner BS. Safety of azathioprine and 6-mercaptopurine in pediatric patients with inflammatory bowel disease. Gastroenterol 1998;115:813-21.

27. Connell WR, Kamm MA, Ritchie JK, Lennard-Jones JE. Bone marrow toxicity caused by azathioprine in inflammatory bowel disease: 27 years of experience. Gut 1993;34:1081-5.

28. Dubinsky MC, Vasiliauskas EA, Singh H, Abreu MT, Papadakis KA, Tran T, Martin P, Vierling JM, Geller SA, Targan SR, Poordad FF. 6-Thioguanine can cause serious liver injury in inflammatory bowel disease patients. Gastroenterology 2003;125:298-303.

29. Truelove SC, Witts LJ. Cortisone in ulcerative colitis: final report on a therapeutic trial. BMJ 1955;4947:1041-8.

30. Lennard L, Singleton HJ. High performance liquid chromatographic assay of the methyl and nucleotide metabolites of 6-mercaptopurine: quantitation of red blood cell 6-thioguanine nucleotide, 6-thioinosinic acid and 6-mercaptopurine metabolites in a single sample. J Chromatogr 1992;583:83-90.

31. Derijks LJ, Gilissen LP, Engels LG, Bos LP, Bus PJ, Lohman JH, Curvers WL, Van Deventer SJ, Hommes DW, Hooymans PM. Pharmacokinetics of 6-mercaptopurine in patients with inflammatory bowel disease. Implications for therapy. Ther Drug Monit 2004;26:311-8.

32. Pettersson B, Almer S, Albertioni F, Söderhäll S, Peterson C. Differences between children and adults in thiopurine methyltransferase activity and metabolite formation during thiopurine therapy: possible role of concomitant methotrexate. Ther Drug Monit 2002;24:351-8. 
33. Reuther LO, Vainer B, Sonne J, Larsen NE. Thiopurine methyltransferase (TPMT) genotype distribution in azathioprine-tolerant and -intolerant patients with various disorders. The impact of TPMT genotyping in predicting toxicity. Eur J Clin Pharm 2003;59:797-801.

34. Gearry RB, Barclay ML, Burt MJ, Collett JA, Chapman BA, Roberts RL, Kennedy MA. Thiopurine S-methyltransferase (TPMT) genotype does not predict adverse drug reactions to thiopurine drugs in patients with inflammatory bowel disease. Aliment Pharmacol Ther 2003;118:395-400.

35. Curvers WL, Derijks LJ, Stokkers P, Vogels EW, van Kampen AH, Curvers WL, Cohn D, van Deventer SJ, Hommes DW. No predictive value of TPMT genotyping for leukopenia or hepatotoxicity during azathioprine therapy in inflammatory bowel disease. Eur J Gastroent Hep 2003;15:A29.

36. Lennard L, Welch J, Lilleyman JS. Intracellular metabolites of 6-mercaptopurine in children with lymphoblastic leukaemia: a possible indicator of non-compliance. $\mathrm{Br} \mathrm{J}$ Cancer 1995;72:1004-6.

37. Webster S, Sanders DS, Lennard L, Lobo AJ. Azathioprine metabolites in inflammatory bowel disease and incidence of non-compliance. Gut 2002;50(suppl II):A71. 


\section{Chapter}

\section{Is therapeutic drug monitoring useful in exacerbations of adult IBD patients on thiopurine therapy?}

LPL Gilissen, DR Wong, J Bierau, JA Bakker, M Romberg-Camps, A Stronkhorst, PJ Bus, LP Bos, PM Hooymans, RW Stockbrügger, LGJB Engels 


\section{Abstract}

\section{Backgrounds}

Therapeutic drug monitoring (TDM) of thiopurines is a relatively new concept. Proposed therapeutic 6-thioguaninenucleotides (6-TGN) levels in IBD are $\geq 235 \mathrm{pmol} / 8 \times 10^{8}$ erythrocytes, but prospective studies in adult patients are lacking.

\section{Aims}

Comparing 6-TGN levels between exacerbations and remissions of IBD and redefining the therapeutic 6-TGN cut-off level in adult patients.

\section{Methods}

Consecutive thiopurine treated IBD patients were included. Primary outcomes: (correlations between) CDAI or CAI scores, metabolite levels and calculated therapeutic 6-TGN cut-off level. Secondary outcomes: (correlations between) demographic data, thiopurine dose, thiopurine S-methyltransferase (TPMT) activity.

\section{Results}

Forty-one patients had exacerbations, 59 were in remission. Zero or low 6-TGN levels, suggesting non-compliance, were found in $16 \%$ (12\% of exacerbations, $19 \%$ of remissions). 6 -TGN levels were only significantly different between exacerbations and remissions after exclusion of noncompliant remittent patients (237 versus $320 \mathrm{pmol} / 8 \times 10^{8}$ erythrocytes, $\left.\mathrm{p}=0.0007\right)$. In this subanalysis, $6-\mathrm{TGN}$ and disease activity correlated ( $\mathrm{r}=-0.24, \mathrm{Cl} 95 \%-0.42--0.029)$. The therapeutic cut-off 6-TGN level was $235-250 \mathrm{pmol} / 8 \times 10^{8}$ erythrocytes, but sensitivity, specificity and positive predictive value were low $(71,73$ and $67 \%$ ). Nevertheless, active disease was found in $52 \%$ of patients below, versus $30 \%$ above this threshold (OR 2.5, CI95\% 1.11-5.75, p=0.04).

\section{Discussion}

Differences in 6-TGN levels between exacerbations and remissions were only found after exclusion of non-compliant remittent patients. Importantly, a high rate of non-compliance was found.

\section{Conclusions}

The therapeutic 6 -TGN cut-off level of $235 \mathrm{pmol} / 8 \times 10^{8}$ erythrocytes was confirmed, but less convincing than in previous reports. TDM seems useful in case of thiopurine refractory IBD to reveal non-compliance, but has a minor role in detecting under-dosing and unfavourable metabolite profiles. 


\section{Introduction}

Gastroenterologists, treating inflammatory bowel disease (IBD) patients, are often confronted with exacerbations or refractory disease during immunomodulatory therapy, such as the thiopurines azathioprine (AZA) and 6-mercaptopurine (6-MP), cyclosporin or methotrexate. In those patients, a therapy switch to biologicals or surgery is frequently considered, without deeper insight in the efficacy of the therapy presently used. In case of thiopurine therapy, therapeutic drug monitoring (TDM) of metabolite concentrations is a theoretical option ${ }^{1,2}$. Thiopurine metabolism has large interindividual variations due to enzyme polymorphisms. Thiopurine S-methyltransferase (TPMT) is the most important enzyme influencing the balance between immunosuppressive 6-thioguanine nucleotides (6-TGN) levels and hepatotoxic 6-mercaptopurine ribonucleotides (6-MMPR) (Figure $5.1)^{3-6}$.

In recent years, therapeutic ranges of thiopurine metabolite concentrations were described: 6 -TGN metabolites between 235 and $500 \mathrm{pmol} / 8 \times 10^{8}$ red blood cells (RBC) have been correlated with clinical response ${ }^{1,3} .6-T G N$ levels above $500 \mathrm{pmol} / 8 \times 10^{8} \mathrm{RBC}$ increase the risk for leucocytopenia, and 6-MMPR levels higher than $5700 \mathrm{pmol} / 8 \times 10^{8} \mathrm{RBC}$ are correlated with hepatotoxicity ${ }^{1,2}$. A 6-MMPR/6-TGN ratio higher than 11 is correlated with a lower frequency of clinical respons ${ }^{2,7}$. Although these studies find no correlation between metabolite levels and drug dose, due to inter-individual differences in metabolism, thiopurine is still dosed on patient's bodyweight in clinical practice (AZA 2-3 $\mathrm{mg} / \mathrm{kg}$ and 6-MP $1-1.5 \mathrm{mg} / \mathrm{kg})^{8}$.

Some remarks have to be made about the proposed metabolite thresholds. These were often based on retrospective studies, described relatively small patient numbers, or were performed in pediatric IBD cohorts ${ }^{1,2,7,9-17}$. Recently, a meta-analysis of six studies showed that higher 6-TGN levels are correlated with clinical remission of IBD: $62 \%$ of the patients with 6 -TGN levels above $230-260 \mathrm{pmol} / 8 \times 10^{8} \mathrm{RBC}$ were in remission versus $36 \%$ remissions with 6-TGN levels lower than $230 \mathrm{pmol} / 8 \times 10^{8} \mathrm{RBC}^{10,14-17}$.

One reason for performing TDM could be inter-individual differences in thiopurine metabolism. Another reason may be the relative high prevalence of non-compliance in chronic diseases in general, especially in asymptomatic conditions $^{18}$. In IBD treatment it has been demonstrated that non-adherence can arrive at $60 \%$ with sulphasalazine, mesalazine and azathioprine, especially during remission ${ }^{9-24}$.

The aim of the present study is: 1) to compare thiopurine metabolite levels between adult IBD patients with an exacerbation and those in clinical remission in a prospective study, and 2) to find the best possible threshold 6-TGN level for therapeutic efficacy in adult IBD patients. These endpoints are relevant to 
determine the role of TDM in clinical decision making in case of an exacerbation of IBD during thiopurine treatment in adult IBD patients, in order to either optimise thiopurine dosage or to choose for an alternative therapy.

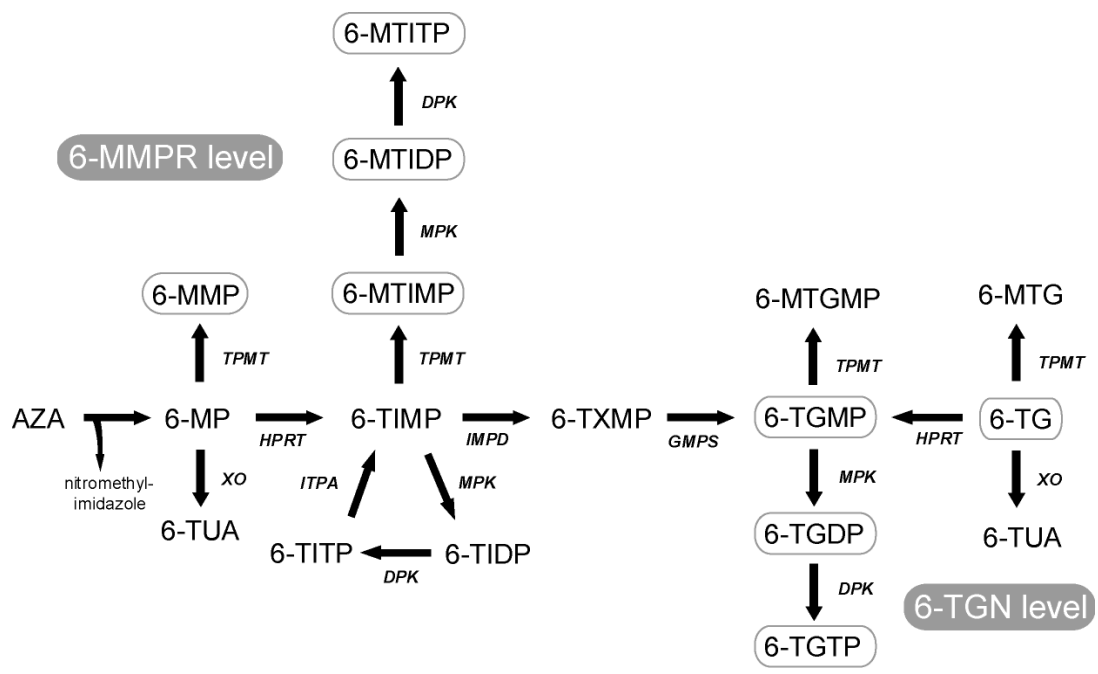

Figure 5.1 Proposed thiopurine metabolism.

AZA, azathioprine; 6-MP, 6-mercaptopurine; 6-TUA, 6-thiouric acid; 6-MMP, 6-methylmercaptopurine; 6-TIMP, 6-thioinosine-5'-monophosphate; 6-MMPR level, 6-methylmercaptopurine ribonucleotides; 6-TITP, 6-thioinosine triphosphate; 6-TIDP, 6-thioinosine diphosphate; 6-TG, 6-thioguanine; 6-TGN level, 6-thioguanine nucleotides; 6-MTG, 6-methylthioguanine; HPRT, hypoxanthine phosphoribosyltransferase; $\mathrm{XO}$, xanthine oxidase; ITPA, inosine triphosphate pyrophosphohydrolase; MPK, monophosphokinase; DPK, diphosphokinase; TPMT, thiopurine S-methyltransferase; IMPDH, inosine monophosphate dehydrogenase; GMPS, guanosine monophosphatase synthetase 6-MTIMP, 6-MTIDP and 6-MTITP together form the 6-methylmercaptopurine ribonucleotides (6-MMPR). 6-TGMP, 6-TGDP and 6-TGTP together form the 6-thioguanine nucleotides (6-TGN). In therapeutic drug monitoring, 6-MMPR levels consist of the sum of 6-MMP, 6-MTIMP, 6-MTIDP and 6-MTITP levels, while 6-TGN levels consist of the sum of 6-TGMP, 6-TGDP, 6-TGTP (if AZA or 6-MP is administered) and 6-TG (if 6-TG is administered as such) levels.

\section{Patients and methods}

\section{Patient selection}

A prospective study was performed in a group of IBD patients in four hospitals in the southern part of the Netherlands: one university hospital (University Hospital Maastricht) and three general district hospitals (Maasland Hospital Sittard, Laurentius Hospital Roermond and Catharina Hospital Eindhoven). 
Between November $1^{\text {st }}, 2005$ and November $1^{\text {st }}, 2006$, consecutive adult IBD patients treated with a steady maintenance dose of AZA or 6-MP for at least three months, presenting with an acute exacerbation at the outpatient clinic or during admission, were asked to participate. Subsequently, consecutive IBD patients in clinical remission, treated with a steady maintenance thiopurine dose for at least three months, were asked to join the study during their regular visit to the outpatient clinic. Also, concomitant medication had to be stable for three months. At inclusion, haematological and biochemical analyses were performed (haemoglobin, haematocrit, erythrocytes, leucocytes, thrombocytes, bilirubin, aspartate transaminase (ASAT), amylase, C-reactive protein and albumin), 6-TGN and 6-MMPR metabolite levels and TPMT activity were measured. All patients completed either a Crohn's Disease Activity Index (CDAI) or a Colitis Activity Index (CAI) score list ${ }^{25}$. These parameters were all taken immediately after informing the patients about the study and having them sign the informed consent, thus making sure that the metabolite levels were realistic and not influenced by the notification of inclusion in a study. In this way camouflage of non-compliance was excluded.

\section{Outcome measures}

Primary outcome measures were 6-TGN and 6-MMPR metabolite levels, to be used for correlations with CDAl or CAI scores and the calculation of a therapeutic 6-TGN threshold level. An exacerbation was defined as a CDAI score $\geq 200$ for Crohn's disease patients or a CAl score $\geq 8$ for patients with ulcerative colitis (UC) or indeterminate colitis. Remission was defined as a CDAl score $<150$ or CAl $<8$. Patients with CDAl scores between 150 and 200 were excluded. This had been decided before initiation of the study, to be assured of a clear distinction between exacerbations and remissions, and thus excluding patients with possible irritable bowel syndrome-like complaints. Secondary outcomes were correlations between primary outcomes and drug dose, 6-MMPR/6-TGN ratio, TPMT activity and CDAl or CAI disease activity scores.

\section{Analytical procedures}

6-TGN and 6-MMPR levels are measured with the modified high performance liquid chromatography (HPLC) method of Lennard as published previously $y^{2,26}$. This method is equal to that used in other reports about TDM in thiopurine therapy of IBD $^{1,3}$. TPMT activity was measured in erythrocyte lysates as described by Jacques-Aigrain ${ }^{27}$. Briefly, the washed erythrocyte lysate was incubated with 6-mercaptopurine in a dithiothreitol and S-adenosylmethionine containing phosphate buffer at $\mathrm{pH} 7.5$ at $37^{\circ} \mathrm{C}$ for one hour. 2-Amino6-methylmercaptopurine (6-AMMP) was used as the internal standard. After the incubation period, the reaction was stopped by the addition of hydrogen 
chloride, followed by neutralization with a basic ammonium chloride solution. 6-MP, 6-MMP and 6-AMMP were extracted with dichloromethane/2-propanol. After evaporation of the organic solvent, the samples were dissolved in buffer and analyzed using reversed-phase HPLC. The inter-assay co-variation of the procedure was less than $10 \%$, the typical recovery was $99 \%$.

\section{Statistical analysis}

Normality was tested by the Kolmogorov-Smirnov normality test. Data are expressed as means with $95 \%$ confidence interval (C195\%) or range. Pearson's correlation test is used for correlations. $\mathrm{P}$ values $<0.05$ are considered significant. Statistics are based on a clinically relevant difference of 6-TGN levels of $50 \mathrm{pmol} / 8 \times 10^{8} \mathrm{RBC}$ and a standard deviation of $75 \mathrm{pmol} / 8 \times 10^{8}$ RBC, according to our previous reports ${ }^{2,19}$. Based on these data a power analysis, demonstrated that 74 patients (37 in either group) should be included to show a significant difference in 6-TGN levels between both groups with a probability of $80 \%$. A total of 100 patients was aimed at before initiation of the study. The study was to be closed when at least 40 exacerbations were included. To find a therapeutic threshold 6-TGN level several analyses were performed, with in- or exclusion of non-compliant patients. Receiver Operating Characteristic (ROC) curves of the 6-TGN levels have been plotted to find a 6-TGN cut-off level with an optimal sensitivity, specificity, positive predictive value and accuracy. At last, a quartile analysis was performed according to the original report of Dubinsky, to compare 6-TGN thresholds ${ }^{1}$.

\section{Medical ethics}

The study was approved by the local Medical Ethical Committee of the Maasland Hospital Sittard.

\section{Results}

From November $1^{\text {st }}, 2005$ until November $1^{\text {st }}, 2006,123$ IBD patients were asked to join the study (Figure 5.2). Fifteen patients refused, had incomplete data or were pregnant. Inclusion criteria were met by 108 patients, of whom eight patients with a CDAl between 150 and 200 were excluded. Thus, 100 patients were enrolled for primary analysis, 41 patients with an exacerbation and 59 patients with IBD in remission. Patient characteristics are summarized in Table 5.1. Outcome measures of all patients are described in Table 5.2. No significant differences were found in drug dose or thiopurine metabolite levels between patients with Crohn's disease and ulcerative colitis. Therefore, all 
further analyses were performed for all IBD phenotypes together. No hepato- or pancreaticotoxicity was found, neither leucopenia.

In five of 41 patients (12\%) with an exacerbation no metabolites were measurable, suggesting non-compliance (Figure 5.2). In eleven of 59 patients $(19 \%)$ in remission no or very low metabolite levels were measured, suggesting non-compliance. The non-compliance rate for all 100 patients was $16 \%$, without a significant difference between exacerbations and remissions (Table $5.2)$.

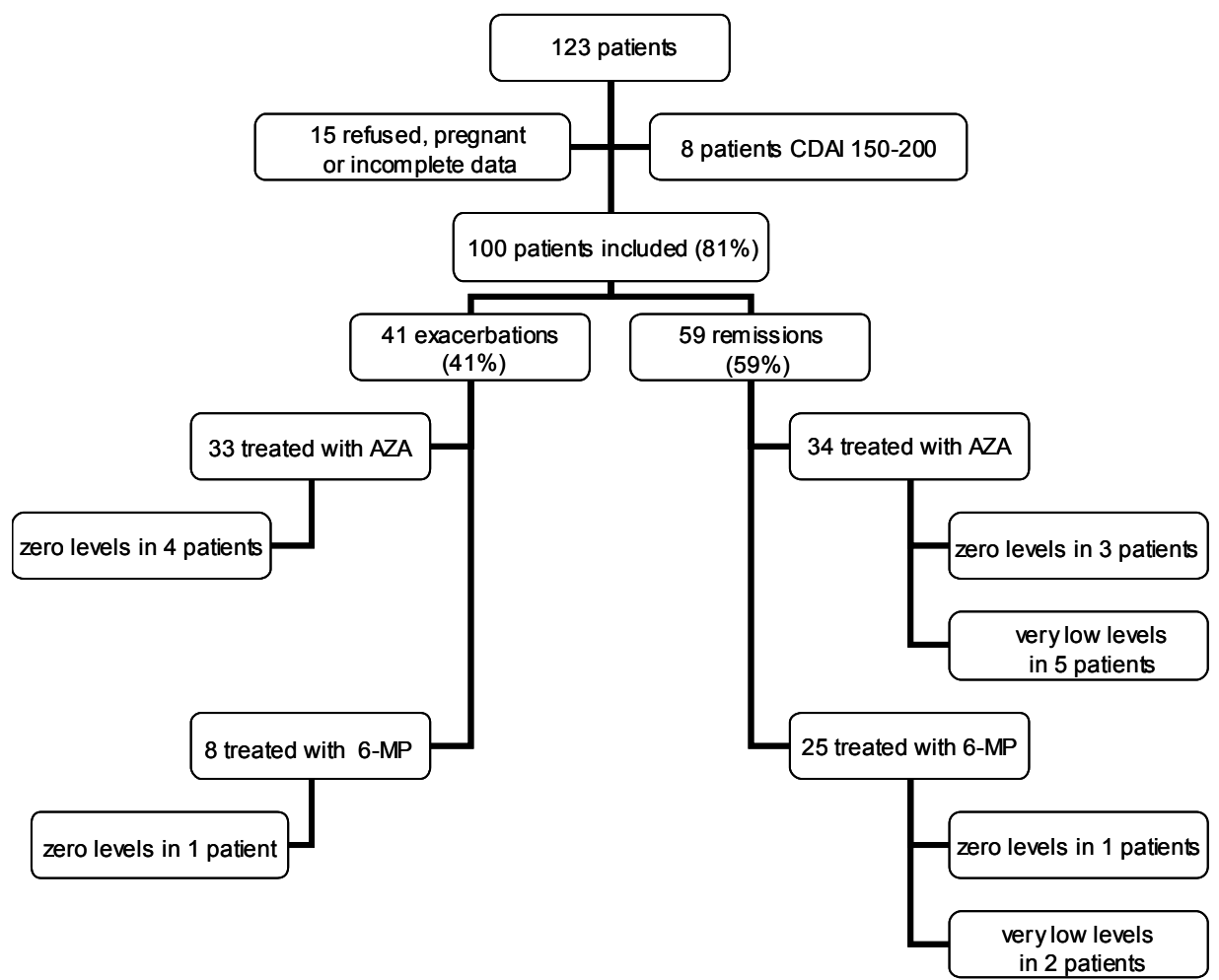

Figure 5.2 Flow chart of inclusion.

CDAl, Crohn's Disease Activity Index; AZA, azathioprine; 6-MP, 6-mercaptopurine. 
Table 5.1 Characteristics of the included patients.

\begin{tabular}{|c|c|c|c|c|}
\hline & All patients & Exacerbation & Remission & $\mathrm{p}$-value \\
\hline $\mathrm{N}$ & 100 & 41 & 59 & \\
\hline mean age in years (range) & $42.3(15-79)$ & $38.6(15-79)$ & $44.6(18-75)$ & 0.057 \\
\hline male/female & $60 / 40$ & $19 / 22$ & $41 / 18$ & 0.024 \\
\hline mean bodyweight $(\mathrm{kg})$ & 75.4 & 73.7 & 76.5 & 0.34 \\
\hline CDAI & 157 & 281 & 72 & $<0.0001$ \\
\hline CAI & 6.8 & 11.9 & 3.1 & $<0.0001$ \\
\hline \multicolumn{5}{|l|}{ IBD } \\
\hline type & & & & 1.0 \\
\hline Crohn & 57 & 23 & 34 & \\
\hline Ulcerative colitis & 40 & 16 & 24 & \\
\hline Indeterminate colitis & 3 & 2 & 1 & \\
\hline location & & & & 0.99 \\
\hline proctosigmoid & $35(35 \%)$ & $15(37 \%)$ & $20(34 \%)$ & \\
\hline colon & $24(24 \%)$ & $9(22 \%)$ & $16(27 \%)$ & \\
\hline ileocolon & $23(23 \%)$ & $11(27 \%)$ & $12(20 \%)$ & \\
\hline terminal ileum & $12(12 \%)$ & $5(12 \%)$ & $7(12 \%)$ & \\
\hline perianal disease & $7(7 \%)$ & $3(7 \%)$ & $4(7 \%)$ & \\
\hline upper GI tract & $2(2 \%)$ & $1(2 \%)$ & $1(2 \%)$ & \\
\hline \multicolumn{5}{|l|}{ mean disease duration } \\
\hline in months (range) & $98.7 \quad(3-624)$ & $99.9(3-432)$ & $97.9(5-624)$ & 0.93 \\
\hline \multicolumn{5}{|l|}{ Medication } \\
\hline Azathioprine $(\mathrm{N})$ & 67 & $33(80 \%)$ & $34(58 \%)$ & 0.02 \\
\hline mean AZA dose in mg (range) & $140(50-225)$ & $136(50-200)$ & $145(50-225)$ & 0.33 \\
\hline mean AZA dose in $\mathrm{mg} / \mathrm{kg}$ (range) & $2.0(0.6-3.0)$ & $1.9(0.8-2.5)$ & $1.8(0.6-3.0)$ & 0.75 \\
\hline 6-Mercaptopurine $(\mathrm{N})$ & 33 & $8(20 \%)$ & $25(42 \%)$ & 0.02 \\
\hline mean 6-MP dose in mg (range) & $56(50-100)$ & $56(50-100)$ & $56(50-100)$ & 0.96 \\
\hline mean 6-MP dose in $\mathrm{mg} / \mathrm{kg}$ (range) & $1.0(0.45-1.22)$ & $0.8(0.6-1.2)$ & $0.8(0.4-1.2)$ & 0.99 \\
\hline
\end{tabular}

$\mathrm{N}$, number of patient; kg, kilograms bodyweight; IBD, inflammatory bowel disease; upper $\mathrm{GI}$ tract, upper gastrointestinal tract; AZA, azathioprine; mg, milligrams; 6-MP, 6-mercaptopurine; CDAI, Crohn's Disease Activity Index; CAI, Colitis Activity Index; pmol, picomoles; $p<0.0 .5$ is considered significant.

Table 5.2 Outcome measures of all included patients.

\begin{tabular}{|c|c|c|c|c|}
\hline Mean outcome measures & $\begin{array}{c}\text { All } \\
\text { patients }\end{array}$ & $\begin{array}{l}\text { Exacerbations } \\
(\mathrm{N}=41)\end{array}$ & $\begin{array}{l}\text { Remissions } \\
(N=59)\end{array}$ & $\mathrm{p}$-value \\
\hline 6-TGN (pmol/8x10 $\left.10^{8} \mathrm{RBC}\right)$ & 260 & 237 & 274 & 0.30 \\
\hline 6-MMPR (pmol/ $\left.8 \times 10^{8} \mathrm{RBC}\right)$ & 1493 & 1461 & 1525 & 0.89 \\
\hline 6-MMPR/6-TGN ratio & 7.3 & 7.3 & 7.4 & 0.97 \\
\hline Number of non-compliant patients (\%) & $16(16)$ & $5(12)$ & $11(19)$ & 0.42 \\
\hline TPMT activity (pmol/mg Hb/hr) & 7.0 & 6.7 & 7.2 & 0.16 \\
\hline
\end{tabular}

$\mathrm{N}$, number of patients; kg, kilograms bodyweight; mg, milligrams; 6-TGN, 6-thioguanine nucleotides level; 6-MMPR, 6-methylmercaptopurine ribonucleotides level; pmol, picomoles; RBC, red blood cells; TPMT, thiopurine S-methyltransferase; Hb, haemoglobin; hr, hour; $p<0.05$ is considered significant. 
No correlation was found between thiopurine dose and metabolite levels or 6-MMPR/6-TGN ratio. 6-TGN levels and TPMT activity were negatively correlated $(r=-0.318, p=0.01)$, without significant differences in TPMT activity between exacerbations and remissions. High TPMT activity was found in five patients (5\%, including one exacerbation) and low TPMT activity in two patients ( $2 \%$, one exacerbation). Both patients with low TPMT activity had high 6-TGN levels ( 712 and $934 \mathrm{pmol} / 8 \times 10^{8} \mathrm{RBC}$ ) and low 6-MMPR levels (zero and 225 and $\mathrm{pmol} / 8 \times 10^{8} \mathrm{RBC}$ respectively). Low TPMT activity was not related with myelotoxicity in this study.

In the following, the correlations between the outcome measures on one side and exacerbations/remissions on the other, will be presented in three different selections of the patient group: a) all patients $(\mathrm{N}=100)$, b) all patients with exacerbations ( $\mathrm{N}=41)$ compared to a control group of compliant patients in remission $(\mathrm{N}=48)$ and c) all compliant patients $(\mathrm{N}=84)$. 6-TGN levels and their predictive accuracy for exacerbation versus remission are given in Table 5.3.

Table 5.3 Optimal therapeutic 6-TGN cut-off level (pmol/8x $\left.10^{8} \mathrm{RBC}\right)$ for several analyses.

\begin{tabular}{lccc}
\hline Patients & All patients & $\begin{array}{c}\text { All except non- } \\
\text { compliant patients in } \\
\text { remission }\end{array}$ & $\begin{array}{c}\text { All compliant } \\
\text { patients }\end{array}$ \\
\hline $\mathrm{N} \mathrm{(E/R)}$ & $100(41 / 59)$ & $89(41 / 48)$ & $84(36 / 48)$ \\
Mean 6-TGN levels E (CI95\%) & $237(183-291)$ & $237(183-291)$ & $270(216-323)$ \\
Mean 6-TGN levels R (CI95\%) & $274(229-319)$ & $320(275-365)$ & $320(275-365)$ \\
Significant difference 6-TGN E vs R & no & yes & no \\
Correlation 6-TGN and disease activity & no & yes, r =-0.24 & no \\
(Cl95\%) & & $(-0.42--0.029)$ & \\
6-TGN cut-off (AUC) & $235-250(0.59)$ & $235(0.70)$ & $235(0.66)$ \\
Sensitivity (\%) & 67 & 72 & 72 \\
Specificity (\%) & 56 & 64 & 60 \\
Positive predictive value (\%) & 52 & 67 & 52 \\
Negative predictive value (\%) & 72 & 70 & 70 \\
Accuracy (\%) & 61 & 69 & 67 \\
p-value 6-TGN cut-off & 0.02 & 0.0007 & 0.007 \\
Odds ratio & 2.5 & 4.7 & 3.8 \\
\hline
\end{tabular}

$\mathrm{N}$, number of patients; E, exacerbations; R, remissions; C195\%, 95\% confidence interval; AUC, area under the curve; $p$-value $<0.05$ is considered as significant.

\section{a) outcome measures of all included patients $(\mathrm{N}=100)$}

No correlation was found between 6-TGN levels and disease activity score. No significant difference in mean 6-TGN levels between exacerbations and remissions was found (237 versus $274 \mathrm{pmol} / 8 \times 10^{8} \mathrm{RBC}$, Table 5.3). The optimal 6-TGN cut-off was approximately $235-250 \mathrm{pmol} / 8 \times 10^{8} \mathrm{RBC}$ with a positive predictive value of $52 \%$ for exacerbations when having $6-$ TGN levels 
below 235 and a negative predictive value of $73 \%$ when having 6 -TGN levels above $250 \mathrm{pmol} / 8 \times 10^{8} \mathrm{RBC}$ in case of remissions (Table 5.4). Twenty-six of the 41 patients with active IBD (63\%) had 6-TGN levels below the proposed therapeutic threshold of $235 \mathrm{pmol} / 8 \times 10^{8} \mathrm{RBC}$, versus 24 of 59 patients in remission $(41 \%)$. On the contrary, $30 \%$ of patients with 6 -TGN levels above $235 \mathrm{pmol} / 8 \times 10^{8} \mathrm{RBC}$ had exacerbations versus $52 \%$ of the patients with 6-TGN levels below 235. Both differences were significant $(p=0.04)$. The odds ratio (OR) for having a 6-TGN level below $235 \mathrm{pmol} / 8 \times 10^{8} \mathrm{RBC}$ in case of active disease was 2.5 ( $\mathrm{Cl}$ 95\% 1.1-5.8).

\section{b) outcome measures of all exacerbations versus compliant patients in remission $(\mathrm{N}=89)$}

All patients with an exacerbation $(\mathrm{N}=41)$ had a mean 6-TGN level of $237 \mathrm{pmol} / 8 \times 10^{8} \mathrm{RBC}$, versus the control group of compliant patients in remission ( $\mathrm{N}=48$ ), having mean 6 -TGN levels of $320 \mathrm{pmol} / 8 \times 10^{8} \mathrm{RBC}$ (SD 155). This analysis showed significantly different 6-TGN levels, a therapeutic 6-TGN cut-off of $235-250 \mathrm{pmol} / 8 \times 10^{8} \mathrm{RBC}$, with a sensitivity and specificity of $72 \%$ and $64 \%$ respectively, a positive and negative predictive value of $67 \%(<235)$ and $73 \%(>250)$, an area under the curve (AUC) of 0.70 and an OR of 4.7 (Table 5.3 and 5.4).

\section{c) outcome measures of all compliant patients $(\mathrm{N}=84)$}

The compliant patients with an exacerbation $(\mathrm{N}=36)$ had mean 6 -TGN levels of $270 \mathrm{pmol} / 8 \times 10^{8} \mathrm{RBC}$, versus $320 \mathrm{pmol} / 8 \times 10^{8} \mathrm{RBC}$ in the control group of compliant patients in remission. This analysis showed no significantly different 6 -TGN levels. The optimal cut-off $6-T G N$ value was $235-250 \mathrm{pmol} / 8 \times 10^{8} \mathrm{RBC}$, with a sensitivity and specificity of $72 \%$ and $60 \%$ respectively, a positive and negative predictive value of $62 \%$ and $73 \%$, AUC of 0.66 and an OR of 3.8 (Table 5.3 and 5.4). 


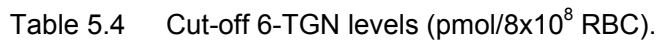

\begin{tabular}{|c|c|c|c|c|c|c|c|}
\hline $\begin{array}{c}\text { Cut-off } \\
6-T G N \\
\text { level }\end{array}$ & $\begin{array}{c}\text { Sensitivity } \\
(\%)\end{array}$ & $\begin{array}{l}\text { Specificity } \\
(\%)\end{array}$ & $\begin{array}{l}\text { Positive } \\
\text { predictive } \\
\text { value (\%) }\end{array}$ & $\begin{array}{l}\text { Negative } \\
\text { predictive } \\
\text { value (\%) }\end{array}$ & p-value & $\begin{array}{l}\text { Likelihood } \\
\text { ratio }\end{array}$ & $\begin{array}{l}\text { Odds ratio and } \\
\qquad \text { CI95\% }\end{array}$ \\
\hline \multicolumn{8}{|c|}{ All patients $(\mathrm{N}=100)$} \\
\hline 100 & 12 & 88 & 42 & 59 & 1.0 & 1.0 & $1.0(0.3-1.5)$ \\
\hline 150 & 24 & 78 & 43 & 59 & 0.8 & 1.1 & $1.1(0.4-2.9)$ \\
\hline 200 & 39 & 69 & 47 & 62 & 0.4 & 1.3 & $1.5(0.6-3.4)$ \\
\hline 235 & 63 & 59 & 52 & 70 & 0.04 & 1.6 & $2.5(1.1-5.7)$ \\
\hline 250 & 71 & 54 & 52 & 73 & 0.02 & 1.5 & $2.9(1.6-6.7)$ \\
\hline 300 & 83 & 37 & 48 & 76 & 0.04 & 1.3 & $2.9(1.1-7.6)$ \\
\hline \multicolumn{8}{|c|}{ All patients, except non-compliant patients in remission $(\mathrm{N}=89)$} \\
\hline 100 & 12 & 98 & 83 & 57 & 0.09 & 5.9 & $6.5(0.7-58)$ \\
\hline 150 & 24 & 94 & 77 & 59 & 0.03 & 3.9 & $4.8(1.2-19)$ \\
\hline 200 & 39 & 85 & 70 & 62 & 0.01 & 2.7 & $3.7(1.4-10.3)$ \\
\hline 235 & 60 & 73 & 67 & 70 & 0.0007 & 2.3 & $4.7(1.9-11.5)$ \\
\hline 250 & 70 & 67 & 64 & 73 & 0.0006 & 2.1 & $4.6(2.0-12.0)$ \\
\hline 300 & 83 & 46 & 57 & 76 & 0.006 & 1.5 & $4.1(1.5-11.1)$ \\
\hline 350 & 85 & 27 & 50 & 68 & 0.2 & 1.2 & $2.2(0.74-6.3)$ \\
\hline \multicolumn{8}{|c|}{ All compliant patients $(\mathrm{N}=84)$} \\
\hline 100 & 0 & 98 & 0 & 57 & 1.0 & 0 & $0.02(0.04-11.0)$ \\
\hline 150 & 14 & 94 & 63 & 59 & 0.3 & 2.2 & $2.4(0.5-10.9)$ \\
\hline 200 & 31 & 85 & 61 & 62 & 0.1 & 2.1 & $2.6(0.9-7.5)$ \\
\hline 235 & 58 & 73 & 62 & 70 & 0.007 & 2.2 & $3.8(1.5-9.4)$ \\
\hline 250 & 67 & 67 & 60 & 73 & 0.004 & 2.0 & $4.0(1.6-10.0)$ \\
\hline 300 & 81 & 46 & 53 & 76 & 0.02 & 1.5 & $3.5(1.3-9.5)$ \\
\hline 350 & 83 & 27 & 46 & 68 & 0.3 & 1.1 & $1.9(0.6-5.5)$ \\
\hline
\end{tabular}

6-TGN, 6-thioguanine nucleotides level; RBC, red blood cells; CI95\%, 95\% confidence interval; $\mathrm{N}$, number of patients; $p<0.05$ is considered significant.

\section{Discussion}

In the longstanding discussion about TDM of thiopurines in the maintenance treatment of IBD, this study provides some novel insights for adult patients. At first, an important result is the overall high prevalence of non-compliance in case of both remissions and exacerbations. Non-compliance is very important in treatment of chronic diseases, but often underestimated in clinical practice $^{18-24}$. TDM is the only way to reveal non-compliance, indicating an important role for TDM in case of refractory disease. The results of this study subscribe this, although no significant difference in non-compliance was found between exacerbations and remissions. Alternatively, zero or very low 6-TGN levels could theoretically be caused by thiopurine malabsorption, a (yet unknown) enzyme defect or extremely high enzyme activity. Recently, very high XO-activity was suggested to be a cause of zero 6-TGN levels in a case report ${ }^{28}$. 
Secondly, no significant differences in 6-TGN or 6-MMPR metabolite levels between patients with exacerbations and remissions were found, neither a correlation between 6-TGN levels and disease activity, when examining the originally included patients. These are disappointing results with regard to TDM of thiopurines, but they are in accordance with several other reports ${ }^{10,14-16}$.

Thirdly, the previously indicated therapeutic threshold 6-TGN level of $235 \mathrm{pmol} / 8 \times 10^{8} \mathrm{RBC}$ does really discern patients with exacerbations from those with remissions in this study, but with a low predictive value for individual patients, especially if non-compliance is not taken into account. However, after creating a control population of compliant patients in remission, the discriminative value of 6-TGN levels is more convincing, with the highest sensitivity and specificity between $235-250$ pmol/ $8 \times 10^{8}$ RBC, resulting in moderate predictive values and an OR of 4.7 for having 6-TGN levels below this threshold in case of an exacerbation.

In all calculations in this study a cut-off therapeutic 6-TGN level is found between $235-250 \mathrm{pmol} / 8 \times 10^{8} \mathrm{RBC}$, however having a low sensitivity, specificity and positive predictive value of maximum 71,73 and $67 \%$ respectively, resulting in an accuracy of $69 \%$. This cut-off level is similar to the proposed 6-TGN threshold of $235 \mathrm{pmol} / 8 \times 10^{8} \mathrm{RBC}$ in a study in paediatric IBD patients ${ }^{1}$. A quartile analysis of the present results, performed according to the method used in that study, finds corresponding therapeutic threshold 6-TGN levels. Only in that study metabolite levels were significantly different between exacerbations and remissions (199 versus $312 \mathrm{pmol} / 8 \times 10^{8} \mathrm{RBC}$ ). We find a significant difference between exacerbations and remissions in reaching the proposed $6-\mathrm{TGN}$ threshold of $235 \mathrm{pmol} / 8 \times 10^{8} \mathrm{RBC}$ : $37 \%$ of patients with an exacerbation versus $59 \%$ in remission, in accordance with the findings of a recent meta-analysis, which indicated $38 \%$ and $62 \%$ respectively ${ }^{17}$. The OR for having clinical remission in case of 6-TGN levels above the threshold, in the analysis of all compliant patients is 3.8 in the present study, also comparable to the findings of the meta-analysis: $3.3 .^{17}$ When excluding only non-compliant patients in remission, this OR is even better: 4.7.

The present study gave also the possibility to study the potential influence of genetically determined metabolic pathways by measuring TPMT activity. Abnormal TPMT activity had a relatively low prevalence, in contrast with previous reports $1,6,7,29-32$. Probably this is due to the fact that all patients had used a thiopurine for at least three months. Therefore, patients with early toxicity had already been excluded. Nevertheless, an expected negative correlation between 6-TGN levels and TPMT activity was found $(r=-0.318$ and $\mathrm{p}=0.014$ ) and both patients with low TPMT activity had low or zero 6-MMPR and high 6-TGN levels. 
Some remarks should be made about this study. We are conscious of the fact that this evaluation is based on a quite narrow selection of patients, regarding their number, the artificial exclusion of an intermediate group of patients with mildly active Crohn's disease (CDAl 150-200) and the fact that all patients had used thiopurines for at least three months, thereby excluding early adverse events. It was decided on beforehand to exclude patients with mildly active Crohn's disease to get a more pronounced definition of exacerbation. Irritable bowel like complaints have a relatively large weight in the CDAI and may bias the score. These overlap patients made the discussion about the efficacy of thiopurines somewhat unclear in the past: e.g. one of the first studies, based on a population with a mean CDAl of only 152 , concluded that thiopurines had low efficacy, but in fact the included patients did not have clearly active disease ${ }^{33,34}$. Secondly, we realise that the included patients have a broad spectrum of IBD phenotypes, although demographic characteristics were very similar. However, this criticism counts for many IBD studies. Thirdly, both AZA and 6-MP treated patients were included. AZA is a prodrug of 6-MP (Figure 1). When using a conversion factor of 0.5 , AZA dose is equivalent with 6-MP dose. Efficacy is equal for both drugs ${ }^{25}$. Fourthly, the effect of other concomitant medication -contributing to therapeutic response- was not considered in this study, though co-treatment had to be stable before inclusion. Nevertheless, this is the fifth study demonstrating a threshold 6 -TGN between $230-260 \mathrm{pmol} / 8 \times 10^{8} \mathrm{RBC}$, with significant differences in the prevalence of exacerbations and remissions above and below this cut-off, confirming some value of TDM, but indicating a low sensitivity and specificity ${ }^{1,2,9,13}$. At last, this study is in fact descriptive, although prospectively performed. A future prospective study on usefulness of TDM in efficacy and safety of thiopurines should follow treatment from the start, comparing a group of patients with dose optimization by TDM with a group with conventional follow up, in a randomised way, examining failures of treatment, efficacy and toxicity at several time points. However, that type of study should include more than 250 patients in both groups to find significant results, based on the known prevalence of leukopenia (2-5\%), hepatotoxicity (10-15\%) and other adverse events. This study would take years and probably necessitates a (multi)national approach. 


\section{Conclusions}

The clinical consequences of our findings seem to be the following: in an individual IBD patient with an exacerbation, TDM of 6-TGN metabolite levels should at first be used to exclude non-compliance. If TDM shows 6-TGN levels below $235 \mathrm{pmol} / 8 \times 10^{8} \mathrm{RBC}$, an attempt to dose increase could be made. However, the sensitivity and specificity of the confirmed cut-off therapeutic 6-TGN level of $235 \mathrm{pmol} / 8 \times 10^{8} \mathrm{RBC}$ is rather low. 


\section{References}

1. Dubinsky MC, Lamothe S, Yang HY, Targan SR, Sinnett D, Théorêt Y, Seidman EG. Pharmacogenomic and metabolite measurement for 6-mercaptopurine therapy in inflammatory bowel disease. Gastroenterology 2000;118:705-13.

2. Derijks LJJ, Gilissen LPL, Engels LGJB, Bos LP, Bus PJ, Lohman JJHM, Curvers WL, Van Deventer SJH, Hommes DW, Hooymans PM. Pharmacokinetics of 6-mercaptopurine in patients with inflammatory bowel disease; implications for therapy. Ther Drug Monit 2004;26:311-8.

3. Cuffari C, Theoret Y, Latour S, Seidman G. 6-Mercaptopurine metabolism in Crohn's disease: correlation with efficacy and toxicity. Gut 1996;39:401-6.

4. Weinshilboum RM, Sladek SL. Mercaptopurine pharmacogenetics: monogenic inheritance of erythrocyte thiopurine methyltransferase activity. Am J Hum Genet 1980;32:651-62.

5. Krynetski EY, Evans WE. Genetic polymorphism of thiopurine S-methyltransferase: molecular mechanisms and clinical importance. Pharmacology 2000;61(3):136-46.

6. Lennard L. TPMT in the treatment of Crohn's disease with azathioprine, Gut 2002;51;143-6.

7. Dubinsky MC, Yang H, Hassard PV, Seidman EG, Kam LY, Abreu MT, Targan SR, Vasiliauskas EA. 6-MP metabolite profiles provide a biochemical explanation for 6-MP resistance in patients with inflammatory bowel disease. Gastroenterology 2002;122:904-15.

8. Sandborn WJ. Rational dosing of azathioprine and 6-mercaptopurine. Gut 2001;48:591-2.

9. Achkar JP, Stevens T, Easley K, Brzezinski A, Seidner D, Lashner B. Indicators of clinical response to treatment with six-mercaptopurine or azathioprine in patients with inflammatory bowel disease. Inflamm Bowel Dis 2004;10:339-45.

10. Goldenberg BA, Rawsthorne P, Bernstein CN. The utility of 6-thioguanine metabolite levels in managing patients with inflammatory bowel disease. Am J Gastroenterol 2004;99:1744-8.

11. Hindorf U, Lyrenas E, Nilsson A, Schmiegelow K. Monitoring of long-term thiopurine therapy among adults with inflammatory bowel disease. Scand J Gastroenterol 2004;39:1105-12.

12. Wright S, Sanders DS, Lobo AJ, Lennard L. Clinical significance of azathioprine active metabolite concentrations in inflammatory bowel disease. Gut 2004;53: 1123-8.

13. Cuffari C, Hunt S, Bayless T. Utilisation of erythrocyte 6-thioguanine metabolite levels to optimise azathioprine therapy in patients with inflammatory bowel disease. Gut 2001;48:642-6.

14. Belaiche J, Desager JP, Horsmans Y, Louis E. Therapeutic drug monitoring of azathioprine and 6-mercaptopurine metabolites in Crohn disease. Scand J Gastroenterol 2001;36:71-6.

15. Lowry PW, Franklin CL, Weaver AL, Pike MG, Mays DC, Tremaine WJ, Lipsky JJ, Sandborn WJ. Measurement of thiopurine methyltransferase activity and azathioprine metabolites in patients with inflammatory bowel disease. Gut 2001;49:665-70.

16. Gupta P, Gokhale R, Kirschner BS. 6-mercaptopurine metabolite levels in children with inflammatory bowel disease. J Pediatr Gastroenterol Nutr 2001;33:450-4. 
17. Osterman MT, Kundu R, Lichtenstein GR and Lewis JD. Association of 6-thioguanine nucleotide levels and inflammatory bowel disease activity: a metaanalysis. Gastroenterology 2006;130:1047-53.

18. Miller $\mathrm{NH}$. Compliance with treatment regimens in chronic asymptomatic diseases, Am J Med 1997;102:43-9.

19. Gilissen LP, Derijks LJ, Bos LP, Bus PJ, Hooymans PM, Engels LG. Therapeutic drug monitoring in 15 patients with inflammatory bowel disease and established azathioprine therapy. Clin Drug Invest 2004;24:479-86.

20. Kane SV, Cohen RD, Aikens JE, Hanauer SB. Prevalence of nonadherence with maintenance mesalamine in quiescent ulcerative colitis. Am J Gastroenterol 2001;96:2929-33.

21. Sewitch MJ, Abrahamowicz M, Barkun A, Bitton A, Wild GE, Cohen A, Dobkin PL. Patient nonadherence to medication in inflammatory bowel disease. Am $\mathrm{J}$ Gastroenterol 2003;98:1535-44.

22. Nigro G, Angelini G, Grosso SB, Caula G, Sategna-Guidetti C. Psychiatric predictors of non-compliance in inflammatory bowel disease: psychiatry and compliance. J Clin Gastroenterol 2001;32:66-8.

23. Kane SV, Huo D, Aikens JE, Hanauer SB. Medication nonadherence and the outcome of patients with quiescent ulcerative colitis. Am J Med 2003;114:39-43.

24. Van Hees PA, Van Tongeren JH. Compliance to therapy in patients on a maintenance dose of sulfasalazine. J Clin Gastroenterol 1982;4:333-6.

25. Lichtiger S, Present DH, Kornbluth A, Gelernt I, Bauer J, Galler G, Michelassi F, Hanauer S. Cyclosporine in severe ulcerative colitis refractory to steroid therapy. N Engl J Med. 1994;330:1841-5.

26. Lennard L, Singleton HJ. High-performance liquid chromatographic assay of the methyl and nucleotide metabolites of 6-mercaptopurine: quantitation of red blood cell 6-thioguanine nucleotide, 6-thioinosinic acid and 6-methylmercaptopurine metabolites in a single sample. J Chromatogr 1992;583:83-90.

27. Jacques-Aigrain E, Bessa E, Medard Y, Mircheva Y, Vilmer E. Thiopurine methyltransferase activity in a French population: HPLC assay conditions and effects of drugs and inhibitors. Br J Clin Pharmacol. 1994;38:1-8.

28. Ansari A, Hassan C, Duley J, Marinaki A, Shobowale-Bakre EM, Seed P, Meenan J, Yim A, Sanderson J. Thiopurine methyltransferase activity and the use of azathioprine in inflammatory bowel disease. Aliment Pharmacol Ther 2002;16:1743-50.

29. Campbell S, Kingstone K, Ghosh S. Relevance of thiopurine methyltransferase activity in inflammatory bowel disease patients maintained on low-dose azathioprine. Aliment Pharmacol Ther 2002;16:389-98.

30. Regueiro M, Mardini $H$. Determination of thiopurine methyltransferase genotype or phenotype optimizes initial dosing of azathioprine for the treatment of Crohn's disease. J Clin Gastroenterology 2002;35:240-4.

31. Kaskas BA, Louis E, Hindorf U, Schaeffeler E, Deflandre J, Graepler F, Schmiegelow K, Gregor M, Zanger UM, Eichelbaum M, Schwab M. Safe treatment of thiopurine S-methyltransferase deficient Crohn's disease patients with azathioprine. Gut 2003;52:140-2.

32. Summers RW, Switz DM, Sessions JT, Becktel JM, Best WR, Kern F, Singleton JW. National Cooperative Crohn's Disease Study: results of drug treatment. Gastroenterology 1979;77:847-869.

33. Mayer L. When is too much enough? Gastroenterology 2006;130:1352-4. 
Section

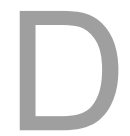

Monitoring of interactions with thiopurine therapy by therapeutic drug monitoring 


\section{Chapter}

\section{The pharmacokinetic effect of discontinuation of mesalazine on 6-mercaptopurine metabolite levels in inflammatory bowel disease patients}

LPL Gilissen, J Bierau, LJJ Derijks, LP Bos, PM Hooymans, A van Gennip, RW Stockbrügger, LP Bos, LGJB Engels

Aliment Pharmacol Ther 2005;22:605-11 


\section{Abstract}

\section{Introduction}

In vitro studies suggest interactions between mesalazine (5-ASA) and thiopurines by thiopurineS-methyltransferase (TPMT) inhibition, influencing the balance of hepatotoxic 6-methylmercaptopurine ribonucleotides (6-MMPR) and immunosuppressive 6-thioguanine nucleotides (6-TGN) metabolites.

\section{Aims}

Examining the in vivo interaction between mesalazine and 6-mercaptopurine (6-MP) in IBD patients.

\section{Methods}

A prospective study was performed in quiescent IBD patients using the combination of 6-MP and 5-ASA. Laboratory parameters, 6-MMPR and 6-TGN levels and TPMT activity in erythrocytes (RBC) were measured at stable medication, after 5-ASA discontinuation and 5-ASA reintroduction. 6-MP was continued.

\section{Results}

17 patients participated. Mean 6-MP dose was $0.78 \mathrm{mg} / \mathrm{kg} /$ day, median $5-A S A$ dose $3000 \mathrm{mg} /$ day. After 5-ASA discontinuation, mean 6-TGN levels changed significantly from 262 to $209 \mathrm{pmol} / 8 \times 10^{8}$ RBC, increasing to 270 after reintroduction. Mean 6-MMPR levels were 1422, 2149 and 1503 $\mathrm{pmol} / 8 \times 10^{8} \mathrm{RBC}$ respectively. Mean 6-MMPR/6-TGN ratio increased significantly from 6.3 at baseline to 11.2. Mean baseline TPMT activity was $0.58 \mathrm{pmol} / 10^{6} \mathrm{RBC} /$ hour and stable. All patients had wildtype TPMT genotypes. Leukocyte counts were stable.

\section{Discussion}

Significantly higher 6-TGN levels and improving 6-MMPR/6-TGN ratio were found during 5-ASA/6-MP combination. Theoretically, 5-ASA inhibits TPMT activity. In vivo TPMT activity did not change, however.

\section{Conclusions}

5-ASA has synergistic effects on 6-MP therapy, but the mechanism is unclear. Combining these drugs may be further indication for 5-ASA in IBD treatment. 


\section{Introduction}

5-aminosalicylic acid compounds (5-ASA) are widely used in inflammatory bowel disease (IBD). Several compounds of 5-ASA exist: sulfasalazine, the newer mesalazine products and azo-bond formulations (eg balsalazide and olsalazide) $)^{1}$. Nowadays, mesalazine is the most frequently used compound.

All 5-ASA products have a direct effect on the gut mucosa by a combination of anti-inflammatory effects like inhibition of prostaglandin synthesis, a decrease in radical formation due to oxygen radical scavenging and an inhibition of activation of lymphocytes ${ }^{2}$.

In ulcerative colitis (UC) 5-ASA has proven to be effective in induction of remission and in maintenance treatment ${ }^{3,4}$. In treatment of Crohn's disease (CD) however, there is much debate on the use of mesalazines. Meta-analyses show only weak evidence for benefit in induction of remission and maintenance treatment in subgroups of patients (eg postsurgical, ileitis or prolonged disease duration $)^{5-7}$. Also, they might protect against colorectal cancer in ulcerative and Crohn's colitis ${ }^{8}$.

6-Mercaptopurine (6-MP), a thiopurine, is widely used in steroid dependent or refractory IBD. Its pro-drug, azathioprine (AZA), is used for the same indications. Thiopurines are metabolised by several enzymes (Figure 6.1). Thiopurine S-methyltransferase (TPMT) is one of the most critical, because of its genetic polymorphism, responsible for large interindividual differences in activity. Recently, inosine triphosphate pyrophosphatase (ITPase) was discovered as another important enzyme in thiopurine metabolism ${ }^{9-11}$. TPMT activity influences the balance between two types of thiopurine metabolites: the immunosuppressive 6-thioguanine nucleotides (6-TGN) and hepatotoxic 6-methylmercaptopurine ribonucleotides (6-MMPR).

In recent years the interest in therapeutic drug monitoring of thiopurines has been accentuated by pharmacokinetic and genomic studies ${ }^{12,13}$. Threshold levels of thiopurine metabolites were described: 6-TGN levels higher than 235 $\mathrm{pmol} / 8 \times 10^{8}$ red blood cells (RBC) were defined as therapeutic and 6-MMPR levels higher than $5700 \mathrm{pmol} / 8 \times 10^{8} \mathrm{RBC}$ were associated with hepatotoxicity ${ }^{13-15}$. Some other studies could not confirm these cut off levels ${ }^{16,17}$. A 6-MMPR/6-TGN ratio of less than 11 was found to correlate with response to $6-\mathrm{MP}$ treatment ${ }^{18}$. Above this point a lack of efficacy is seen, even after dose elevation. 


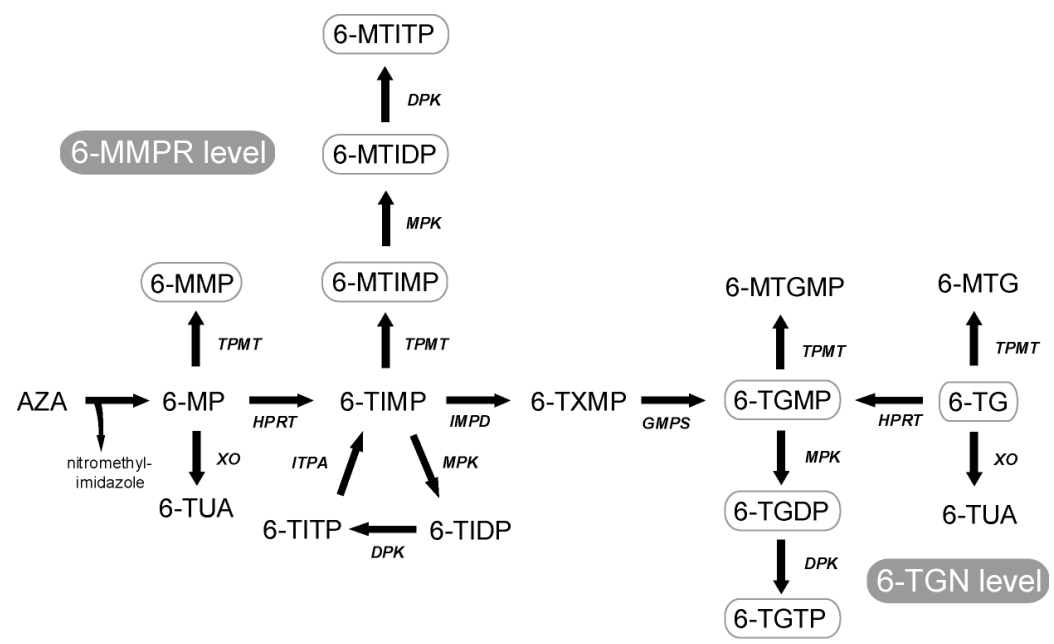

Figure 6.1 Thiopurine metabolism.

AZA, azathioprine; 6-MP, 6-mercaptopurine; 6-TUA, 6-thiouric acid; 6-MMP, 6-methylmercaptopurine; 6-TIMP, 6-thioinosine 5'-monophosphate; 6-MMPR level, 6-methylmercaptopurine ribonucleotides; 6-TITP, 6-thioinosine triphosphate; 6-TIDP, 6-thioinosine diphosphate; 6-TG, 6-thioguanine; 6-TGN level, 6-thioguanine nucleotides; 6-MTG, 6-methylthioguanine; HPRT, hypoxanthine phosphoribosyltransferase; $\mathrm{XO}$, xanthine oxidase; ITPA, inosine triphosphate pyrophosphatase; MPK, monophosphokinase; DPK, diphosphokinase; TPMT, thiopurine S-methyltransferase; IMPDH, inosine monophosphate dehydrogenase; GMPS, guanosine monophosphatase synthetase.

The gene encoding TPMT is subject to a genetic polymorphism, causing great inter-individual differences in metabolite levels. More than twenty mutant TPMT alleles are known ${ }^{19}$. High TPMT activity is associated with the wildtype TPMT $^{\mathrm{H} / \mathrm{H}}$ genotype ( ${ }^{*} 1$ allele), seen in $89 \%$ of the Caucasian population and leading to normal or high 6-MMPR levels. Intermediate and low TPMT activity is associated with mutant alleles (TPMT ${ }^{\mathrm{L} / \mathrm{H}}$ genotype in $11 \%$ and $\mathrm{TPMT}^{\mathrm{L} / \mathrm{L}}$ in $0.3 \%$ of Caucasians, respectively), leading to high 6-TGN levels, with an increased risk of developing myelosuppression. Some reports showed elevated 6-TGN levels and leukopenia in presence of mutant TPMT alleles ${ }^{20,21}$. A prospective study showed an increased relative risk of 12 on myelosuppression in patients with at least one mutant allele ${ }^{22}$.

Several medications can interact with thiopurine metabolism. TPMT is inhibited by angiotensine I converting enzyme inhibitors and diuretics (eg. furosemide, bendroflumethiazide and trichlorthiazide) ${ }^{23}$. In vitro studies showed that sulfasalazine and other 5 -ASA containing products inhibit TPMT ${ }^{24,25}$. These investigators demonstrated that IC50 values (the concentration of an agent halving TPMT activity) were 31, 104, 197 and $1380 \mu \mathrm{mol} / \mathrm{l}$, respectively, for 
olsalazine, sulfasalazine, balsalazide and 5-ASA. The same group performed an in vivo interaction study showing an increase in 6-TGN levels and prevalence of leukopenia due to the concurrent use of 5-ASA. TPMT activity did not change significantly for sulfasalazine and balsalazide and even increased after 8 weeks of mesalazine treatment ${ }^{26}$. Another in vivo interaction study on thiopurines and 5-ASA showed decreasing 6-TGN levels after 5-ASA discontinuation, but again without significant changes in TPMT activity ${ }^{27}$.

Recently an ex vivo study in red blood cells showed that only sulfasalazine would have the potential to inhibit TPMT in vivo, based on human plasma concentrations of sulfasalazine, 5-ASA and its metabolites ${ }^{28}$.

Only two in vivo studies were published yet about the interaction between 5-ASA and thiopurines. Therefore, a prospective in vivo interaction study was performed in our IBD patients, using the combination of 6-mercaptopurine and 5-ASA, by measuring the relevant metabolite levels and TPMT activity.

\section{Patients and methods}

\section{Patient selection}

We traced all IBD patients in a general district hospital (Maasland Hospital Sittard, the Netherlands) using the combination of 6-MP and one of the oral mesalazine products. Patients were considered for the study when using 6-MP and 5-ASA in a stable dose for at least three months. Exclusion factors were age under 16 years and active disease (moderate to severe disease according to the Truelove-Witts disease activity index for Ulcerative Colitis and the Crohn's disease activity index $(\mathrm{CDAl})>150)^{29}$. All included patients signed an informed consent form.

\section{Study design}

A prospective open-label study was carried out. Laboratory parameters (blood cell counts, bilirubin, aspartate transaminase (ASAT), alanine transaminase (ALAT), amylase, lipase, albumin and C-reactive protein), 6-MMPR, 6-TGN levels and TPMT activity were measured at baseline $(t=0 \mathrm{w})$, four weeks after 5-ASA discontinuation $(\mathrm{t}=4 \mathrm{w})$ and four weeks after reintroduction of 5-ASA $(\mathrm{t}=8 \mathrm{w})$ (Table 6.1). 6-MP was continued on a steady dose throughout the study interval. TPMT genotype was determined once. 


\section{Outcome measures}

Primary study outcomes were 6-TGN and 6-MMPR metabolite levels and TPMT activity at $t=0,4$ and 8 weeks. Secondary outcomes were correlations between 6-TGN, 6-MMPR, TPMT activity, 6-MP and 5-ASA dose in $\mathrm{mg} / \mathrm{kg}$ bodyweight, laboratory parameters and disease activity.

Table 6.1 Time table.

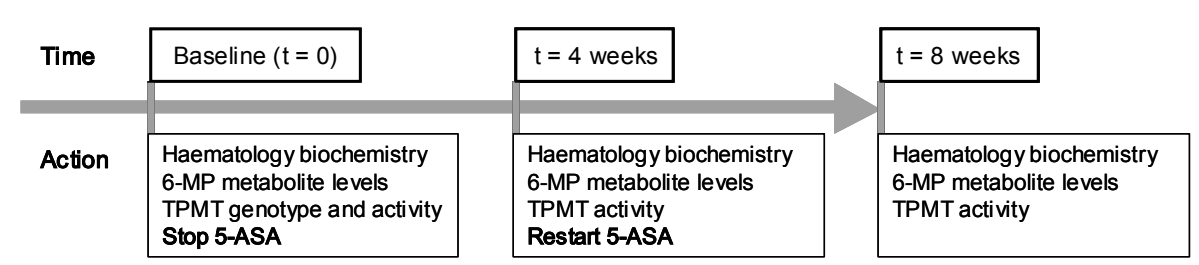

\section{Analytical procedures}

6-TGN and 6-MMPR levels were measured with the modified high performance liquid chromatography (HPLC) method of Lennard as published previously ${ }^{22}$. TPMT genotyping of leukocyte DNA was performed using a previously reported assay $^{22}$. TPMT activity in erythrocyte lysates was measured as described by Jacques-Aigrain and colleagues ${ }^{30}$. Briefly, the washed erythrocyte lysate was incubated with 6-mercaptopurine in a dithiothreitol and S-adenosylmethionine containing phosphate buffer at $\mathrm{pH} 7.5$ at $37^{\circ} \mathrm{C}$ for one hour. 2-Amino6-methylmercaptopurine (6-AMMP) was used as the internal standard. After the incubation period, the reaction was stopped by the addition of hydrogen chloride, followed by neutralization with a basic ammonium chloride solution. 6-MP, 6-MMP and 6-AMMP were extracted with dichloromethane/2-propanol. After evaporation of the organic solvent, the samples were dissolved in buffer and analyzed using reversed-phase HPLC. The inter-assay co-variation of the procedure was $10 \%$, the typical recovery was $99 \%$.

\section{Statistical analysis}

Normality of metabolite levels and TPMT activity was tested by the Kolmogorov-Smirnov normality test. Data are expressed as means with with range or 95\% confidence interval (CI95\%). Pearson's correlation test was used for correlations. $P$ values $<0.05$ were considered significant. 


\section{Results}

Twenty-seven patients of the total IBD cohort of 679 patients in the Maasland Hospital in Sittard, the Netherlands were using the combination of 6-MP simultaneously with an oral mesalazine product (Table 6.2). Oral 5-ASA products used were Salofalk ${ }^{\circledR}$ (Tramedico, Weesp, the Netherlands), Pentasa ${ }^{\circledR}$ (Ferring, Hoofddorp, the Netherlands) and Asacol ${ }^{\circledR}$ (Altana Pharma, Hoofddorp, the Netherlands).

Table 6.2 Characteristics of the patients.

\begin{tabular}{|c|c|c|c|}
\hline \multicolumn{2}{|c|}{ Total IBD cohort Maaslandhospital Sittard } & \multicolumn{2}{|l|}{679 patients } \\
\hline \multicolumn{2}{|c|}{ Patients using 5-ASA and 6-MP } & \multicolumn{2}{|l|}{27} \\
\hline \multicolumn{2}{|l|}{ Included } & \multicolumn{2}{|l|}{17} \\
\hline \multirow[t]{2}{*}{ Excluded } & Active disease & 3 & \\
\hline & Refused & 7 & \\
\hline \multicolumn{4}{|c|}{ Characteristics patients at inclusion } \\
\hline \multicolumn{2}{|c|}{ Male / Female } & \multicolumn{2}{|l|}{$10 / 7$} \\
\hline \multicolumn{2}{|c|}{ Age (mean + range) } & 45 years & $(16-72)$ \\
\hline \multicolumn{2}{|c|}{$\mathrm{CD} / \mathrm{UC}$} & $0.78 \mathrm{mg} / \mathrm{kg}$ & $(0.69-0.86)$ \\
\hline \multicolumn{2}{|c|}{ 6-MP dose (mean + Cl95\%) } & $12 / 5$ & \\
\hline \multicolumn{2}{|c|}{ 5-ASA dose (median + range) } & $3000 \mathrm{mg}$ & $(2400-3000)$ \\
\hline \multicolumn{4}{|c|}{ 5-ASA preparation } \\
\hline & Salofalk $^{\circledR}$ & 9 & \\
\hline & Pentasa ${ }^{\circledR}$ & 6 & \\
\hline & Asacol $^{\circledR}$ & 2 & \\
\hline
\end{tabular}

Mean 6-TGN levels were $262 \mathrm{pmol} / 8 \times 10^{8} \mathrm{RBC}(\mathrm{Cl} 95 \%$ 212-312) at baseline ( $\mathrm{t}=0 \mathrm{w}$ ), 209 (170-247) after four weeks of discontinuation of 5-ASA ( $\mathrm{t}=4 \mathrm{w})$ and 270 (217-322), four weeks after reintroduction of 5-ASA ( $t=8 w$ ) (Figure 6.2A). Mean 6-TGN levels were significantly lower at $\mathrm{t}=4 \mathrm{w}$ than at baseline and at 8 $w(p<0.01)$.

Mean 6-MMPR levels were 1422 (CI95\% 721-2122), 2149 (730-3568) and $1503(721-2284) \mathrm{pmol} / 8 \times 10^{8} \mathrm{RBC}$ at $\mathrm{t}=0,4$ and $8 \mathrm{w}$ respectively, but did not change significantly (figure $2 \mathrm{~B}$ ).

Mean 6-MMPR/6-TGN ratio was 6.3 at baseline (range 1.0-20.6). At $t=4 \mathrm{w}$ this ratio increased significantly to $11.2(p=0.04, C 195 \%-9.6$ to -0.25$)$. At $t=8 w$ the ratio decreased again to 6.2 , but not significantly $(p=0.07$ and $\mathrm{Cl} 95 \%-0.41$ to 10.4).

TPMT genotyping showed a wildtype TPMT ${ }^{\mathrm{H} / \mathrm{H}}\left(\mathrm{TPMT}^{*} 1 /{ }^{*} 1\right)$ genotype in all patients. TPMT activity was evaluated in 16 of 17 patients, due to a missing sample in one of the ulcerative colitis patients. At baseline mean TMPT activity was $0.58 \mathrm{pmol} / 10^{6} \mathrm{RBC} /$ hour (CI95\% 0.48-0.69). Four weeks after 5-ASA discontinuation mean TPMT activity was 0.57 (CI95\% 0.45-0.70) and 4 weeks 
after reintroduction 0.61 (CI95\% 0.50-0.72). Statistical analysis showed no significant change in mean TPMT activity during the study interval $(p=0.52$ and $\mathrm{p}=0.29$ ).

Mean leukocyte counts were comparable $\left(6.5,6.6\right.$ and $6.2 \times 10^{9} / 1$ at the respective timepoints, range 3.8-11.2), no leukopenia with counts below $3.5 \times 10^{9} / l$ occurred. All other laboratory parameters did not change significantly. No correlations were found between 6-MMPR or 6-TGN levels or between these levels and 6-MP dose. No correlation was found between TPMT activity and 6-TGN or 6-MMPR levels or 6-MMPR/6-TGN ratio. TPMT activity did not correlate with 5-ASA or 6-MP dose. Leukocyte counts did not correlate with 6-TGN levels or TPMT activity.
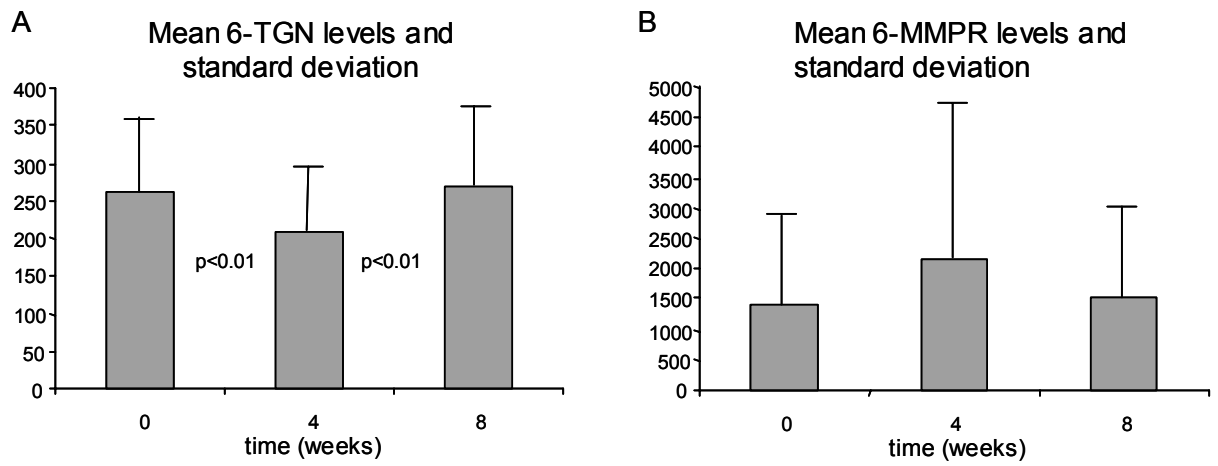

Figure 6.2 Mean 6-TGN and 6-MMPR levels in pmol/8x $10^{8}$ RBC.

\section{Discussion}

This open, prospective study on the interaction of 5-ASA and 6-MP in 17 IBD patients shows a significant decrease of $20 \%$ in 6-TGN levels after discontinuation of mesalazine, reversible after reintroduction. These results are in accordance with previous publications ${ }^{26,27}$. Only, we found baseline 6-TGN levels above the therapeutic threshold of $235 \mathrm{pmol} / 8 \times 10^{8} \mathrm{RBC}$ according to Dubinsky et al. as Dewit found mean 6-TGN levels of $148 \mathrm{pmol} / 8 \times 10^{8} \mathrm{RBC}^{13,27}$. These therapeutic levels decreased under the threshold after 5-ASA discontinuation.

Dubinsky proposed a 6-MMPR/6-TGN ratio of 11 as a cut off point above which the frequency of response to 6-MP treatment decreases and other immunosuppressive therapies should be considered ${ }^{18}$. Although our study was not powered to make conclusions about therapeutic efficacy, it is noticeable that after discontinuation of 5-ASA the mean 6-MMPR/6-TGN ratio increased 
above the proposed cut off of 11. Apparently, 5-ASA improves metabolite profiles, thereby potentiating efficacy of 6-MP treatment. Theoretically, the risk of a leukopenia increases due to the shift towards 6-TGN metabolites. Lowry found leukocyte counts lower than $3.0 \times 10^{9} / /$ in $10 \%$ of patients after initiation of 5-ASA next to steady state azathioprine or 6-MP therapy ${ }^{26}$. Leukocyte counts lower than $3.5 \times 10^{9} /$ were found in $50 \%$ of patients. We neither found a variation in leukocyte counts nor a case of leukopenia, but all patients had already been treated with an established combination of 5-ASA and 6-MP. Patients with (early) myelotoxicity were thus excluded. Still, the increase of 6TGN levels is important in clinical practice, emphasizing the possible need for 6-MP dose adjustment and for regular checks of leukocyte counts, when prescribing 6-MP in combination with 5-ASA.

The significantly higher concentration of 6-TGN metabolites during combination therapy of 5-ASA and 6-MP could theoretically be explained by inhibition of the TPMT enzyme, as was suggested by two in vitro studies ${ }^{24,25}$. However, none of the two in vivo interaction studies performed so far could demonstrate a significant change in TPMT activity in patients ${ }^{26,27}$. In accordance with these findings, no significant change in TPMT activity after discontinuation of mesalamine was seen in this study. By coincidence, all patients had a wild type TPMT genotype, excluding bias due to the influence of TPMT genotype on phenotype or activity.

What is the explanation for the effect of 5-ASA products on 6-MP metabolism then? Possibly the analytical procedure of TPMT activity measurement itself explains the unchanged TPMT activity during the study interval. During preparation of the erythrocyte lysates all metabolites are washed out. It is unknown whether 5-ASA metabolites are washed out as well or whether 5-ASA metabolites irreversibly inhibit TPMT. If these metabolites are removed during TPMT analysis this might lead to normalisation of inhibition of TPMT activity. Alternatively, other and even still unknown enzymes of the thiopurine metabolism could be influenced by 5-ASA.

\section{Conclusions}

Oral 5-ASA products lead to an increase of 6-TGN levels in combination with $6 \mathrm{MP}$ therapy. They potentate efficacy of 6-MP treatment by improving the 6-MMPR/6-TGN ratio, which is related to treatment response. Theoretically, this combination therapy gives a higher risk for myelosuppression due to higher 6-TGN concentrations. No study demonstrated any effect of 5-ASA on TPMT activity yet. The reasons for the observed interaction remain unexplained. Clinicians should be prepared to use lower 6-MP doses when combining 6-MP with 5-ASA and check leukocyte counts regularly in these patients. 
The synergistic effect of 5-ASA with 6-MP may support the indication for 5-ASA in maintenance therapy of $C D$. 


\section{References}

1. Feagan BG and Sandborn WJ. Initial therapy for mild to moderate Crohn's disease: mesalamine or budenoside? Reviews in Gastroenterological disorders 2002;2(suppl.2):S9-15.

2. Nikolaus S, Fölscn U, Schreiber S. Immunopharmacology of 5-aminosalicylic acid and of glucocorticoids in the therapy of inflammatory bowel disease. Hepatogastroenterology 2000;47:71-82.

3. Sutherland L, MacDonald JK. Oral 5-aminosalicylic acid for induction of remission in ulcerative colitis. Cochrane database syst rev 2003;3:CD000543.

4. Sutherland L, Roth D, Beck P, May G, Makiyama K. Oral 5-aminosalicylic acid for maintenance of remission in ulcerative colitis. Cochrane database syst rev 2002;4:CD000544.

5. Cama C, Giunta M, Rosselli M and Cottone M. Mesalamine in the maintenance treatment of Crohn's disease: a meta-analysis adjusted for confounding variables. Gastroenterology 1997;113:1465-73.

6. Lochs H, Mayer M, Fleig WE, Mortensen PB, Bauer P, Genser D, Petrtitsch W, Raithel M, Hoffmann R, Gross V, Plauth M, Staun M, Nesje LB and the European Cooperative Crohn's disease study VI group. Prophylaxis of postoperative relapse in Crohn's disease with mesalamine: European Cooperative Crohn's Disease Study VI. Gastroenterology 2000;118:264-73.

7. Hanauer SB, Stromberg U. Oral Pentasa in the treatment of active Crohn's disease: a meta-analysis of double-blind, placebo-controlled trials. Clin Gastroenterol Hepatol 2004;2:379-88.

8. Eaden JA, Abrams KR, Mayberry JF. The risk of colorectal cancer in ulcerative colitis: a meta-analysis. Gut 2001;48:526-35.

9. Sumi S, Marinaki A, Arenas M, Fairbanks L, Shobowale-Bakre M, Rees D, Thein S, Ansari A, Sanderson J, De Abreu R, Simmonds A, Duley J. Genetic basis of inosine triphosphate pyrophosphohydrolase deficiency. Hum Genet 2002;111:360-7.

10. Marinaki AM, Ansari A, Duley JA, Arenas M, Sumi S, Lewis CM, Shobowale-Bakre el M, Escuredo E, Fairbanks LD, Sanderson JD. Adverse drug reactions to azathioprine therapy are associated with polymorphism in the gene encoding inosine triphosphate pyrophosphatase (ITPase). Pharmacogenetics 2004;14: 181-7.

11. Zelinkova Z, Derijks LJ, Stokkers PC, Vogels EW, van Kampen AH, Curvers WL, Cohn D, van Deventer SJ, Hommes DW. Inosine triphosphate pyrophosphatase and thiopurine s-methyltransferase genotypes relationship to azathioprine-induced myelosuppression. Clin Gastroenterol Hepatol. 2006;4:44-9.

12. Cuffari C, Theoret $\mathrm{Y}$, Latour S, Seidman G. 6-Mercaptopurine metabolism in Crohn's disease: correlation with efficacy and toxicity. Gut 1996;39:401-6.

13. Dubinsky MC, Lamothe S, Yang HY, Targan SR, Sinnett D, Théorêt Y, Seidman EG. Pharmacogenomic and metabolite measurement for 6-mercaptopurine therapy in inflammatory bowel disease. Gastroenterology 2000;118:705-13.

14. Roblin X, Serre-Debeaubais F, Phelip JM, Faucheron JL, Hardy G, Chartier A, Helluwaert F, Bessard $G$ and Bonaz B. 6-Tioguanine monitoring in steroid dependent patients with inflammatory bowel diseases receiving azathioprine. Aliment Pharmacol Ther 2005;21:829-39. 
15. Cuffari C, Hunt S, Bayless T. Enhanced bioavailability of azathioprine compared to 6-mercaptopurine therapy in inflammatory bowel disease: correlation with treatment efficacy. Aliment Pharmacol Ther 2000;14:1009-14.

16. Lowry PW, Franklin CL, Weaver AL, Pike MG, Mays DC, Tremaine WJ, Lipsky JJ, Sandborn WJ. Measurement of thiopurine methyltransferase activity and azathioprine metabolites in patients with inflammatory bowel disease. Gut 2001;49:665-70.

17. Gupta P, Gokhale R, Kirschner B. 6-Mercaptopurine (6MP) metabolite levels in children with IBD. J Ped Gastroent Nutr 2001;33:450-4.

18. Dubinsky MC, Yang H, Hassard PV, Seidman EG, Kam LY, Abreu MT, Targan SR, Vasiliauskas EA. 6-MP metabolite profiles provide a biochemical explanation for 6MP resistance in patients with inflammatory bowel disease. Gastroenterology 2002;122:904-15.

19. Schaeffeler E, Fischer C, Brockmeier D, Wernet D, Moerike K, Eichelbaum M, Zanger UM, Schwab M. Comprehensive analysis of thiopurine S-methyltransferase phenotype-genotype correlation in a large population of German-Caucasians and identification of novel TPMT variants. Pharmacogenetics 2004;14:407-17.

20. Black AJ, McLeod HL, Capell HA. Thiopurine methyltransferase genotype predicts therapy-limiting severe toxicity from azathioprine. Annals of Internal Medicine 1998;129:716-8.

21. Lennard L. Clinical implications of thiopurine methyltransferase--optimization of drug dosage and potential drug interactions. Ther Drug Monit 1998;20:527-31.

22. Derijks LJJ, Gilissen LPL, Engels LGJB, Bos LP, Bus PJ, Lohman JJHM, Curvers WL, Van Deventer SJH, Hommes DW and Hooymans PM. Pharmacokinetics of 6-mercaptopurine in patients with inflammatory bowel disease; implications for therapy. Ther Drug Monit 2004;26:311-8.

23. Lysaa RA, Giverhaug T, Wold HL and Aarbakke J. Inhibition of human thiopurine methyltransferase by furosemide, bendroflumethiazide and trichlormethiazide. Eur J Pharmacol 1996;49:393-6.

24. Szumlanski CL and Weinshilboum RM. Sulphasalazine inhibition of thiopurine methyltransferase: possible mechanism for interaction with 6-mercaptopurine and azathioprine, Br J Clin Pharmacol 1995;39:456-9.

25. Lewis LD, Benin A, Szumlanski CL, Otterness DM, Lennard L, Weinshilboum RM, Nierenberg DW. Olsalazine and 6-mercaptopurine -related bone marrow suppression: a possible drug-drug interaction. Clin Pharmacol Ther 1997;62: 464-75.

26. Lowry PW, Franklin CL, Weaver AL, Szumlanski CL, Mays DC, Loftus EV, Tremaine WJ, Lipsky JJ, Weinshilboum RM, Sandborn WJ. Leucopenia resulting from a drug interaction between azathioprine or 6-mercaptopurine and mesalamine, sulphasalazine or balsalazide. Gut 2001;49:656-64.

27. Dewit O, Vanheuverzwyn R, Desager JP and Horsmans Y. Interaction between azathioprine and aminosalicylates: an in vivo study in patients with Crohn's disease. Aliment Pharmacol Ther 2002;16:79-85.

28. Xin $\mathrm{H}$, Fischer $\mathrm{C}$, Schwab M and Klotz U. Effects of aminosalicylates on thiopurine S-methyltransferase activity: an ex vivo study in patients with inflammatory bowel disease. Aliment Pharmacol Ther 2005;21:1105-9.

29. Truelove SC, Witts LJ. Cortisone in ulcerative colitis: final report on a therapeutic trial. BMJ 1955;4947:1041-8. 
30. Jacques-Aigrain E, Bessa E, Medard Y, Mircheva Y, Vilmer E. Thiopurine methyltransferase activity in a French population: HPLC assay conditions and effects of drugs and inhibitors. Br J Clin Pharmacol. 1994;38:1-8. 
Section $E$

6-Thioguanine: the revival of an old drug 
Chapter

\section{Pharmacokinetics of 6-thioguanine in patients with inflammatory bowel disease}

LJJ Derijks, LPL Gilissen, LGJB Engels, LP Bos, PJ Bus, JJHM Lohman, SJH van Deventer, DW Hommes, PM Hooymans 


\section{Abstract}

\section{Introduction}

6-Thioguanine (6-TG) seems to be an attractive alternative in both AZA and 6-MP intolerant and resistant IBD populations. However, little is known of 6-TG pharmacokinetics in IBD patients, metabolite levels and their correlation with drug efficacy and toxicity.

\section{Aims}

This study reports the 6-TG pharmacokinetics in a population of IBD patients and the predictive value of metabolite concentrations.

\section{Patients and methods}

Red blood cell (RBC) 6-thioguanine nucleotides (6-TGN) concentrations were measured in twentyeight IBD-patients at $\mathrm{t}=1,2,4$ and 8 weeks after starting 6-TG $20 \mathrm{mg}$ once daily. Outcome measures included mean $6-\mathrm{TGN}$ concentrations $( \pm 95 \%$ confidence interval $(\mathrm{Cl} 195 \%))$, and their associations with TPMT genotype, 6-TG dose, hematologic, hepatic, pancreatic and efficacy parameters during the 8 week period.

\section{Results}

Steady state 6-TGN concentrations were reached after four weeks, indicating a half life of

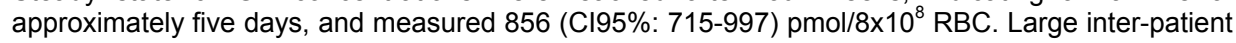
variability occurred at all time-points. No correlation was found between steady state 6-TGN concentrations and drug dose per $\mathrm{kg}$ bodyweight. No significant differences in 6-TGN concentrations were found between patients with adverse events versus patients without any event. Also, mean 6-TGN concentrations did not differ in patients with active disease versus patients in remission.

\section{Discussion and conclusions}

In IBD patients on 6-TG treatment, large interindividual differences in metabolite concentrations occur. In our population, we could not demonstrate a clear relationship between 6-TGN concentrations on one hand and toxicity and efficacy on the other, like in AZA and 6-MP treated patients. 


\section{Introduction}

6-Mercaptopurine (6-MP) and its prodrug azathioprine (AZA) have proven efficacy in the treatment of inflammatory bowel disease (IBD) ${ }^{1-3}$. Thiopurines themselves are inactive and require intracellular metabolism (Figure 7.1) to the active 6-thioguanine nucleotides (6-TGN), which are incorporated into DNA, causing immunosuppression ${ }^{4,5}$. Also, 6-thioguanine triphosphate (6-TGTP), one of the 6-TGN, is considered to contribute to the immunosuppressive effects due to inhibition of Rac1, inducing apoptosis ${ }^{6}$. However, these immunosuppressives are ineffective in one-third of patients ${ }^{7}$ and $10-20 \%$ of AZA or 6-MP treated patients is forced to discontinue drug therapy due to the occurrence of adverse events ${ }^{8-10}$. Administration of 6-thioguanine (6-TG), an agent much closer to effective 6-TGN, seems to be an attractive alternative in both AZA and 6-MP intolerant ${ }^{11,12}$ and resistant populations ${ }^{13,14}$. Recently discovered disturbing high frequencies of nodular regenerative hyperplasia $(\mathrm{NRH})$ in the liver in patients treated with 6-TG tempered initial enthusiasm ${ }^{15}$. In patients treated with 6-MP it is shown that red blood cell (RBC) 6-TGN levels correlate with both drug efficacy and myelotoxicity and a therapeutic window of $250-500 \mathrm{pmol} / 8 \times 10^{8} \mathrm{RBC}$ was proposed ${ }^{16,17}$. However, in patients treated with 6 -TG much higher metabolite levels develop without any sign of myelotoxicity ${ }^{12}$. In fact, very little is known of 6-TG pharmacokinetics in IBD patients, metabolite levels and their correlation with drug efficacy and toxicity. Therefore, we performed a prospective pharmacokinetic study of 6-TG in a population of IBD patients.

\section{Material and methods}

\section{Patient selection}

IBD patients in which 6-TG was indicated, aged between 18 and 75 years and attending the out-patient clinics of Maasland Hospital Sittard or St. Laurentius Hospital Roermond, were eligible for the study. Considered as indications for 6-TG treatment were steroid-dependency, steroid-resistancy and AZA- or 6-MP intolerance (both hypersensitivity reactions and dose-dependent events). Exclusion criteria were: pregnancy or expected pregnancy within six months, inadequate contraception in women, lactation, presence of active infection, history of tuberculosis, HIV, hepatitis B or C, severe pancreatitis (necrotizing pancreatitis or pancreatitis leading to multi organ failure), malignancy, ongoing treatment with other immunosuppressive drugs like cyclosporin, methotrexate, thalidomide or infliximab, impaired renal function (serum creatinin $>2$ times normal upper limit), elevated liver function tests ( $>2$ times normal upper limit) and bone marrow suppression. 


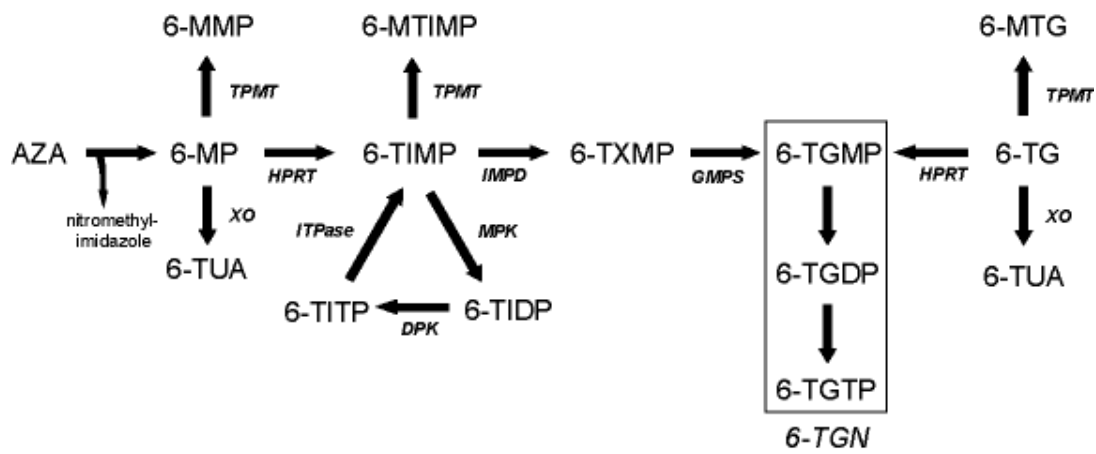

Figure 7.1 Thiopurine metabolism.

AZA, azathioprine; 6-MP, 6-mercaptopurine; 6-MMP, 6-methylmercaptopurine; 6-TUA, 6-thiouric acid; 6-TIMP, 6-thioinosine monophosphate; 6-MTIMP, 6-methylthioinosine monophosphate; 6-TIDP, 6-thioinosine diphosphate; 6-TITP, 6-thioinosine triphosphate; 6-TXMP, 6-thioxanthosine monophosphate; 6-TGMP, 6-thioguanine monophosphate; 6-TGDP, 6-thioguanine diphosphate; 6-TGTP, 6-thioguanine triphosphate; 6-TGN; 6-thioguanine nucleotides; 6-TG, 6-thioguanine; 6-MTG, 6-methylthioguanine; XO, xanthine oxidase; TPMT, thiopurine S-methyltransferase; HPRT, hypoxanthine phosphoribosyl transferase; IMPD, inosine monophosphate dehydrogenase; GMPS, guanosine monophosphate synthetase; MPK, monophosphate kinase; DPK, diphosphate kinase; ITPase, inosine triphosphatase.

\section{Study design}

The trial design was a prospective open-label multicentre study. At entry patient demographics and clinical history were collected as well as medicationuse during the past year. Subsequently, 6-TG (Lanvis ${ }^{\mathrm{TM}}$, tablet $40 \mathrm{mg}$, Glaxo Wellcome, Zeist, the Netherlands) was prescribed as a single oral $20 \mathrm{mg}$ evening dose. Therefore, the commercially available $40 \mathrm{mg}$ tablets were divided into half by a tablet-splitter in the production-unit of the Department of Clinical Pharmacy, Maasland Hospital, Sittard. Concomitant medication was continued: aminosalicylates were allowed as stable comedication throughout the study and steroid dose could be tapered according to clinical response. Laboratory parameters, disease activity scores (Crohn's Disease Activity Index (CDAI) for CD and Truelove-Witts Disease Activity Index (TWDAI) for UC) and quality of life (according VAS-score) were obtained at 0 (baseline), 1, 2, 4 and 8 weeks after start of medication. Blood was drawn each visit for measurement of 6-TGN concentrations, alanine transaminase (ALT), aspartate transaminase (AST), bilirubins, amylase, lipase, leukocytes (plus differentiation), platelets and haemoglobin $(\mathrm{Hb})$. Additionally, in three randomly chosen patients with 6-TGN concentrations at steady state blood was drawn for the measurement of 6-TGN concentrations during a twenty-four hours period at $0,2,4,8,12$ and 24 hours after 6-TG intake to study concentration fluctuations during the day. 


\section{Ethical considerations}

The protocol was approved by the local medical ethics committee and in accordance with the Helsinki Declaration. Informed written consent was obtained before enrolment.

\section{Outcome measures}

Outcome measures were individual 24-hours- and eight-week curves, mean 6 -TGN concentrations $\pm 95 \%$ confidence interval (Cl95\%), correlation between steady state 6-TGN concentrations with several other parameters including dose per $\mathrm{kg}$ bodyweight, TPMT genotype (TPMT*1/TPMT*2/TPMT*3A/ $\mathrm{TPMT}^{*} 3 \mathrm{~B} / \mathrm{TPMT}^{*} 3 \mathrm{C}$ ), the occurrence of myelotoxicity (leukocyte count $<4.0 \times 10^{9} /$, platelet count $<100 \times 10^{9} /$ l), the occurrence of hepatic toxicity (ALT>80 U/l, AST >80 U/l, bilirubins $>40 \mu \mathrm{mol} / \mathrm{l}$ ), pancreatic toxicity (amylase $>220 \mathrm{U} / \mathrm{l}$, lipase >120 U/I (elevations >2 times normal upper limit)), CDAI (CD) or TWDAI (UC) during the eight week period. The relationship of adverse events with the use of 6-TG was established by the following method: unrelated, no temporal relation and other aetiology likely; possibly related, potential temporal relation and other aetiologies possible; probably related, potential temporal relation and other aetiologies unlikely; related, clear temporal relation not otherwise explained.

\section{Analytical procedures}

6-TGN concentrations were measured in the laboratory of the Department of Clinical Pharmacy, Maasland Hospital, Sittard, using a previously published assay ${ }^{17}$. Erythrocytes are a good surrogate matrix as they are easily obtained, exist in sufficient numbers and contain concentrations of 6-TGN that reflect concentrations of 6-TGN in the less accessible putative target-tissue, the leukocytes ${ }^{18}$. In brief, the thiopurines are separated by reversed-phase HPLC and quantified using UV-detection. For measurement of intracellular thionucleotides the free base is obtained by acid hydrolysis of the nucleotide back to the purine. The resulting purines are extracted from the biological matrix by forming a phenyl mercury adduct into dichloromethane. During backextraction with hydrochloric acid the adduct is splitted and the free thiopurine is liberated into the acid layer once again. The run-to-run coefficient of variation was $6.6 \%$. The lower limit of quantification of the assay was determined at $30 \mathrm{pmol} / 8 \times 10^{8} \mathrm{RBC}$.

TPMT-genotyping of leukocyte DNA was carried out by the laboratory of the Department of Gastroenterology and Hepatology, Academic Medical Centre, Amsterdam, based on a previously reported assay ${ }^{19}$. 


\section{Statistical analysis}

Normality was tested by the Kolmogorov-Smirnov test. Data are expressed as means with range or C195\%. Pearson's correlation was used to test the relationship between the measured parameters. $P$ values $<0.05$ were considered significant. SPSS for Windows (version 10.0.7) software was used to perform statistics.

\section{Results}

Patient characteristics and reasons for 6-TG initiation are shown in Table 7.1. Twenty-eight patients were enrolled between May 2001 and November 2003. Of the 28 patients, 27 patients (96\%) were on 6-TG treatment for four weeks and 24 patients (86\%) completed the eight week period. Steady state was reached after a period of four weeks. Four patients failed to reach the end of the observed period because of the occurrence of adverse events.

Table 7.1 Patient characteristics $(n=28)$.

\begin{tabular}{|c|c|c|c|}
\hline \multicolumn{3}{|l|}{$\operatorname{Sex}(M / F)$} & $6 / 22$ \\
\hline \multicolumn{3}{|l|}{ Age (yrs) (mean + range) } & $38(19-70)$ \\
\hline \multicolumn{3}{|l|}{ Disease (CD/UC) } & $16 / 12$ \\
\hline \multirow[t]{5}{*}{ Location of disease } & & small bowel & 5 \\
\hline & & large bowel & 6 \\
\hline & & combination & 5 \\
\hline & & distal colitis & 9 \\
\hline & & pancolitis & 3 \\
\hline \multicolumn{3}{|c|}{ Duration of disease (yrs) (mean + Cl95\%) } & $10.0(7.4-12.6)$ \\
\hline \multirow[t]{4}{*}{ Disease activity at baseline } & CD & remission, CDAI<150 & 5 \\
\hline & & active, CDAI 150-300 & 11 \\
\hline & UC & remission, TWDAI $\leq 6$ & 7 \\
\hline & & active, TWDAI>6 & 5 \\
\hline \multicolumn{3}{|l|}{ Quality of Life at baseline* } & 56 \\
\hline \multicolumn{3}{|l|}{ 5-ASA / no 5-ASA } & $23 / 5$ \\
\hline \multicolumn{3}{|c|}{ 5-ASA dose (mg) (median + range) } & $3000(1500-3200)$ \\
\hline \multirow[t]{5}{*}{ Reason for 6-TG initiation } & \multicolumn{2}{|c|}{ Disease activity/steroid dependency } & 1 \\
\hline & \multicolumn{2}{|c|}{ AZA intolerance } & 9 \\
\hline & \multicolumn{2}{|c|}{ 6-MP intolerance } & 8 \\
\hline & \multicolumn{2}{|c|}{ AZA and 6-MP intolerance } & 8 \\
\hline & \multicolumn{2}{|c|}{ Other } & 2 \\
\hline \multicolumn{3}{|c|}{ 6-TG dose $(\mathrm{mg} / \mathrm{kg})($ mean + Cl95\%) } & $0.32(0.29-0.34)$ \\
\hline \multicolumn{4}{|l|}{ TPMT genotype } \\
\hline \multicolumn{3}{|l|}{$* 1 / * 1$} & 17 \\
\hline \multicolumn{3}{|c|}{ not determined } & 11 \\
\hline
\end{tabular}

M, male; F, female; $C D$, Crohn's disease; UC, ulcerative colitis; CDAI, Crohn's disease activity index; TWDAI, Truelove-Witts disease activity index; 5-ASA, 5-aminosalicylic acid (-analogues); 6-TG, 6-thioguanine; 6-MP, 6-mercaptopurine; AZA, azathioprine; TPMT, thiopurine S-methyltransferase. *according VAS-score (0-100\%). 


\section{Metabolite concentrations}

Metabolite concentrations were normally distributed. Mean 6-TGN concentrations are shown in Table 7.2. Individual eight week and 24-hours 6-TGN curves are shown in Figure 7.2 and 7.3 respectively. Seven patients had measurable 6-TGN concentrations at inclusion because AZA or 6-MP therapy was discontinued only recently. 6-TGN concentrations reached steady state concentrations after four weeks in all but one patient with questionable compliance. No correlation was found between steady state 6-TGN concentrations and dose per kg bodyweight, as shown in Figure 7.4.

Table 7.2

6-TGN concentrations

\begin{tabular}{llll}
\hline Week & $\mathrm{N}$ & $\begin{array}{l}\text { Mean 6-TGN level } \\
\left(\mathrm{pmol} / 8 \times 10^{8} \mathrm{RBC}\right)\end{array}$ & range \\
\hline 1 & 27 & 481 & $35-1254$ \\
2 & 25 & 678 & $123-1763$ \\
4 & 27 & 856 & $192-2112$ \\
8 & 24 & 848 & $284-1888$ \\
\hline
\end{tabular}

$\mathrm{N}$, number of patients; 6-TGN, 6-thioguanine nucleotides.

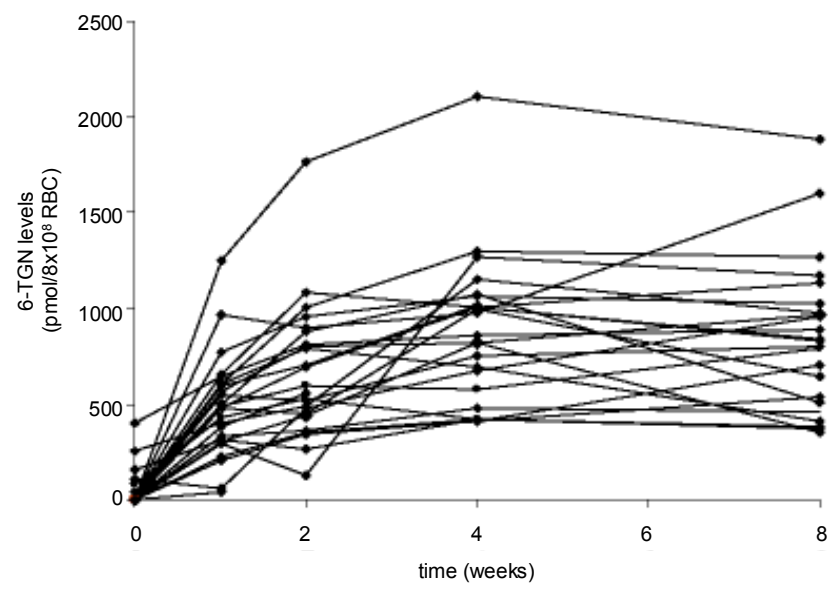

Figure 7.2 Individual 6-TGN concentrations curves (eight weeks). 6-TGN, 6-thioguanine nucleotides; RBC, red blood cells. 


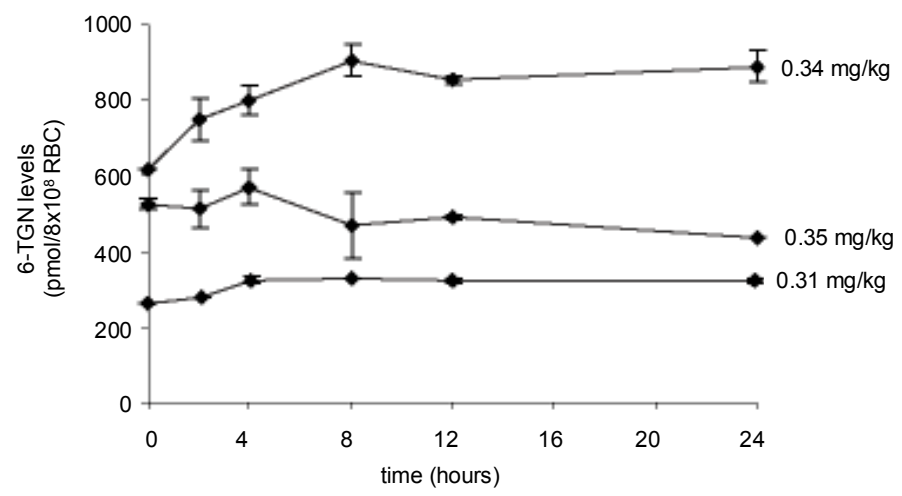

Figure 7.3 Individual steady state 6-TGN concentrations curves (24 hours). 6-TGN, 6-thioguanine nucleotides; RBC, red blood cells. The depicted standard deviations express the margin of error of our assay for 6-TGN measurement.

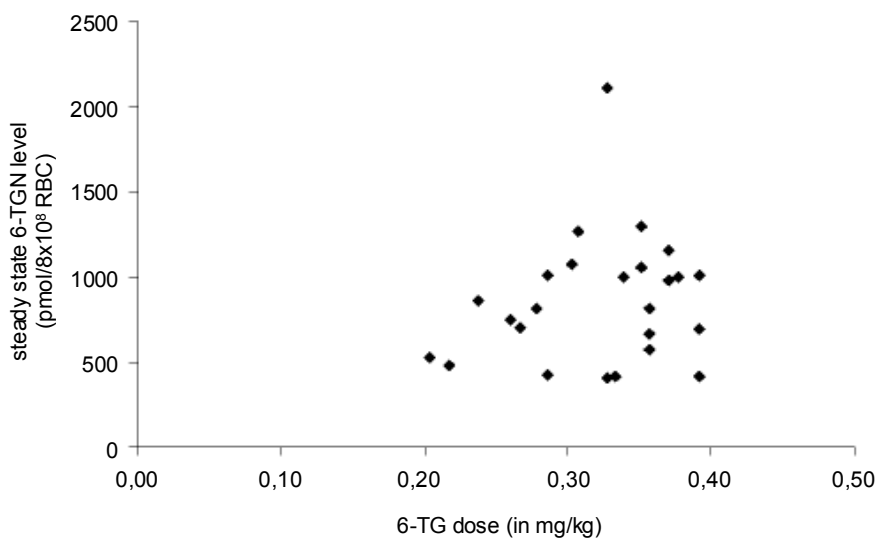

Figure 7.4 Correlation between 6-TGN concentrations and dose per kg bodyweight. 6-TGN, 6-thioguanine nucleotides; RBC, red blood cells.

\section{TPMT genotype}

TPMT genotype was determined in 17 of 28 patients (61\%) and all genotyped subjects possessed wild type alleles (Table 7.1). In two of the four patients intolerant to 6-TG TPMT genotype could not assessed because of loss to follow-up. In the other two patients a wild type TPMT genotype was found. The patient with the clearly highest 6-TGN concentrations possessed wildtype alleles. 


\section{Adverse events}

Four patients discontinued therapy because of adverse events. Adverse events leading to discontinuation of 6-TG treatment are summarized in Table 7.3. In these patients, 6-TGN concentrations varied considerably. No myelotoxicity or hepatotoxicity occurred in the observed period. In one patient amylase (158 $\mathrm{U} / \mathrm{l})$ and lipase $(273 \mathrm{U} / \mathrm{l})$ levels temporarily increased without any symptoms of a clinically present pancreatitis.

Table 7.3 Adverse events leading to discontinuation of 6-TG treatment.

\begin{tabular}{|c|c|c|c|c|c|c|}
\hline No. & $\begin{array}{c}\text { Dose } \\
(\mathrm{mg} / \mathrm{kg})\end{array}$ & $\begin{array}{l}\text { Last 6-TGN level } \\
\left(\mathrm{pmol} / 8 \times 10^{8} \mathrm{RBC}\right)\end{array}$ & $\begin{array}{c}\text { Time to } A E \\
\text { (days) }\end{array}$ & Character of $\mathrm{AE}$ & Relationship & TPMT \\
\hline 1 & 0.26 & 552 & 24 & $\begin{array}{l}\text { nausea* }^{*} \text { diarrhoea* } \\
\text { stomach cramps* }\end{array}$ & $\begin{array}{l}\text { probably } \\
\text { related }\end{array}$ & ${ }^{*} 1 /{ }^{*} 1$ \\
\hline 2 & 0.29 & 1013 & 42 & total malaise* & $\begin{array}{l}\text { possibly } \\
\text { related }\end{array}$ & ${ }^{*} 1 /{ }^{*} 1$ \\
\hline 3 & 0.20 & 229 & 7 & $\begin{array}{c}\text { fever*, erythema } \\
\text { nodosum*, arthralgia* }\end{array}$ & related & n.d. \\
\hline 4 & 0.34 & - & 7 & $\begin{array}{l}\text { nausea*, stomach } \\
\text { cramps, headache* }^{*}\end{array}$ & $\begin{array}{l}\text { probably } \\
\text { related }\end{array}$ & n.d. \\
\hline
\end{tabular}

6-TGN, 6-thioguanine nucleotides; AE, adverse events; TPMT, thiopurine S-methyltransferase; n.d., not determined. * same AE as previously shown on AZA or 6-MP.

\section{Efficacy}

Disease activity was assessed in all patients at baseline and after eight weeks. Sixteen of the 28 patients had active disease at baseline (Table 7.4). The mean CDAl of the eleven CD patients was 224 and the TWDAl of the five UC patients was 10. Five of the eleven (45\%) CD patients achieved clinical remission $(C D A l<150)$ after the study period of eight weeks versus two of the five $(40 \%)$ UC patients. In the CD patients, the mean 6-TGN concentration in patients with active disease was $933 \mathrm{pmol} / 8 \times 10^{8} \mathrm{RBC}$ (Cl95\%: 677-1190) compared to 916 $\mathrm{pmol} / 8 \times 10^{8}$ RBC (CI95\%: 810-1023) in patients that achieved clinical remission. In the UC patients both means were 590 (CI95\%: 238-942) and 675 (Cl95\%: 393-957) for active disease and remission respectively. No significant differences in mean 6-TGN concentrations were found. 
Table 7.4 Disease activity and metabolite levels in 16 patients with active disease at baseline.

\begin{tabular}{|c|c|c|c|c|}
\hline $\begin{array}{l}\text { Active Crohn's disease disease } \\
(\mathrm{CDAl}>150)\end{array}$ & & $\begin{array}{c}\text { Remission } \\
\text { after } 8 \text { weeks } \\
(\mathrm{N}=5)\end{array}$ & & $\begin{array}{l}\text { Active disease } \\
\text { after } 8 \text { weeks } \\
(\mathrm{N}=6)\end{array}$ \\
\hline \multirow{6}{*}{ 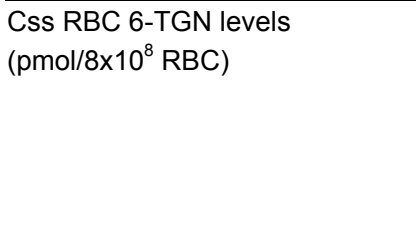 } & Pt 1 & 1013 & Pt 6 & 1269 \\
\hline & Pt 2 & 819 & Pt 7 & 1060 \\
\hline & Pt 3 & 996 & Pt 8 & 1009 \\
\hline & Pt 4 & 1001 & Pt 9 & 411 \\
\hline & Pt 5 & 753 & Pt 10 & 696 \\
\hline & & & Pt 11 & 1155 \\
\hline \multicolumn{2}{|l|}{ Active ulcerative colitis (TWDAI >6) } & $(\mathrm{N}=2)$ & \multicolumn{2}{|r|}{$(\mathrm{N}=3)$} \\
\hline \multirow{3}{*}{$\begin{array}{l}\text { Css RBC 6-TGN levels } \\
\left.\text { (pmol/8x } 10^{8} \mathrm{RBC}\right)\end{array}$} & Pt 12 & 531 & Pt 14 & 863 \\
\hline & Pt 13 & 819 & Pt 15 & 423 \\
\hline & & & Pt 16 & 483 \\
\hline
\end{tabular}

$\mathrm{CD}$, Crohn's disease; CDAI, Crohn's Disease Activity Index; N, number of patients; Css, steady state level; UC, ulcerative colitis; TWDAI, Truelove-Witts Disease Activity Index; RBC, red blood cells; 6-TGN, 6-thioguanine nucleotides; Pt, patient.

\section{Discussion}

6-TG has been available for decades for the treatment of patients suffering from leukaemia, but its use was virtually abandoned by the arrival of other more effective regimens. Recently, the interest in 6-TG has been renewed as it may be an alternative for AZA or 6-MP intolerant or -resistant IBD patients. It is much debated whether the measurement of 6-TG derived 6-TGN, the main metabolites, should guide dosing ${ }^{11,12}$. That is, therapeutic drug monitoring is suggested in AZA or 6-MP treated patients ${ }^{16,17}$. Similar pharmacokinetic studies with 6-TG derived 6-TGN are scarce ${ }^{20}$ and we therefore performed such a study in 28 IBD patients. No distinction was made between CD and UC patients because we did not expect a difference in thiopurine metabolism.

The absorption of oral 6-TG is incomplete and variable, resulting in a bioavailability of $14-46 \%{ }^{21,22}$. Plasma 6 -TG concentrations may range up to thirty-fold ${ }^{23}$. After six hours 6-TG becomes undetectable in plasma ${ }^{24,25}$, whereas it is rapidly transported into the cell in which 6-TG is immediately metabolised to 6-TGN.

We found that 6-TGN concentrations showed large inter-patient variability. 6-TGN concentrations reached steady state after four weeks, suggesting a half-life of approximately five days. Twenty-four hour curves showed almost constant 6-TGN concentrations. At steady state there was a five-fold range in 6-TGN concentrations, which is considerable however less pronounced than the range in 6-TGN originating from AZA or 6-MP ${ }^{17}$. Theoretically, this was to be expected as 6-TGN derived from 6-TG are formed in one single step compared to multiple steps when originating from AZA and 6-MP. Also, 6-TG is 
less affected by TPMT and a poor substrate for xanthine oxidase (XO) when compared to $6-\mathrm{MP}^{25}$ and genetic polymorphisms of these metabolizing enzymes are of less influence. Despite this fact, Herrlinger and colleagues identified one patient with TPMT heterozygosity (TPMT*1S/*3A) with bone marrow toxicity on 6-TG after a dose escalation from 40 to $80 \mathrm{mg} /$ day in a cohort of $26 \mathrm{CD}$ patients ${ }^{20}$. Furthermore, 6-TG caused severe and prolonged pancytopenia in an eight year-old boy suffering from acute lymphoblastic leukaemia with inherited TPMT deficiency ${ }^{26}$. In our cohort all genotyped subjects possessed wild type alleles, so the high variability in metabolite levels could not be explained by genetic polymorphisms. Unfortunately, in half number of patients with 6-TG intolerance TPMT genotype was not assessed and conclusions about the contribution of pharmacogenetics can not be drawn. In this study, drug dose in milligrams per kilogram bodyweight did not correlate with 6-TGN concentrations. In a previous study with 6-MP we were not able to demonstrate correlation between drug dose and 6-TGN concentrations either ${ }^{17}$. 6-TGN concentrations were considerably higher when compared with those in patients receiving standard treatment with AZA $(2-3 \mathrm{mg} / \mathrm{kg} / \mathrm{d})$ or $6-\mathrm{MP}$ $(1-2 \mathrm{mg} / \mathrm{kg} / \mathrm{d})$. Similar results were found by others: four to nine-fold higher concentrations are reported on daily doses from 10-80 mg ${ }^{11,12,20}$. Despite 6-TGN concentrations well above the proposed therapeutic upper limit of approximately $500 \mathrm{pmol} / 8 \times 10^{8} \mathrm{RBC}$ in patients using AZA or $6-\mathrm{MP}$, no myelotoxicity occurred in our cohort of patients, herewith confirming the results of a still increasing number of studies ${ }^{11-14}$. It was speculated that 6-TG derived 6-TGN are biochemically different from 6-MP derived 6-TGN ${ }^{11}$. A more convincing explanation was offered by Lancaster and colleagues: despite the accumulation of significantly higher erythrocyte 6-TGN concentrations for 6-TG compared with 6-MP, the accumulation of leucocyte 6-TGN in patients taking 6-TG was similar to the range of leucocyte 6-TGN in patients taking 6-MP ${ }^{27}$. In other words, when correlating intracellular 6-TGN to efficacy and myelotoxicity, RBC 6-TGN concentrations will be higher for patients taking 6-TG than in those taking 6-MP, whereas this is not the case in the putative target-tissue, the leukocytes.

In addition to this explanation, 6-methylmercaptopurine ribonucleotides (6-MMPR), which arise from 6-MP but not from 6-TG, are believed to contribute to the immunosuppressive and myelotoxic effects by inhibition of de novo purine synthesis ${ }^{28}$. The methylated 6-TGN, the 6-methylthioguanine nucleotides (6-MTGN), also inhibit the first step in de novo purine synthesis and consequently also have cytotoxic potential ${ }^{20}$. The 6-MTGN however, were not assessed in present study.

No hepatotoxicity occurred in the observed period of time. In a former study with patients on 6-MP treatment, hepatotoxicity correlated with 6-MMPR concentrations above $5700 \mathrm{pmol} / 8 \times 10^{8} \mathrm{RBC}^{16}$. 6-MMPR concentrations in our 
cohort on 6-TG treatment were undetectable as we demonstrated before in a short-term safety assessment ${ }^{12}$. This is an obvious finding because 6-MMPR are not formed when 6-TG instead of 6-MP is given (see Figure 7.1). Recently, Dubinsky and colleagues discouraged using 6-TG in IBD because of serious liver injury ${ }^{15,29}$. Disturbing high frequencies of $\mathrm{NRH}$ were reported in an IBD population treated with 6-TG. Steady state 6-TGN concentrations measured in Dubinsky's population ( $\left.1250 \mathrm{pmol} / 8 \times 10^{8} \mathrm{RBC}\right)$ were significantly higher than in our population ( $\left.850 \mathrm{pmol} / 8 \times 10^{8} \mathrm{RBC}\right)$. 6-TG induced $\mathrm{NRH}$ may in fact be dependent of the reached 6-TGN concentrations.

In one patient amylase and lipase levels temporarily increased, but no pancreatitis developed and levels normalised without discontinuation of 6-TG. It is at least questionable whether this temporary elevation of enzymes was caused by 6-TG, because in AZA or 6-MP treated patients is thought to be an idiosyncratic reaction, independent of drug dose or metabolite levels ${ }^{30}$. That is, dose-independent drug related side effects cannot disappear without drug withdrawal.

Four patients discontinued 6-TG within the observed eight weeks, mainly due to the same adverse events as previously shown on AZA or 6-MP. 6-TGN concentrations were measured in three of four patients. In the patients with a probable and obvious relationship between 6-TG use and the occurrence of adverse events, 6-TGN levels were below the mean steady state concentration, herewith making a relationship between 6-TGN concentrations and discontinuation of 6-TG very unlikely.

Although our study was not primarily designed to study drug efficacy, we compared 6-TGN concentrations in patients with active disease with those in patients in remission after eight weeks of 6-TG treatment. Mean 6-TGN concentrations in both groups did not significantly differ. Similar results were reported by Herrlinger and colleagues ${ }^{20}$. Besides, our data do not support the proposed therapeutic lower limit of $1300 \mathrm{pmol} / 8 \times 10^{8} \mathrm{RBC}$ in IBD patients on 6 -TG treatment ${ }^{31}$. All the patients who achieved remission in the observed period had 6-TGN concentrations below the proposed value. These findings are supported by the results from another study in which lower therapeutic target 6-TGN levels were proposed ${ }^{14}$. 


\section{Conclusions}

In IBD patients on 6-TG treatment, large inter-individual differences in metabolite concentrations occur. In our population, we could not demonstrate a clear relationship between 6-TGN concentrations on one hand and toxicity and efficacy on the other like in AZA and 6-MP treated patients. It may be advisable however not to exceed 6-TGN concentrations of $1000 \mathrm{pmol} / 8 \times 10^{8} \mathrm{RBC}$ hereby reducing the risk of developing $\mathrm{NRH}$ and veno-occlusive disease subsequently. 


\section{References}

1. Adler DJ, Korelitz BI. The therapeutic efficacy of 6-mercaptopurine in refractory ulcerative colitis. Am J Gastroenterol 1990;85:717-22.

2. Pearson DC, May GR, Fick GH, Sutherland LR. Azathioprine and 6-mercaptopurine in Crohn disease. A meta-analysis. Ann Intern Med 1995;123:132-42.

3. Sandborn WJ. A review of immune modifier therapy for inflammatory bowel disease: azathioprine, 6-mercaptopurine, cyclosporine, and methotrexate. Am J Gastroenterol 1996;91:423-33.

4. Lennard L. The clinical pharmacology of 6-mercaptopurine. Eur J Clin Pharmacol 1992;43:329-39.

5. Fairchild CR, Maybaum J, Kennedy KA. Concurrent unilateral chromatid damage and DNA strand breakage in response to 6-thioguanine treatment. Biochem Pharmacol 1986;35:3533-41.

6. Tiede I, Fritz G, Strand S, Poppe D, Dvorsky R, Strand D, Lehr HA, Wirtz S, Becker C, Atreya R, Mudter J, Hildner K, Bartsch B, Holtmann M, Blumberg R, Walczak H, Iven $\mathrm{H}$, Galle PR, Ahmadian MR, Neurath MF. CD28-dependent Rac1 activation is the molecular target of azathioprine in primary human CD4+ T lymphocytes. J Clin Invest 2003;111:1133-45.

7. Korelitz BI, Adler DJ, Mendelsohn RA, Sacknoff AL. Long-term experience with 6-mercaptopurine in the treatment of Crohn's disease. Am J Gastroenterol 1993;88:1198-205.

8. Kirschner BS. Safety of azathioprine and 6-mercaptopurine in pediatric patients with inflammatory bowel disease. Gastroenterology 1998;115:813-21.

9. Present DH, Meltzer SJ, Krumholz MP, Wolke A, Korelitz BI. 6-Mercaptopurine in the management of inflammatory bowel disease: short- and long-term toxicity. Ann Intern Med 1989;111:641-9.

10. Connell WR, Kamm MA, Ritchie JK, Lennard-Jones JE. Bone marrow toxicity caused by azathioprine in inflammatory bowel disease: 27 years of experience. Gut 1993;34:1081-5.

11. Dubinsky MC, Hassard PV, Seidman EG, Kam LY, Abreu MT, Targan SR, Vasiliauskas EA. An open-label pilot study using thioguanine as a therapeutic alternative in Crohn's disease patients resistant to 6-mercaptopurine therapy. Inflamm Bowel Dis 2001;7:181-9.

12. Derijks LJ, De Jong DJ, Gilissen LP, Engels LG, Hooymans PM, Jansen JB, Mulder CJ. 6-Thioguanine seems promising in azathioprine- or 6-mercaptopurineintolerant inflammatory bowel disease patients: a short-term safety assessment. Eur J Gastroenterol Hepatol 2003;15:63-7.

13. Herrlinger KR, Kreisel $W$, Schwab $M$, Schoelmerich J, Fleig WE, Ruhl A, Reinshagen M, Deibert P, Fellermann K, Greinwald R, Stange EF. 6-Thioguanine-efficacy and safety in chronic active Crohn's disease. Aliment Pharmacol Ther 2003;17:503-8.

14. Bonaz B, Boitard J, Marteau P, Lémann M, Coffin B, Flourié B, Belaiche J, Cadiot G, Metman EH, Cortot A, Colombel JF; Getaid. Tioguanine in patients with Crohn's disease intolerant or resistant to azathioprine/mercaptopurine. Aliment Pharmacol Ther 2003;18:401-8. 
15. Dubinsky MC, Vasiliauskas EA, Singh H, Abreu MT, Papadakis KA, Tran T, Martin P, Vierling JM, Geller SA, Targan SR, Poordad FF. 6-Thioguanine can cause serious liver injury in inflammatory bowel disease patients. Gastroenterology 2003;125:298-303.

16. Dubinsky MC, Lamothe S, Yang HY, Targan SR, Sinnett D, Théorêt $Y$, Seidman EG. Pharmacogenomics and metabolite measurement for 6-mercaptopurine therapy in inflammatory bowel disease. Gastroenterology 2000;118:705-13.

17. Derijks LJ, Gilissen LP, Engels LG, Bos LP, Bus PJ, Lohman JJ, Curvers WL, Van Deventer SJ, Hommes DW, Hooymans PM. Pharmacokinetics of 6-mercaptopurine in patients with inflammatory bowel disease: implications for therapy. Ther Drug Monit 2004;26:311-8.

18. Cuffari C, Seidman EG, Latour S, Théorêt Y. Quantitation of 6-thioguanine in peripheral blood leukocyte DNA in Crohn's disease patients on maintenance 6-mercaptopurine therapy. Can J Physiol Pharmacol 1996;74:580-5.

19. Yates CR, Krynetski EY, Loennechen T, Fessing MY, Tai HL, Pui CH, Relling MV, Evans WE. Molecular diagnosis of thiopurine S-methyltransferase deficiency: genetic basis for azathioprine and mercaptopurine intolerance. Ann Intern Med 1997;126:608-14.

20. Herrlinger KR, Fellermann K, Fischer C, Kreisel W, Deibert P, Schoelmerich J, Fleig WE, Ruhl A, Reinshagen M, Greinwald R, Stange EF, Schwab M. Thioguanine-nucleotides do not predict efficacy of tioguanine in Crohn's disease. Aliment Pharmacol Ther 2004;19:1269-76.

21. Micromedex.

22. Deibert P, Dilger K, Fischer C, Hofmann U, Nauck S, Stoelben S, Kreisel W. High variation of tioguanine absorption in patients with chronic active Crohn's disease. Aliment Pharmacol Ther 2003;18(2):183-9.

23. Brox LW, Birkett L, Belch A. Clinical pharmacology of oral 6-thioguanine in acute myelogenous leukemia. Cancer Chemother Pharmacol 1981;6:35-8.

24. Lancaster DL, Patel N, Lennard L, Lilleyman JS. 6-Thioguanine in children with acute lymphoblastic leukaemia: influence of food on parent drug pharmacokinetics and 6-thioguanine nucleotide concentrations. Br J Clin Pharmacol 2001;51:531-9.

25. Lennard L, Davies HA, Lilleyman JS. Is 6-thioguanine more appropriate than 6-mercaptopurine for children with acute lymphoblastic leukaemia? $\mathrm{Br} \mathrm{J}$ Cancer 1993;68:186-90.

26. McBride KL, Gilchrist GS, Smithson WA, Weinshilboum RM, Szumlanski CL. Severe 6-thioguanine-induced marrow aplasia in a child with acute lymphoblastic leukemia and inhibited thiopurine methyltransferase deficiency. J Pediatr Hematol Oncol 2000;22:441-5.

27. Lancaster DL, Patel N, Lennard L, Lilleyman JS. Leucocyte versus erythrocyte thioguanine nucleotide concentrations in children taking thiopurines for acute lymphoblastic leukaemia. Cancer Chemother Pharmacol 2002;50:33-6.

28. Dervieux T, Blanco JG, Krynetski EY, Vanin EF, Roussel MF, Relling MV. Differing contribution of thiopurine methyltransferase to mercaptopurine versus thioguanine effects in human leukemic cells. Cancer Res 2001;61:5810-6.

29. Geller SA, Dubinsky MC, Poordad FF, Vasiliauskas EA, Cohen AH, Abreu MT, Tran T, Martin P, Vierling JM, Targan SR. Early hepatic nodular hyperplasia and submicroscopic fibrosis associated with 6-thioguanine therapy in inflammatory bowel disease. Am J Surg Pathol 2004;28:1204-11. 
30. de Jong DJ, Derijks LJ, Naber AH, Hooymans PM, Mulder CJ. Safety of thiopurines in the treatment of inflammatory bowel disease. Scand J Gastroenterol Suppl 2003(239):69-72.

31. Dubinsky MC, Feldman EJ, Abreu MT, Targan SR, Vasiliauskas EA. Thioguanine: a potential alternate thiopurine for IBD patients allergic to 6-mercaptopurine or azathioprine. Am J Gastroenterol 2003;98:1058-63. 


\section{Chapter 8}

\section{6-Thioguanine seems promising in azathioprine or 6-mercaptopurine intolerant inflammatory bowel disease patients: a short-term safety assessment}

LJJ Derijks, DJ de Jong, LPL Gilissen, LGJB Engels, PM Hooymans, JBMJ Jansen, CJJ Mulder

Eur J Gastroenterol Hepatol 2003;15:63-67 


\section{Abstract}

\section{Introduction}

6-Mercaptopurine (6-MP) and azathioprine (AZA) have proven efficacy in the treatment of inflammatory bowel disease (IBD). However, adverse events leading to discontinuation may occur in $10-20 \%$ of patients. The efficacy of AZA and $6-\mathrm{MP}$ is based on formation of their active metabolites, the 6-thioguanine nucleotides (6-TGN). Therefore, 6-thioguanine (6-TG), an agent more directly leading to formation of 6-TGN and until recently only used in patients suffering from leukaemia, may be an alternative in case of AZA or 6-MP intolerance.

Aims

The purpose of our study was to assess short-term safety of 6-TG.

\section{Methods}

Thirty-two IBD patients with previously established AZA or 6-MP intolerance were treated with 6-TG as such in a dose of $20 \mathrm{mg}(n=19)$ or $40 \mathrm{mg}(n=13)$ once daily. Safety parameters were obtained at $0,1,2,4$ and 8 weeks after start of medication. Primary outcome measures were the ability to tolerate 6-TG and the occurrence of adverse events. Secondary outcome definitions included laboratory parameters.

\section{Results}

Twenty-six $(81 \%)$ patients were able to tolerate 6-TG during the first eight weeks. In three of six patients, side effects leading to discontinuation were probably $(n=2)$ or obviously $(n=1)$ 6-TG related. No clinically relevant hematological events or hepatotoxicity occurred in the observed period. Steady state 6 -TGN levels were significantly higher on $40 \mathrm{mg}\left(1621 \pm 828 \mathrm{pmol} / 8 \times 10^{8} \mathrm{RBC}\right)$ than on $20 \mathrm{mg}$ once daily $\left(937 \pm 325 \mathrm{pmol} / 8 \times 10^{8} \mathrm{RBC}, \mathrm{p}=0.001\right)$.

\section{Conclusions}

6-TG treatment seems promising in AZA or 6-MP intolerant IBD patients. However, long-term safety and efficacy have yet to be determined. 


\section{Introduction}

Thiopurine analogues 6-mercaptopurine (6-MP) and its prodrug azathioprine (AZA) are widely used in the second-line treatment of inflammatory bowel disease (IBD). These immunosuppressive agents have proven to be effective for both inducing and maintaining long-term remission of Crohn's disease (CD) and ulcerative colitis (UC) $)^{1-3}$. AZA is rapidly converted to 6-MP by a nonenzymatic reaction, which is further metabolised to the pharmacological active 6-thioguanine nucleotides (6-TGN) and 6-methylmercaptopurine ribonucleotides (6-MMPR). 6-TGN are purine nucleotides, which are incorporated into DNA, inducing cytotoxicity and immunosuppression ${ }^{4}$. In patients treated with 6-MP it is shown that red blood cell (RBC) 6-TGN levels correlated with drug efficacy and bone marrow suppression and 6-MMPR levels, on the other hand, correlated with hepatotoxicity ${ }^{5}$. In patients treated with AZA or 6-MP the lower limit therapeutic 6-TGN level has recently been established on $235 \mathrm{pmol} / 8 \times 10^{8} \mathrm{RBC}$, whereas 6-MMPR levels above $5700 \mathrm{pmol} / 8 \times 10^{8} \mathrm{RBC}$ were associated with hepatotoxicity ${ }^{6}$.

A drawback of AZA and 6-MP is the occurrence of side effects. Adverse events leading to discontinuation may occur in approximately $10-20 \%$ of patients ${ }^{7-9}$. In general, adverse events may be distinguished in hypersensitivity reactions and dose dependent events. Hypersensitivity reactions to thiopurines or their metabolites occur mostly within 3-4 weeks and result in immune-mediated symptoms such as fever, rash, and arthralgia ${ }^{10,11}$.

Furthermore dose-dependent, pharmacological explainable reactions characterised by myelosuppression, increased susceptibility to infections and hepatotoxicity may occur. These reactions seem to be directly associated with high RBC 6-TGN or 6-MMPR levels and often reveal themselves in a subsequent stage.

Toxicity due to the 6-TGN metabolites may be explained by polymorphisms in the gene encoding thiopurine S-methyltransferase (TPMT), the enzyme that methylates 6-MP to 6-MMPR. In case of reduced enzyme activity toxic 6-TGN levels may be reached on regular doses of AZA or 6-MP ${ }^{12}$. Alternatively, some patients develop high 6-MMPR levels, whereas 6-TGN levels remain subtherapeutic. In these patients the available 6-MP is largely transformed into 6-MMPR due to preferential metabolism through TPMT, while the enzymatic pathway through hypoxanthine phosphoribosyltransferase (HPRT) leading to the formation of 6-TGN is hardly exploited. Recently Dubinsky and colleagues successfully treated seven out of ten non-responding IBD patients with preferential 6-MMPR formation on $100 \mathrm{mg} \mathrm{6-MP}$ with 6-TG $40 \mathrm{mg}$ once daily. In these patients 6-MMPR levels were undetectable and no hepatic or haematologic toxicity was observed ${ }^{13}$. Until recently 6-TG as such only was used in patients suffering from lymphoblastic leukaemia. 
Theoretically, therapy with 6-TG is a good alternative in patients with AZA and 6-MP intolerance of any kind. The idea of using a metabolite at the end of the enzymatic pathway seems to be an attractive approach. In this study we prospectively studied 6-TG short-term safety in AZA and 6-MP intolerant IBD patients.

\section{Material and methods}

\section{Patient selection}

Patients aged between 18 and 75 years attending the out-patient clinics of Maasland Hospital Sittard, University Medical Center Nijmegen or Rijnstate Hospital Arnhem were eligible for the study if CD or UC was diagnosed for more than six months and an established AZA or 6-MP intolerance was observed. Exclusion criteria were: pregnancy or expected pregnancy within six months, inadequate contraception in women, lactation, presence of active infection, history of tuberculosis, HIV, hepatitis B or C, severe pancreatitis (necrotizing pancreatitis or pancreatitis leading to multi organ failure), malignancy, ongoing treatment with other immunosuppressive drugs like ciclosporine, methotrexate, thalidomide or infliximab, impaired renal function (serum creatinin $>2$ times normal upper limit), impaired hepatic function (>2 times normal upper limit) and persistent bone marrow suppression.

\section{Study design}

The trial design was a prospective open-label multicentre study. At entry patient demographics and anamnesis were recorded and medication-use during the past year was obtained from the community pharmacy. 6-TG (Lanvis $^{\mathrm{TM}}$, tablet $40 \mathrm{mg}$, Glaxo Wellcome) was administered orally once daily in the evening in a dose of $20 \mathrm{mg}$ (two centres) or $40 \mathrm{mg}$ (one centre). Concomitant medication was continued. Safety parameters were obtained at 0 (base-line), 1, 2, 4 and 8 weeks after start of medication. Blood was drawn each visit for measurement of RBC 6-TGN and 6-MMPR levels, alanine transaminase (ALT), aspartate transaminase (AST), bilirubins, amylase, lipase, leukocytes (plus differentiation), platelets and haemoglobin $(\mathrm{Hb})$. Doseadjustments of 6-TG were carried out by the attending physician based on one or more of the parameters mentioned above.

\section{Ethics}

The protocol was approved by the local medical ethics committee and in accordance with the Helsinki Declaration. Informed written consent was obtained before enrolment. 


\section{Outcome measures}

Primary outcome measures were the ability to tolerate 6-TG and the occurrence of adverse events during eight weeks of 6-TG treatment. The relationship of the adverse event with the use of 6-TG was established by the following method: unrelated, no temporal relation and other aetiology likely; possibly related, potential temporal relation and other aetiologies possible; probably related, potential temporal relation and other aetiologies unlikely; related, clear temporal relation not otherwise explained. Secondary outcome definitions included RBC 6-TGN and 6-MMPR levels, the occurrence of haematological events (leukocyte count $<4.0 \times 10^{9} /$, platelet count $<100 \times 10^{9} /$ ) and the occurrence of hepatic toxicity (ALT $>80 \mathrm{U} / \mathrm{l}, \mathrm{AST}>80 \mathrm{U} / \mathrm{l}$, bilirubins $>40$ $\mu \mathrm{mol} / \mathrm{l}$, amylase $>220 \mathrm{U} / \mathrm{l}$, or lipase $>120 \mathrm{U} / \mathrm{l}$ (elevations $>2$ times normal upper limit)).

\section{Analytical procedures}

Blood samples were taken at least twelve hours after medication intake. The samples were centrifuged to isolate erythrocytes and after washing with PBS buffer solution, erythrocyte counts were done. Samples were stored at $-20^{\circ} \mathrm{C}$ until required. RBC 6-TGN and 6-MMPR levels were measured in the laboratory of the Department of Clinical Pharmacy, Maasland Hospital Sittard, using a slightly modified assay previously reported by Lennard and colleagues $^{14}$. In brief, the thiopurines are separated by reversed-phase HPLC and quantified using UV-detection. For measurement of intracellular thionucleotides the free base is obtained by acid hydrolysis of the nucleotide back to the purine. The resulting purines are extracted from the biological matrix by forming a phenyl mercury adduct into dichloromethane. During backextraction with hydrochloric acid the adduct is splitted and the free thiopurine is liberated into the acid layer once again. The run-to-run coefficient of varation was $6.6 \%$ and $9.7 \%$ for 6 -TGN and 6 -MMPR respectively. The detection limit of the assay was $30 \mathrm{pmol} / 8 \times 10^{8} \mathrm{RBC}$ for $6-\mathrm{TGN}$ and $300 \mathrm{pmol} / 8 \times 10^{8} \mathrm{RBC}$ for 6-MMPR.

\section{Statistical analysis}

Data are expressed as means \pm standard deviation. Significance was evaluated by the Student $t$ test for paired or independent data, $\mathrm{p}$ values $<0.05$ were considered significant. Pearson's correlation was used to test the relationship between the measured parameters. SPSS for Windows (version 10.0.7) software was used to perform statistics.

\section{Role of the funding source}

This study was not sponsored by external sources. 


\section{Results}

\section{Patients}

Thirty-two patients were enrolled, of whom seven (22\%) were male and 25 (78\%) were female. The mean age at entry was 37 years (range 19-64). Twenty-two patients (69\%) were suffering from CD and in ten patients $(31 \%)$ UC was diagnosed. Twenty-one patients (66\%) emerged AZA-intolerant, five $(16 \%)$ could not tolerate 6-MP and six (19\%) patients showed intolerance for both thiopurines. AZA or 6-MP intolerance was established with rechallenge in twelve patients (38\%). The adverse events leading to discontinuation of AZA or 6 -MP included total malaise $(41 \%)$, nausea and vomiting $(38 \%)$, fever $(25 \%)$, arthralgia (13\%), amylase elevations (13\%), epigastric pains (13\%), pancreatitis (amylase elevations with symptoms) (9\%), indefinite symptoms $(9 \%)$, headache $(6 \%)$, diarrhoea $(3 \%)$, myalgia $(3 \%)$, erythema nodosum $(3 \%)$, edema $(3 \%)$ and pruritus $(3 \%)$. In ten patients AZA or 6-MP intolerance manifested itself within two weeks, in five within one month, in six within two months and in six after two months. In four patients time to intolerance was not documented. The initial dose of 6-TG was $20 \mathrm{mg}$ daily in 19 patients and thirteen received $40 \mathrm{mg}$ a day. The mean initial 6-TG dose was $0.40 \pm 0.03$ $\mathrm{mg} / \mathrm{kg} / \mathrm{day}$. The mean 6-TG dose during the eight week period was 25.9 $\mathrm{mg} /$ day (range 10-40).

\section{Primary outcomes}

Twenty-six (81\%) of the 32 subjects were able to tolerate 6-TG 20 or $40 \mathrm{mg}$ 1 dd during the first eight weeks. In six patients (19\%) 6-TG was discontinued because of adverse effects. Data of the 6-TG intolerant patients are summarised in Table 8.1.

In two patients indefinite joints pains occurred on $40 \mathrm{mg} 1 \mathrm{dd}$ that resolved after dose-reduction to $20 \mathrm{mg} 1 \mathrm{dd}$. One patient temporary stopped after developing nausea on $40 \mathrm{mg} 1 \mathrm{dd}$ that disappeared after restart on $20 \mathrm{mg} 1 \mathrm{dd}$. Another patient had a dry cough and was not feeling well on $20 \mathrm{mg} 1 \mathrm{dd}$ which resolved after dose-reduction to $20 \mathrm{mg}$ every two days.

\section{Secondary outcomes}

\section{RBC 6-TGN and 6-MMPR levels}

Base-line RBC 6-TGN levels were negative in all but four patients who just recently stopped AZA $(n=2)$ or $6-M P(n=2)$ therapy. Steady state 6 -TGN levels were significantly higher on $40 \mathrm{mg} 1 \mathrm{dd}\left(1621 \pm 828 \mathrm{pmol} / 8 \times 10^{8} \mathrm{RBC}\right)$ than on 20 $\mathrm{mg} 1 \mathrm{dd}\left(937 \pm 325 \mathrm{pmol} / 8 \times 10^{8} \mathrm{RBC}, \mathrm{p}=0.001\right)$ according on treatment analysis. RBC 6-TGN levels were considered to reach steady state after four weeks, 
having a half life of approximately five days ${ }^{15}$. RBC 6-MMPR levels were undetectable at all times during treatment with 6-TG, except at base-line in the four patients mentioned before. Correlation was found between dose and RBC 6 -TGN level $(0.70, p=0.01)$. The mean RBC 6-TGN level increased most during in the first part of the eight week period and levelled out between four and eight weeks (Figure 8.1).

Table 8.1 Adverse events leading to discontinuation of 6-thioguanine treatment.

\begin{tabular}{|c|c|c|c|c|c|}
\hline No. & $\begin{array}{l}\text { Initial dose } \\
(\mathrm{mg})\end{array}$ & $\begin{array}{l}\text { Final dose } \\
(\mathrm{mg})\end{array}$ & $\begin{array}{l}\text { Time to AE } \\
\text { (days) }\end{array}$ & Character of $\mathrm{AE}$ & $\begin{array}{l}\text { Relationship AE } \\
\text { with 6-TG }\end{array}$ \\
\hline 1 & 20 & 20 & 24 & $\begin{array}{l}\text { nausea*, diarrhoea*, } \\
\text { stomach cramps* }\end{array}$ & probably related \\
\hline 2 & 20 & 10 & 42 & total malaise ${ }^{*}$ & possibly related \\
\hline 3 & 20 & 20 & 7 & $\begin{array}{l}\text { fever }{ }^{*} \text {, erythema nodosum }{ }^{*} \text {, } \\
\text { arthralgia* }\end{array}$ & related \\
\hline 4 & 20 & 10 & 7 & $\begin{array}{l}\text { nausea* }{ }^{*} \text { stomach cramps, } \\
\text { headache }{ }^{*}\end{array}$ & probably related \\
\hline 5 & 20 & 20 & 35 & rigid fingers & probably related \\
\hline 6 & 40 & 40 & 10 & stomach symptoms & possibly related \\
\hline
\end{tabular}

$\mathrm{AE}$, adverse events; 6-TG, 6-thioguanine; "same AE as previously shown on AZA or 6-MP

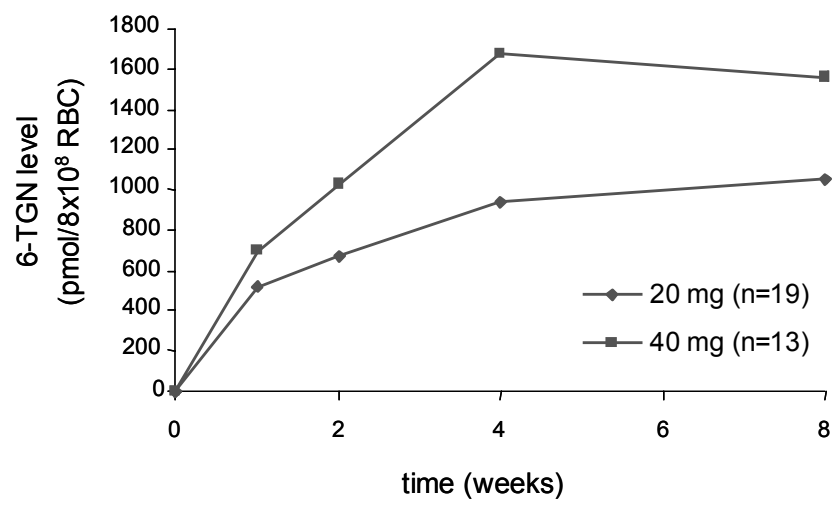

Figure 8.1 Mean RBC 6-TGN levels during the first eight weeks of 6-TG treatment.

\section{Haematological events}

No clinically relevant myelotoxicity occurred in the eight week period. However, the mean leukocyte count decreased significantly from base-line $\left(11.4 \pm 3.9 \times 10^{9} / l\right)$ to eight weeks of 6 -TG treatment $\left(10.0 \pm 4.1 \times 10^{9} / l, p=0.008\right)$. Leukocyte counts were never below $4.0 \times 10^{9} /$, no leukopenia was observed. 
RBC 6-TGN levels showed moderate correlation with leukocyte counts $(-0.29$, $\mathrm{p}=0.01$ ). A minor thrombocytopenia was observed in one patient (platelet count: $\left.130 \times 10^{9} / \mathrm{l}\right)$. In this cohort of 32 patients, platelet count neither decreased nor correlated with RBC 6-TGN level in the observed period. In addition no change in $\mathrm{Hb}$ was established.

\section{Hepatotoxicity}

The ALT level was elevated $>80 \mathrm{U} / \mathrm{l}$ in one patient, but this was the case at base-line already. The mean ALT level did increase significantly from $19.8 \pm 19.9 \mathrm{U} / \mathrm{l}$ at base-line to $23.5 \pm 25.7 \mathrm{U} / \mathrm{l}$ at eight weeks, even though not clinically relevant. Amylase level was above $220 \mathrm{U} / \mathrm{l}(234 \mathrm{U} / \mathrm{l})$ in one patient. Moderate correlation was found between RBC 6-TGN level and amylase level $(0.30, p=0.01)$. No AST, bilirubins or lipase elevations were observed and mean levels did not change during the eight weeks. No correlation was found between RBC 6-TGN level on the one hand and ALT, AST, bilirubins or lipase for another.

\section{Discussion}

6-TG was well tolerated during the first eight weeks of treatment in $81 \%$ of patients with previously established AZA or 6-MP intolerance. In some patients intolerance for AZA or 6-MP manifested itself after eight weeks. Therefore, we must be reserved in drawing firm conclusions as the number of patients with adverse events on 6-TG may increase over time. Six patients (19\%) were unable to complete the eight week period on 6-TG. The relationship of adverse events with 6-TG was unclear but possible in three of the six patients whose 6-TG treatment ended prematurely. In two patients the side effects were probably 6-TG related. In these patients, adverse events on 6-TG were very similar to the previous side effects on AZA or 6-MP, suggesting a causal role for 6-TGN in the development of these events. Moreover, these adverse events resolved after discontinuation of 6-TG. In one patient the side effects were obviously 6-TG related, being identical and occurring at exactly the same time as previously shown on AZA. Also, in this patient adverse events disappeared with discontinuation of 6-TG. In four other patients transient side-effects occurred, which all dissolved after a $50 \%$ dose-reduction (three patients from $40 \mathrm{mg}$ to $20 \mathrm{mg}$ daily and one patient from $20 \mathrm{mg}$ to $10 \mathrm{mg}$ daily).

Mean RBC 6-TGN levels were high in comparison with 6-TGN levels measured in AZA or 6-MP treated patients. In the latter group we previously measured mean 6-TGN level of 246 and $264 \mathrm{pmol} / 8 \times 10^{8} \mathrm{RBC}$ on AZA $100 \mathrm{mg} 1 \mathrm{dd}$ and 6-MP $100 \mathrm{mg} 1 \mathrm{dd}$, respectively ${ }^{16}$. The mean steady state 6-TG levels after 6-TG as such once daily (20 mg: 937 pmol/ $8 \times 10^{8}$ RBC; 40 mg: 1621 
$\mathrm{pmol} / 8 \times 10^{8} \mathrm{RBC}$ ) were approximately four- to seven-fold higher. This is consistent with the observations of Dubinsky and colleagues ${ }^{13}$. In present study, RBC 6-TGN levels were well above the proposed lower limit of 235 $\mathrm{pmol} / 8 \times 10^{8} \mathrm{RBC}$ for therapy with AZA and 6-MP, which was associated with efficacy. However, it remains unclear whether the same level should be used when 6-TG is given as such. Therefore, efficacy data from prospective randomised trials are needed.

RBC 6-TGN level correlated significantly with the dose given. However, major inter-individual differences occur as is seen with the other thiopurines ${ }^{17,18}$. Therapeutic drug monitoring (TDM) may be a helpful tool in dosing 6-TG. In this study we used TDM to control patient compliance and to prevent extremely high RBC 6-TGN levels ( $>2500 \mathrm{pmol} / 8 \times 10^{8} \mathrm{RBC}$ ). The presumed period necessary to reach steady state of four weeks seems reliable, as the RBC 6-TGN concentrations levelled out somewhere between four and eight weeks after start of medication. In patients treated with AZA or 6-MP, myelotoxicity is a major concern, which seems to be associated with the RBC 6-TGN level. However, in the present study, despite high RBC 6-TG levels no leukopenia was observed in our 6-TG treated patients. Although the mean leukocyte count decreased from base-line $\left(11.4 \times 10^{9} / \mathrm{l}\right)$ to eight weeks of 6-TG treatment $\left(10.0 \times 10^{9} / \mathrm{l}\right)$, the clinical relevance is restricted as there still is a large margin to the critical lower limit of $4.0 \times 10^{9} /$. A moderate inverse correlation of leukocyte count with RBC 6-TGN level was observed and because 6-TGN levels seemed to have reached a steady state, further leukocyte count reduction is unlikely. The fact that no leukopenia occurred may be explained by the absence of the 6-MMPR metabolite, which seems to have antiprolerative properties of its own $^{5,19}$. No 6-MMPR is formed, when a patient is given 6-TG as such. In AZA or 6-MP treated patients however, substantial 6-MMPR levels arise, which may contribute to myelotoxicity. The role of 6-MMPR needs further elucidation. In spite of absence of leukopenia in this cohort of patients, alertness remains mandatory as leukopenia is a serious complication.

Mild thrombocytopenia occurred in one patient. This patient had a history of open heart surgery and was still receiving antithrombotic prophylaxis during 6-TG treatment. Thrombocyte count normalised without 6-TG dose-reduction and therefore a relationship between thrombocytopenia and 6-TG treatment seems unlikely.

No serious hepatotoxic events occurred in the observed period, not even in the five patients which showed earlier hepatic or pancreatic events (amylase- or ALT elevations) on AZA or 6-MP. In one patient the ALT level was elevated, but as this already was the case before inclusion this elevation can not be accounted for by 6-TG treatment. Furthermore, in this patient ALT level decreased with ongoing therapy with 6-TG. Although mean ALT levels builded up during 6-TG treatment to a value of $23.5 \mathrm{U} / \mathrm{l}$, the increase was of no clinical 
importance, as this is far from the standard upper limit of $40 \mathrm{U} / \mathrm{l}$. In another patient the amylase level was slightly elevated which normalised after 6-TG dose was reduced from $40 \mathrm{mg}$ to $20 \mathrm{mg}$ once daily. Three patients with nonsevere pancreatitis within four weeks of AZA or 6-MP treatment, did not develop pancreatitis in eight weeks of 6-TG treatment. Unfortunately in only one of these patients a RBC 6-MMPR level was previously measured on 6-MP treatment and this level was substantial $\left(4893 \mathrm{pmol} / 8 \times 10^{8} \mathrm{RBC}\right.$ after two weeks on 6-MP $50 \mathrm{mg}$ once daily). This may indicate a role for 6-MMPR in the development of pancreatitis in this patient. Although high RBC 6-MMPR levels are often detected in patients developing pancreatitis, sometimes pancreatitis ensues despite the absence of 6-MMPR ${ }^{5,6}$. The role of 6-MMPR levels in the occurrence of pancreatitis is still unclear.

\section{Conclusions}

Treatment with 6-TG seems a promising alternative in AZA and 6-MP intolerant IBD patients. The results on short-term safety are encouraging for the future. However, long-term safety in IBD has yet to be determined as adverse events like veno-occlusive disease and portal hypertension are reported in 6-TG treatment of leukaemia. Also efficacy has to be proven before 6-TG can be added to standard therapy. For future trials a dose of $20 \mathrm{mg}$ once daily results in presumably adequate RBC 6-TGN levels and seems well tolerated. The impact of high 6-TGN levels during a longer period of time remains unclear and merits further exploration for both efficacy- and safety reasons. 


\section{References}

1. Adler DJ, Korelitz BI. The therapeutic efficacy of 6-mercaptopurine in refractory ulcerative colitis. Am J Gastroenterol 1990;85:717-22.

2. Pearson DC, May GR, Fick GH, Sutherland LR. Azathioprine and 6-mercaptopurine in Crohn disease. A meta-analysis. Ann Intern Med 1995;123:132-42.

3. Sandborn WJ. A review of immune modifier therapy for inflammatory bowel disease: azathioprine, 6-mercaptopurine, cyclosporine, and methotrexate. Am J Gastroenterol 1996;91:423-33.

4. Lennard L. The clinical pharmacology of 6-mercaptopurine. Eur J Clin Pharmacol 1992;43(4):329-39.

5. Cuffari C, Theoret Y, Latour S, Seidman G. 6-Mercaptopurine metabolism in Crohn's disease: correlation with efficacy and toxicity. Gut 1996;39:401-6.

6. Dubinsky MC, Lamothe S, Yang HY, Targan SR, Sinnett D, Theoret Y, Seidman EG. Pharmacogenomics and metabolite measurement for 6-mercaptopurine therapy in inflammatory bowel disease. Gastroenterology 2000;118:705-13.

7. Kirschner BS. Safety of azathioprine and 6-mercaptopurine in pediatric patients with inflammatory bowel disease. Gastroenterology 1998;115:813-21.

8. Present DH, Meltzer SJ, Krumholz MP, Wolke A, Korelitz BI. 6-Mercaptopurine in the management of inflammatory bowel disease: short- and long-term toxicity. Ann Intern Med 1989;111:641-9.

9. Connell WR, Kamm MA, Ritchie JK, Lennard-Jones JE. Bone marrow toxicity caused by azathioprine in inflammatory bowel disease: 27 years of experience. Gut 1993;34(8):1081-5.

10. Korelitz $\mathrm{BI}$, Zlatanic J, Goel F, Fuller S. Allergic reactions to 6-mercaptopurine during treatment of inflammatory bowel disease. J Clin Gastroenterol 1999;28: $341-4$.

11. Sandborn WJ. Azathioprine: state of the art in inflammatory bowel disease. Scand J Gastroenterol Suppl 1998;225:92-9.

12. Lennard L. Clinical implications of thiopurine methyltransferase -optimization of drug dosage and potential drug interactions. Ther Drug Monit 1998;20:527-31.

13. Dubinsky MC, Hassard PV, Seidman EG, Kam LY, Abreu MT, Targan SR, Vasiliauskas EA. An open-label pilot study using thioguanine as a therapeutic alternative in Crohn's disease patients resistant to 6-mercaptopurine therapy. Inflamm Bowel Dis 2001;7:181-9.

14. Lennard L, Singleton HJ. High-performance liquid chromatographic assay of the methyl and nucleotide metabolites of 6-mercaptopurine: quantitation of red blood cell 6-thioguanine nucleotide, 6-thioinosinic acid and 6-methylmercaptopurine metabolites in a single sample. J Chromatogr 1992;583:83-90.

15. Lennard L, Lilleyman JS. Individualizing therapy with 6-mercaptopurine and 6-thioguanine related to the thiopurine methyltransferase genetic polymorphism. Ther Drug Monit 1996;18:328-34.

16. Derijks LJJ, Engels LGJB, Hooymans PM, Lohman JJHM. Pharmacokinetics of 6-mercaptopurine and azathioprine in patients with inflammatory bowel disease. $\mathrm{Br}$ J Clin Pharmacol 2001;51:503P.

17. Cuffari C, Hunt S, Bayless T. Utilisation of erythrocyte 6-thioguanine metabolite levels to optimise azathioprine therapy in patients with inflammatory bowel disease. Gut 2001;48:642-6. 
18. Belaiche J, Desager JP, Horsmans Y, Louis E. Therapeutic drug monitoring of azathioprine and 6-mercaptopurine metabolites in Crohn disease. Scand J Gastroenterol 2001;36:71-6.

19. Dervieux T, Blanco JG, Krynetski EY, Vanin EF, Roussel MF, Relling MV. Differing contribution of thiopurine methyltransferase to mercaptopurine versus thioguanine effects in human leukemic cells. Cancer Res 2001;61:5810-6. 


\section{Chapter}

\section{On tolerability and safety of a maintenance treatment with 6-thioguanine in azathioprine or 6-mercaptopurine intolerant inflammatory bowel disease patients}

NKH de Boer, LJJ Derijks, LPL Gilissen, DW Hommes, LGJB Engels, SY de Boer, G den Hartog, PM Hooymans, ABU Mäkelburg, BD Westerveld, AHJ Naber, DJ de Jong, CJJ Mulder

World J Gastroenterol 2005;11:5540-5544 


\section{Abstract}

Introduction

The use of 6-thioguanine (6-TG) may lead to an avoidance of toxic pathways as it is directly converted to the pharmacologically active metabolites (the 6-thioguanine nucleotides (6-TGN)).

\section{Aims}

The aim of our study was to determine the tolerability and safety profile of a low-dose maintenance therapy with 6-TG in azathioprine (AZA) or 6-mercaptopurine (6-MP) intolerant IBD patients over a treatment period of at least one year.

\section{Methods}

Database analysis.

\section{Results}

Twenty out of $95(21 \%)$ patients discontinued 6-TG (mean dose $24.6 \mathrm{mg}$ ) within one year. Reasons for discontinuation were Gl-complaints (31\%), malaise (15\%) and hepatotoxicity (15\%). Haematological events occurred in three patients, one discontinued treatment. In the 6-TG tolerant group $9 \%(7 / 75)$ could be classified as hepatotoxicity. An abdominal ultrasound was performed in $54 \%$ of patients, one patient had splenomegaly.

\section{Conclusions}

The majority of AZA or 6-MP intolerant IBD patients $(79 \%)$ is able to tolerate maintenance treatment with 6-TG (dosages between 0.3 to $0.4 \mathrm{mg} / \mathrm{kg} /$ day). 6-TG may still be considered as an escape maintenance immunosuppressant in this difficult to treat group of patients, taking into account potential toxicity and efficacy of other alternatives. The recently reported hepatotoxicity is worrisome and 6-TG should therefore only be administered in prospective trials. 


\section{Introduction}

Until now, no definite medical or surgical therapy is available for the treatment of inflammatory bowel disease (IBD) as the aetiology remains essentially unknown. Therefore, the aims of medical therapy in IBD are to relief symptoms and to prevent long-term complications. Maintenance therapy should preferably be efficient, safe and cost-effective. The immune modulating thiopurines 6-mercaptopurine (6-MP) and its pro-drug azathioprine (AZA) have proven efficacy in active IBD and in maintenance of an induced clinical remission ${ }^{1}$. These thiopurines are prescribed on a large scale in IBD and are considered as a mainstay treatment option. However, issues concerning delayed onset of activity, refractoriness and toxicity have limited the general use of AZA and 6-MP. In previous reports, up to $20 \%$ of patients discontinued AZA or 6-MP prematurely due to adverse events ${ }^{2}$. The metabolism of thiopurines has been partly elucidated in recent years (Figure 9.1). The toxicity profile depends at least partly on the generated metabolites of AZA and 6-MP ${ }^{3}$. At first, AZA is converted to 6-MP by a non-enzymatic reaction, which is then converted by a multi-step enzymatic pathway into a number of active, inactive or toxic metabolites. The efficacy of AZA and 6-MP appears to be correlated with the formation of the 6-thioguanine nucleotides (6-TGN). During this complex metabolisation process possible hepatotoxic metabolites are generated under influence of the enzyme thiopurine methyltransferase (TPMT). The methylation products of 6-MP, 6-methylmercaptopurine (6-MMP) and their ribonucleotides (6-MMPR), may be associated with hepatotoxicity ${ }^{3}$. Furthermore, flu-like symptoms, rash, pancreatitis and neutropenia induced by AZA or 6-MP have recently been related to mutations in the inosine triphosphate pyrophosphatase (ITPase) gene leading to accumulation of the proposed metabolite thio-inosine triphosphate ${ }^{4}$. A possible strategy to avoid AZA or 6-MP induced toxicity is the administration of a thiopurine, which is metabolically closer to the 6-TGN. The thiopurine 6-thioguanine (6-TG) is an attractive candidate, which has the advantage of being directly converted to $6-\mathrm{TGN}^{5}$. Therefore, treatment and safety outcomes might be less sensitive for intra- and inter-individual metabolic variations. Furthermore, due to the relative simple metabolisation, the number of possibly toxic metabolites is strongly reduced. Several open label studies in patients with IBD have shown promising efficacy and acceptable short-term toxicity of 6-TG ${ }^{6.7}$. More recently, the use of 6-TG has been associated with the induction of nodular regenerative hyperplasia of the liver $(\mathrm{NRH})$. The aim of the present study was to determine the tolerability and safety profile of a low-dose maintenance therapy with 6-TG in AZA or 6-MP intolerant IBD patients over a treatment period of at least one year. 


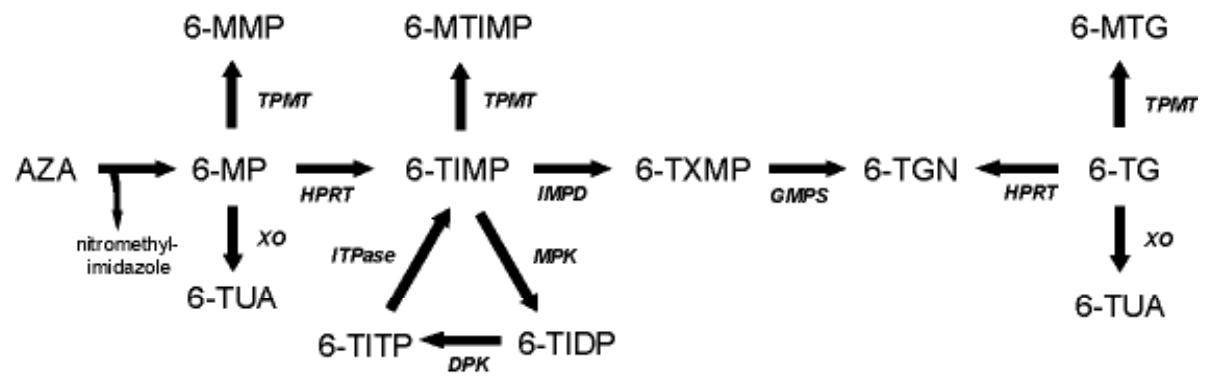

Figure 9.1 Metabolisation process of thiopurines.

AZA is degraded to 6-MP and nitromethyl-imidazole, via a non-enzymatic step. Three competing enzymes metabolize 6-MP. Xanthine oxidase $(X O)$ inactivates 6-MP to thiouric acid (TUA). Thiopurine S-methyltransferase (TPMT) methylates 6-MP, the formed 6-methylmercaptopurine (6-MMP) is associated with hepatotoxicity. By hypoxanthine phosphoribosyl transferase (HPRT) 6-MP is catalysed to 6-thio inosine monophosphate (6-TIMP), then via inosine monophosphate dehydrogenase (IMPD) to 6-thioxanthosine monophosphate (6-TXMP), ultimately leading to the pharmacologically active 6-thioguanine nucleotides (6-TGN) via the enzyme guanosine monophosphate synthetase (GMPS). 6-TIMP can also be methylated to 6-methyl thio inosine monophosphate (6-MTIMP). In a normal useless cycle 6-TIMP is phosphorylated by monophosphate kinase (MPK) to 6-thio inosine diphosphate (6-TIDP), subsequently by diphosphate kinase (DPK) to 6-thio inosine triphosphate (6-TITP) and ultimately back to 6-TIMP due to the inosine triphosphate pyrophosphatase (ITPase). When ITPase activity is impaired or lacking, 6-TITP accumulates. 6-Thioguanine (6-TG) is directly converted by HPRT to the 6-TGN. XO and TPMT metabolize 6-TG to 6-methyl thioguanine (6-MTG) and 6-thiouric acid, respectively. ITPase has no known role in the metabolism of 6-TG.

\section{Material and methods}

\section{Patient selection}

The study is a retrospective database analysis exploring the tolerability and safety of 6-TG over at least a one-year treatment period in AZA or 6-MP intolerant IBD patients, treated in participating university and district hospitals in the Netherlands. In each patient, the attending physician judged the indication for administration of 6-TG. Some patients have been described earlier in a short safety assessment of $6-\mathrm{TG}^{6}$. Patients were eligible for the study if they met the following in- and exclusion criteria. Inclusion criteria were: age between 
18 and 75 years, presence of confirmed CD or UC with an indication for immunosuppressive therapy but in whom standard AZA or 6-MP therapy failed due to adverse events. Immunosuppression was indicated in case of chronic active disease, corticosteroid dependency or recurrent disease. Exclusion criteria were pregnancy, lactation, presence of active infection, history of tuberculosis, HIV, hepatitis B or C, history of severe pancreatitis (necrotizing pancreatitis or pancreatitis leading to multi-organ-failure), ongoing treatment with concomitant immunosuppressive drugs (e.g. cyclosporine, methotrexate, thalidomide or infliximab), impaired renal function (serum creatinin $>2$ times normal upper limit), impaired hepatic function (>2 times normal upper limit) and persistent bone marrow suppression.

\section{Study design}

In all patients, 6-TG (Lanvis $\AA$, tablet $40 \mathrm{mg}$, Glaxo Wellcome) was administered orally in a dose of 20 to $40 \mathrm{mg}$ once daily based on the decision of the attending physician. The following data were collected: patient demographics, history of thiopurine exposure, type of thiopurine intolerance, the use of concomitant medication, blood cell counts and liver enzymes were recorded. Dose of 6-TG, duration of 6-TG, occurrence of adverse events, blood cell counts and liver enzymes were reviewed after a minimum of twelve months after initiation of 6-TG treatment. During the described period the genotyping of TPMT became available and in a subgroup of patients the TPMT status was determined. Red blood cell (RBC) 6-thioguanine nucleotide (6-TGN) levels were determined at least four weeks after giving a stable dose in order to obtain steady-state levels of 6-TGN. Dose adjustments were left to the discretion of the attending physician, but when 6-TGN levels were above 1000$1500 \mathrm{pmol} / 8 \times 10^{8} \mathrm{RBC}$, dose reduction was contemplated. In case of a leukocyte count below $3.5 \times 10^{9} /$, dose reduction was advocated and in case of severe leukopenia (below $1.0 \times 10^{9} /$ ) 6 -TG had to be discontinued. Additionally, in order to explore signs of hepatotoxicity, an abdominal ultrasonography was advised after at least one-year 6-TG administration. Special attention was paid to splenomegaly, signs of portal hypertension and hepatic changes.

\section{Outcome measurements}

Primary outcome measures were the ability to tolerate 6-TG and the occurrence of adverse events leading to discontinuation of 6-TG over the oneyear period. The relationship of any adverse event with the use of 6-TG was established by the following method: unrelated, no temporal relation and other aetiology likely; possibly related, potential temporal relation and other aetiologies possible; probable related, potential temporal relation and other aetiologies unlikely; related, clear temporal relation not otherwise explained. Secondary outcome measures were the occurrence of haematological events 
(defined as leukocyte count $<4.0 \times 10^{9} /$ or platelet count $<100 \times 10^{9} /$ ), the occurrence of hepatotoxicity (defined as a rise of at least two times the upper normal limit of a single liver enzyme level), pancreaticotoxicity (serum amylase $>220 \mathrm{U} / \mathrm{l}$ ) and signs of liver related abnormalities on the abdominal ultrasound. The following data concerning disease activity were analysed as well: erythrocyte sedimentation rate (ESR), C-reactive protein (CRP), serum albumin and a global physician assessment score (features were same, better or worse).

\section{6-TG metabolite monitoring and genotyping of TPMT}

Blood samples for 6-TGN measurements were obtained at least four weeks after the onset of a stable 6-TG dose. The samples were centrifuged to isolate erythrocytes and after washing with PBS buffer solution, erythrocyte counts were done. Samples were stored at $-20^{\circ} \mathrm{C}$ until required. RBC 6-TGN levels were measured in the laboratory of the Department of Clinical Pharmacy, Maasland Hospital Sittard, using a proprietary modified previously published assay $^{8}$. The lower limit of quantification of the assay was $30 \mathrm{pmol} / 8 \times 10^{8} \mathrm{RBC}$ for 6-TGN levels with a run-to-run coefficient of variation of 6.6\%. Extra blood samples were drawn once during the one-year period to assess TPMT (G238C, G460A and A719G, i.e. TPMT ${ }^{\star} 1, T P M T^{\star} 2, T_{P M T}^{*} 3 A, T_{P M T}^{*} 3 B$, $T P M T{ }^{*} 3 C$ ) genotypes in a sub-group of patients, independent of the biochemical or clinical status. The genotyping was performed at the Department of Gastroenterology and Hepatology at the Academic Medical Centre in Amsterdam.

\section{Statistical analysis}

Data are expressed as mean \pm standard deviation (SD). Significance was evaluated by a $t$ test for paired or independent data; $p$ values of less than 0.05 were considered significant. Pearson's correlation was used to determine relationships between parameters. $A X^{2}$ test was used to determine the significance between the TPMT genotype and 6-TG intolerance. SPSS for windows version 11.0 was used for statistical analysis.

\section{Results}

\section{Patients}

In ninety-five patients treatment with 6-TG was initiated in the period June 2001 to July 2003. Fifty-eight patients (61\%) were female (mean age: 40 years, range: $20-74)$ and 37 (39\%) were male (mean age:47 years, range: $20-71$ ). Forty-two (44\%) patients were diagnosed with UC compared to $53(56 \%)$ 
patients with CD. All patients were intolerant to AZA, 6-MP or both. The adverse events leading to discontinuation of AZA or 6-MP use were gastrointestinal complaints, general malaise, allergic reactions, hepatotoxicity or myelotoxicity. The patients characteristics are given in detail in Table 9.1. The mean initial 6-TG dose was $24.6 \mathrm{mg}$ (range 20-40 mg). The mean initial 6-TG dose adjusted to bodyweight was $0.37 \mathrm{mg} / \mathrm{kg}$ (SD 0.16).

Table 9.1 Patient characteristics.

\begin{tabular}{ll}
\hline & $\mathrm{N}=95$ patients \\
\hline Female / male & 58 / 37 patients \\
Age & 43 years (range 20-74) \\
UC : CD & $42: 53$ patients \\
Duration of IBD at start 6-TG & 10.4 years (SD 9.4) \\
AZA intolerance & 78 patients $(82 \%)$ \\
6-MP intolerance & 4 patients $(4 \%)$ \\
AZA and 6-MP intolerance & 13 patients $(14 \%)$ \\
AZA or 6-MP rechallenge & 36 patients (38\%) \\
Adverse events on AZA or 6-MP & $30 \%=$ gastrointestinal complaints \\
& $20 \%=$ general malaise \\
& $14 \%=$ allergic reactions \\
& $10 \%=$ pancreaticotoxicity \\
& $6 \%=$ hepatotoxicity \\
& $5 \%=$ myelotoxicity \\
6-TG dosage at the start & $14 \%=$ rest (e.g. myalgia or alopecia) \\
\hline
\end{tabular}

$\mathrm{N}$, number of patients; UC, ulcerative colitis; CD, Crohn's disease; IBD, inflammatory bowel disease; 6-TG, 6-thioguanine; AZA, azathioprine; 6-MP, 6-mercaptopurine.

\section{Primary outcomes}

Seventy-five $(79 \%)$ of the 95 patients were able to tolerate 6-TG during one year use. In twenty $(21 \%)$ patients the administration was discontinued due to side effects. The twenty intolerant patients (nine females and eleven males) encountered 26 side effects. The data concerning the adverse events leading to withdrawal and the relationship with 6-TG use are summarized in Table 9.2. No mortality was reported. The mean 6-TG dosage was $0.30 \mathrm{mg} / \mathrm{kg}$ in the tolerant group compared to $0.34 \mathrm{mg} / \mathrm{kg}$ in the intolerant group (NS). 
Table 9.2 Adverse events ( $\mathrm{N}=26$ ) leading to discontinuation of 6-TG use in 20 patients.

\begin{tabular}{lccl}
\hline AE on 6-TG & Frequency (\%) & $\begin{array}{c}\text { Mean time to AE } \\
\text { (days) }\end{array}$ & Relationship with 6-TG \\
\hline G.I. complaints & $8 / 26(31)$ & 43 & Probably 6/8 Possibly 2/8 \\
Hepatotoxicity & $4 / 26(15)$ & 182 & $\begin{array}{l}\text { Probably 2/4 Possibly } 1 / 4 \\
\text { Unrelated 1/4 }\end{array}$ \\
Myelodepression & $1 / 26(4)$ & 50 & Related \\
Pancreaticotoxicity & $1 / 26(4)$ & 103 & Possibly \\
General malaise & $4 / 26(15)$ & 51 & Probably 3/4 Possibly $1 / 4$ \\
Allergic reaction & $1 / 26(4)$ & 1 & Related \\
Other AE & $7 / 26(27)$ & 39 & Related 1/7 Probably 2/7 \\
& & & Possibly 4/7 \\
\hline
\end{tabular}

$\mathrm{AE}$, adverse event; 6-TG, 6-thioguanine; G.I. complaints, gastrointestinal complaints

\section{Secondary outcomes}

\section{Haematological events}

Three patients had signs of myelosuppression. One patient had a leukocyte count of $3.2 \times 10^{9} / /$ and a platelet count of $70 \times 10^{9} / /$ after 50 days of 6-TG use $(20 \mathrm{mg})$. Subsequently, 6-TG was discontinued. The second patient had a leucopenia (leucocytes $3.5 \times 10^{9} /$ ) and a third patient had a thrombocytopenia (platelets $87 \times 10^{9} /$ ) at one year measurements, both did not discontinue 6-TG. All other patients, both tolerant and intolerant to 6-TG, had platelet and leucocyte counts above the set lower limits. However, the mean platelet count decreased significantly from baseline $\left(309 \times 10^{9} /\right)$ to one year of 6-TG treatment $\left(290 \times 10^{9} / l, p=0.033\right)$. The mean leucocyte count decreased as well (from 11.9 to $\left.7.8 \times 10^{9} /\right)$ though not significantly. The $6-\mathrm{TGN}$ level did not correlate with the decrease in both leucocytes and platelets counts. Haemoglobin levels remained unchanged in both patient groups.

\section{Hepatotoxicity and pancreaticotoxicity}

In the 6-TG tolerant group the ASAT, ALAT, GGT and AF levels were determined in $65 \%, 71 \%, 60 \%$ and $68 \%$ of patients at one year $6-\mathrm{TG}$ use, respectively. The mean levels of ASAT, ALAT, GGT and AF were $24.7 \mathrm{U} / \mathrm{I}$ (range 6-118), $24.5 \mathrm{U} / \mathrm{l}$ (range 5-206), $48 \mathrm{U} / \mathrm{l}$ (range 6-535) and $84 \mathrm{U} / \mathrm{l}$ (range 42-322), respectively. A significant increase in liver enzymes during treatment in the tolerant group was not established. No correlation was found between the 6-TGN level and ALAT, ASAT, GGT or AF levels. At one year use, in $9 \%$ of patients (seven of 75) hepatotoxicity occurrence on 6-TG treatment could be classified. Four patients of the intolerant group of 20 patients discontinued 6-TG use due to hepatotoxicity. All had normal liver tests at entry and three of these patients encountered allergic reactions but no hepatotoxicity on the prior 
AZA therapy. Three patients had a serum amylase level above $220 \mathrm{U} / \mathrm{l}$ before the start of 6-TG that all became normal during treatment. One patient developed a transitory symptomatic pancreatitis with a serum amylase level of $430 \mathrm{U} / \mathrm{l}$ during 6-TG treatment and discontinued treatment.

\section{Abdominal ultrasonography and liver histology}

In 51 patients $(54 \%)$ an abdominal ultrasonography was performed after at least one year 6-TG use. Five ultrasounds $(10 \%)$ were considered as abnormal: three patients with steatosis, one patient had a choledocholithiasis and the last patient had a hydrops of the gallbladder and a splenomegaly (spleen size $13 \mathrm{~cm}$ ). The latter two patients were also classified as having hepatotoxicity on 6-TG treatment.

\section{Disease activity parameters}

No significant decrease in CRP (15 to $11 \mathrm{mg} / \mathrm{l}$ ) or ESR level (15 to $14 \mathrm{~mm}$ ) was established in the 6-TG tolerant group. The albumin level increased (37.6 to $40.1 \mathrm{~g} / \mathrm{l})$ significantly in the tolerant group $(p=0.002)$. A significant decrease of albumin level $(38.5$ to $36.6 \mathrm{~g} / \mathrm{l})$ was established in the intolerant group $(p=0.03)$. The global physician score was determined at one year 6-TG use in $85 \%$ $(64 / 75)$ of the tolerant patients. Forty-seven patients $(73 \%)$ were classified as better, fifteen patients $(23 \%)$ as the same and four patients $(6 \%)$ as worse during 6-TG treatment.

\section{6-TG metabolite monitoring and genotyping of TPMT}

The mean steady state 6-TGN level, determined in 63\% (47/75) of the tolerant patients, was $540 \mathrm{pmol} / 8 \times 10^{8} \mathrm{RBC}$ (SD 245, range 0-1404). In the eight intolerant patients in whom metabolite levels were measured (40\%), the 6-TGN level was $725 \mathrm{pmol} / 8 \times 10^{8} \mathrm{RBC}$ (SD 422, range 229-1563). The difference in 6-TGN levels between tolerant and intolerant patients was not significant. No statistical significant correlations were established between laboratory parameters (leucocytes, platelets, haemoglobin, AF, GGT, ASAT and ALAT) and 6-TGN level. The TPMT genotyping was performed in 51 patients $(54 \%)$. Two patients $(3.9 \%)$ had one mutant non-functional allele (TPMT*3A and TPMT* ${ }^{*} \mathrm{C}$ ) and both patients were intolerant for 6-TG (myelodepression and hepatotoxicity) (significant, $p=0.003$ ). The $6-T G N$ level was not determined in both patients. Patients with two mutant non-functional alleles of TPMT (homozygous mutants) were not found in our population. 


\section{Discussion}

In this group of AZA or 6-MP intolerant IBD patients, we demonstrated that 6-TG in dosages of 0.3 to $0.4 \mathrm{mg} / \mathrm{kg}$ daily was well tolerated over a period of one year as a maintenance immunosuppressant in $79 \%$ of the patients. This result suggests that during the metabolisation process of AZA or 6-MP metabolites are generated that induce side effects which at least in part are not generated during the 6-TG metabolism. No mortality was reported due to 6-TG use. When 6-TG was discontinued, the side effects leading to withdrawal resolved spontaneously. One patient developed a myelodepression that may be explained by the impaired TPMT activity, probably shunting 6-TG away from methylation by TPMT towards the formation of 6-TGN which have been associated with myelotoxicity. Unfortunately, no 6-TGN level was determined in this patient. The real incidence of 6-TG related histological liver abnormalities like $\mathrm{NRH}$ or veno-occlusive disease (VOD) in the present study remains unknown, as liver biopsies were not performed. The incidence of 6-TG related increase in liver enzymes probably will be lower than seven out of 75 patients, as two patients already had abnormal liver tests before the start of 6-TG and one patient had symptomatic choledocholithiasis.

In the present study we found a mean 6-TGN level of $540 \mathrm{pmol} / 8 \times 10^{8} \mathrm{RBC}$ in the tolerant group which is above the proposed therapeutic threshold of 250 $\mathrm{pmol} / 8 \times 10^{8} \mathrm{RBC}$ and even higher than the proposed upper limit of efficacy (450 $\mathrm{pmol} / 8 \times 10^{8} \mathrm{RBC}$ ) under AZA or 6-MP therapy ${ }^{3,9}$. This is consistent with previous observations $^{6,7}$. It remains to be elucidated whether the same 6-TGN limits should be used when 6-TG is administered. In our study $73 \%$ clinically benefited from 6-TG by using the global physician score and the mean albumin level increased significantly. However, due to the retrospective nature of the study, we must be reserved in drawing firm conclusions as no standard efficacy parameters as the Crohn's disease activity index (CDAI) or Truelove-Witts index were used. Despite the fact that we have not demonstrated a significant relationship between 6-TGN levels, laboratory results and adverse events, we believe that therapeutic drug monitoring may be a helpful tool in dosing 6-TG. Extremely high 6-TGN levels, which have been associated with an increased risk of developing myelotoxicity, can be prevented and compliance can be monitored.

The TPMT status has been associated with the ability to tolerate AZA or 6-MP. Patients with impaired TPMT activity are more prone to develop a myelodepression ${ }^{10}$. However, our study demonstrates that in AZA or 6-MP intolerant patients only two patients $(3.9 \%)$ had one mutant TPMT allele which is even lower than the incidence in the normal Caucasian population ${ }^{11}$. 
Interestingly, both patients did not develop a myelodepression on AZA therapy. This indicates that other metabolic pathways may lead to toxicity of AZA or 6 -MP as was recently demonstrated for the ITPase routing ${ }^{12}$. However, both patients with one mutant TPMT allele discontinued the use of 6-TG. Unfortunately, in these patients no 6-TGN concentrations were measured before discontinuation of 6-TG. Possibly, an impaired TPMT activity leads to more 6-TG being metabolised by the enzymes hypoxanthine guanine phosphoribosyl transferase or xanthine oxidase leading to higher 6-TGN and 6 -thiouric acid levels, respectively (Figure 9.1). The accumulation of these metabolites may lead to intolerance of 6-TG.

Recently, the use of 6-TG in IBD patients has been associated with the induction of $\mathrm{NRH}$ and $\mathrm{VOD}^{13}$. In the present study, we performed an abdominal ultrasonography after at least one year 6-TG use to screen for possible hepatotoxicity in 51 patients. Only one patient showed signs of portal hypertension indicated by an enlarged spleen. $\mathrm{NRH}$ has been associated with a thrombocytopenia and in our evaluation only two patients had platelets counts below $100 \mathrm{U} / \mathrm{I}^{13}$. We are well aware of the fact that by using biochemistry and ultrasound outcomes, we probably underestimate the real incidence of 6-TG induced $\mathrm{NRH}$, as the golden standard is based on histology. Additionally, liver tests abnormalities were shown not to be indicative for $\mathrm{NRH}$. Conversely, it should be taken into account that AZA and 6-MP can induce $\mathrm{NRH}$ or VOD as well but performing liver biopsies during treatment with these compounds is not recommended in clinical practice.

Currently, the use of 6-TG in IBD is abandoned due to potential hepatotoxicity ${ }^{13}$. However, low dose 6-TG may still be considered as an escape maintenance strategy in AZA or 6-MP intolerant IBD patients whom are refractory for alternative therapies. The number of proven effective medical maintenance options is scarce for these patients. Methotrexate (MTX) has a reasonable toxicity profile and seems effective in $C D$, comparable with AZA or 6 -MP but the potential use of MTX in UC patients has yet to be proven ${ }^{14}$. In addition, long-term use of MTX may be limited ${ }^{15}$ Cyclosporine seems to have no role as a maintenance immunosuppressive alternative in IBD ${ }^{16}$. Infliximab can be administered as a maintenance option in CD with acceptable toxicity and may be effective in treating UC. However, concomitant immunosuppressive therapy with thiopurines or MTX next to infliximab therapy seems mandatory to reduce the immunogenic response ${ }^{17}$. 


\section{Conclusions}

Treatment with 6-TG is well tolerated in AZA and 6-MP intolerant IBD patients and seems to be effective. We believe that low dosed 6-TG (0.3 to $0.4 \mathrm{mg}$ per kilogram daily) maintenance therapy may still be an escape option for this difficult to treat group of patients. The benefit of 6-TG use in this sub-group may balance its toxicity profile, especially taking into account the toxicity and efficacy of other therapeutic alternatives. Still, the reported hepatotoxicity is worrisome and 6-TG should therefore only be administered in prospective clinical trials. 


\section{References}

1. Sandborn WJ. A review of immune modifier therapy for inflammatory bowel disease: azathioprine, 6-mercaptopurine, cyclosporine, and methotrexate. Am J Gastroenterol 1996;91:423-33.

2. Present DH, Meltzer SJ, Krumholz MP, Wolke A, Korelitz BI. 6-Mercaptopurine in the management of inflammatory bowel disease: short- and long-term toxicity. Ann Intern Med 1989;111:641-9.

3. Dubinsky MC, Lamothe S, Yang HY, Targan SR, Sinnett D, Théorêt Y, Seidman EG. Pharmacogenomics and metabolite measurement for 6-mercaptopurine therapy in inflammatory bowel disease. Gastroenterology 2000;118:705-13.

4. Marinaki AM, Ansari A, Duley JA, Arenas M, Sumi S, Lewis CM, Shobowale-Bakre E, Escuredo E, Fairbanks LD, Sanderson JD. Adverse drug reactions to azathioprine therapy are associated with polymorphism in the gene encoding inosine triphosphate pyrophosphatase (ITPase). Pharmacogenetics 2004;14: 181-7.

5. De Jong D, Mulder CJ, van Sorge AA. Why measure thiopurine methyltransferase activity? Direct administration of 6-thioguanine might be the alternative for 6mercaptopurine or azathioprine. Gut 2001;49:874.

6. Derijks LJ, de Jong DJ, Gilissen LP, Engels LG, Hooymans PM, Jansen JB, Mulder CJ. 6-Thioguanine seems promising in azathioprine- or 6-mercaptopurine-intolerant inflammatory bowel disease patients: a short-term safety assessment. Eur $\mathrm{J}$ Gastroenterol Hepatol 2003;15:63-7.

7. Dubinsky MC, Feldman EJ, Abreu MT, Targan SR, Vasiliauskas EA. Thioguanine: a potential alternate thiopurine for IBD patients allergic to 6-mercaptopurine or azathioprine. Am J Gastroenterol 2003;98:1058-63.

8. Derijks LJ, Gilissen LP, Engels LG, Bos LP, Bus PJ, Lohman JJ, Curvers WL, Van Deventer SJ, Hommes DW, Hooymans PM. Pharmacokinetics of 6-mercaptopurine in patients with inflammatory bowel disease: implications for therapy. Ther Drug Monit 2004;26:311-8.

9. Cuffari C, Hunt S, Bayless T. Utilisation of erythrocyte 6-thioguanine metabolite levels to optimise azathioprine therapy in patients with inflammatory bowel disease. Gut 2001;48:642-6.

10. Ansari A, Hassan C, Duley J, Marinaki A, Shobowale-Bakre EM, Seed P, Meenan J, Yim A, Sanderson J. Thiopurine methyltransferase activity and the use of azathioprine in inflammatory bowel disease. Aliment Pharmacol Ther 2002;16:1743-50.

11. Weinshilboum R. Thiopurine pharmacogenetics: clinical and molecular studies of thiopurine methyltransferase. Drug Metab Dispos 2001;29:601-5.

12. Zelinkova Z, Derijks LJ, Stokkers PC, Vogels EW, van Kampen AH, Curvers WL, Cohn D, van Deventer SJ, Hommes DW. Inosine triphosphate pyrophosphatase and thiopurine s-methyltransferase genotypes relationship to azathioprine-induced myelosuppression. Clin Gastroenterol Hepatol 2006;4:44-9.

13. Dubinsky MC, Vasiliauskas EA, Singh H, Abreu MT, Papadakis KA, Tran T, Martin P, Vierling JM, Geller SA, Targan SR, Poordad FF. 6-Thioguanine can cause serious liver injury in inflammatory bowel disease patients. Gastroenterology 2003;125:298-303. 
14. Ardizzone S, Bollani S, Manzionna G, Imbesi V, Colombo E, Bianchi PG. Comparison between methotrexate and azathioprine in the treatment of chronic active Crohn's disease: a randomised, investigator-blind study. Dig Liver Dis 2003;35:619-27.

15. Bell SJ, Kamm MA. Review article: the clinical role of anti-TNFalpha antibody treatment in Crohn's disease. Aliment Pharmacol Ther 2000;14:501-14.

16. Hanauer SB, Present DH. The state of the art in the management of inflammatory bowel disease. Rev Gastroenterol Disord 2003;3:81-92.

17. Rutgeerts $P$, Van Assche $G$, Vermeire $S$. Optimizing anti-TNF treatment in inflammatory bowel disease. Gastroenterology 2004;126:1593-610. 


\section{Chapter 10}

Toxicity of 6-thioguanine: no hepatotoxicity in a series of IBD patients treated with longterm, low dose 6-thioguanine Some evidence for dose or metabolite level dependent effects?

LPL Gilissen, LJJ Derijks, A Driessen, LP Bos, PM Hooymans, RW Stockbrügger, LGJB Engels

Dig Liv Dis 2007;39:156-9. 


\section{Abstract}

\section{Background}

6-Thioguanine (6-TG) is used in inflammatory bowel disease (IBD) since 2001, with promising short term results. In 2003, liver histology of some 6-TG treated patients showed nodular regenerative hyperplasia $(\mathrm{NRH})$. Recently, MRI revealed $\mathrm{NRH}$ in patients with normal histology.

\section{Aims}

Investigating the presence of $\mathrm{NRH}$ in longterm 6-TG treated patients.

\section{Patients and methods}

IBD patients, using 6-TG minimally 24 months, were asked to undergo liver biopsy and MRI.

\section{Results}

Fourteen patients used 6-TG minimally 24 months, thirteen participated. Mean 6-TG therapy duration, daily dose and 6-TGN levels were: 36 months, $18.8 \mathrm{mg}(0.28 \mathrm{mg} / \mathrm{kg})$ and $705 \mathrm{pmol} / 8 \times 10^{8}$ erythrocytes respectively. Liver histology and MRI showed no NRH.

\section{Discussion}

Liver biopsy and MRI showed no NRH in these longterm 6-TG treated IBD patients. 6-TG dose and metabolite levels were lower compared with previous NRH reports, suggesting dose or metabolite level-dependent effects. Otherwise, NRH is related with IBD itself and immunosuppressives, including azathioprine and 6-mercaptopurine.

\section{Conclusions}

6-TG is debated due to NRH. We found no NRH in IBD patients with longterm, low dosed 6-TG, suggesting metabolite level-dependent effects. Therefore, 6-TG still seems useful, but in selected patients, intolerant for other immunosuppressives, low dosed and under close surveillance of metabolite levels and hepatotoxity. 


\section{Introduction}

Since the early nineties both azathioprine (AZA) and 6-mercaptopurine (6-MP) are widely used in steroid refractory or dependent inflammatory bowel disease $(\text { IBD })^{1,2}$. These thiopurines are metabolised by several enzymes, but thiopurine S-methyltransferase (TPMT) is considered as the most important ${ }^{3}$. TPMT has a genetic polymorphism and determines the balance between hepatotoxic 6-methylmercaptopurine ribonucleotides (6-MMPR) and the effective, myelosuppressive 6-thioguanine nucleotides (6-TGN). Due to the developing knowledge of thiopurine metabolism, 6-thioguanine (6-TG) was introduced in IBD therapy in 2001, because this thiopurine is closely related to the active 6TGN metabolites ${ }^{4,5}$. The first results with 6-TG in AZA or 6MP intolerant IBD patients were promising, with good short term efficacy and safety ${ }^{6-12}$.

In 2003, Dubinsky reported a high frequency (16\%) of nodular regenerative hyperplasia (NRH), found in the liver biopsies of 111 IBD patients treated with $6-\mathrm{TG}^{13}$. Recently, Seiderer described NRH in eight of 45 (18\%) 6-TG treated IBD patients ${ }^{14}$. Magnetic resonance imaging (MRI) was presented as an alternative diagnostic test, but its sensitivity $(77 \%)$ and specificity $(72 \%)$ were relatively low. Otherwise, MRI revealed NRH in some patients with normal liver histology. Still, liver biopsy seems most sensitive for the detection of $\mathrm{NRH}$, but specific impregnation techniques like silver-reticulin or trichrome are required, as hematoxylin-eosin alone does not reveal all cases ${ }^{13}$.

Since 2001, we started 6-TG treatment in AZA and 6-MP intolerant IBD patients in the Maasland Hospital Sittard, Netherlands according to a study protocol. Short term results were favourable with good efficacy and low toxicity $^{7}$. No hepatotoxicity was found by regular laboratory analysis and ultrasonography. After the reports about NRH we decided to take biopsies in our 6-TG treated IBD patients to investigate hepatotoxicity.

\section{Methods and patients}

All IBD patients in the Maasland Hospital Sittard, Netherlands, treated with 6-TG for at least 24 months, were informed about the risk of NRH and were asked to undergo an undirected, ultrasonography monitored, percutaneous liver biopsy. Histopathologic criteria for $\mathrm{NRH}$ were micronodularity without cirrhosis; hyperplastic hepatocytes in the centre of the nodules are surrounded by atrophic appearing compressed hepatocytes; hepatocytes lay in two cells thick plates; compressed sinusoidal space; fibrosis in the portal areas without septae. Red blood cell (RBC) 6-TGN metabolite levels, blood cell counts and liver function tests were measured as well. The protocol was approved by the Medical Ethical Committee. All included patients gave written informed 
consent. After the report about patients with $\mathrm{NRH}$ negative liver histology, but $\mathrm{NRH}$ positive MRI we asked our patients to undergo a MRI as well ${ }^{14}$. The MRI was performed according to Seiderer's protocol ${ }^{14}$. In summary, the patients were scanned before and after infusion of two intravenous contrast agents, gadolinium $(0.2 \mathrm{mg} / \mathrm{kg})$ and liver specific super paramagnetic ferrumoxide $\left(1.4 \mathrm{ml}\right.$ ferocarbutran - Resovist ${ }^{\circledR}$ ).

\section{Results}

Fourteen patients had used 6-TG for at least 24 months. These patients have all been described in two previous reports about a 6-TG treated IBD cohort ${ }^{7,12}$. Thirteen patients were included, one refused (Table 10.1). Mean age was 41 years (SD 10.0, range 25-53). Eight patients had Crohn's disease, five had ulcerative colitis. Man/female ratio was $3 / 10$. All patients were in remission at inclusion. All patients had started 6-TG therapy because of intolerability for AZA and/or 6-MP. One patient (F) previously had a mild hepatitis due to 6-MP, which was recovered before starting 6-TG. Mean 6-TG therapy duration was 36 months (SD 6.0, range 27-45). Mean daily 6-TG dose was $18.8 \mathrm{mg}$ (SD 3.7, range $6.6-20$ ) and $0.28 \mathrm{mg} / \mathrm{kg}$ bodyweight (SD 0.08). Mean 6-TGN levels were $705 \mathrm{pmol} / 8 \times 10^{8} \mathrm{RBC}$ (SD 332) at the moment of liver biopsy. All patients had normal liver function tests and blood cell counts. With hematoxylin-eosin and silver-reticulin impregnation techniques no $\mathrm{NRH}$ was found by two independent pathologists. Two patients had mild steatosis hepatis without fibrosis, assigned to obesity.

Table 10.1 Patient characteristics.

\begin{tabular}{|c|c|c|c|c|c|c|c|c|c|c|}
\hline Patient & Sex & $\begin{array}{c}\text { Age } \\
\text { (years) }\end{array}$ & $\begin{array}{c}\text { Weight } \\
(\mathrm{kg})\end{array}$ & IBD type & $\begin{array}{l}\text { 6-TG use } \\
\text { (months) }\end{array}$ & $\begin{array}{l}\text { 6-TG daily } \\
\text { dose (mg) }\end{array}$ & $\begin{array}{c}\text { 6-TG dose } \\
(\mathrm{mg} / \mathrm{kg})\end{array}$ & $\begin{array}{c}\text { 6-TGN } \\
\text { level }\end{array}$ & Liver histology & MRI \\
\hline A & $f$ & 52 & 54 & UC & 41 & 20 & 0.37 & 1092 & no NRH & no NRH \\
\hline $\mathrm{C}$ & $f$ & 28 & 55 & $C D i+c$ & 45 & 20 & 0.36 & 669 & no NRH & no NRH \\
\hline $\mathrm{D}$ & $f$ & 30 & 64 & $C D i+c$ & 38 & 20 & 0.31 & 890 & mild steatosis & mild steatosis \\
\hline $\mathrm{F}$ & $\mathrm{m}$ & 53 & 83 & UC & 38 & 20 & 0.24 & 1072 & no NRH & refused \\
\hline G & $f$ & 53 & 60 & $\mathrm{CD} i+\mathrm{c}$ & 41 & 20 & 0.33 & 986 & mild steatosis & mild steatosis \\
\hline $\mathrm{H}$ & $\mathrm{m}$ & 36 & 74 & UC & 30 & 20 & 0.27 & 392 & no NRH & no NRH \\
\hline I & $\mathrm{m}$ & 35 & 91 & UC & 30 & 20 & 0.22 & 225 & no NRH & no NRH \\
\hline$M$ & $f$ & 48 & 60 & $C D i$ & 36 & 6.6 & 0.11 & 828 & no NRH & no NRH \\
\hline mean & & 41 & 68 & & 36 & 18.8 & 0.28 & 705 & & \\
\hline
\end{tabular}

F, female; m, male; UC, ulcerative colitis; CD, Crohn's disease; i, ileitis terminalis; c, colitis; pa, perianal disease; 6-TG,

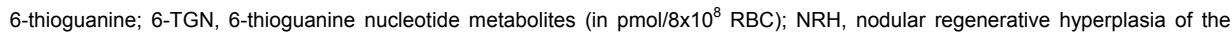
liver; MRI, magnetic resonance imaging. 
Eleven of the thirteen biopsied patients underwent the MRI protocol, two refused (one because of claustrophobia). No signs of $\mathrm{NRH}$, portal hypertension or splenomegaly were found. In both patients with mild steatosis hepatis, MRI confirmed these findings. Patient $F$, with hepatitis due to 6-MP treatment, had no signs of drug induced hepatitis in his liver histology. Unfortunately, he refused MRI.

\section{Discussion}

What are possible explanations for the fact that no NRH was found by liver biopsy and MRI in these longterm treated IBD patients, in contrary to the much shorter treated patients of Dubinsky (median 12 months, range 1-26) and Seiderer (median 16 months, range 2-27)? At first, 6-TG doses used by Dubinsky were relatively high (above $40 \mathrm{mg} /$ day, estimated on the presented data), resulting in approximately two times higher 6-TGN levels: median $1230 \mathrm{pmol} / 8 \times 10^{8} \mathrm{RC}$ (range 502-2310) ${ }^{13}$. Seiderer even used daily 6-TG doses up to $80 \mathrm{mg}$, but unfortunately no 6 -TGN levels were reported ${ }^{14}$. Therefore it seems possible that 6-TG induced $\mathrm{NRH}$ is a dose or metabolite leveldependent phenomenon. In our series the patients used relatively low doses (mean $18.8 \mathrm{mg}$ daily, not exceeding $20 \mathrm{mg}$ ), with good efficacy, as previously reported $^{7,12}$. No dose-finding studies have been performed for 6-TG in IBD, but using higher doses than $20 \mathrm{mg}$ (approximately $0.2-0.3 \mathrm{mg} / \mathrm{kg}$ bodyweight) seems unnecessary.

Secondly, NRH is not specifically correlated with 6-TG, but also with IBD itself and with several immunosuppressives like cyclosporin, corticosteroids and -importantly- with AZA and 6-MP ${ }^{15-19}$. All patients described by Dubinsky and Seiderer used AZA or 6-MP for a relatively long period, before 6-TG was started (median 12 months, range 0.5-96 and median 11 months, range 0.5-60, respectively). No liver histology before start of 6-TG therapy was reported by them and therefore already existing liver damage by AZA or 6-MP before start of 6-TG can not be excluded. All our patients had used AZA or 6-MP as well, but only for some weeks, because of adverse events (nausea, pancreatitis and hepatitis). The only patient with hepatitis in our series did not show any signs of $\mathrm{NRH}$ or drug induced liver damage in his liver histology.

A striking point, which is often not mentioned in the discussion about the role of 6-TG in the development of NRH, is that AZA and 6-MP are prodrugs, metabolised to the same 6-TGN metabolites as 6-TG. And again, in studies about these prodrugs lower 6-TGN levels are measured, compared to 6-TG treatment ${ }^{20,3,8}$. This may explain the less frequent prevalence of NRH in AZA or 6-MP treated patients compared to the 6-TG treated patients. 
At last, NRH is found by coincidence in autopsy studies in $2.5-5 \%$, suggesting its presence in an asymptomatic background population ${ }^{21}$.

On the other hand, some remarks about our study can be made. At first, the patient number is quite low. When taking the $16-18 \%$ prevalence in former studies on NRH into account, two patients were expected to have NRH in our group. Finding no NRH does not automatically mean that 6-TG is totally safe in low doses. Otherwise, in these patients with very longterm 6-TG treatment one would expect to find at least some minor histopathological changes in the liver. Secondly, a male predominance in developing hepatotoxicity or NRH in thiopurine treatment has been suggested ${ }^{13,22}$. Our patient group included only three men, which could underestimate $\mathrm{NRH}$ prevalence in this series theoretically.

Although our findings regard a small number of patients, we find them important to report, because they may explain a part of the pathogenesis of $\mathrm{NRH}$ in 6-TG treated IBD patients: a 6-TG dose or metabolite level-dependent effect. No reports have been published yet about such a long therapy interval, intensive follow up and screening for NRH in 6-TG treated IBD patients.

\section{Conclusions}

There is much concern about the use of 6-TG in IBD due to the findings of $\mathrm{NRH}$. This small observational study shows no hepatotoxicity by laboratory analysis, liver histology and MRI in longterm, low dose 6-TG treated IBD patients. A possible metabolite level-dependent effect is suggested. So far, the effects of longterm IBD treatment with AZA or 6-MP on NRH development are little studied, while all three thiopurines mentioned result in 6-TGN metabolites, which are held responsible for NRH. Therefore, studies about NRH in 6-MP or AZA treated patients seem important, but are still lacking. In expectation of these studies, we believe that 6-TG can be used, but only in selected patients, intolerant for all other immunosuppressives, in a low dose and under close surveillance of 6-TGN metabolite levels and hepatotoxity. This is in accordance with a recent advise given by an European 6-TG Working Party ${ }^{23}$. 


\section{References}

1. Present DH, Meltzer SJ, Krumholz MP, Wolke A, Korelitz BI. 6-Mercaptopurine in the management of inflammatory bowel disease: short- and long-term toxicity. Ann Intern Med 1989;111:641-9.

2. Adler DJ, Korelitz BI. The therapeutic efficacy of 6-mercaptopurine in refractory ulcerative colitis. Am J Gastroenterol 1990;85:717-22.

3. Dubinsky MC, Lamothe S, Yang HY, Targan SR, Sinnett D, Théorêt Y, Seidman EG. Pharmacogenomics and metabolite measurement for 6-mercaptopurine therapy in inflammatory bowel disease. Gastroenterology 2000;118:705-13.

4. Dubinsky MC, Hassard PV, Seidman EG, Kam LY, Abreu MT, Targan SR, Vasiliauskas EA. An open-label pilot study using thioguanine as a therapeutic alternative in Crohn's disease patients resistant to 6-mercaptopurine therapy. Inflamm Bowel Dis 2001;7:181-9.

5. Al Hadithy AF, de Boer NK, Derijks LJ, Escher JC, Mulder CJ, Brouwers JR. Thiopurines in inflammatory bowel disease: pharmacogenetics, therapeutic drug monitoring and clinical recommendations. Dig Liver Dis 2005;37:282-97.

6. Baert F, Rutgeerts P. 6-Thioguanine: a naked bullet? (Or how pharmacogenomics can make old drugs brand new). Inflamm Bowel Dis 2001;7:190-1.

7. Derijks LJ, De Jong DJ, Gilissen LP, Engels LG, Hooymans PM, Jansen JB, Mulder CJ. 6-Thioguanine seems promising in azathioprine- or 6-mercaptopurineintolerant inflammatory bowel disease patients: a short-term safety assessment. Eur J Gastroenterol Hepatol 2003;15:63-7.

8. Dubinsky MC, Feldman EJ, Abreu MT, Targan SR, Vasiliauskas EA. Thioguanine: a potential alternate thiopurine for IBD patients allergic to 6-mercaptopurine or azathioprine. Am J Gastroenterol 2003;98:1058-63.

9. Bonaz B, Boitard J, Marteau P, Lemann M, Coffin B, Flourie B, Belaiche J, Cadiot G, Metman EH, Cortot A, Colombel JF; Getaid. Tioguanine in patients with Crohn's disease intolerant or resistant to azathioprine/ mercaptopurine. Aliment Pharmacol Ther 2003;18:401-8.

10. Herrlinger KR, Deibert P, Schwab M, Kreisel W, Fischer C, Fellermann K, Stange EF. Remission maintenance by tioguanine in chronic active Crohn's disease. Aliment Pharmacol Ther 2003;17:1459-64.

11. Herrlinger KR, Kreisel W, Schwab M, Schoelmerich J, Fleig WE, Ruhl A, Reinshagen M, Deibert P, Fellermann K, Greinwald R, Stange EF. 6-Thioguanineefficacy and safety in chronic active Crohn's disease. Aliment Pharmacol Ther 2003;17:503-8.

12. de Boer NK, Derijks LJ, Gilissen LP, Hommes DW, Engels LG, de-Boer SY, den Hartog G, Hooymans PM, Mäkelburg AB, Westerveld BD, Naber AH, Mulder CJ, de Jong DJ. On tolerability and safety of a maintenance treatment with 6 -thioguanine in azathioprine or 6-mercaptopurine intolerant IBD patients. World J Gastroenterol 2005;11:5540-4.

13. Dubinsky MC, Vasiliauskas EA, Singh H, Abreu MT, Papadakis KA, Tran T, Martin P, Vierling JM, Geller SA, Targan SR, Poordad FF. 6-Thioguanine can cause serious liver injury in inflammatory bowel disease patients. Gastroenterology 2003;125:298-303.

14. Seiderer J, Zech CJ, Reinisch W, Lukas M, Diebold J, Wrba F, Teml A, Chalupna P, Stritesky J, Schoenberg SO, Schima W, Göke B, Ochsenkühn T. A multicenter assessment of liver toxicity by MRI and biopsy in IBD patients on 6-thioguanine. J Hepatol 2005;43:303-9. 
15. Stromeyer FW, Ishak KG. Nodular transformation (nodular regenerative hyperplasia) of the liver. A clinicopathologic study of 30 cases. Human Pathology 1981;12:60-71.

16. Naber AHJ, Van Haelst U, Yap SH. Nodular regenerative hyperplasia of the liver: in important cause of portal hypertension in non-cirrhotic patients. J Hepatology 1991;12:94-99

17. Zarday Z, Veith FJ. Irreversible liver damage after azathioprine. JAMA 1972;222:690-1.

18. Russmann S, Zimmermann A, Krähenbühl S, Kern B, Reichen J. Veno-occlusive disease, nodular regenerative hyperplasia and hepatocellular carcinoma after azathioprine treatment in a patient with ulcerative colitis. Eur J Gastroenterol Hepatol 2001;13:287-90.

19. Daniel F, Cadranel JF, Seksik P, Cazier A, Duong Van Huyen JP, Ziol M, Coutarel $P$, Loison $P$, Jian $R$, Marteau $P$. Azathioprine induced nodular regenerative hyperplasia in IBD patients. Gastroenterol Clin Biol 2005;29:600-3.

20. Tremaine WJ, Editorial: 6-TG for IBD: simple, but safe? Am J Gastroenterol 2003;98: 950-2.

21. Wanless IR. Micronodular transformation (nodular regenerative hyperplasia) of the liver: a report of 64 cases among 2500 autopsies and a new classification of benign hepatocellular nodules. Hepatology 1990;11:787-97.

22. Katzka DA, Saul SH, Jorkasky D, Sigal H, Reynolds JC and Soloway RD. Azathioprine and hepatic venocclusive disease in renal transplant patients. Gastroenterology 1986;90:446-54.

23. de Boer NK, Reinisch W, Teml A, van Bodegraven AA, Schwab M, Lukas M, Ochsenkühn T, Petritsch W, Knoflach P, Almer S, van der Merwe SW, Herrlinger $\mathrm{KR}$, Seiderer J, Vogelsang $\mathrm{H}$, Mulder CJ; Dutch 6-TG working group. 6-Thioguanine treatment in inflammatory bowel disease: a critical appraisal by a European 6-TG working party. Digestion 2006;73:25-31. 
Section F

General discussion, conclusions and clinical advice, summary 
Chapter 11

General discussion 
Chapter 11 


\section{General discussion}

Inflammatory bowel diseases (IBD) include Crohn's disease (CD), ulcerative colitis (UC) and indeterminate colitis. Until now, it is still not clear why and how someone gets IBD. Many contributing factors have been revealed: genetic, environmental, nutritional, smoking and medication ${ }^{1}$. However, the trigger which starts IBD is still not known. Due to an unknown agent or process, a proinflammatory cascade is set up, leading to bowel inflammation differing from mild local mucositis to deep penetrating or even perforating ulcerations. Crohn's disease can manifest from mouth to anus, while ulcerative colitis is limited to the colon. Several extra-intestinal organs can be involved: eyes, liver, joints and skin. These great inter-individual differences in disease phenotype make IBD difficult to study in clinical research, but also fascinating.

Because of the lacking identification of a causative agent, it has been very difficult to develop a targeting treatment for IBD. Recently, biologicals such as infliximab, adalimumab and certolizumab have been developed. These antibodies against a specific cytokine in the inflammatory cascade, tumor necrosis factor alfa (TNFa), show good short term efficacy and safety ${ }^{2,3}$. However, they are expensive and their long term safety profiles are not known yet. Therefore traditional medications like mesalamines, corticosteroids and thiopurines (azathioprine and 6-mercaptopurine) are still very important in daily practice.

In thiopurine therapy new strategies, such as therapeutic drug monitoring (TDM) and genotyping or measurement of activity of crucial enzymes, were developed in last decades to improve efficacy and safety, as discussed in the review about thiopurines in Chapter 1. TDM includes measurement of thiopurine metabolite levels with the purpose of improving safety and efficacy of thiopurine therapy. From 1996 on, several reports have suggested a correlation between metabolite levels and efficacy and/or toxicity of thiopurine therapy ${ }^{4-8}$. In all studies no correlation is found between thiopurine dose and metabolite levels or disease activity. This contrasts with the fact that until now most gastroenterologists dose thiopurine therapy on patient bodyweight: $2-3 \mathrm{mg} / \mathrm{kg}$ for azathioprine (AZA) and $1.0-1.5 \mathrm{mg} / \mathrm{kg}$ for 6-mercaptopurine (6-MP) ${ }^{9}$. This thesis presents several aspects of TDM in thiopurine therapy of IBD patients and explores the clinical usefulness of TDM in daily practice.

\section{Thiopurine metabolism}

\section{Pharmacokinetics}

Thiopurine metabolite levels have large inter-individual variations, due to enzyme polymorphisms ${ }^{4-8}$. Thiopurine S-methyltransferase (TPMT) is the most 
important enzyme influencing the balance between immunosuppressive 6-thioguanine nucleotides (6-TGN) levels and hepatotoxic 6-mercaptopurine ribonucleotides (6-MMPR), in favour of the latter metabolites (Figure $11.1)^{4,13-15}$. This enzyme has a trimodal genetic variation, determining its activity. In Chapter 2, 3 and 5 of this thesis this finding is confirmed ${ }^{10-12}$. 6-TGN metabolites have a 7 fold range and 6-MMPR metabolites a 16 fold range. In a prospective study described in Chapter 2, a half life of 6-TGN and 6-MMPR metabolites of five days is demonstrated: metabolite concentrations reach a steady state after $25-30$ days ${ }^{10}$. This means that metabolite concentrations are stable during the day, suggesting that it makes no difference at what time of the day TDM is performed after ingestion of a thiopurine during steady state maintenance therapy. In case of 6-thioguanine therapy this is also shown by measuring 6-TGN curves during the day in Chapter $7^{16}$. The relatively long half life of thiopurine metabolites may also be the reason why thiopurines are only effective after several weeks of treatment: it takes one month to have steady state metabolite levels. With an intravenous loading dose, higher 6-TGN levels are found after one week of thiopurine therapy, but steady state doses are reached at the same moment as in patients with only oral thiopurine treatment ${ }^{17}$. Hence, thiopurines are not suitable for acute therapy of IBD (in contrast to corticosteroids).

\section{Pharmacodynamics}

Until recently thiopurines were believed to be effective due to the incorporation of 6-TGN metabolites into DNA of leucocytes. These metabolites inhibit cell proliferation due to a structural similarity to the endogenous purine-base guanine as demonstrated in Figure 11.3 of Chapter 1. More recently, new details in the mechanism of action of thiopurines have been discovered. AZA and its metabolites were found to be responsible for $T$ cell apoptosis by modulation of Rac1 activation upon CD28 costimulation ${ }^{18}$. Rac1, a small GTPase that plays a role in inhibiting $T$ cell apoptosis, is a target for 6-thioguanine triphosphate (6-thio-GTP), a metabolite of thiopurines, which is one of the measured nucleotides of the 6-TGN level (see Figure 11.1). 6-ThioGTP binds to Rac1 in stead of GTP, thereby suppressing the activation of Rac1 target genes like mitogen activated protein kinase MEK, NF-KB and bcl- $\mathrm{x}_{\mathrm{L}}$, leading to apoptosis. CD28 is a transmembrane protein which plays a role in the anti-apoptotic signaling pathway as well. T-cell apoptosis by 6-thio-GTP is increased upon co-stimulation of Rac1 by CD28. It was demonstrated that especially specific $T$ memory lymphocytes (CD45RO), which are the main effector cells in IBD, become apoptotic. These recent findings suggest a new molecular mechanism of action of AZA. In future, 6-thio-GTP derivatives with more affinity for Rac1 may be designed, leading to stronger and more specific immunosuppressive effects. 
In 2004, a correlation between 6-TGN metabolite levels and decreased interferon gamma (IFNy) production was found in azathioprine treated Crohn's disease patients ${ }^{19}$. IFNy is a mediator of intestinal inflammation, which has an inhibitory effect on interleukine-10 (IL-10), which is a down-regulator of inflammation.

Additionally, 6-MMPR metabolites may have some myelosuppressive effects as well, as demonstrated in the fifth case presented in Chapter $3^{11,20}$. This case has been described more extensively in a recently published case-report, showing that extremely high 6-MMPR metabolite levels $\left(57000 \mathrm{pmol} / 8 \times 10^{8}\right.$ $\mathrm{RBC}$ ) may cause pancytopenia ${ }^{21}$.

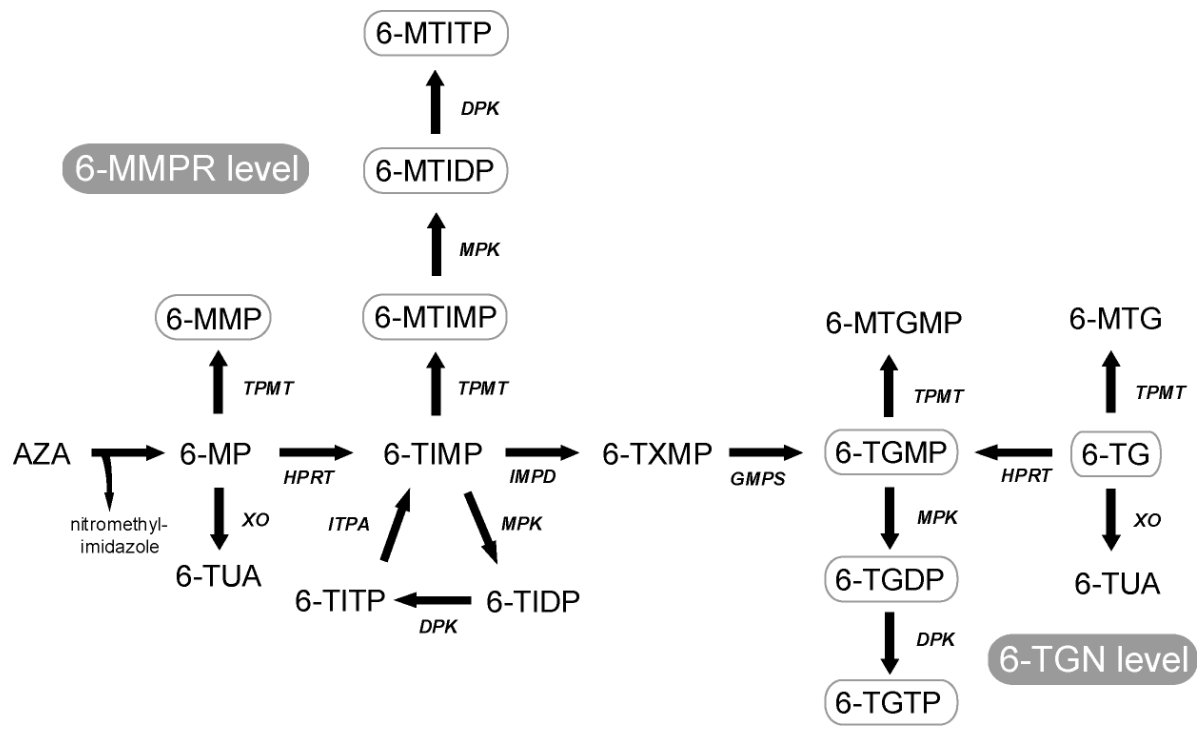

Figure 11.1 Proposed thiopurine metabolism.

AZA, azathioprine; 6-MP, 6-mercaptopurine; 6-TUA, 6-thiouric acid; 6-MMP, 6-methylmercaptopurine; 6-TIMP, 6-thioinosine-5'-monophosphate; 6-MMPR level, 6-methylmercaptopurine ribonucleotides; 6-TITP, 6-thioinosine triphosphate; 6-TIDP, 6-thioinosine diphosphate; 6-TG, 6-thioguanine; 6-TGN level, 6-thioguanine nucleotides; 6-MTG, 6-methyl thioguanine; HPRT, hypoxanthine phosphoribosyltransferase; XO, xanthine oxidase; ITPA, inosine triphosphate pyrophosphohydrolase; MPK, monophosphokinase; DPK, diphosphokinase; TPMT, thiopurine S-methyltransferase; IMPDH, inosine monophosphate dehydrogenase; GMPS, guanosine monophosphatase synthetase.

6-MTIMP, 6-MTIDP and 6MTITP together form the 6-methylmercaptopurine ribonucleotides (6-MMPR). 6-TGMP, 6-TGDP and 6-TGTP together form the 6-thioguanine nucleotides (6-TGN). In therapeutic drug monitoring, 6-MMPR levels consist of the sum of 6-MMP, 6-MTIMP, 6-MTIDP and 6-MTITP levels, while 6-TGN levels consist of the sum of 6-TGMP, 6-TGDP, 6-TGTP (if AZA or 6-MP is administered) and 6-TG levels (if 6-TG is administered as such). 


\section{Therapeutic and toxic ranges of thiopurine metabolites}

\section{a) Azathioprine and 6-mercaptopurine therapy}

Therapeutic and toxic ranges of thiopurine metabolite concentrations have been described in the past: therapeutic 6-TGN metabolites should be between 235 and $500 \mathrm{pmol} / 8 \times 10^{8}$ red blood cells $(\mathrm{RBC})^{4-8}$. In case of $6-\mathrm{TGN}$ levels above $500 \mathrm{pmol} / 8 \times 10^{8} \mathrm{RBC}$ the risk for leukocytopenia is increased $\mathrm{d}^{5-9}$. 6-MMPR levels higher than $5700 \mathrm{pmol} / 8 \times 10^{8} \mathrm{RBC}$ are correlated with hepatotoxicity ${ }^{4-5}$. Pancreatitis is not associated with metabolite levels and seems an idiosyncratic reaction ${ }^{1,5,10,22}$. 6-MMPR/6-TGN ratio should be below $11^{23}$. In case of a ratio above 11 , the balance between toxic 6-MMPR and therapeutic 6-TGN levels is unfavourable. Dose increment will lead to relatively more 6-MMPR metabolites in this situation, increasing the risk for hepatotoxicity. In case of a 6-MMPR/6-TGN ratio above 11 and ineffective thiopurine therapy, other immunomodulating therapy should be considered ${ }^{23}$. Only recently, it has been shown that thiopurine dose decrease in combination with allopurinol $100 \mathrm{mg}$ would improve $6-\mathrm{MMPR} / 6-\mathrm{TGN}$ ratio ${ }^{24}$. Some remarks should be made about the studies proposing these therapeutic and toxic thresholds: the first studies were performed in paediatric populations, often with small patient numbers, were descriptive and sometimes retrospective. Other studies, some of which were performed in adults, found contradictory results $^{25-29}$. A recent meta-analysis of six studies on TDM of thiopurines confirmed this therapeutic $6-\mathrm{TGN}$ threshold of $235 \mathrm{pmol} / 8 \times 10^{8} \mathrm{RBC}^{30}$. The therapeutic and toxic thresholds have also been studied in this thesis. In Chapter 2 the therapeutic $6-$ TGN threshold is confirmed: $83 \%$ of the patients with initially active IBD and remission after eight weeks of 6-MP treatment had 6-TGN levels above the proposed therapeutic threshold level of $235 \mathrm{pmol} / 8 \times 10^{8} \mathrm{RBC}$. Inversely, $75 \%$ of the patients without clinical improvement of IBD activity after eight weeks of 6-MP treatment had 6-TGN levels below $235 \mathrm{pmol} / 8 \times 10^{8} \mathrm{RBC}$. The toxic $6-\mathrm{TGN}$ threshold was also confirmed: all four patients who developed leukopenia had 6-TGN levels above $500 \mathrm{pmol} / 8 \times 10^{8} \mathrm{RBC}^{10}$. Moreover, these patients had 6-TGN levels higher than $300 \mathrm{pmol} / 8 \times 10^{8} \mathrm{RBC}$ after one week of 6 -MP therapy. This could be a useful predictive factor when starting thiopurine therapy. In this study, 6-MMPR levels above the toxic threshold of $5700 \mathrm{pmol} / 8 \times 10^{8} \mathrm{RBC}$ did not correlate with hepatotoxicity. A prospective study, presented in Chapter 5, comparing 6-TGN levels between IBD patients with exacerbations versus remissions, found that the relation between disease activity and 6-TGN levels seems to be less clear $^{12}$. Although the proposed 6-TGN threshold level of $235 \mathrm{pmol} / 8 \times 10^{8} \mathrm{RBC}$ is confirmed in an adult IBD population in several analyses in our study, it has a low sensitivity $(71 \%)$ and specificity $(73 \%)$, positive and negative predictive values $(67$ and $73 \%)$ and accuracy $(69 \%)$. This is in accordance with earlier 
mentioned studies showing no clear correlation between disease activity and 6TGN levels ${ }^{25-29}$.

Although Chapter 5 describes a poor correlation between 6-TGN levels and disease activity, a significant difference in reaching the therapeutic 6-TGN threshold is found: $59 \%$ of remissions and $37 \%$ exacerbations had sufficient 6-TGN levels above $235 \mathrm{pmol} / 8 \times 10^{8} \mathrm{RBC}$, with an OR of 3.7 for having an exacerbation in case of $6-\mathrm{TGN}$ levels below $235 \mathrm{pmol} / 8 \times 10^{8} \mathrm{RBC}^{12}$. Similar results were found in the earlier mentioned meta-analysis: $62 \%$ of the patients with 6 -TGN levels above $230-260 \mathrm{pmol} / 8 \times 10^{8} \mathrm{RBC}$ were in remission versus $36 \%$ remissions in case of $6-\mathrm{TGN}$ levels lower than $230 \mathrm{pmol} / 8 \times 10^{8} \mathrm{RBC}$ with an OR of 3.3 for having $6-$ TGN levels higher than $230-260 \mathrm{pmol} / 8 \times 10^{8} \mathrm{RBC}$ in case of clinical remission ${ }^{30}$. Chapter 5 is in fact the fifth study, demonstrating a threshold of $230-260 \mathrm{pmol} / 8 \times 10^{8} \mathrm{RBC}$, however with a relatively low sensitivity and specificity. Another important result of this chapter is the high prevalence of non-compliance which is revealed by TDM. Therefore, the conclusion of the chapter is that TDM may be useful in a clinical setting, in case of thiopurine refractory IBD, mostly to reveal non-compliance and secondly to identify underdosing and unfavourable metabolite profiles, although with low sensitivity and specificity. Chapter 3 demonstrates in some individual cases, demonstrating the potential usefulness of TDM in daily practice ${ }^{11}$.

One of the critical remarks on the mentioned meta-analysis should be the exclusion of several studies, including our study mentioned in Chapter 2, although all inclusion criteria are met (data on 6-TGN levels, patients treated with AZA or 6-MP, disease activity measured, published before November 2004 , written in English) ${ }^{10,30}$. Nevertheless, our study would have strengthened the conclusion of this meta-analysis, as would have the results presented in Chapter 5.

Recently, a prospective study on 6-TGN metabolites in AZA treated IBD patients found no difference in reaching clinical remission between patients dosed and followed in a conventional way (AZA dose $2.5 \mathrm{mg} / \mathrm{kg}$ and follow up by blood counts and liver function test) compared to patients with dose adjustments by $\mathrm{TDM}^{31}$. Only, the patient number of this study seems to be too small $(\mathrm{N}=57)$. We calculated in a power analysis that at least 74 patients would be needed tot find a significant difference in 6-TGN metabolite concentrations between exacerbations and remissions, as shown in Chapter $5^{12}$.

Nevertheless, the discussion about the value of TDM in optimising efficacy and safety of thiopurine therapy is not closed yet, with several studies pro and contra TDM. In fact, a prospective study on TDM versus conservative follow up (blood cell counts, liver test and amylase or lipase testing) of thiopurine therapy should be performed. This study should be prospective, randomised, examining efficacy, failures of treatment and toxicity at several time points, with dose adjustments based on TDM. However, such an interventional study 
should include more than 250 patients in both groups to find significant results, based on the known prevalence of leukopenia (2-5\%), hepatotoxicity (10-15\%) and other adverse events. This study would also take years and would probably demand a (multi)national approach.

\section{b) 6-Thioguanine therapy}

For 6-thioguanine (6-TG) therapy no therapeutic threshold levels have been defined yet, although the original pilot-study in only ten patients suggested a threshold therapeutic 6-TGN level of $1400 \mathrm{pmol} / 8 \times 10^{8} \mathrm{RBC}^{32}$. No clear association between 6-TGN levels and disease activity has been found in other reports ${ }^{33,34}$. Strikingly, 6-TGN levels are four to seven-fold higher than with AZA or 6-MP therapy in all reports and leukopenia seems to be related with higher 6-TGN levels as well ${ }^{30,33}$. The results presented in Chapters 7-9 of this thesis are similar ${ }^{16,35,36}$. One explanation might be the fact that no 6-MMPR metabolites are formed in case of 6-TG therapy, as 6-MMPR metabolites may have some myelosuppressive effect as well ${ }^{11,19,20}$. Thus, the myelosuppressive effect of 6-TGN metabolites starts at higher concentrations in case of a lack of 6-MMPR metabolites. Accordingly, Chapter 7 shows no correlation between 6-TGN levels and 6-TG dose or between 6-TGN levels and disease activity ${ }^{16}$. A five-fold range of 6-TGN levels is found. In Chapter 8 a correlation between 6-TG dose and 6-TGN levels is suggested in a short term study of 8 weeks ${ }^{16}$. Mean 6-TGN levels are $937 \mathrm{pmol} / 8 \times 10^{8} \mathrm{RBC}$ in case of $20 \mathrm{mg} 6$-TG daily and $1621 \mathrm{pmol} / 8 \times 10^{8} \mathrm{RBC}$ in case of $40 \mathrm{mg}$ daily. The risk of hepatotoxicity of 6-TG therapy seems to increase when 6-TGN concentrations are higher than 1000 $\mathrm{pmol} / 8 \times 10^{8} \mathrm{RBC}$ : nodular regenerative hyperplasia $(\mathrm{NRH})$ of the liver is demonstrated in reports describing patients with mean 6-TGN levels above this threshold ${ }^{37}$. Chapter 10 suggests that lower 6-TGN levels may decrease the risk of developing NRH during 6-TG therapy ${ }^{38}$. It is the first long term study examining hepatotoxicity during 6-TG treatment. The toxicity of 6-TG is discussed in the last part of this chapter.

\section{Important enzymes in thiopurine therapy}

The most important enzyme in thiopurine metabolism seems to be TPMT. TPMT has a trimodal variation in genetics. Ninety percent of Caucasians have a wildtype $\mathrm{TPMT}^{\mathrm{H} / \mathrm{H}}$ genotype with high activity, $10 \%$ have one mutant allele with decreased activity (TPMT ${ }^{\mathrm{H} / \mathrm{L}}$ ) and $0.3 \%$ of patients have homozygous mutant TPMT ${ }^{\mathrm{L} / \mathrm{L}}$, with no activity. Wildtype TPMT alleles are *1 and *1S, mutant alleles are ${ }^{*} 2,{ }^{*} 3 \mathrm{~A},{ }^{*} 3 \mathrm{~B},{ }^{*} 3 \mathrm{C},{ }^{*} 3 \mathrm{D},{ }^{*} 4,{ }^{*} 5,{ }^{*} 6,{ }^{*} 7,{ }^{*} 8,{ }^{*} 9,{ }^{*} 10,{ }^{*} 11,{ }^{*} 12,{ }^{*} 13,{ }^{*} 14$, ${ }^{*} 15,{ }^{*} 16,{ }^{*} 17,{ }^{*} 18$, responsible for TPMT deficiency ${ }^{39,40}$. TPMT deficiency is correlated with higher 6-TGN concentrations and leukopenia. In the study of 
Chapter 2 the prevalence of $\mathrm{TPMT}^{\mathrm{H} / \mathrm{H}}, \mathrm{TPMT}^{\mathrm{H} / \mathrm{L}}$ and $\mathrm{TPMT}^{\mathrm{L} / \mathrm{L}}$ genotypes was $80 \%, 16 \%$ and $4 \%$ respectively, but patient numbers were relatively small $(25$ patients of 30 included patients were genotyped $)^{10}$. Importantly, patients with one or two mutant TPMT alleles had a twelve times higher risk of developing leukopenia, which stresses the usefulness of TPMT genotyping before starting thiopurine therapy. In fact it was a poor chance to find one patient with homozygous deficient TPMT in this relatively small group of patients. In Chapter 5 TPMT activity measurements in 100 patients show normal to high activity in $98 \%$ and low activity in only $2 \%$ : relatively few patients with deficient TPMT activity were found ${ }^{12}$. The included patients had used a thiopurine for at least three months, thus excluding patients with early toxicity, such as leukopenia, which is theoretically caused by high 6-TGN levels in case of deficient TPMT activity. In fact there was some selection bias in this study, because of possible deletion of TPMT deficient patients. TPMT activity was inversely correlated with 6-TGN levels $(r=-0.318, p=0.01)$ and the two patients with low TPMT activity had high 6-TGN levels and relatively low 6-MMPR levels, as expected.

TPMT genotyping is useful when performed before starting thiopurine therapy ${ }^{41-48}$. Genotyping may help to reveal patients with low or no activity ( $10 \%$ and $0.3 \%$ respectively), which is also shown in Chapters 2 and $3^{10,11}$. In case of low TPMT activity dose reduction should be performed from the start of thiopurine therapy or alternative immunomodulating therapy should be chosen $^{46-50}$. TPMT genotyping or determining TPMT activity in a retrospective way seems not useful, as all patients with early toxicity have already discontinued thiopurine therapy then. This is also shown in Chapter 5: only two patients $(2 \%)$ have low TPMT activity (instead of expected $10 \%$ ), with high 6 -TGN levels as expected, but without any signs of myelotoxicity ${ }^{12}$. However, it should be mentioned that leukopenia is not exclusively caused by mutant TPMT alleles: in only $27 \%$ of leukopenic patients treated with a thiopurine, TPMT deficiency is found, as shown in two studies ${ }^{48,49}$. A relation between extremely high 6-MMPR levels and and leukopenia has been demonstrated in case 5 in Chapter $3^{11}$. No other mechanism is known yet.

Inosine triphosphate pyrophosphohydrolase (ITPase) has recently been discovered as another important enzyme in the thiopurine pathway. Decreased ITPase activity is correlated with flu-like symptoms, rash, leucopenia and pancreatitis due to accumulation of 6-TITP ${ }^{42,51}$. ITPase has no influence on 6-TGN or 6-MMPR levels. In the research performed for this thesis, ITPase was only measured in the study described in Chapter 5 (results not published). In a steady state thiopurine treated cohort of IBD patients no clinical relevance was found for determining the activity of this enzyme. As expected no correlation with 6-TGN or 6-MMPR was found. 
All other enzymes noted in Figure 11.1 are theoretically important, but clinical relevancy is unclear yet and therefore these enzymes were not studied in this thesis. However, XO inhibition by allopurinol leads to severe myelotoxicity. Therefore thiopurine dose should be decreased with $25-33 \%$ when used in combination with allopurinol $^{52}$. In two recent studies from the same group the usefulness of allopurinol in case of non-responders to AZA or 6-MP therapy with unfavourably high 6-MMPR and low 6-TGN levels has been demonstrated $^{24,53}$. After thiopurine dose reduction to $25-50 \%$ of original dose and introduction of $100 \mathrm{mg}$ allopurinol 6-TGN levels increased from 199 to 400 $\mathrm{pmol} / 8 \times 10^{8} \mathrm{RBC}$ and 6-MMPR levels decreased from 10605 to 2001 $\mathrm{pmol} / 8 \times 10^{8} \mathrm{RBC}$, with improving disease scores ${ }^{24}$. Due to an unknown mechanism the unfavourable 6-MMPR/6-TGN ratio is improved by introducing allopurinol in these patients.

In theory, extremely high XO activity may lead to undetectable 6-MMPR and 6-TGN metabolite levels. This can theoretically serve as an alternative explanation for undetectable metabolite levels, such as described in Chapter 4 and 5, instead of non-compliance. Recently a case report has been published demonstrating this theoretical concept ${ }^{54}$. In a thiopurine treated patient zero metabolite levels were measured even when medication was taken under supervision. After introduction of allopurinol high 6-TGN and 6-MMPR levels were measured (1163 and $10015 \mathrm{pmol} / 8 \times 10^{8} \mathrm{RBC}$ respectively, after two weeks of treatment).

\section{Non-compliance and TDM}

Inter-individual differences in metabolism could be a reason for performing TDM. Another reason may be the detection of non-compliance. It is well known that a relatively high prevalence of non-compliance is found in chronic diseases in general, especially in asymptomatic conditions ${ }^{55}$. It has been demonstrated in IBD patients, that non-adherence can exceed $60 \%$ in treatment with sulphasalazine, mesalazine and azathioprine ${ }^{56-62}$. Nevertheless, when an individual IBD patient is presenting with an exacerbation during thiopurine treatment, very often an alternative immuno-modulator is chosen instead of excluding non-compliance or under-dosing. In Chapter 4 a non-compliance rate of $40 \%$ is described in a cohort of steady state azathioprine treated IBD patients in remission, in an outpatient clinic setting ${ }^{63}$. Patient numbers were however small $(\mathrm{N}=15)$. Chapter 5 shows a non-compliance rate of $12 \%$ in exacerbations and $19 \%$ in remissions (16\% overall) in a larger study of 100 AZA or 6-MP treated adult IBD patients ${ }^{12}$. This means that almost one out of eight patients with an exacerbation of IBD during thiopurine therapy is not compliant! Both studies demonstrate one of the main indications for performing 
TDM in thiopurine treated IBD patients: non-compliance appears to be very common and TDM is the only way to reveal this. Non-compliance has only been reported incidentally in earlier reports about TDM, but it is not clear whether patients with zero metabolite levels were in- or excluded for analysis in these reports ${ }^{4-6,25,26}$. Otherwise, one could discuss if very low or even unmeasurable metabolite levels are always caused by non-compliance. In theory, malabsorption due to severe inflammation of the gut, or still unknown abnormalities in enzyme activity (such as very high XO activity, as discussed earlier) could be alternative explanations ${ }^{54}$. However, in these cases TDM seems useful as well as it reveals low metabolite levels.

\section{Interactions and TDM}

As demonstrated in Figure 11.1 many enzymes play a role in thiopurine metabolism. In theory, enzymes can be inhibited or stimulated by several causes such as (metabolites of) drugs. TPMT seems the most important enzyme in thiopurine metabolism because it interferes in several steps of the metabolic pathway. Therefore this enzyme is best studied. In vitro studies have demonstrated that 5 -aminosalicylic acid (5-ASA) compounds (i.e. mesalazine, balsalazide, olsalazine and sulphasalazine) are potent TPMT inhibitors ${ }^{64-66}$. In vivo, 6-TGN concentrations are significantly higher when thiopurines are combined with 5-ASA. Consequently, a higher frequency of leukopenia is observed in patients using this combination ${ }^{64-67}$. The observed higher 6-TGN levels can not solely be explained by TPMT inhibition. Other, yet unknown interaction mechanisms may exist ${ }^{68}$.

In Chapter 6 the third in vivo study on effects of 5-ASA on thiopurine metabolite levels is described ${ }^{69}$. A significant $20 \%$ decrease of 6 -TGN levels from $262 \mathrm{pmol} / 8 \times 10^{8} \mathrm{RBC}(\mathrm{Cl} 95 \% 212-312)$ at baseline to $209 \mathrm{pmol} / 8 \times 10^{8}$ RBC (CI95\% 170-247) has been noted when 5-ASA has been discontinued for four weeks. The effect on clinical outcomes has not been studied yet, neither in this study. Unexpectedly, no significant change of TPMT activity was found during or without the combination of thiopurine therapy and 5-ASA. Nevertheless, this is in accordance with previous studies ${ }^{67,68}$. Possibly the analytical procedure of TPMT activity measurement itself is the explanation herefore: during preparation of the erythrocyte lysates all metabolites are washed out. It is unknown whether 5-ASA metabolites are washed out as well or whether 5-ASA metabolites irreversibly inhibit TPMT. If these metabolites are removed during TPMT analysis this might lead to normalisation of inhibition of TPMT activity. Alternatively, other and even still unknown enzymes of the thiopurine metabolism could be influenced by 5-ASA as well. 
Other frequently prescribed TPMT inhibitors include acetylsalicylic acid, angiotensin I converting enzyme inhibitors and diuretics (eg. furosemide, bendroflumethiazide and trichlorthiazide $)^{70,71}$. These have not been extensively studied and were not examined in this thesis.

Allopurinol potently inhibits $\mathrm{XO}$. When combining, a thiopurine dose-reduction to $25-50 \%$ of standard daily dosages is recommended ${ }^{24,52,53}$. Mycophenolate inhibits IMPD, theoretically reducing the conversion of 6-TIMP to 6-TXMP and consequently $6-\mathrm{TGN}^{72}$. These two enzymes were not studied in this thesis.

\section{New therapeutic options in IBD due to the knowledge of thiopurine metabolism: 6-thioguanine}

Thiopurines are well-known medications, existing for more than four decades. Originally, 6-MP was used in maintenance treatment of acute lymphoblastic leukaemia in children ${ }^{73}$. AZA was one of the first medications applied in immunosuppressive prophylaxis of acute rejection in organ transplantation ${ }^{74}$. Thirty years ago, the indication of thiopurine treatment was extended to other immune disorders and inflammatory bowel diseases. However, until 1990 there was ample debate about efficacy of AZA and 6-MP treatment in IBD patients. Only few centres used this medication then ${ }^{75}$. The interest in thiopurine treatment in IBD began to grow around 1990 after publications about successful treatment of approximately 500 patients with ulcerative colitis by Present and Adler respectively ${ }^{76,77}$. Nowadays, thiopurines are widely used in IBD therapy.

Since 2000 a third thiopurine, 6-thioguanine (6-TG), has become of interest in IBD treatment, due to the increasing knowledge about thiopurine metabolism. It had already been used in therapy of childhood lymphoblastic leukaemia for several decades ${ }^{73,78}$. When studying the metabolism of thiopurines, as illustrated in Figure 11.1, it is understandable why 6-TG is a potential candidate in IBD therapy, especially in case of AZA or 6-MP intolerance. 6-TG is closer to the effective 6-TGN metabolites than AZA or 6-MP. By treating with 6-TG, several enzymatic pathways are excluded, decreasing the amount of many -potentially toxic- metabolites and diminishing the effect of mutant alleles or co-medication on enzyme activity. The first report on short term 6-TG therapy in paediatric IBD patients was very promising ${ }^{32}$. The second report on his subject was the study presented in Chapter 8 , also demonstrating good short term tolerability and safety in $81 \%$ of AZA and/or 6-MP intolerant IBD patients, without any myelo- or hepatotoxicity ${ }^{35}$. This study shows that 6-TG may be considered as a safe alternative in case of intolerancy for other myelomodulators. 
A second, longer term study on tolerability of 6-TG in AZA and/or 6-MP intolerant IBD patients is presented in Chapter $9^{36}$. In this retrospective, multicentre study, 6-TGN metabolite levels, laboratory and disease activity parameters and ultrasonography of the liver are described. Mean 6-TG dose was $24.6 \mathrm{mg}$ daily, which is lower than other studies (at least $40 \mathrm{mg}$ and even up to $80 \mathrm{mg}$ daily $)^{37,79}$. Tolerability was $79 \%$ for one year of 6 -TG treatment in 95 patients. Reasons for discontinuation ( $\mathrm{N}=20)$ were $\mathrm{Gl}$-complaints $(31 \%)$, malaise $(15 \%)$, hepatotoxicity $(15 \%)$, myelodepression $(4 \%)$, pancreatitis $(4 \%)$, allergic reactions $(4 \%)$ and others $(27 \%)$. Haematological events occurred in three patients, one discontinued treatment. In the 6-TG tolerant group 9\% (7/75) had elevated liver tests, but two patients had these on beforehand and one had symptomatic choledocholithiasis. An abdominal ultrasound was performed in $54 \%$ of patients: one patient had splenomegaly, no other signs of portal hypertension were found. Liver histology was not examined. This study shows that the majority of AZA or 6-MP intolerant IBD patients (79\%) is able to tolerate maintenance treatment with 6-TG (dosages between 0.3 to 0.4 $\mathrm{mg} / \mathrm{kg} /$ day). 6-TG may be considered as an escape maintenance immunosuppressant in this group of patients, that is difficult to treat.

One of the limitations of 6-TG is that no adequate dose finding studies have been performed until now. The short term study in Chapter 8 shows that a 6 -TG dose of $20 \mathrm{mg}$ daily is equally effective compared to $40 \mathrm{mg}$ daily ${ }^{35}$. Strikingly, $20 \mathrm{mg} \mathrm{6-TG} \mathrm{gives} \mathrm{rise} \mathrm{to} \mathrm{very} \mathrm{high} 6$-TGN levels of $937 \mathrm{pmol} / 8 \times 10^{8}$ RBC, which is four to seven-fold higher than on AZA $100 \mathrm{mg}$ and 6-MP 50 $\mathrm{mg}^{10,80}$. On $40 \mathrm{mg}$ 6-TG, 6-TGN levels are even higher: $1621 \mathrm{pmol} / 8 \times 10^{8}$ $\mathrm{RBC}^{11}$. Surprisingly, no myelotoxicity has been found despite these high 6-TGN levels. This has already been discussed earlier in this chapter. So far, TDM seems not very useful in case of 6-TG therapy, as no therapeutic or toxic threshold levels have been described yet. Prospective studies on this subject might be lacking in the future, because of the recently reported toxicity of 6-TG. It seems, however, that $6-\mathrm{TGN}$ levels below $800 \mathrm{pmol} / 8 \times 10^{8} \mathrm{RBC}$ are effective and that hepatotoxicity is related with levels higher than $1000 \mathrm{pmol} / 8 \times 10^{8} \mathrm{RBC}$, as described in Chapters 8, 9 and $10^{35,36,38}$.

In recent years, reports have been published about nodular regenerative hyperplasia (NRH) of the liver, veno-occlusive disease and non-cirrhotic portal hypertension during 6-TG therapy in IBD patients. In 2003, ultrasonography guided liver histology showed NRH in up to $16 \%$ of 6 -TG treated IBD patients, even without biochemical signs of hepatotoxicity ${ }^{37}$. Later, a report on a special magnetic resonance imaging (MRI) technique with two contrast agents (gadolinium and ferrocarbutran) showed that some patients with normal liver histology, had signs of $\mathrm{NRH}$ on $\mathrm{MRI}^{79}$. This latter study demonstrated the complementary findings of both diagnostics in the search for NRH. In fact, $\mathrm{NRH}$ 
or veno-occlusive disease in combination with 6-TG is not new, as it has been described in 6-TG treated children with leukaemia ${ }^{81,82}$.

In Chapter 10 the results of the search for hepatotoxicity and mainly NRH are described in an IBD cohort from a general district hospital, using 6-TG for a long term ${ }^{38}$. Thirteen of fourteen patients using 6-TG for at least 24 months volunteered to undergo blood analysis for liver chemistry, ultrasonography guided liver biopsy and MRI. Mean 6-TG therapy duration was 36 months, mean daily 6-TG dose was $18.8 \mathrm{mg}(0.28 \mathrm{mg} / \mathrm{kg})$ and mean 6 -TGN levels were $705 \mathrm{pmol} / 8 \times 10^{8} \mathrm{RBC}$. No signs of hepatotoxicity or portal hypertension were found by biochemical analysis and ultrasonography of the liver and spleen. Liver histology and MRI showed no NRH. This study is the first to describe such long term 6-TG treated IBD patients, examined according to a uniform protocol. 6-TG dose and metabolite levels were lower compared to previous $\mathrm{NRH}$ reports: $6-\mathrm{TG}$ dose of $20 \mathrm{mg}(0.2-0.3 \mathrm{mg} / \mathrm{kg})$ with 6-TGN levels of 705 $\mathrm{pmol} / 8 \times 10^{8} \mathrm{RBC}$ versus $6-\mathrm{TG}$ dose of $40-80 \mathrm{mg}$ and $6-\mathrm{TGN}$ levels of 1230 $\mathrm{pmol} / 8 \times 10^{8} \mathrm{RBC}$ in previous reports ${ }^{37,38,79}$. This suggests a yet unknown metabolite level or dose dependent effect on the development of $\mathrm{NRH}$.

Some remarks should be made about NRH. NRH is found in combination with many diseases and medications, as described in case reports or patient series $^{83-88}$. It has been related to IBD itself and several immunosuppressives, including AZA, 6-MP and corticosteroids ${ }^{89}$. Also, it has been described in $2.5 \%$ of a general population in a post-mortem study ${ }^{90}$. In the study presented in Chapter 10 , only short term AZA or 6-MP treatment has been given before initiation of 6-TG therapy, because of intolerance ${ }^{38}$. The two main reports about $\mathrm{NRH}$ reported longer lasting AZA or 6-MP treatment prior to the switch to 6-TG therapy: median twelve months (range 0.5-96) and median eleven months (range 0.5-60) respectively ${ }^{37,79}$. Hence, the discussion about the effects of long term 6-TG treatment and the influence of other confounding factors like IBD itself or previously/concurrently used medications seems not yet closed therefore. Nevertheless, we believe that 6-TG can still be useful in IBD treatment, but in selected patients, intolerant for other immunosuppressives, at low dose and under close surveillance of metabolite levels and hepatotoxity. Prior to initiation, all patients should be informed extensively about the risks of 6-TG. In future, a larger group of long term 6-TG treated IBD patients should be examined to explore the correlation between 6-TG dose, metabolites and NRH. In addition, it seems necessary to perform liver histology and/or MRI in a large group of long term AZA or 6-MP treated IBD patients to examine whether NRH is found regularly in these patients as well. 


\section{References}

1. Inflammatory bowel disease, from bench tot bedside. Second edition by Stephen $\mathrm{R}$ Targan, Fergus Shanahan, Loren C Karp. Kluwer Academic Publishers, 2003.

2. Nakamura K, Honda K, Mizutani T, Akiho H, Harada N. Novel strategies for the treatment of inflammatory bowel disease: Selective inhibition of cytokines and adhesion molecules. World J Gastroenterol 2006;12:4628-35.

3. Schreiber S, Khaliq-Kareemi M, Lawrance IC, Thomsen OO, Hanauer SB, McColm J, Bloomfield R, Sandborn WJ; PRECISE 2 Study Investigators. Maintenance therapy with certolizumab pegol for Crohn's disease. N Engl J Med 2007;357: 239-50.

4. Cuffari C, Theoret Y, Latour S, Seidman G. 6-Mercaptopurine metabolism in Crohn's disease: correlation with efficacy and toxicity. Gut 1996;39:401-6.

5. Dubinsky MC, Lamothe S, Yang HY, Targan SR, Sinnett D, Théorêt Y, Seidman EG. Pharmacogenomics and metabolite measurement for 6-mercaptopurine therapy in inflammatory bowel disease. Gastroenterology 2000;118:705-13.

6. Cuffari C, Hunt S, Bayless T. Utilisation of erythrocyte 6-thioguanine metabolite levels to optimise azathioprine therapy in patients with inflammatory bowel disease. Gut 2001;48:642-6.

7. Achkar JP, Stevens T, Easley K, Brzezinski A, Seidner D, Lashner B. Indicators of clinical response to treatment with six-mercaptopurine or azathioprine in patients with inflammatory bowel disease. Inflamm Bowel Dis 2004;10:339-45.

8. Hindorf U, Lyrenas E, Nilsson A, Schmiegelow K. Monitoring of long-term thiopurine therapy among adults with inflammatory bowel disease. Scand $\mathrm{J}$ Gastroenterol 2004;39:1105-12.

9. Sandborn WJ. 6-MP metabolite levels: a potential guide to Crohn's disease therapy. Gastroenterology 1997;113:690-2.

10. Derijks LJ, Gilissen LP, Engels LG, Bos LP, Bus PJ, Lohman JJ, Curvers WL, Van Deventer SJ, Hommes DW, Hooymans PM. Pharmacokinetics of 6-mercaptopurine in patients with inflammatory bowel disease: implications for therapy. Ther Drug Monit 2004;26:311-8.

11. Gilissen LP, Derijks LJ, Bos LP, Verhoeven HM, Bus PJ, Hooymans PM and Engels LG. Some cases demonstrating the clinical usefulness of therapeutic drug monitoring in thiopurine treated IBD patients. Eur J Gastroenterol Hepatol 2004,16:705-10.

12. Gilissen LP, Wong DR, Bierau J, Bakker JA, Romberg-Camps M, Stronkhorst A, Bus $P$, Bos LP, Hooymans PM, Stockbrügger RW, Engels LG. Is therapeutic drug monitoring useful in exacerbations of adult IBD patients on thiopurine treatment? submitted.

13. Weinshilboum RM, Sladek SL. Mercaptopurine pharmacogenetics: monogenic inheritance of erythrocyte thiopurine methyltransferase activity. Am J Hum Genet 1980;32:651-62.

14. Krynetski EY, Evans WE. Genetic polymorphism of thiopurine S-methyltransferase: molecular mechanisms and clinical importance. Pharmacology 2000;61:136-46.

15. Lennard L. TPMT in the treatment of Crohn's disease with azathioprine, Gut 2002;51;143-6.

16. Derijks LJ, Gilissen LP, Engels LG, Bos LP, Bus PJ, Lohman, Van Deventer SJ, Hommes DW and Hooymans PM. Pharmacokinetics of 6-thioguanine in patients with inflammatory bowel disease. Ther Drug Monit 2006;28:45-50. 
17. Sandborn WJ, Tremaine WJ, Wolf DC, Targan SR, Sninsky CA, Sutherland LR, Hanauer SB, McDonald JW, Feagan BG, Fedorak RN, Isaacs KL, Pike MG, Mays DC, Lipsky JJ, Gordon S, Kleoudis CS, Murdock RH Jr. Gastroenterology 1999;117:527-35.

18. Tiede I, Fritz G, Strand S, Poppe D, Dvorsky R, Strand D, Lehr HA, Wirtz S, Becker C, Atreya R, Mudter J, Hildner K, Bartsch B, Holtmann M, Blumberg R, Walczak H, Iven H, Galle PR, Ahmadian MR, Neurath MF. CD28-dependent Rac1 activation is the molecular target of azathioprine in primary human CD4+ T lymphocytes. J Clin Invest 2003;111:133-45.

19. Cuffari C, Li DY, Mahoney J, Barnes Y, Bayless TM. Peripheral blood mononuclear cell DNA 6-thioguanine metabolite levels correlate with decreased interferongamma production in patients with Crohn's disease on AZA therapy. Dig Dis Sci 2004;49:133-7.

20. Dervieux T, Blanco JG, Krynetski EY, Vanin EF, Roussel MF, Relling MV. Differing contribution of thiopurine methyltransferase to mercaptopurine versus thioguanine effects in human leukemic cells. Cancer Res 2001;61:5810-6.

21. Gilissen LP, Derijks LJ, Verhoeven HM, Bierau J, Hooymans PM, Hommes DW and Engels LG. Pancytopenia due to high 6-methylmercaptopurine levels in a 6-mercaptopurine treated patient with Crohn's disease. Dig Liver Dis 2007;39: 182-6.

22. Weersma RK, Peters FT, Oostenbrug LE, Van den Berg AP, Van Haastert M, Ploeg RJ, Posthumus MD, Homan van der Heide JJ, Jansen PL, Van Dullemen HM. Increased incidence of azathioprine-induced pancreatitis in Crohn's disease compared with other disease. Aliment Pharmacol Ther 2004;20:843-50.

23. Dubinsky MC, Yang H, Hassard PV, Seidman EG, Kam LY, Abreu MT, Targan SR, Vasiliauskas EA. 6-MP metabolite profiles provide a biochemical explanation for $6-\mathrm{MP}$ resistance in patients with inflammatory bowel disease. Gastroenterology 2002;122:904-15.

24. Sparrow MP, Hande SA, Friedman S, Cao D and Hanauer SB. Effect of allopurinol on clinical ourcomes in inflammatory bowel disease nonresponders tot azathioprine or 6-mercaptopurine. Clin Gastroenterol Hepatol 2007;5:209-14.20.

25. Belaiche J, Desager JP, Horsmans Y, Louis E. Therapeutic drug monitoring of azathioprine and 6-mercaptopurine metabolites in Crohn disease. Scand J Gastroenterol 2001;36:71-6.

26. Lowry PW, Franklin CL, Weaver AL, Pike MG, Mays DC, Tremaine WJ, Lipsky JJ, Sandborn WJ. Measurement of thiopurine methyltransferase activity and azathioprine metabolites in patients with inflammatory bowel disease. Gut 2001;49:665-70.

27. Gupta P, Gokhale R, Kirschner BS. 6-mercaptopurine metabolite levels in children with inflammatory bowel disease. J Pediatr Gastroenterol Nutr 2001;33(4):450-4.

28. Goldenberg BA, Rawsthorne $\mathrm{P}$, Bernstein CN. The utility of 6-thioguanine metabolite levels in managing patients with inflammatory bowel disease. Am J Gastroenterol 2004;99:1744-8.

29. Cohen RD. Forecast for using metabolite measurements in the dosing of azathioprine or 6-mercaptopurine for IBD patients: "partly cloudy". Gastroenterology 2002;122:2082-4; discussion 2084.

30. Osterman MT, Kundu R, Lichtenstein GR and Lewis JD. Association of 6-thioguanine nucleotide levels and inflammatory bowel disease activity: a metaanalysis. Gastroenterology 2006;130:1047-53. 
31. Reinshagen $M$, Schutz Dagger E, Armstrong VW, Behrens $C$, von Tirpitz $C$, Stallmach A, Herfarth H, Stein J, Bias P, Adler G, Shipkova M, Kruis W, Oellerich $\mathrm{M}$, von Ahsen N. 6-Thioguanine nucleotide-adapted azathioprine therapy does not lead to higher remission rates than standard therapy in chronic active crohn disease: results from a randomized, controlled, open trial. Clin Chem 2007 53(7):1306-14.

32. Dubinsky MC, Hassard PV, Seidman EG, Kam LY, Abreu MT, Targan SR, Vasiliauskas EA. An open-label pilot study using thioguanine as a therapeutic alternative in Crohn's disease patients resistant to 6-mercaptopurine therapy. Inflamm Bowel Dis 2001;7:181-9.

33. Herrlinger KR, Fellermann K, Fischer C, Kreisel W, Deibert P, Schoelmerich J, Fleig WE, Ruhl A, Reinshagen M, Greinwald R, Stange EF, Schwab M. Thioguanine-nucleotides do not predict efficacy of tioguanine in Crohn's disease. Aliment Pharmacol Ther 2004;19:1269-76.

34. Bonaz B, Boitard J, Marteau P, Lémann M, Coffin B, Flourié B, Belaiche J, Cadiot G, Metman EH, Cortot A, Colombel JF; Getaid. Tioguanine in patients with Crohn's disease intolerant or resistant to azathioprine/mercaptopurine. Aliment Pharmacol Ther 2003;18:401-8.

35. Derijks LJ, De Jong DJ, Gilissen LP, Engels LG, Hooymans PM, Jansen JB, Mulder CJ. 6-Thioguanine seems promising in azathioprine- or 6-mercaptopurineintolerant inflammatory bowel disease patients: a short-term safety assessment. Eur J Gastroenterol Hepatol 2003;15:63-7.

36. de Boer NKH, Derijks LJJ, Gilissen LPL, Hommes DW, Engels LGJB, de Boer SY, Hommes DW, Engels LG, de-Boer SY, den Hartog G, Hooymans PM, Mäkelburg $A B$, Westerveld BD, Naber AH, Mulder CJ, de Jong DJ. On tolerability and safety of a maintenance treatment with 6-thioguanine in azathioprine or 6-mercaptopurine intolerant IBD patients. World J Gastroenterol 2005;11:5540-4.

37. Dubinsky MC, Vasiliauskas EA, Singh H, Abreu MT, Papadakis KA, Tran T, Martin P, Vierling JM, Geller SA, Targan SR, Poordad FF. 6-Thioguanine can cause serious liver injury in inflammatory bowel disease patients. Gastroenterology 2003;125:298-303.

38. Gilissen LP, Derijks LJ, Driessen A, Bos LP, Hooymans PM, Stockbrügger RW and Engels LG. Toxicity of 6-thioguanine: no hepatotoxicity in a series of IBD patients treated with longterm, low dose 6-thioguanine. Some evidence for dose or metabolite level dependent effects? Dig Liver Dis 2007;39:156-9.

39. Schaeffeler E, Lang T, Zanger UM, Eichelbaum M, Schwab M.. High-throughput genotyping of thiopurine S-methyltransferase by denaturing HPLC. Clin Chem 2001;47:548-55.

40. Schaeffeler E, Fischer C, Brockmeier D, Wernet D, Moerike K, Eichelbaum M, Zanger UM, Schwab M. Comprehensive analysis of thiopurine S-methyltransferase phenotype-genotype correlation in a large population of German-Caucasians and identification of novel TPMT variants. Pharmacogenetics 2004;14:407-17.

41. Black AJ, McLeod HL, Capell HA. Thiopurine methyltransferase genotype predicts therapy-limiting severe toxicity from azathioprine. Annals of Internal Medicine 1998;129:716-8.

42. Zelinkova Z, Derijks LJ, Stokkers PC, Vogels EW, van Kampen AH, Curvers WL, Cohn D, van Deventer SJ, Hommes DW. Inosine triphosphate pyrophosphatase and thiopurine s-methyltransferase genotypes relationship to azathioprine-induced myelosuppression. Clin Gastroenterol Hepatol 2006;4:44-9. 
41. Campbell S, Kingstone K, Ghosh S. Relevance of thiopurine methyltransferase activity in inflammatory bowel disease patients maintained on low-dose azathioprine. Aliment Pharmacol Ther 2002;16:389-98.

43. Regueiro M, Mardini $H$. Determination of thiopurine methyltransferase genotype or phenotype optimizes initial dosing of azathioprine for the treatment of Crohn's disease. J Clin Gastroenterol 2002;35:240-4.

44. Sandborn WJ. Rational dosing of azathioprine and 6-mercaptopurine. Gut 2001;48:591-2.

45. Seidman EG. Clinical use and practical application of TPMT enzyme and 6-mercaptopurine metabolite monitoring in IBD. Rev Gastroenterol Disord 2003;3 Suppl 1:S30-8.

47. Kaskas BA, Louis E, Hindorf U, Schaeffeler E, Deflandre J, Graepler F, Schmiegelow K, Gregor M, Zanger UM, Eichelbaum M, Schwab M. Safe treatment of thiopurine S-methyltransferase deficient Crohn's disease patients with azathioprine. Gut 2003;52:140-2.

48. Colombel JF, Ferrari N, Debuysere H, Marteau P, Gendre JP, Bonaz B, Soulé JC, Modigliani R, Touze Y, Catala P, Libersa C, Broly F. Genotypic analysis of thiopurine S-methyltransferase in patients with Crohn's disease and severe myelosuppression during azathioprine therapy. Gastroenterology 2000;118: 1025-30.

49. Gearry RB, Barclay ML, Burt MJ, Collett JA, Chapman BA, Roberts RL, Kennedy MA. Thiopurine S-methyltransferase (TPMT) genotype does not predict adverse drug reactions to thiopurine drugs in patients with inflammatory bowel disease. Aliment Pharmacol Ther 2003;18:395-400.

50. Duley JA, Simmonds HA, Hopkinson DA, Levinsky RJ. Inosine triphosphate pyrophosphohydrolase deficiency in a kindred with adenosine deaminase deficiency. Clin Chim Acta 1990;188:243-52.

51. Marinaki AM, Ansari A, Duley JA, Arenas M, Sumi S, Lewis CM, Shobowale-Bakre el M, Escuredo E, Fairbanks LD, Sanderson JD. Adverse drug reactions to azathioprine therapy are associated with polymorphism in the gene encoding inosine triphosphate pyrophosphatase (ITPase). Pharmacogenetics 2004;14: 181-7.

52. Kennedy DT, Hayney MS, Lake KD. Azathioprine and allopurinol: the price of an avoidable drug interaction. Ann Pharmacother 1996;30:951-4.

53. Sparrow MP, Hande SA, Friedman S, Lim WC, Reddy SI, Cao D and Hanauer SB. Allopurinol safely and effectively optimizes tioguanine metabolites in inflammatory bowel disease patients not responding to azathioprine and mercaptopurine. Aliment Pharmacol Ther 2005;22:441-6.

54. Wong DR, den Dulk MO, Derijks LJ, Gemmeke EH, Hooymans PM. Nondetectable levels of 6-thioguanine nucleotides and 6-methylmercaptopurine in a patient treated with azathioprine: a case report. Br J Clin Pharmacol 2007;63:508.

55. Miller NH. Compliance with treatment regimens in chronic asymptomatic diseases, Am J Med 1997;102:43-9.

56. Kane SV, Cohen RD, Aikens JE, Hanauer SB. Prevalence of nonadherence with maintenance mesalamine in quiescent ulcerative colitis. Am J Gastroenterol 2001;96:2929-33.

57. Sewitch MJ, Abrahamowicz M, Barkun A, Bitton A, Wild GE, Cohen A, Dobkin PL. Patient nonadherence to medication in inflammatory bowel disease. Am J Gastroenterol 2003;98:1535-44. 
58. Nigro G, Angelini G, Grosso SB, Caula G, Sategna-Guidetti C. Psychiatric predictors of non-compliance in inflammatory bowel disease: psychiatry and compliance. J Clin Gastroenterol 2001;32:66-8.

59. Kane SV, Huo D, Aikens JE, Hanauer SB. Medication nonadherence and the outcome of patients with quiescent ulcerative colitis. Am J Med 2003;114:39-43.

60. Van Hees PA, Van Tongeren JH. Compliance to therapy in patients on a maintenance dose of sulfasalazine. J Clin Gastroenterol 1982;4:333-6.

61. Bokemeyer B, Teml A, Roggel C, Hartmann P, Fischer C, Schaeffeler E, Schwab $\mathrm{M}$. Adherence to thiopurine treatment in out-patients with Crohn's disease. Aliment Pharmacol Ther 2007;26:217-25.

62. Oliva-Hemker MM, Abadom V, Cuffari C, Thompson RE. Nonadherence with thiopurine immunomodulator and mesalamine medications in children with Crohn's disease. J Pediatr Gastroenterol Nutr 2007;44:180-4.

63. Gilissen LP, Derijks LJ, Bos LP, Bus PJ, Hooymans PM and Engels LG. Therapeutic drug monitoring in 15 patients with inflammatory bowel disease and established azathioprine therapy. Clin Drug Invest 2004;24:479-86.

64. Lewis LD, Benin A, Szumlanski CL, Otterness DM, Lennard L, Weinshilboum RM, Nierenberg DW. Olsalazine and 6-mercaptopurine-related bone marrow suppression: a possible drug-drug interaction. Clin Pharmacol Ther 1997;62: 464-75.

65. Lowry PW, Szumlanski CL, Weinshilboum RM, Sandborn WJ. Balsalazide and azathioprine or 6-mercaptopurine: evidence for a potentially serious drug interaction. Gastroenterology 1999;116:1505-6.

66. Szumlanski CL, Weinshilboum RM. Sulphasalazine inhibition of thiopurine methyltransferase: possible mechanism for interaction with 6-mercaptopurine and azathioprine. Br J Clin Pharmacol 1995;39:456-9.

67. Lowry PW, Franklin CL, Weaver AL, Szumlanski CL, Mays DC, Loftus EV, Tremaine WJ, Lipsky JJ, Weinshilboum RM, Sandborn WJ. Leucopenia resulting from a drug interaction between azathioprine or 6-mercaptopurine and mesalamine, sulphasalazine, or balsalazide. Gut 2001;49:656-64.

68. Dewit O, Vanheuverzwyn R, Desager JP, Horsmans Y. Interaction between azathioprine and aminosalicylates: an in vivo study in patients with Crohn's disease. Aliment Pharmacol Ther 2002;16:79-85.

69. Gilissen LP, Bierau J, Derijks LJ, Bos LP, Hooymans PM, Van Gennip A, Stockbrügger RW and Engels LG. The pharmacokinetic effect of discontinuation of mesalazine on mercaptopurine metabolite levels in inflammatory bowel disease patients. Aliment Pharmacol Ther 2005;22:605-11.

70. Woodson LC, Ames MM, Selassie CD, Hansch C, Weinshilboum RM. Thiopurine methyltransferase. Aromatic thiol substrates and inhibition by benzoic acid derivatives. Mol Pharmacol 1983;24:471-8.

71. Lysaa RA, Giverhaug T, Wold HL, Aarbakke J. Inhibition of human thiopurine methyltransferase by furosemide, bendroflumethiazide and trichlormethiazide. Eur J Pharmacol 1996;49:393-6.

72. Sanderson J, Ansari A, Marinaki T, Duley J. Thiopurine methyltransferase: should it be measured before commencing thiopurine drug therapy? Ann Clin Biochem 2004;41:294-302.

73. Lancaster DL, Lennard L, Rowland K, Vora AJ, Lilleyman JS. Thioguanine versus mercaptopurine for therapy of childhood lymphoblastic leukaemia: a comparison of haematological toxicity and drug metabolite concentrations. British Journal of Hematology 1998;102:439-43. 
74. Bergan S, Rugstad HE, Bentdal O, Endresen L, Stokke O. Kinetics of mercaptopurine and thioguanine nucleotides in renal transplant recipients during azathioprine treatment. Ther Drug Monit 1994;16:13-20.

75. Sandborn WJ. A review of immune modifier therapy for inflammatory bowel disease: azathioprine, 6-mercaptopurine, cyclosporine and methotrexate. Am J Gastroenterol 1996;91:423-33.

76. Present DH. Meltzer SJ, Krumholz MP, Wolke A, Korelitz BI. 6-Mercaptopurine in the management of inflammatory bowel disease: short- and long-term toxicity. Ann Intern Med 1989;111:641-9.

77. Adler DJ, Korelitz BI. The therapeutic efficacy of 6-mercaptopurine in refractory ulcerative colitis. Am J Gastroenterol 1990;85:717-22.

78. Steuber CP. Therapy in childhood acute nonlymphocytic leukemia (ANLL). Evolution of current concepts of chemotherapy. Am J Pediatr Hematol Oncol 1981;3:379-88.

79. Seiderer J, Zech CJ, Reinisch W, Lukas M, Diebold J, Wrba F, Teml A, Chalupna P, Stritesky J, Schoenberg SO, Schima W, Göke B, Ochsenkühn T. A multicenter assessment of liver toxicity by MRI and biopsy in IBD patients on 6-thioguanine. J Hepatol 2005;43:303-9.

80. Derijks LJJ, Engels LGJB, Hooymans PM, Lohman JJHM. Pharmacokinetics of 6-mercaptopurine and azathioprine in patients with inflammatory bowel disease. $\mathrm{Br}$ J Clin Pharmacol 2001;51:503P.

81. Key NS, Kelly PM, Emerson PM, Chapman RW, Allan NC, McGee JO. Oesophageal varices associated with busulphan-thioguanine combination therapy for chronic myeloid leukaemia. Lancet 1987;2(8567):1050-2.

82. De Bruyne R, Portmann B, Samyn M, Bansal S, Knisely A, Mieli-Vergani G, Dhawan $A$. Chronic liver disease related to 6-thioguanine in children with acute lymphoblastic leukaemia. J Hepatology 2006;44:407-10.

83. Stromeyer FW and Ishak KG. Nodular transformation (nodular regenerative hyperplasia) of the liver. A clinicopathologic study of 30 cases. Human Pathology 1981;12:60-71.

84. Naber AHJ, Van Haelst $\mathrm{U}$ and Yap SH. Nodular regenerative hyperplasia of the liver: in important cause of portal hypertension in non-cirrhotic patients. J Hepatology 1991;12:94-99.

85. Zarday $Z$ and Veith FJ. Irreversible liver damage after azathioprine. JAMA 1972;222:690-1.

86. Russmann S, Zimmermann A, Krähenbühl S, Kern B and Reichen J. Venoocclusive disease, nodular regenerative hyperplasia and hepatocellular carcinoma after azathioprine treatment in a patient with ulcerative colitis. Eur J Gastroenterol Hepatol 2001;13:287-90.

87. Daniel F, Cadranel JF, Seksik P, Cazier A, Duong Van Huyen JP, Ziol M, Coutarel $\mathrm{P}$, Loison $\mathrm{P}$, Jian $\mathrm{R}$, Marteau $\mathrm{P}$. Azathioprine induced nodular regenerative hyperplasia in IBD patients. Gastroenterol Clin Biol 2005;29:600-3.

88. Katzka DA, Saul SH, Jorkasky D, Sigal H, Reynolds JC, Soloway RD. Azathioprine and hepatic venocclusive disease in renal transplant patients. Gastroenterology 1986;90:446-54.

89. Vernier-Massouille G, Cosnes J, Lemann M, Marteau P, Reinisch W, Laharie D, Cadiot G, Bouhnik Y, De Vos M, Bourreille A, Duclos B, Seksik P, Mary JY, Colombel JF. Nodular regenerative hyperplasia in patients with inflammatory bowel disease treated with azathioprine. Gut 2007 56(10):1404-9. 
90. Wanless IR. Micronodular transformation (nodular regenerative hyperplasia) of the liver: a report of 64 cases among 2500 autopsies and a new classification of benign hepatocellular nodules. Hepatology 1990;11:787-97. 


\section{Chapter 12}

Conclusions and clinical advice 
Chapter 12 
This thesis describes several aspects of therapeutic drug monitoring (TDM) of thiopurine therapy in IBD patients. It shows that the knowledge about thiopurine metabolism gives rise to new concepts such as TDM, genotyping and phenotyping of crucial enzymes and even the rebirth of 6-thioguanine (6-TG), an old thiopurine. Thereby the clinical usefulness of thiopurines has been enlarged. After reading this manuscript one could ask when to perform TDM. Several aspects of TDM will be mentioned shortly, referring to the associated chapters in this manuscript for more detailed information.

1. Thiopurines, such as azathioprine (AZA) and 6-mercaptopurine (6-MP) are metabolised in several steps as described in Figure 12.1.

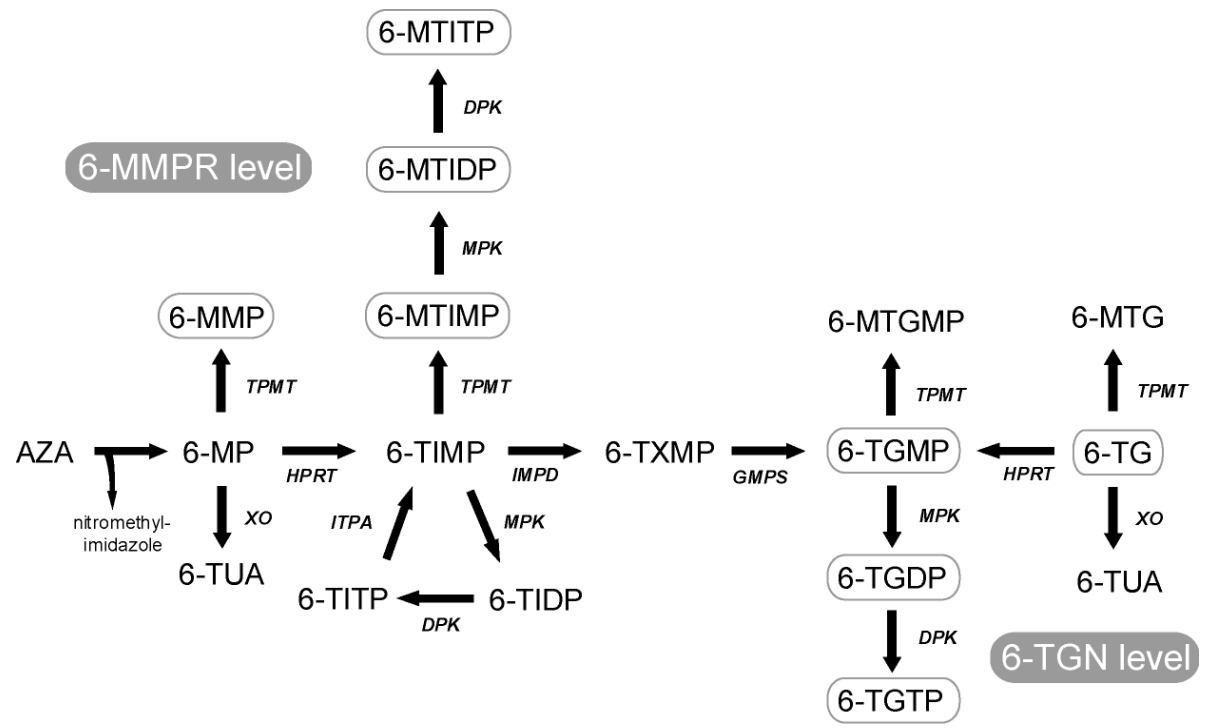

Figure 12.1 Proposed thiopurine metabolism. AZA, azathioprine; 6-MP, 6-mercaptopurine; 6-MMP, 6-methylmercaptopurine; 6-TUA, 6-thiouric acid; 6-MTIMP,

6-methylthioinosine monophosphate; 6-MTIDP, 6-methylthioinosine diphosphate; 6-MTITP, 6-methylthioinosine triphosphate; 6-TIMP, 6-thioinosine monophosphate; 6-TIDP, 6-thioinosine diphosphate; 6-TITP, 6-thioinosine triphosphate; 6-TXMP, 6-thioxanthosine monophosphate; 6-TGMP, 6-thioguanine monophosphate; 6-TGDP, 6-thioguanine diphosphate; 6-TGTP, 6-thioguanine triphosphate; 6-MTGMP, 6-methylthioguanine monophosphate; 6-TG, 6-thioguanine; 6-MTG, 6-methylthioguanine; $\mathrm{XO}$, xanthine oxidase; TPMT, thiopurine S-methyltransferase; HPRT, hypoxanthine phosphoribosyl transferase; IMPD, inosine monophosphate dehydrogenase; GMPS, guanosine monophosphate synthetase; MPK, monophosphate kinase; DPK, diphosphate kinase; ITPA, inosine triphosphate pyrophosphatase.

In therapeutic drug monitoring, the 6-MMPR level consists of the sum of 6-MMP, 6-MTIMP, 6-MTIDP and 6-MTITP levels, while the 6-TGN level consists of the sum of 6-TGMP, 6-TGDP, 6-TGTP (if AZA or 6-MP is administered) and 6-TG levels (if 6-TG is administered as such). 
2. Two groups of metabolites are formed:

- 6-TGN metabolites, which are immunosuppressive. In case of AZA/6-MP therapy, therapeutic 6-TGN levels should be between 235 and $500 \mathrm{pmol} / 8 \times 10^{8} \mathrm{RBC}$.

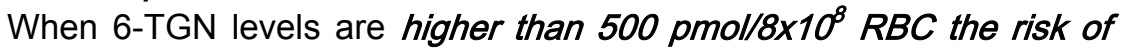
leukopenia or even pancytopenia is increased (Chapter 2).

When 6-TGN levels are higher than 300 pmol/8x10 $R B C$ after one week of therapy, TPMT deficiency is strongly suspected. Hence thiopurine dose should be decreased to prevent myelotoxicity (Chapter 2).

- 6-MMPR metabolites, which are correlated with hepatotoxicity in case

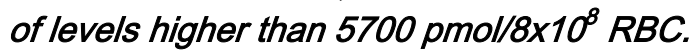

3. Thiopurine metabolites have a half life of five days (Chapter 2). This means that metabolite concentrations will reach a steady state level after 25 days one month. Also, when patients discontinue ingestion of thiopurines, metabolite levels can be measured during 25 days (five times half life). Metabolite levels are very stable therefore, as shown in 6-TG treated patients (Chapter 7). When steady state is reached, blood samples can be taken at any time of the day after ingestion of thiopurines for TDM. When thiopurine dose is adjusted, new TDM is only useful after at least one month.

4. Mean therapeutic 6-TGN metabolite levels are not significantly different between patients with exacerbations and remissions in the study presented in Chapter 5, but this is in contrast with a recent meta-analysis.

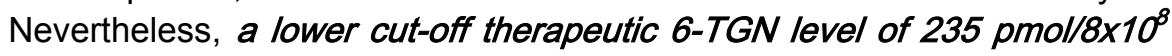
$R B C$ has been identified by several studies (Chapter 5).

5. In cohort studies, thiopurine metabolite levels do not correlate with thiopurine dose. In contrast, intra-individually there is a correlation: when drug dose is increased in an individual patient, 6-TGN and 6-MMPR metabolite levels will increase as well (Chapter 3 ). The genetic polymorphism of the TPMT enzyme seems an important reason for these inter-individual differences.

6. TDM is the only objective method to reveal non-compliance, especially in case of thiopurine refractory disease (Chapter 4 and 5). 
7. TDM may give insight in adverse events, such as the cause of leukopenia or hepatotoxicity (Chapter 2 and 3). Pancreatitis, an adverse event of thiopurine therapy occurring in $1.5-10 \%$ of IBD patients (mostly Crohn's disease), seems to be an idiosyncratic reaction, which means that thiopurine metabolite concentrations and drug dose are not correlated (Chapter 2).

8. TDM may give insight in interactions of medications with thiopurine metabolism (Chapter 6).

9. TPMT genotyping before initiation may predict the chance on leukopenia: in case of at least one mutant allele the relative risk is twelve times higher (Chapter 2).

10. Importantly, TDM does not replace or exclude frequent checking of blood cell counts and liver tests!

The following recommendations can be made based on the results of Chapter 2, 3 and 5 (see also Table 12.1):

TDM in case of azathioprine of 6-mercaptopurine therapy:

When starting AZA or 6-MP therapy:

- after one week: to prevent early toxicity: 6-TGN should not exceed $300 \mathrm{pmol} / 8 \times 10^{8} \mathrm{RBC}$.

- after at least four weeks: to detect suboptimal dosing: 6-TGN lower than $235 \mathrm{pmol} / 8 \times 10^{8} \mathrm{RBC}$.

- late toxicity: $6-T G N$ should not be higher than $500 \mathrm{pmol} / 8 \times 10^{8} \mathrm{RBC}$ (not in this manuscript).

Indications for TDM in established AZA or 6-MP therapy:

- in case of an exacerbation: -to exclude non-compliance -to exclude under-dosing or unfavourable metabolite profiles

- in case of a remission: -to consider dose reduction. 
Table 12.1 Possible utilization of metabolite measurement in IBD patients treated with azathioprine or 6-mercaptopurine.

\begin{tabular}{lcc}
\hline Explanation & $\begin{array}{c}6-\text { TGN level } \\
\left(\mathrm{pmol} / 8 \times 10^{8} \mathrm{RBC}\right)\end{array}$ & $\begin{array}{c}6-\mathrm{MMPR} \text { level } \\
\left(\mathrm{pmol} / 8 \times 10^{8} \mathrm{RBC}\right)\end{array}$ \\
\hline therapeutic target achieved & $235-500$ & $<5700$ \\
non-compliance & $<<235$ & $<<5700$ \\
under-dosing & $<235$ & $<5700$ \\
potential myelotoxicity (absent TPMT activity) & $>>500$ & $<<5700$ \\
possible myelotoxicity (low TPMT activity) & $>500$ & $<5700$ \\
possible myelotoxicity, when measured & $>300$ & \\
after one week of therapy & & $>5700$ \\
possible hepatotoxicity (high TPMT activity) & $<235-500$ & $>>5700$ \\
potential myelotoxicity (very high TPMT activity) & $<<235$ &
\end{tabular}

6-TGN, 6-thioguanine nucleotides; 6-MMPR, 6-methylmercaptopurine ribonucleotides; pmol, picomoles; RBC, red blood cells; TPMT, thiopurine S-methyltransferase.

TDM in case of 6-thioguanine therapy:

- 6-Thioguanine (6-TG) is an effective alternative in case of intolerance for other immunomodulators, but should only be used for this indication (Chapter 7-9). The findings of nodular regenerative hyperplasia of the liver are very important, although a possible metabolite level dependent effect has been shown (Chapter 10). The possible dangers of 6-TG use should be discussed with the patient and strict monitoring of blood counts, liver tests, ultrasonography and regular liver biopsy should be performed as published in a recommended guideline mentioned in Chapter 10.

- In case of 6-TG use, no 6-MMPR levels can be measured as to be expected from thiopurine metabolism. 6-TGN levels reach a steady state level after four weeks of 6-TG treatment, in accordance with AZA or 6-MP therapy. 6-TGN levels can be four to seven times higher than in the case of AZA or 6-MP use. No clear therapeutic or toxic 6-TGN levels have been described yet. It seems however, that 6 -TGN levels below $800 \mathrm{pmol} / 8 \times 10^{8}$ $\mathrm{RBC}$ are effective and that hepatotoxicity is related with levels higher than $1000 \mathrm{pmol} / 8 \times 10^{8} \mathrm{RBC}$, as described in Chapters 8, 9 and 10. 


\section{Limitations of TDM of thiopurine therapy}

- No significant difference between mean 6-TGN levels of patients with active IBD and remission (Chapter 5).

- No clear upper limit defined for 6-TGN levels (not studied in this manuscript).

- $\quad$ No relation between metabolite levels and pancreatitis.

- Leucopenia is not always related to high 6-TGN levels.

- No clear therapeutic and toxic 6-TGN levels defined in case of 6-TG therapy.

- Metabolite level measurements are very labour-intensive and therefore quite expensive (approximately 55 euro's in the Netherlands per set of 6-TGN/6-MMPR levels).

- Still, not many hospitals can measure thiopurine metabolites.

What should you do when considering TDM during thiopurine therapy?

1. Take blood in two lithium heparinised containers of $10 \mathrm{ml}$ (sprayed, no heparinised granules).

2. Send these cooled containers to a nearby (toxicology) laboratory, which can perform thiopurine metabolite measurements, eg. the Laboratory of Toxicology in the Department of Clinical Pharmacy, Maasland Hospital, PO Box $5500,6130 \mathrm{MB}$, Sittard, the Netherlands.

3. In case of questions call the Laboratory of Toxicology in the Department of Clinical Pharmacy in Sittard, the Netherlands, for information, tel.+31-464597391. 
Chapter 13

Summary 
Chapter 13 


\section{Summary}

Chapter 1 starts with a short introduction about inflammatory bowel diseases (IBD). IBD consist of Crohn's disease, ulcerative colitis and indetermined colitis. The cause of these diseases seems multifactorial. IBD are characterised by an overactive, pro-inflammatory immune system in-, or even outside the bowel. One group of immunomodulatory medications used in IBD therapy are thiopurines, such as azathioprine (AZA), 6-mercaptopurine (6-MP) and 6-thioguanine (6-TG).

In the second part of this chapter a review is presented about thiopurine pharmacology, pharmacogenetics, interactions and new strategies for optimization of pharmacotherapy, including therapeutic drug monitoring (TDM) and genotyping of thiopurine S-methyltransferase (TPMT), an important enzyme in thiopurine metabolism. Thiopurines are metabolised to therapeutic 6-thioguanine nucleotides (6-TGN) and hepatotoxic 6-methylmercaptopurine ribonucleotides (6-MMPR), which both can be measured in red blood cells (RBC).

In the third part the outline of this thesis is described: the clinical usefulness of TDM of thiopurine therapy in IBD. Theoretically, measuring metabolite levels of thiopurines could improve individual efficacy and safety of this therapy. The possible clinical usefulness of TDM in thiopurine therapy is demonstrated in several clinical trials.

Chapter 2 describes in detail the method of metabolite measurements and TPMT genotyping in a prospective study in 30 IBD patients, who have started with 6-MP treatment. TDM is performed at $\mathrm{t}=0,1,2,4$ and 8 weeks after starting $50 \mathrm{mg}$ 6-MP daily. Large inter-individual differences in metabolite concentrations were demonstrated. No correlation was found between metabolite levels and 6-MP dose. Steady state 6-TGN and 6-MMPR metabolite levels were found after four weeks, thus the half life of these metabolites is approximately five days. One patient had homozygous mutant TPMT alleles, four patients had heterozygous TPMT mutants. A correlation between TPMT genotype and 6-TGN level was found. One mutation of a TPMT allele increased the risk of leukopenia twelve times. All patients with leukopenia had 6 -TGN levels of at least $300 \mathrm{pmol} / 8 \times 10^{8} \mathrm{RBC}$ after one week of 6-MP therapy. No correlation was found between metabolite levels and hepatotoxicity (one patient) or pancreatitis (three patients). Interestingly, $83 \%$ of the patients with initially active IBD and remission after eight weeks of 6-MP treatment had 6-TGN levels above the proposed therapeutic threshold level of $235 \mathrm{pmol} / 8 \times 10^{8}$ RBC. Inversely, $75 \%$ of the patients without clinical improvement of IBD activity after eight weeks of 6-MP treatment had 6-TGN levels below $235 \mathrm{pmol} / 8 \times 10^{8} \mathrm{RBC}$. This is in accordance with previous 
literature on this subject.

This study clearly indicates the usefulness of TPMT genotyping and especially TDM of thiopurine therapy in this population. TPMT genotyping before start of thiopurine treatment may prevent early myelotoxicity due to thiopurine treatment in a selection of patients. TDM may facilitate the clinician to improve 6-MP efficacy by demonstrating suboptimal dosing and predicting the risk of leukopenia. Based on this study following recommendations can be made: TDM after one week (to prevent early toxicity: 6-TGN should not exceed $300 \mathrm{pmol} / 8 \times 10^{8} \mathrm{RBC}$ ) and after four weeks (to detect suboptimal dosing: $6-\mathrm{TGN}$ are lower than $235 \mathrm{pmol} / 8 \times 10^{8} \mathrm{RBC}$ then).

Five thiopurine treated IBD patients from daily clinical practice are described in Chapter 3. The first case demonstrated non-compliance, as is often seen in chronic patients in general. TDM is the only method to detect this phenomenon. The second case showed that high 6-MMPR levels may give rise to a toxic hepatitis. This patient with wildtype $\mathrm{TPMT}^{\mathrm{H} / \mathrm{H}}$ genotype had a preferential metabolism of 6-MP to 6-MMPR, resulting in a failure to achieve adequate clinical benefit (which is associated with 6-TGN levels), but leading to hepatitis due to high 6-MMPR metabolite concentrations. This case subscribes earlier findings that TDM can reveal a subgroup of patients resistant to 6-MP treatment, in danger of hepatotoxicity when 6-MP dose is increased. Case 2 is also an example of treatment with 6-TG, a product near the end of the metabolic pathway of thiopurines, which can be used as an alternative immunosuppressive therapy in case of AZA or 6-MP intolerance, as described in Chapters 7-9.

In case 3 relatively high 6-TGN and low 6-MMPR levels were measured. Sufficient 6 -TGN levels were reached at $50 \%$ of the initial dose. This patient is an example of an intermediate metaboliser (heterozygous $\mathrm{TPMT}^{\mathrm{L} / \mathrm{H}}$ ). This case also illustrates the inter-individual differences in TPMT activity and corresponds with earlier findings in which clinical response only correlates with 6-TGN levels and not with any other variable such as drug dose.

The fourth case represents the one out of 300 patients with no functional TPMT activity (TPMT ${ }^{\mathrm{L} / \mathrm{L}}$ ), showing extremely high 6-TGN levels within just one week of 6 -MP treatment. This patient had a homozygous variant allele (TPMT * $3 A /{ }^{*} 3 A$ ). Case 5 is extraordinarily interesting, presenting reversible pancytopenia due to extremely high 6-MMPR levels. This is the first case showing this phenomenon and points out the relation between myelotoxicity and other 6-MP metabolites than just 6-TGN alone.

This chapter illustrates in a descriptive way some clinical situations, in which it is worthwhile to employ TDM during initiation of thiopurine treatment. TDM improves efficacy of treatment and diminishes risks of serious complications such as myelodepression and hepatitis. TDM can also be used to reveal bad 
compliance or undertreatment in steady state treated patients and might help clinicians to overcome their fear for overdosing. TPMT-genotyping before starting thiopurine treatment may be complementary to TDM. TPMT genotype predicts the chance of early neutropenia, while TDM can be used to adjust 6-TGN and 6-MMPR levels.

Chapter 4 describes a prospective pharmacokinetic study in IBD patients with steady state AZA treatment. The original intention of this study was to examine the metabolite levels in a small cohort of AZA treated IBD patients, after previous publications about the 6-TGN metabolite threshold. TDM was performed at $\mathrm{t}=0,1,4$ and 8 weeks in fifteen IBD patients with established AZA therapy. Primary outcomes were 6-TGN and 6-MMPR metabolite levels, secondary were the correlation between metabolite levels, drug dose, disease activity and laboratory parameters and compliance. Eleven patients completed the eight week study interval (one intolerant and three non-compliant patients dropped out). Mean baseline 6-TGN levels were relatively low: $158 \mathrm{pmol} / 8 \times 10^{8}$ $\mathrm{RBC}$ and increased during the study interval, but not significantly. Overall, noncompliance was found in six of fifteen cases (40\%), TDM revealed noncompliance in four of these six patients, two patients did not show up for blood withdrawal. This result is in accordance with literature on non-compliance in other chronic diseases, such as diabetes mellitus.

In Chapter 5 a prospective study is reported about a relevant clinical question: is TDM useful in case of an exacerbation of IBD during thiopurine therapy? In daily practice a switch to different therapy, for example to a biological immunomodulator (infliximab, adalimumab or certolizumab), is considered in this situation. In case of an exacerbation the question should be however, whether the patient has been compliant and whether the thiopurine dose was adequate in the individual patient.

This study was performed to examine the possible difference of thiopurine metabolite levels between exacerbations versus remissions and to redefine a therapeutic threshold 6-TGN level in adult IBD patients. Forty-one adult IBD patients with an exacerbation of IBD were compared with 59 patients with IBD in remission during thiopurine therapy (AZA or 6-MP). Thiopurine metabolite levels and TPMT phenotype were measured. Disease activity was scored by CAI (UC) and CDAI (CD). Primary outcomes were 6-TGN and 6-MMPR metabolite levels, secondary were TPMT activity, laboratory parameters and correlations between metabolite levels, disease activity and laboratory parameters.

At first, a high prevalence of non-compliance was found. Zero 6-TGN levels were measured in $12 \%$ of the patients with an exacerbation versus zero or very 
low levels in $19 \%$ of the patients in remission (16\% in all included patients). It is well known that non-compliance is seen in up to $60 \%$ of treatment of chronic diseases in general. Nevertheless, this is often underestimated in daily clinical practice, especially in IBD patients. The only way to exclude non-compliance as the cause of an exacerbation is by measuring metabolite levels. This seems one of the most important arguments to perform TDM in case of thiopurine refractory disease, presenting in daily clinical practice.

Secondly, no significant differences in 6-TGN or 6-MMPR metabolite levels were found between patients with exacerbations and remissions. Beside, no correlation between thiopurine dose (in $\mathrm{mg}$ or $\mathrm{mg}$ per kilograms bodyweight) and metabolite levels was found.

Calculations for three different situations were made: in all included patients $(\mathrm{N}=100)$, in all exacerbations versus compliant patients in remission $(\mathrm{N}=89)$, and in all compliant patients $(\mathrm{N}=84)$. In all calculations a cut-off therapeutic 6-TGN level was found between $235-250 \mathrm{pmol} / 8 \times 10^{8} \mathrm{RBC}$. Optimal values of sensitivity, specificity and positive predictive value were found in the subanalysis without non-compliant remittent patients $(71,73$ and $67 \%$, AUC 0.70 respectively), but were relatively low. Only in this sub-group 6-TGN levels showed a difference between exacerbations and remissions (237 versus 320 $\mathrm{pmol} / 8 \times 10^{8} \mathrm{RBC}, \mathrm{p}=0.0007$ ) and a correlation was found between 6 -TGN and disease activity ( $r=-0.24, C 195 \%-0.42--0.029)$. The OR for having an exacerbation in case of 6-TGN levels below the proposed threshold of $235 \mathrm{pmol} / 8 \times 10^{8} \mathrm{RBC}$ was 4.7 (CI95\% 1.9-11.5).

In the first analysis (all included patients), active disease was found in $52 \%$ of patients below, versus 30\% above this threshold (OR 2.5, Cl95\% 1.11-5.75, $p=0.04$ ), although no significant difference in mean 6-TGN levels was found.

At last, a quartile analysis, as originally described by Dubinsky, showed a very similar cut-off 6 -TGN level between $233-236 \mathrm{pmol} / 8 \times 10^{8} \mathrm{RBC}$ and significantly more remissions above this threshold.

This is the fifth study demonstrating a threshold 6-TGN within the interval of 230-260 pmol/8 $8 \times 10^{8} \mathrm{RBC}$, with significant differences in the prevalence of remission above and below this cut-off, confirming its value, but also with a relatively low sensitivity and specificity. In conclusion, TDM may be useful in a clinical setting, in case of thiopurine refractory IBD, mostly to reveal noncompliance and secondly to find underdosing or unfavourable metabolite profiles, however, with low sensitivity, specificity and predictive values.

Chapter 6 demonstrates the effect of mesalamine use on thiopurine metabolite levels in IBD patients. In vitro studies had indicated a potentiating effect of mesalamines on 6-TGN levels by inhibition of TPMT activity. In this pharmacokinetic study in 17 patients, TDM was performed during a steady 6 -MP therapy in combination with a steady mesalamine dose $(\mathrm{t}=0)$, as well as 
four weeks after mesalamine discontinuation ( $t=4$ weeks) and four weeks after reintroduction ( $\mathrm{t}=8$ weeks). A significant decrease of 6-TGN levels was measured after four weeks of discontinuation compared to baseline (from 262 to $209 \mathrm{pmol} / 8 \times 10^{8} \mathrm{RBC}$ ), significantly increasing to $270 \mathrm{pmol} / 8 \times 10^{8} \mathrm{RBC}$ after reintroduction. In contrary to in vitro experiments, in vivo TPMT activity did not change significantly during the study. Maybe the method of measurement of TPMT activity plays a role in this contrasting result. The mechanism of the measured synergistic effect of mesalamine on 6-TGN levels remains unclear therefore.

In 2001 6-Thioguanine (6-TG) was introduced as an alternative for AZA or 6MP intolerant IBD patients. By using 6-TG, the effective 6-TGN metabolites are formed more directly, without the formation of several potentially toxic metabolites. Chapter 7 describes a short term prospective pharmacokinetic study in 6-TG treated IBD patients. TDM was performed at $\mathrm{t}=0,1,2,4$ and 8 weeks in $28 \mathrm{AZA} / 6 \mathrm{MP}$ intolerant IBD patients. Eight week and 24 hour 6-TGN curves were measured. High steady state 6-TGN levels (mean $856 \mathrm{pmol} / 8 \times 10^{8}$ RBC, C195\% 715-997) were found, when compared to AZA or 6-MP treatment, with a large, five-fold inter-patient variability. No correlation with drug dose was found. 6-TGN levels reached steady state after four weeks, suggesting a half life of five days. Twenty-four hour curves in steady state patients showed constant levels, as expected with this half life of 6-TGN metabolites. No correlation between 6-TGN levels and myelo- or hepatotoxicity, or pancreatitis was found (one patient had temporarily elevated lipase values without symptoms). Sixteen patients had active disease at baseline: five out of eleven CD patients (45\%) and three out of five UC $(60 \%)$ achieved remission. However, no correlation between disease activity and 6-TGN levels was found.

In Chapter 8 an open, prospective, multicentre, short term safety study on 6-TG treatment in AZA or 6-MP intolerant IBD patients is presented. The occurrence of adverse events, 6-TGN metabolite levels and laboratory parameters were obtained in 32 AZA/6MP intolerant IBD patients at baseline, 1, 2, 4 and 8 weeks after initiation of 6-TG therapy. Primary outcomes were 6-TG tolerance and adverse events, secondary outcomes were 6-TGN levels and laboratory parameters. 6-TG was tolerated in 26 patients $(81 \%)$ during the first eight weeks. In two patients side effects were probable (gastro-intestinal symptoms) and in one patient obvious (fever and erythema nodosum). No clinically relevant myelo- or hepatotoxicity occurred. Steady state 6-TGN levels were $1621 \mathrm{pmol} / 8 \times 10^{8} \mathrm{RBC}$ on $40 \mathrm{mg}$ daily and $937 \mathrm{pmol} / 8 \times 10^{8} \mathrm{RBC}$ on $20 \mathrm{mg}$, showing a significant difference. In conclusion, 6-TG safety seems promising in AZA/6-MP intolerant IBD patients in this short term study. A relatively low 6-TG dose was used in contrary to previously reported studies, and measured 
6-TGN levels were lower as well. Efficacy of 6-TG was not examined in this study.

Chapter 9 describes the tolerability and safety of 6-TG in 95 IBD patients, intolerant for AZA or 6-MP, during at least one year of 6-TG treatment. In this retrospective, multicentre study primary outcomes were tolerance and safety of 6-TG, secondary were clinical and laboratory parameters, metabolite levels and ultrasonography of the liver. Mean 6-TG dose was $24.6 \mathrm{mg}(0.34 \mathrm{mg} / \mathrm{kg} / \mathrm{day})$, which is lower than other studies. Twenty out of $95(21 \%)$ patients discontinued 6-TG within one year. Altogether they had 26 adverse events, such as gastrointestinal complaints $(31 \%)$, malaise $(15 \%)$, hepatotoxicity $(15 \%)$, myelodepression $(4 \%)$, pancreatitis $(4 \%)$, allergic reactions $(4 \%)$ and others $(27 \%)$. Haematological events occurred in three patients, one discontinued treatment. In the 6-TG tolerant group 9\% (7/75) were classified as having hepatotoxicity, but two patients had mildly disturbed liver tests before initiation of 6-TG and one had symptomatic choledocholithiasis. An abdominal ultrasound was performed in $54 \%$ of patients: one patient had splenomegaly, no other signs of portal hypertension were found. No liver histology was examined in this study.

This study shows that the majority of AZA or 6-MP intolerant IBD patients $(79 \%)$ is able to tolerate maintenance treatment with 6-TG. 6-TG may (still) be considered as an escape maintenance immunosuppressant in this difficult group of patients.

In 2003, some reports showed nodular regenerative hyperplasia (NRH) in liver biopsies in up to $16 \%$ of 6 -TG treated IBD patients, even without biochemical signs of hepatotoxicity. Later, a report on a special magnetic resonance imaging (MRI) technique showed that some patients with normal liver histology, had signs of $\mathrm{NRH}$ on their MRI, demonstrating the complementary findings of both methods in the search for NRH. In Chapter 10 the results of liver histology and MRI in long term 6-TG treated IBD patients are presented.

All IBD patients of the Sittard IBD cohort, using 6-TG for at least 24 months, were asked to undergo a liver biopsy and MRI with two intravenous contrast agents (gadolinium and ferrocarbutran). Thirteen of fourteen patients participated. Mean 6-TG therapy duration was 36 months, mean daily 6-TG dose was $18.8 \mathrm{mg}(0.28 \mathrm{mg} / \mathrm{kg})$ and mean $6-\mathrm{TGN}$ levels were $705 \mathrm{pmol} / 8 \times 10^{8}$ RBC. No signs of hepatotoxicity or portal hypertension were found by biochemical analysis and ultrasonography of the liver and spleen. Liver histology and MRI showed no NRH.

This study is the first to describe a long term follow-up of 6-TG treated IBD patients. 6-TG dose and 6-TGN levels were lower compared with previous $\mathrm{NRH}$ reports, suggesting dose or metabolite level-dependent effects (6-TG 
dose of $20 \mathrm{mg}$ or $0.28 \mathrm{mg} / \mathrm{kg}$ versus $40-80 \mathrm{mg}$ and 6-TGN levels of 705 $\mathrm{pmol} / 8 \times 10^{8} \mathrm{RBC}$ versus $1230 \mathrm{pmol} / 8 \times 10^{8} \mathrm{RBC}$, respectively).

No NRH has been found in our IBD patients with longterm, low dosed 6-TG with low 6-TGN metabolite levels. Hence, 6-TG still seems useful, in selected patients intolerant for other immunosuppressives, when it is low dosed and close surveillance is kept of metabolite levels and hepatotoxity. Also, patients should be informed extensively about the risks of 6-TG prior to initiation. 
Chapter 14

Samenvatting 
Chapter 14 


\section{Samenvatting}

Hoofdstuk 1 begint met een korte introductie over inflammatoire darmziekten (IBD). Onder IBD worden de ziekte van Crohn (CD), colitis ulcerosa (UC) en indetermined colitis verstaan. De oorzaak van deze ziekten lijkt multifactorieel te zijn. IBD kenmerken zich door een overactief, pro-inflammatoir immuunsysteem in en buiten de darm. Er worden verschillende immuunmodulerende medicijnen gebruikt in de behandeling van IBD, zoals bijvoorbeeld de thiopurines, bestaande uit azathioprine (AZA), 6-mercaptopurine (6-MP) en 6-thioguanine (6-TG).

In het tweede gedeelte van dit hoofdstuk wordt een overzicht gegeven over de farmacologie, farmacogenetica en interacties van thiopurines en nieuwe strategieën voor optimalisatie van de behandeling met thiopurines bij IBD patiënten, zoals het meten van metaboliet concentraties, ook wel therapeutic drug monitoring (TDM) genaamd en genotypering van thiopurine S-methyltransferase (TPMT), een belangrijk enzym in het metabolisme van thiopurines. Thiopurines worden gemetaboliseerd tot twee groepen metabolieten: therapeutische 6-thioguanine nucleotiden (6-TGN) en hepatotoxische 6-methylmercaptopurine ribonucleotiden (6-MMPR), welke allebei gemeten kunnen worden in rode bloedcellen (RBC).

In het derde deel van dit hoofdstuk wordt de opzet van dit proefschrift beschreven: patiëntgebonden onderzoek naar de klinische bruikbaarheid van TDM in de behandeling van IBD met thiopurines.

Hoofdstuk 2 beschrijt in detail de bepaling van metabolieten van thiopurines en TPMT genotypering middels een prospectieve studie bij 30 IBD patiënten, tijdens start van de behandeling met 6-MP. TDM werd uitgevoerd op $t=0,1,2$, 4 en 8 weken na de start van $50 \mathrm{mg} \mathrm{6-MP} \mathrm{per} \mathrm{dag.} \mathrm{Grote} \mathrm{inter-individuele}$ verschillen in concentraties van thiopurine metabolieten werden gevonden. $\mathrm{Er}$ was geen correlatie tussen 6-MP dosis en metaboliet spiegels. Stabiele concentraties van 6-TGN en 6-MMPR werden gevonden na vier weken, waaruit een halfwaardetijd van ongeveer vijf dagen kan worden berekend. Eén patiënt was homozygoot voor mutante TPMT allelen, vier hadden één mutant allel. Er werd een correlatie tussen TPMT genotype en 6-TGN spiegel gevonden. Eén mutant TPMT allel verhoogde het risico op leukopenie twaalf keer. Alle patiënten met een leukopenie hadden een week na het starten van 6-MP 6-TGN spiegels van minimaal $300 \mathrm{pmol} / 8 \times 10^{8} \mathrm{RBC}$. Er werd geen correlatie gevonden tussen metaboliet concentraties en hepatotoxiciteit (een patiënt) en pancreatitis (drie patiënten). Opvallend was het feit dat $83 \%$ van de patiënten met vooraf actieve IBD en remissie na acht weken behandeling, een 6-TGN spiegel had boven de in de literatuur voorgestelde therapeutische drempel van $235 \mathrm{pmol} / 8 \times 10^{8} \mathrm{RBC}$. Omgekeerd, had $75 \%$ van de patiënten 
zonder klinische verbetering van de ziekte-activiteit na acht weken behandeling met 6-MP 6-TGN spiegels onder deze drempel. Deze resultaten komen overeen met eerdere publicaties.

Deze studie toont duidelijk het klinische nut van TPMT genotypering en vooral TDM van de behandeling met 6-MP. TPMT genotypering voor de start van 6-MP kan vroege myelodepressie voorkomen door het aantonen van mutante TPMT allelen. TDM kan de clinicus helpen om de effectiviteit van 6-MP te verbeteren door onderdosering aan te tonen en het risico op leukopenie te voorspellen. Gebaseerd op deze studie kan het volgende advies gegeven worden: TDM na één week behandeling (om vroege myelotoxiciteit te voorkomen: 6 -TGN moeten lager dan $300 \mathrm{pmol} / 8 \times 10^{8} \mathrm{RBC}$ zijn) en na vier weken (om suboptimale dosering op te sporen: 6-TGN zouden dan hoger moeten zijn dan $235 \mathrm{pmol} / 8 \times 10^{8} \mathrm{RBC}$ ).

In Hoofdstuk 3 worden vijf IBD patiënten uit de dagelijkse praktijk beschreven, die worden behandeld met een thiopurine. In de eerste casus wordt door TDM non-compliance onthuld. Non-compliance komt veel voor bij chronische ziekten in het algemeen en TDM is de enige methode om dit objectief aan te tonen. De tweede casus laat zien dat hoge 6-MMPR concentraties aanleiding kunnen geven tot toxische hepatitis. Deze patiënt met een wildtype $\mathrm{TPMT}^{\mathrm{H} / \mathrm{H}}$ genotype had een preferentieel metabolisme van 6-MP naar 6-MMPR, leidend tot onvoldoende effectiviteit van de behandeling door te lage 6-TGN concentraties, maar wel tot hepatitis door hoge 6-MMPR concentraties. Deze casus bevestigt eerdere bevindingen dat TDM een subgroep van patiënten kan onderscheiden, die weerstandig is aan de behandeling met 6-MP, met een verhoogd risico op hepatotoxiciteit als de dosis 6-MP wordt verhoogd. De tweede casus is daarnaast een voorbeeld van de behandeling met 6-TG, een medicament dat zich dichter bij de effectieve metabolieten in het thiopurine metabolisme bevindt. Het kan worden gebruikt als een alternatief immuunsuppressivum in geval van intolerantie voor AZA of 6-MP, zoals ook beschreven wordt in Hoofdstuk 7-9.

In Casus 3 werden relatief hoge 6-TGN en lage 6-MMPR concentraties gemeten. Sufficiënte $6-$ TGN spiegels werden bereikt met $50 \%$ van de initiële dosis. Deze patiënt is een voorbeeld van een intermediaire metaboliseerder (heterozygoot $\mathrm{TPMT}^{\mathrm{L} / \mathrm{H}}$ ). Deze casus illustreert ook de inter-individuele verschillen in TPMT activiteit, corresponderend met de eerder gerapporteerde bevindingen dat de klinische respons op de behandeling met een thiopurine alleen correleert met 6-TGN concentraties en niet met de thiopurine dosis.

De vierde casus is een voorbeeld van de één op 300 patiënten zonder functioneel TPMT (TPMT ${ }^{\mathrm{L} / \mathrm{L}}$ ), met extreem hoge 6-TGN spiegels binnen een week na start van de behandeling met 6-MP. Deze patiënt heeft een homozygoot variant TPMT *3A/*3A. 
Casus 5 is buitengewoon interessant, omdat het een reversibele pancytopenie door extreem hoge 6-MMPR concentraties toont. Dit is de eerste casus die dit fenomeen beschrijft. Het demonstreert dat niet alleen 6-TGN metabolieten myelotoxiciteit kunnen veroorzaken tijdens behandeling met een thiopurine.

Dit hoofdstuk beschrijft enkele alledaagse klinische situaties tijdens de beginfase van de behandeling met een thiopurine, waarin het nuttig is om TDM toe te passen. TDM verbetert de effectiviteit van de behandeling en vermindert de kans op ernstige complicaties, zoals myelodepressie en hepatitis. TDM kan daarnaast ook gebruikt worden om non-compliance of onderdosering aan te tonen in patiënten met een onderhoudsbehandeling en kan theoretisch clinici helpen om hun angst voor overdosering te overwinnen. TPMT-genotypering voor de start van de behandeling met een thiopurine kan een complementaire rol vervullen naast TDM. Het TPMT genotype voorspelt de kans op een vroege neutropenie, terwijl TDM toegepast kan worden om de 6-TGN en 6-MMPR concentraties te beïnvloeden.

Hoofdstuk 4 beschrijft een prospectieve, farmacokinetische studie bij IBD patiënten met een onderhoudsbehandeling met AZA. De oorspronkelijke bedoeling van deze studie was om de metaboliet concentraties van AZA te bestuderen van een kleine groep IBD patiënten, naar aanleiding van recente publicaties over de therapeutische drempel van de 6-TGN spiegel. TDM werd uitgevoerd op $\mathrm{t}=0,1,4$ en 8 weken bij vijftien IBD patiënten met $A Z A$ onderhoudsbehandeling. De primaire uitkomstmaten waren de 6-TGN en 6-MMPR spiegels, secundaire waren de correlatie tussen metaboliet concentraties, AZA dosis, ziekte-activiteit en laboratorium parameters en compliantie. Elf patiënten vervolledigden de acht weken durende onderzoeksperiode (één intolerante en drie niet-compliante patiënten vielen uit). De gemiddelde baseline 6-TGN concentratie was relatief laag: 158 $\mathrm{pmol} / 8 \times 10^{8} \mathrm{RBC}$ en steeg gedurende het studie-interval, maar niet significant. In totaal werd non-compliance aangetoond in zes van de vijftien patiënten (40\%), TDM onthulde er hiervan vier en twee patiënten kwamen niet opdagen voor afspraken om bloed te laten prikken. Dit resultaat komt overeen met de literatuur over non-compliance in andere chronische ziekten, zoals diabetes mellitus.

In Hoofdstuk 5 wordt een prospectieve studie gepresenteerd over een relevante klinische vraag: is TDM bruikbaar in geval van een exacerbatie van IBD tijdens de behandeling met een thiopurine? In de dagelijkse praktijk wordt in dit geval omschakeling naar een ander medicament overwogen, zoals bijvoorbeeld een 'biological' (infliximab, adalimumab of certolizumab). Eigenlijk zou de eerste vraag in geval van een exacerbatie echter moeten zijn of de 
patiënt wel compliant is geweest en of de thiopurine dosis wel correct was voor deze individuele patiënt.

Er werd een studie opgezet om te bestuderen of er een verschil was tussen hoogte van de metaboliet concentraties bij patiënten met een exacerbatie versus remissie en om een nieuwe drempelwaarde voor de therapeutische 6-TGN spiegel te formuleren voor volwassen IBD patiënten.

Eenenveertig IBD patiënten met een exacerbatie werden vergeleken met 59 patiënten in remissie tijdens de behandeling met een thiopurine (AZA of 6-MP). Thiopurine metaboliet concentraties en TPMT activiteit werden gemeten. De ziekte-activiteit werd gemeten met een CAI (UC) en CDAI (CD). Primaire uitkomstmaten waren 6-TGN en 6-MMPR metaboliet spiegels, secundaire waren TPMT activiteit, laboratorium parameters en correlaties tussen metaboliet spiegels, ziekte-activiteit en laboratorium parameters.

Ten eerste werd een hoge prevalentie van non-compliance gevonden: bij $16 \%$ van alle geïncludeerde patiënten. Bij $12 \%$ van de patiënten met een exacerbatie werden 6-TGN spiegels van nul gemeten. Bij $19 \%$ van de patiënten in remissie werden 6-TGN spiegels van nul of zeer lage spiegels gevonden. Het is bekend dat bij tot wel $60 \%$ van de behandeling van chronische ziekten in het algemeen non-compliance voorkomt. Niettemin wordt non-compliance toch nog altijd onderschat in de dagelijkse praktijk, met name bij IBD patiënten. De enige manier om het aan te tonen als oorzaak van een exacerbatie is door metaboliet concentraties te meten. Een van de belangrijkste redenen om TDM uit te voeren in de dagelijkse praktijk lijkt derhalve in geval van een thiopurine refractaire IBD.

Ten tweede werden er geen significante verschillen gevonden in 6-TGN of 6-MMPR spiegels tussen patiënten met een exacerbatie en remissie. Daarnaast werd geen correlatie gevonden tussen thiopurine dosis (in $\mathrm{mg}$ of $\mathrm{mg}$ per kilogram lichaamsgewicht) en metaboliet spiegels.

Er werden berekeningen voor drie afzonderlijke klinische situaties uitgevoerd: voor alle geïncludeerde patiënten $(\mathrm{N}=100)$, voor alle exacerbaties versus compliante patiënten in remissie $(\mathrm{N}=89)$ en voor alle compliante patiënten $(\mathrm{N}=84)$. In alle situaties werd een therapeutische 6-TGN drempelwaarde van

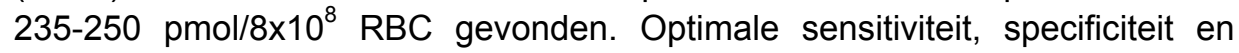
positief predictieve waarde voor exacerbatie werden gevonden in de groep zonder niet-compliante patiënten met een remissie: 71, 73 en 67\% (AUC 0.70), maar waren relatief laag. Alleen in deze subgroep bleken de 6-TGN spiegels significant verschillend tussen exacerbaties en remissies (237 versus 320 $\mathrm{pmol} / 8 \times 10^{8} \mathrm{RBC}, \mathrm{p}=0.0007$ ) en was er een correlatie tussen $6-\mathrm{TGN}$ en ziekteactiviteit ( $r=-0.24$, Cl95\% -0.42- -0.029). De OR om in geval van een exacerbatie een 6-TGN spiegel onder de drempel van $235 \mathrm{pmol} / 8 \times 10^{8} \mathrm{RBC}$ te hebben was 4.7 (CI95\% 1.9-11.5). 
In de eerste analyse (alle geïncludeerde patiënten) werd actieve ziekte gevonden bij $52 \%$ van de patiënten met een 6-TGN spiegel onder, versus $30 \%$ boven de drempelwaarde (OR 2.5, Cl95\% 1.11-5.75, $\mathrm{p}=0.04$ ), hoewel er geen significant verschil werd aangetoond in 6-TGN concentraties.

Ten laatste toonde een quartiel analyse, zoals oorspronkelijk beschreven door Dubinsky, om de 6-TGN drempelwaarde van $235 \mathrm{pmol} / 8 \times 10^{8} \mathrm{RBC}$ te berekenen, een sterk overeenkomende therapeutische 6-TGN drempelwaarde van 233-236 pmol/8 $\times 10^{8} \mathrm{RBC}$, met significant meer remissies boven deze drempel.

Dit is de vijfde studie die een therapeutische 6-TGN drempelwaarde binnen het interval van $230-260 \mathrm{pmol} / 8 \times 10^{8} \mathrm{RBC}$ toont, met significante verschillen in remissies onder en boven deze drempel, wat de waarde van deze drempel lijkt te bevestigen, maar met een relatief lage sensitiviteit en specificiteit.

Concluderend kan worden gesteld dat TDM nuttig is in de dagelijkse praktijk, in geval van een exacerbatie, om vooral non-compliance aan te tonen en ten tweede om onderdosering of ongunstige metabolietprofielen te vinden, maar met een lage sensitiviteit, specificiteit en predictieve waarden.

Hoofdstuk 6 demonstreert het effect van mesalazine op de concentraties van thiopurine metabolieten bij IBD patiënten. In vitro onderzoeken toonden al een potentiërend effect van mesalazines op 6-TGN concentraties door remming van de TPMT activiteit. In de huidige farmacokinetische studie, die uitgevoerd werd bij 17 patiënten, werden 6-TGN en 6-MMPR gemeten tijdens een stabiele onderhoudsbehandeling met $6-\mathrm{MP}$ in combinatie met een stabiele dosis mesalazine $(t=0)$, vier weken na het stoppen van mesalazine $(t=4 \mathrm{w})$ en vier weken na herstart hiervan $(t=8 \mathrm{w})$. Er werd een significante afname van de 6-TGN spiegels gemeten vier weken na stoppen van mesalazine, vergeleken met $\mathrm{t}=0$ (van 262 tot $209 \mathrm{pmol} / 8 \times 10^{8} \mathrm{RBC}$ ), significant toenemend na herstart hiervan tot $270 \mathrm{pmol} / 8 \times 10^{8} \mathrm{RBC}$. In tegenstelling tot eerdere in vitro onderzoeken veranderde de TPMT activiteit niet tijdens de studie. Mogelijk speelt de meetmethode van TPMT hierin een rol. Het mechanisme achter het synergistisch effect van mesalazine op 6-TGN concentratie blijft nog steeds onduidelijk.

In 2001 werd 6-thioguanine (6-TG) geïntroduceerd als alternatief immuunsuppressivum voor AZA of 6-MP intolerante IBD patiënten. Door 6-TG te gebruiken worden de effectieve 6-TGN metabolieten directer gevormd, zonder dat er verschillende potentieel toxische metabolieten ontstaan. In Hoofdstuk 7 wordt een kortdurende prospectieve, farmacokinetische studie beschreven bij IBD patiënten die met 6-TG werden behandeld. TDM werd uitgevoerd op $\mathrm{t}=0,1,2$, 4 en 8 weken bij $28 \mathrm{AZA} / 6-\mathrm{MP}$ intolerante IBD patiënten. Er werden 6-TGN curves getekend voor de acht weekse periode, 
maar ook enkele 24-uurs curves. Er werden hoge steady state 6-TGN spiegels (gemiddeld 856 pmol/8×10 8 RBC, CI95\% 715-997) gevonden, vergeleken met metingen bij eerdere onderzoeken met AZA of 6-MP, met daarnaast een grote, vijfvoudige inter-individuele spreiding. Er werd geen correlatie tussen 6-TG dosis en 6-TGN spiegels gevonden. 6-TGN concentraties bereikten een steady state na vier weken, hetgeen een farmacokinetische halfwaardetijd van vijf dagen suggereert. Vierentwintig uur-curves in steady state toonden constante 6-TGN spiegels, zoals verwacht bij de beschreven halfwaardetijd. Er werd geen correlatie gevonden tussen 6-TGN spiegels en myelo- of hepatotoxiciteit, of pancreatitis (één patiënt had tijdelijk asymptomatisch verhoogde lipasewaarden). Zestien patiënten hadden actieve ziekte bij start van de studie; vijf van de elf Crohn-patiënten (45\%) en drie van de vijf colitis ulcerosa patiënten $(60 \%)$ waren in remissie na acht weken. Toch werd er geen correlatie gevonden tussen 6-TGN concentraties en ziekte-activiteit.

In Hoofdstuk 8 wordt een open, prospectieve, multicenter, korte termijnsstudie beschreven naar de veiligheid van de behandeling met 6-TG bij AZA of 6-MP intolerante IBD patiënten. Het voorkomen van bijwerkingen, laboratoriumparameters en 6-TGN concentraties werden geregistreerd bij 32 IBD patiënten bij start $(t=0)$ en na 1, 2, 4 en 8 weken behandeling met 6 -TG. Primaire uitkomstmaten waren tolerantie voor 6-TG en bijwerkingen, secundaire waren 6-TGN spiegels en laboratoriumparameters. 6-TG werd goed verdragen door 26 patiënten $(81 \%)$ gedurende het studie-interval van acht weken. Bij twee patiënten werden bijwerkingen als waarschijnlijk (gastro-intestinale symptomen) en bij één als duidelijk (koorts en erythema nodosum) geclassificeerd. Er werd geen relevante myelo- of hepatotoxiciteit vastgesteld. Steady state 6-TGN concentraties waren significant verschillend voor de behandeling met $40 \mathrm{mg}$ en $20 \mathrm{mg}$ 6-TG: $1621 \mathrm{pmol} / 8 \times 10^{8} \mathrm{RBC}$ en $937 \mathrm{pmol} / 8 \times 10^{8} \mathrm{RBC}$ respectievelijk. Concluderend lijkt de veiligheid van $6-\mathrm{TG}$ veelbelovend op de korte termijn bij IBD patiënten die intolerant zijn voor AZA of 6-MP. Een relatief lage dosis 6-TG werd gebruikt vergeleken met eerdere studies en de gevonden 6-TGN concentraties waren ook lager. De effectiviteit van 6-TG werd niet onderzocht in deze studie.

Hoofdstuk 9 beschrijft de tolerantie en veiligheid van 6-TG bij 95 IBD patiënten, intolerant voor AZA of 6-MP, gedurende minimaal één jaar behandeling met 6-TG. In deze retrospectieve, multicenter studie waren de primaire uitkomstmaten tolerantie en veiligheid van 6-TG, secundaire waren klinische en laboratorium parameters, metaboliet concentraties en echografie van de lever. De gemiddelde 6-TG dosis was $24.6 \mathrm{mg}(0.31 \mathrm{mg} / \mathrm{kg}$ lichaamsgewicht), wat lager is dan in andere studies. Twintig van de 95 patiënten (21\%) staakten de behandeling met 6-TG binnen een jaar. Zij hadden samen 26 bijwerkingen of 
laboratoriumafwijkingen, waarvan gastro-intestinale bezwaren (31\%), malaise $(15 \%)$, hepatotoxiciteit $(15 \%)$, myelodepressie $(4 \%$, naast deze ene patiënt waren er nog twee andere patiënten die de behandeling niet hoefden te staken), pancreatitis (4\%), allergische reacties $(4 \%)$ en andere oorzaken (27\%). Van de 75 6-TG tolerante patiënten hadden zeven patiënten tekenen van hepatotoxiciteit, waarvan er twee al mild gestoorde levertesten hadden voor start van 6-TG en één bewezen choledocholithiasis had. Abdominale echografie werd verricht bij $54 \%$ van de patiënten: één patiënt had splenomegalie, geen andere tekenen van portale hypertensie werden gevonden. Lever histologie werd niet onderzocht in deze studie.

Deze studie toont dat het grootste deel van de AZA of 6-MP intolerante IBD patiënten $(79 \%)$ een onderhoudsbehandeling gedurende minimaal één jaar met 6-TG (dosis $0.3-0.4 \mathrm{mg} / \mathrm{kg} / \mathrm{dag}$ ) goed verdraagt. 6-TG kan daarom (nog altijd) overwogen worden als alternatief immunosuppressivum in deze moeilijk te behandelen IBD patiënten.

In 2003 beschreven enkele publicaties het voorkomen van nodulaire regeneratieve hyperplasie (NRH) van de lever bij in totaal $16 \%$ van de met 6-TG behandelde IBD patiënten, gediagnosticeerd door een leverbiopt. Niet bij alle patiënten waren er biochemische aanwijzingen voor hepatotoxiciteit. Later verscheen er een rapport over een speciale magnetische resonantie imaging (MRI) techniek, waarbij patiënten met normale lever histologie toch aanwijzingen voor $\mathrm{NRH}$ hadden bij MRI. Dit demonstreerde de complementariteit van beide onderzoeksmethoden in de zoektocht naar NRH. In hoofdstuk 10 worden de resultaten van lever histologie en MRI bij IBD patiënten die langdurig met 6-TG werden behandeld beschreven. Alle IBD patiënten uit het Sittardse IBD cohort, die minimaal 24 maanden met 6-TG werden behandeld, werden gevraagd om een leverbiopt en MRI met twee contrastmiddelen (gadolinium en ferrocarbutran) te ondergaan. Dertien van de veertien patiënten namen deel aan het onderzoek. De gemiddelde duur van de behandeling met 6-TG was 36 maanden, de gemiddelde dagelijkse dosis was $18.8 \mathrm{mg}(0.28 \mathrm{mg} / \mathrm{kg})$ en de gemiddelde 6-TGN spiegels waren $705 \mathrm{pmol} / 8 \times 10^{8} \mathrm{RBC}$. Er waren geen tekenen van hepatotoxiciteit of portale hypertensie bij biochemische analyse en echografie van de lever en milt. Lever histologie en MRI toonden geen argumenten voor $\mathrm{NRH}$.

Dit is de eerste studie die IBD patiënten, behandeld met 6-TG, gedurende een lange termijn heeft gevolgd. De 6-TG dosis en 6-TGN concentraties waren lager vergeleken met eerdere publicaties over $\mathrm{NRH}$, wat een mogelijk dosis- of metabolietconcentratie-afhankelijk effect suggereert (6-TG dosis $20 \mathrm{mg}$ of $0.28 \mathrm{mg} / \mathrm{kg}$ versus $40-80 \mathrm{mg}$ en $6-\mathrm{TGN}$ spiegels van $705 \mathrm{pmol} / 8 \times 10^{8} \mathrm{RBC}$ versus $1230 \mathrm{pmol} / 8 \times 10^{8} \mathrm{RBC}$, respectievelijk). 
Er werd dus geen NRH gevonden bij patiënten, die langdurig een lage dosis 6-TG kregen en waarbij lage 6-TGN spiegels werden gemeten. Daarom lijkt 6-TG toch nog bruikbaar in een geselecteerde groep IBD patiënten die intolerant is voor andere immuunsuppressiva, wanneer 6-TG laag gedoseerd wordt en de metaboliet spiegels en hepatotoxiciteit regelmatig gecontroleerd worden. Daarnaast dienen patiënten vanzelfsprekend goed geïnformeerd te worden over de risico's van 6-TG vóór start van de behandeling hiermee. 
Curriculum vitae 


\section{Curriculum vitae}

Lennard Gilissen werd geboren op 10 mei 1975 in Weert. Na het behalen van het VWO-examen op de Philips van Horne Scholengemeenschap te Weert in 1993, begon hij aan de Katholieke Universiteit te Leuven, België met de opleiding tot Arts. Op 28 juni 2000 behaalde hij het artsenexamen met onderscheiding. Vanaf oktober 2000 startte hij als arts-assistent in opleiding tot internist op de afdeling Interne Geneeskunde en Gastroenterologie van het Maaslandziekenhuis te Sittard, met als opleiders dr. B.J. Looij en prof. dr. H.F.P. Hillen. Tijdens deze opleiding kwam zijn voorliefde voor Gastroenterologie, die al tijdens co-schappen in Roeselare en Leuven was ontstaan, weer bovendrijven. Hij participeerde vanaf medio 2001 op initiatief van dr. L.G.J.B. Engels in een onderzoek naar bloedspiegels van afbraakprodukten van thiopurines bij patiënten met inflammatoire darmziekten, in samenwerking met de afdeling Klinische Farmacie in het Maaslandziekenhuis. Dit onderzoek vormde uiteindelijk de basis voor dit proefschrift.

Vanaf februari 2004 werd de opleiding Interne Geneeskunde voortgezet in het Academisch Ziekenhuis Maastricht (azM), met als opleider prof. dr. K.M.L. Leunissen. $\mathrm{Na} 4$ jaar vooropleiding Interne Geneeskunde begon hij op 1 oktober 2004 met de opleiding Maag-, darm- en leverziekten (MDL) in het azM, met als opleiders prof. dr. R.W. Stockbrügger en later prof. dr. A.A.M. Masclee. Op 1 oktober 2007 volgde zijn registratie als MDL-arts en sindsdien is hij werkzaam in het Catharina ziekenhuis te Eindhoven. Hij is in 2004 getrouwd met Edith Rietra en is vader van Eline (juli 2005) en Luc (september 2007). 
List of publications 


\section{List of publications}

1. Hoet $\mathrm{PH}$, Gilissen $L P$, Leyva $\mathrm{M}$, Nemery B. In vitro cytotoxicity of textile paint components linked to the 'Ardystil syndrome'. Toxicological Sciences 1999;52(2):209-16.

2. Hoet $\mathrm{PH}$, Gilissen $L P$, Nemery B. Polyanions protect against the in vitro pulmonary toxicity of polycationic paint components associated with the 'Ardystil syndrome'. Toxicology and Applied Pharmacology 2001;175(2):184-90.

3. Derijks LJJ, De Jong DJ, Gilissen LPL, Engels LGJB, Hooymans PM, Jansen JBMJ, Mulder CJJ. 6-Thioguanine seems promising in azathioprine- or 6-mercaptopurine-intolerant inflammatory bowel disease patients: a short-term safety assessment. Eur J Gastroenterol Hep 2003;15(1):63-7.

4. Derijks LJJ, Gilissen LPL, Engels LGJB, Bos LP, Bus PJ, Lohman JHM, Curvers WL, Van Deventer SJH, Hommes DW and Hooymans PM. Pharmacokinetics of 6-mercaptopurine in patients with inflammatory bowel disease. Implications for therapy. Ther Drug Monit 2004;26(3):311-8.

5. Gilissen LPL, Derijks LJJ, Bos LP, Verhoeven HMJM, Bus PJ, Hooymans $P M$, Engels LGJB. Some cases demonstrating the clinical usefulness of therapeutic drug monitoring in thiopurine treated IBD patients. Eur $\mathrm{J}$ Gastroenterol Hepatol 2004;16(7):705-10.

6. Gilissen LPL, Kamps CA and Erdkamp FLG. A 51-year old man with upper abdominal pain. Neth J Medicine 2004;62(3):88 and 97.

7. Gilissen LPL, Derijks LJJ, Bos LP, Bus PJ, Hooymans PM and Engels LGJB. Therapeutic drug monitoring inpatients with inflammatory bowel disease and established azathioprine therapy. Clin Drug Invest 2004;24(8):479-86.

8. Gilissen LPL, Bierau J, Derijks LJJ, Bos LP, Hooymans PM, Van Gennip A, RW Stockbrügger, LP Bos and LGJB Engels. The pharmacokinetic effect of discontinuation of mesalazine on mercaptopurine metabolite levels in inflammatory bowel disease patients. Aliment Pharmacol Ther 2005;22:605-11. 
9. De Boer NKH, Derijks LJJ, Gilissen LPL, Hommes DW, Engels LGJB, De Boer SY, Den Hartog G, Hooymans PM, Mäkelburg ABU, Westerveld BD, Naber AHJ, De Jong DJ, Mulder CJJ. On tolerability and safety of a maintenance treatment with 6-thioguanine in azathioprine or 6-mercaptopurine intolerant IBD patients. World J Gastroenterol 2005;11(35):5540-4.

10. Derijks LJJ, Gilissen LPL, Engels LGJB, Bos LP, Bus PJ, Lohman JHM, Van Deventer SJH, Hommes DW and Hooymans PM. Pharmacokinetics of 6-thioguanine in patients with inflammatory bowel disease. Ther Drug Monit 2006;28(1):45-50.

11. Derijks LJ, Gilissen LP, De Boer NK, Mulder CJ. 6-Thioguanine-related hepatotoxicity in patients with inflammatory bowel disease: dose or level dependent? J Hepatol 2006;44(4):821-2.

12. Derijks LJJ, Gilissen LPL, Hooymans PM, Hommes DW. Review article: thiopurines in inflammatory bowel disease. Aliment Pharm Ther 2006;24:715-29.

13. Gilissen LP, Derijks LJ, Driessen A, Bos LP, Hooymans PM, Stockbrügger RW and Engels LG. Toxicity of 6-thioguanine: no hepatotoxicity in a series of IBD patients treated with longterm, low dose 6-thioguanine. Some evidence for dose or metabolite level dependent effects? Dig Liver Dis 2007;39(2):156-9.

14. Gilissen LP, Derijks LJ, Verhoeven HM, Bierau J, Hooymans PM, Hommes DW and Engels LG. Pancytopenia due to high 6-methylmercaptopurine levels in a 6-mercaptopurine treated patient with Crohn's disease. Dig Liver Dis 2007;39(2):182-6. 
Dankwoord 


\section{Dankwoord}

Het is klaar! Een gevoel van opluchting, tevredenheid en onwerkelijkheid vult mijn lichaam. Als ik vooraf had geweten hoeveel uren vrije tijd in dit proefschrift zouden gaan zitten, was ik er misschien niet aan begonnen. Maar de basis van dit onderzoek was altijd plezier. Plezier in het onderzoeken van een nieuw concept, om onze patiënten beter te kunnen behandelen. Plezier in het schrijven van protocollen en van artikelen over de resultaten. En na een tiental publicaties kom je tot de conclusie dat het met een mooi kaftje eromheen wel eens een promotie zou kunnen opleveren. Het klinkt eenvoudig, maar grotendeels is het wel zo gegaan...

Toch werd mijn gevoel de laatste jaren heen en weer geslingerd tussen enerzijds nieuwsgierigheid en interesse om onderzoek te doen en anderzijds onrust, omdat er wel interessante resultaten waren, maar onvoldoende tijd om ze te beschrijven. Dit onderzoek vond namelijk parallel aan mijn opleiding tot MDL-arts plaats, dus naast alle dagelijkse werkzaamheden, onderwijsmomenten en referaten. Met name in het begin van de opleiding was er daarom weinig tijd en energie over om in de vrije avonduren nog gegevens te verwerken of een artikel te schrijven.

Maar nu dit boekje er ligt, kijk ik natuurlijk met veel voldoening terug op de afgelopen jaren. Ik ben trots dat het me gelukt is om naast mijn specialisatie een perifeer onderzoek om te buigen naar een promotie-onderzoek.

Dit was natuurlijk onmogelijk geweest als er niet de juiste mensen op het juiste tijdstip mijn pad kruisten en als mijn vertrouwde omgeving mij niet zo warm ondersteund had. Ik doe een poging om iedereen die betrokken is geweest te bedanken. Mijn excuses als ik iemands bijdrage over het hoofd gezien heb.

De belangrijkste persoon die ik wil bedanken is natuurlijk dr. L. Engels. Leopold, ik noem je wel eens gekscherend mijn 'tweede vader', maar als ik bedenk hoe jij me in de wondere wereld van de gastro-enterologie hebt ingewijd en welke deuren er door jouw toedoen voor mij zijn opengegaan, kan ik geen andere benaming bedenken. Je hebt me bij mijn nekvel gegrepen toen ik direct na mijn arts-examen in Leuven, nog Vlaams pratend en groen achter de oren, bij jullie in Sittard in opleiding kwam. Een eerste opzet voor een onderzoek lag al klaar en je zocht iemand die een paar jaar zou blijven, terwijl ik hard bezig was om als 'broekie' te overleven op jullie afdeling. Slechts enkele maanden later stond ik al de eerste resultaten op de Voorjaarsvergadering te presenteren en dat smaakte naar meer! Nu ben ik, na Luc Derijks de tweede telg uit het Maasland, die op dit onderwerp gaat promoveren. En ik ben denk ik niet de laatste!

Daarnaast heb ik van jou de kneepjes van het MDL-vak geleerd. Op de afdeling leerde ik het klinisch redeneren en communiceren met patiënten. 
Daarnaast heb je bij mij IBD als zwakke plek veranderd in een zwak hebben voor IBD. Mijn eerste endoscopische ervaringen deed ik op onder jouw vleugels. Je had steeds een haast grenzeloos vertrouwen in me. Je hebt me dan ook al snel bij prof. dr. Stockbrügger aanbevolen om in opleiding tot MDLarts te komen. Mijn dank hiervoor is groot!

Naast deze serieuze zaken, heb ik ook verschillende bourgondische herinneringen aan je. Ik denk even aan de multipele Notfälle bei dem Franz in St. Christoph, aan het IBD congres in Leuven, voorafgegaan door een stevig aantal Stella's en een flesje St. Joseph van een uitgelezen jaartal dat ik me niet meer kan herinneren, aan het cultureel uitstapje naar de Ständige Vertretung in Oost-Berlijn. Overal waar je komt weet je wel een gezellig cafeetje, goed restaurant of jazz-club te vinden, ongelofelijk! Ik heb bewondering voor jouw bourgondische levensstij!!

De leukste ervaring bewaar ik echter tot het laatst: we hebben samen regelmatig in een Oostenrijkse lounge muziek gemaakt, waarbij het vaak leek alsof we al jaren samenspeelden: jij op de vleugel (met de zonnebril van Rens) en ik op de sax, terwijl we nog nooit een noot geoefend hadden. Of alle hotelgasten onze interpretaties van Autumn leaves, Blue bossa, My funny Valentine en Tequila (met Bert-Jan op zijn knieën met de vier-snarige gitaar!) even veel gewaardeerd hebben als wijzelf weet ik niet, maar het waren onvergetelijke momenten. Een ding hoop ik wel nog: dat je een keer Al/ blues met mijn jazz-combo meespeelt, als we weer eens in de buurt optreden!

Prof. dr. R. Stockbrügger, beste Reinhold. Ik werd vanaf het begin met open armen ontvangen op je afdeling. Ook na jouw emeritaat zijn onze contacten steeds hartelijk, maar ook productief gebleven. Ik heb enorme bewondering voor je wetenschappelijk inzicht, je gedrevenheid en je snelheid bij het corrigeren van manuscripten. Je bent een Europeaan pur sang, daar kunnen veel Nederlanders nog een voorbeeld aan nemen. Hoewel het onderwerp van mijn onderzoek aanvankelijk misschien niet in jouw domein thuis hoorde, hebben jouw interesse, enthousiasme en neutrale visie een belangrijke rol gespeeld in het totstandkomen van een wetenschappelijk verantwoorde thesis.

Dr. P. Hooymans, beste Piet. Wat een unieke samenwerking tussen de kliniek en farmacie heb jij samen met Leopold opgezet! Twee verschillende werelden binnen een huis zijn weer samengesmolten tot één; daar kunnen veel ziekenhuizen nog wat van opsteken. Ik heb je leren kennen als een zeer correcte en deskundige man. Je plaatst je zelden op de voorgrond, maar bent wel degelijk onmisbaar geweest door het faciliteren van dit onderzoek. Daarnaast speel je verdienstelijk sambabal (of niet Luc?)! 
Dr. L. Derijks, beste Luc. Wie had nou bij onze eerste ontmoeting in 2000 gedacht, dat we allebei zouden gaan promoveren? Jouw gedrevenheid en schrijf-tempo waren nauwelijks bij te benen, daar ben ik in de begin-fase vaak jaloers op geweest. Door jouw drive raakten ook andere ziekenhuizen geïnteresseerd in ons onderwerp, wat weer nieuwe onderzoeken genereerde. Maar veel belangrijker nog vind ik de persoonlijke vriendschap die we hebben overgehouden aan onze vruchtbare samenwerking. Ons wederzijds paranimfschap onderstreept dit nog eens. Ik hoop dat we samen met Judith en Edith nog veel gezellige avonden mogen beleven.

Dr. E. Keulen, beste Eric. Het is al even geleden, maar onze opleidingstijd in Sittard blijft in mijn herinnering als het gezelligste deel van mijn specialisatie. We kunnen zowel privé als op de werkvloer altijd prima met elkaar overweg. Ik hoop dat onze contacten als "concurrenten" in de regio Eindhoven goed blijven. Ik ben blij dat je een van mijn paranimfen wilt zijn!

Geachte leden van de beoordelingscommissie, prof. dr. R.P. Koopmans, prof. dr. J.M.J.P. van der Linden, prof. dr. A.A.M. Masclee, dr. M.G.V.M. Russel en prof. dr. S. Vermeire. Ik wil u danken voor de kritische beoordeling van mijn manuscript.

Prof. dr. C. Mulder. Chris, na mijn presentatie tijdens de Voorjaarsvergadering in $2001 \mathrm{kwam}$ jij met het idee om onderzoek naar 6-thioguanine te doen bij IBD patiënten. Zoals ik inmiddels van je gewend ben, werd het onderzoek in een razend tempo opgezet. Je hebt een enorm enthousiasme, ongekende energie en 1001 ideeën. Ik heb grote waardering voor je inzet voor de MDL-wereld in Nederland en daarbuiten. Bedankt, dat je in de commissie zitting hebt willen nemen.

Dr. N. de Boer. Nanne, ongelofelijk wat je in een paar jaar hebt gepresteerd! Zo help je mee bij een IBD onderzoek tijdens het afstuderen in Maastricht en zo ben je zelf al gepromoveerd in Amsterdam! Je hebt in een heel korte tijd een groot aantal artikelen gepubliceerd. Het was voor mij een enorme stimulans om zelf ook te blijven schrijven. Onze boekjes bijten elkaar uiteindelijk niet en zijn een bewijs van de veelzijdigheid van ons onderwerp. Ik ben blij dat ik met je heb mogen samenwerken. Veel succes bij je opleiding tot MDL-arts.

Dr. R. Bos. Rens, jij hebt natuurlijk naast Leopold en alle andere Sittardse internisten een belangrijke rol gespeeld in mijn opleiding in het Maasland ziekenhuis. Daarnaast ben je een van de hofleveranciers geweest van patiënten voor ons onderzoek, waarvoor hartelijke dank! 
Drs. P. Bus. Paul, bedankt voor je betrokkenheid bij het onderzoek en je enthousiasme. Ik hoop dat je ook in de toekomst patiënten blijft includeren in onze onderzoeken.

Dr. J. Bierau, drs. J. Bakker en dr. A. van Gennip (†). Beste Jörgen en Jaap, thiopurinofielen in het azM. Toevalligerwijze bleek dat we dezelfde voorliefde en interesse in thiopurines hebben. Bedankt voor jullie bijdrage aan de laatste twee onderzoeken. Ik hoop dat de samenwerking op dezelfde wijze voortgezet wordt.

Drs. D. Wong. Dennis, ik wil je bedanken voor je inzet, die het laatste onderzoek heeft doen slagen. Ik kan me voorstellen dat het niet gemakkelijk moet zijn geweest om in de voetsporen te treden van Luc, maar inmiddels heb je je draai volledig gevonden in de materie. Nog een paar originele onderzoeken en dan komt jouw promotie er ook aan. Succes!!

Dr. A. Voogd. Beste Adri, ik ben je veel dank verschuldigd voor de statistische ondersteuning van Hoofdstuk 5 ! Je nam steeds de tijd om mij, als statistisch onbenul, rustig uitleg te geven en om de zoveelste berekening te maken.

Dr. De Jong. Beste Dirk, jij hebt op het juiste moment de juiste input vanuit Arnhem/Nijmegen in ons onderzoek gegeven. Inmiddels ben je zelf gepromoveerd en een van de IBD-specialisten in Nederland. Bedankt voor onze samenwerking.

Alle laboranten die bij het onderzoek betrokken zijn geweest. Ik wil met name de laboranten van het Toxicologisch Laboratorium in het Maaslandziekenhuis Sittard bedanken: Jean Cilissen, Jean-Pierre Bollen, Miet Fiddelaers, Milevis Reitsma - Emanuel en Marielle Maas, maar ook Esther Vogels van het laboratorium Gastro-enterologie (o.l.v. prof. SJ van Deventer) in het AMC en Marc Breuer van het laboratorium voor Erfelijke Metabole Ziekten in het azM, Maastricht. Jullie hebben allemaal je uiterste best gedaan om betrouwbare resultaten te presenteren, waarvoor mijn dank.

Alle patiënten die hebben meegedaan aan het onderzoek. Zonder jullie bereidwilligheid was dit proefschrift nooit tot stand gekomen. Ik heb vooral diep respect voor de mensen die een leverbiopt hebben ondergaan!

Prof. dr. D. Hommes en prof. dr. S. van Deventer, beste Daan en Sander. We hebben dan wel niet direct samen zaken gedaan, maar via Luc, die als spin in het web tussen de verschillende centra fungeerde, heb ik toch de gelegenheid gekregen om met zulke gerenommeerde IBD-specialisten als jullie te mogen 
publiceren. Daarnaast wil ik jullie bedanken voor de inzet van het laboratorium in het AMC.

Ik wil alle MDL-artsen en internisten van het Rijnstate ziekenhuis in Arnhem, Universitair ziekenhuis St. Radboud in Nijmegen, Isala kliniek in Zwolle en het VU medisch centrum in Amsterdam, die patiënten hebben geïncludeerd hartelijk danken. Een speciaal woord van dank voor Mariëlle Romberg-Camps, vanwege de enthoesiaste inclusie tijdens de laatste studie. Succes met het afronden van je eigen proefschrift!

De maatschap Interne Geneeskunde van het Maaslandziekenhuis in Sittard. Ik wil jullie bedanken voor het vertrouwen dat er in mij gesteld werd om direct vanuit de schoolbanken in Leuven in opleiding te mogen komen. Ik heb een erg fijne en leerzame tijd gehad. Met name de ski-weekenden zal ik natuurlijk nooit meer vergeten. Veel succes in het nieuwe ziekenhuis!

De maatschap Interne Geneeskunde en Maag-, darm- en leverziekten van het Catharina ziekenhuis in Eindhoven. Ik ben nog steeds vereerd en trots, dat ik al een jaar voor afronding van mijn MDL-opleiding door jullie benaderd werd om toe te treden tot jullie maatschap. Ik hoop dat onze samenwerking net zo prettig en vruchtbaar blijft als die tot nu toe is geweest.

Dr. J. van Spreeuwel, dr. A. Stronkhorst en dr. E. Schoon. Beste Jan, Arnold en Erik, mijn directe collega's. Zo kijk je enorm op tegen drie gepromoveerde bazen in een hoog aangeschreven ziekenhuis en zo mag je in het rijtje aanschuiven, ongelofelijk. Ik hoop dat ik de verwachtingen waar kan maken en een waardige uitbreiding ben van de MDL-afdeling.

Alle collega assistenten Maag-, darm- en leverziekten in het azM. Jullie hebben me snel thuis laten voelen op de afdeling toen ik in 2004 begon (Frank, Jan, Marielle, Silvia en Ulrike) en altijd geprobeerd de sfeer er goed in te houden (Susan, Annick, Rogier, Bas, Alexander, Sita, Michiel en Wout). Ik wil jullie bedanken voor de fijne tijd in het azM en de collegialiteit. Ik ben blij dat ik dankzij jullie op de valreep nog kennis heb kunnen maken met Tripel Carmeliet in café Thembi, proost!!

Alle (voormalige) stafleden MDL in het azM. Ik wil jullie bedanken voor de opleiding die ik heb mogen volgen. Ik heb enorm respect voor de wijze waarop jullie ondanks jarenlange onderbezetting toch het hoofd boven water hebben gehouden en een volwaardige opleiding hebben kunnen verzorgen. 
Alle secretaresses van de polikliniek en afdeling Maag-, darm- en leverziekten in het Maaslandziekenhuis Sittard, Laurentius ziekenhuis Roermond, Academisch ziekenhuis Maastricht en Catharina ziekenhuis Eindhoven. Ik wil jullie hartelijk danken voor jullie ondersteuning bij het onderzoek en het verzamelen van medische dossiers. Met name Ingrid Mols, voormalige secretaresse van dr. Engels, wil ik bedanken.

Tiny Wouters. Beste Tiny, zonder jouw zorgvuldige blik en je tips zou dit boekje bestaan uit schots en scheve tabellen, verschillende lettertypes en diverse afkortingen. Bedankt voor al je uren (vrije) tijd die je in dit werk hebt willen steken.

Peter Gorter. Beste Peter, als peetoom/petekind hebben we door de jaren heen een onregelmatig, maar altijd hartelijk contact gehad. Ik ben erg blij dat je met jouw ervaring in de wereld van vormgeving een belangrijke steen aan dit boekje hebt willen bijdragen. De vraag blijt of thiopurines ook helpen bij 'ulcerative saxophonitis'; de eerste studie moet nog uitgevoerd worden.

Zoals inmiddels wel duidelijk is, speelt muziek een belangrijke rol in mijn leven. Het vanaf jongsaf aan optreden heeft me zelfvertrouwen en een open kijk op de wereld gegeven, wat me dagelijks van pas komt. Ik wil dan ook alle muzikanten bedanken die me de afgelopen jaren geholpen hebben om de gedachten even van werk en onderzoek af te leiden. Met name de jongens van Guarantee, JazzMinded! en Harry \& de Gebroeëke Zwiegelkes wil ik bedanken voor alle mooie optredens die ik heb mogen meemaken en nog hoop te gaan geven. Het zal schipperen worden tussen het gezinsleven en werk (en diensten) door, maar ik blijf spelen tot ik er bij neerval! Daarnaast bedank ik ook het bestuur en de leden van de Kerkelijke Harmonie St. Joseph 1880 voor het ondersteunen van mijn muzikale vorming en de warme contacten die er altijd zijn gebleven.

De Poodtjes en de Eckjes: twee doktersfamilies in wording. Bij jullie bourgondische en mediterrane levensstijl voelen Edith en ik ons steeds weer thuis. De deur staat altijd open en het glas wijn is al ingeschonken. We hopen nog vele mooie reizen naar de zon en/of sneeuw te mogen maken met jullie!

Martine, met je interesse en hartelijkheid laat je altijd weer de zon bij ons thuis schijnen, als een heuse huisvriendin. Nog even en dan zit jouw 'karwei' er ook op en kan je aan het echte werk gaan beginnen: kinderarts worden. Zet hem op! 
Het wordt tijd om mijn wortels in het zonnetje te zetten. Lieve pa en ma, jullie hebben me nooit gedwongen, maar altijd gesteund om de wegen in te slaan die ik wilde kiezen. Ik ben dankbaar dat jullie (weer) in goede gezondheid zijn en hoop dat jullie nog lang van het leven, elkaar en ons gezin mogen blijven genieten.

Allan, van buiten lijken we niet direct op elkaar ('je bent mijn broer, man!'), maar in ons binnenste loopt er een synchroon ritme: muziek maken, verbeteren en er over praten blijft een enorme passie van ons allebei. Het wordt tijd dat we weer eens samen op het podium staan, niet?

Oma Lies, ik ben een enorme bewonderaar van $\mathrm{u}$. $U$ bent een krachtige vrouw die ondanks verschillende tegenslagen in het leven toch steeds een positieve kijk heeft gehouden. Uw 90-jaar jonge levensvisie is er een die ik in mijn dagelijkse leven goed kan gebruiken: geef elkaar de ruimte, geniet van de dag en de mooie dingen die de natuur ons geeft. Wanneer gaan we weer eens eten bij De Cuyp?

Jan en Tiny. Fijnere schoonouders had ik niet kunnen wensen. Jullie zijn een perfecte combinatie van vooruitstrevendheid en behoudenheid, houden van bourgondisch leven, blijven niet stil zitten en zijn warm en geïnteresseerd. Mijn slogan blijft dan ook: je ouders kun je niet kiezen, je schoonouders wel! Vanaf nu hoop ik zelf weer het onkruid in onze tuin bij te kunnen houden.

Marc, Guido, Marielle, Louise, Olivier en tante Toos. Jullie zijn echt familie van mij geworden. Ik voel me bij jullie altijd op mijn gemak als we lekker eten, discussiëren, ravotten en spelen. Zo'n fijn familieleven is belangrijker dan een promotie.

Edith, mijn liefje, de grootste drijfveer achter dit proefschrift. Jij hebt een zwarte dag in april omgetoverd in een zonovergoten avond. Ik ben zo dankbaar dat ik jou ben tegengekomen! Je bent vlot, spontaan, elegant en sportief. Je weet als geen ander wat mooi, maar soms ook moeilijk is aan het werk met patiënten. Ik ben blij dat we de stap gezet hebben om jouw eigen praktijk te starten en heel trots hoe jij deze organiseert, in combinatie met het moederschap! Zonder jou was dit boekje nooit tot stand gekomen.

Eline en Luc. Papa is blij dat dit werk erop zit voordat jullie groot genoeg zijn om te beseffen dat ik de afgelopen periode iedere avond voor de computer zat. Jullie aanwezigheid en komst hebben mij de energie gegeven om de eindsprint in te zetten. 